DOE/ER/70224--T6

DE83 005018

$\therefore$ DOE|ER/70224--T6

FXNAT REPORT

DR2 $128-8$

to

Department of Energy

on

"The Reiationship of Rock Physics to Geothermal Exicrgy Technology"

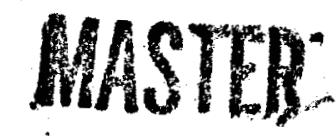

Contract No. DE-AMO3-76SF00034

Project Agreement No. DE-AT03-76ER70224

For the Period: February 1, 1981 - January 31, 1982

Orson I.. Anderson, Principal Investigator Institute of Geophysics and Planetary Physics

Nicix Varren, Co-Principal Investigatcr: Institute of Ceophysice and Planetary Physics

Report By:

Dr. Nick Warren

and

Nicli Coffey

The Regents of the University of California

University of California, Los Angeles 405 Hilgard Avenue

Los Angeles, California 90024

Date of Submission: October $30,1.982$

NOTICE

THIS REPORT IS ILLEGIBLE TO A DEGREE

THAT PRECLUDES SATISFACTONY REPRODUCTION 


\section{DISCLAIMER}

This report was prepared as an account of work sponsored by an agency of the United States Government. Neither the United States Government nor any agency Thereof, nor any of their employees, makes any warranty, express or implied, or assumes any legal liability or responsibility for the accuracy, completeness, or usefulness of any information, apparatus, product, or process disclosed, or represents that its use would not infringe privately owned rights. Reference herein to any specific commercial product, process, or service by trade name, trademark, manufacturer, or otherwise does not necessarily constitute or imply its endorsement, recommendation, or favoring by the United States Government or any agency thereof. The views and opinions of authors expressed herein do not necessarily state or reflect those of the United States Government or any agency thereof. 


\section{DISCLAIMER}

Portions of this document may be illegible in electronic image products. Images are produced from the best available original document. 


\section{DOE|ER|70224--T6}

FINAL REPORT

to

Department of Energy

"The Relationship of Rock Physics to

Geothermal-Energy Technology"

Contract No. DE-AMO3-76SF00034

Project Agreement No. DE-AT03-76ER70224

For the Period: February 1, 1981 - January 31, 1982

Orson L. Anderson, Principal Investigator Institute of Geophysics and Planetary Physics

Nick Warren, Co-Principal Investigator Institute of Geophysics and Planetary Physics

Report By:

Dr. Nick Warren

and

Nick Coffey

The Regents of the Unfversity of California

University of California, Las Angeles 405 Hilgard Avenue

Los Angeles, California 90024

Date of Submission: October 30,1982

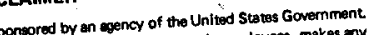

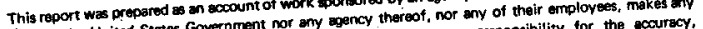

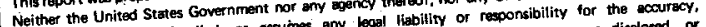
warrenty, express or implied, or essumes muto sparatus, product, or process disclosed, of completeness, or usefulness of any inte privately owned rights. Reterencos herein to anv Dalic

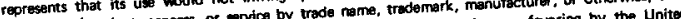

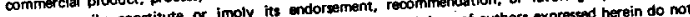

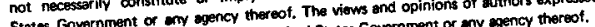

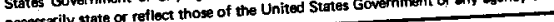



FINAL REPORT

\section{OVERVIEW}

Research under the grant, "The Relationship of Rock Physics to Geothermal Energy Technology," has been directed to aspects of the fundamental problem of establishing quantitative and predicative relations between rock 'architecture' (at the level of grain size) and bulk properties. Our work became a search for regularizing systematics in such relations and, therefore, our approach has increasingly become one of statistics in rock mechanics.

Within this frame there have been three areas of focus. The first has used velocity and strain data as basic measures of bulk properties. We have developed increasingly precise experimental and analysis techniques to resolve the detailed influence of microstructure on such data and to establish global trends or systematics in these bulk properties as functions of broad 'architectural' classes.

Second, we have worked to develop techniques to quantitatively characterize this architecture. This has been done by inventing methods to decompose complex (thin-section) rock patterns into statistical characterization of the structure. Broadly, this study has grown into 'quantitative petrostructure analysis' which has indicated its promise as an exact and powerful tool. 
Third, we have worked to develop theory relating petrostructure and bulk properties. Our approach has differed fundamentaliy from most others in that we have sought to formulate the problem in a manner which allows statistical analysis at the first level, and which is also fundamentally flexible enough to model material behavior from competent rock to soils.

February 1, 1981 through January 31,1982 formed the terminal year for this grant. During this period, we completed as many new experiments as possible. A cost-free extension was granted for the period February 1, 1982 through September 30, 1982. This has been essentially a period of analys is and writing.

Over the course of this grant a number of papers have been published in each of the three research areas. Based on this last year's work, a number of additional papers are currently in press or being written. The majority of these are becoming jointly authored papers. Therefore, the publication schedule for papers growing out of these most recent studies cannot be predicted at present. Once analysis and publication of these new results is completed, much of the overall study may be appropriately condensable into a monograph.

\section{FINANCIAI STATEMENT}

This financial and work statement covers the last year of our grant pius the cost-free extension. The total awarded

$$
-4-
$$


grant for the year was $\$ 121,000$. Ninety-five percent of this budget was spent by the end of the actual grant period. This expenditure level was based on the decision to concentrate on and complete as many experiments as possible, and to continue the support of the portion of the staff that had been hired with an understanding of being supported for the entire grant period. Approximately $\$ 6000$ was carried over for the analysis and report writing during the cost-free extension. This has supported 1 to $11 / 2$ week/month salary for N. Warren. The total expenditure commitment by September 30,1982 has equalled the funds granted for the final period, $\$ 121,000$.

\section{PUBLICATIONS FOR THE PERIOD}

\section{JANUARY 1981 TO PRESENT}

The following articles have been published, accepted for publication, or finished as preprints:

1. Warren, N. and M. Tiernan, "Systematics of Crack-Controlled Mechanical Properties for a Suite of Conway Granites from the White Mountains, New Hampshire." This report, discussed in our progress report, 1980, appeared in print: Tectonophysics, 73 (1981) 295-322.

2. Two papers on petrostructure are in press.

a. N. Warren, "Quantitative Petrostructure Analysis," is being published as a Los Alamos manuscript. This report was written to be the chief introduction and outline of quantitative petrostructure analysis and is to serve as my original reference in subsequent studies. 
b. N. Warren, "Statistical Characterization of Complex Crack and Petrographic Texture: Application to Predicting Bulk Physical Properties". This paper is a shortened article which appeared in Issues in Rock Mechanics: 23rd US Symposium in Rock Mechanics, August 25-27, 1982.

In adation to $2 a, b, a$ short paper, also titled "Quantitative Petrostructure Analysis" appears in Conference Report on Properties of Materials Under Extreme Conditions, IGPP Director's office Report No. 2LANL81, LANL-IGPP conference, May 17-19, 1981.

3. Warren, N. and Nick Coffey, "Microcrack Formation and Hysteresis Under Hydrostatic Cycling". This paper is currently in draft form with submission planned for a journal such as JGR.

Besides these, as discussed in the next section, four other papers are scheduled based on reports here. These include:

1. Warren, N., Nick Coffey, and Chou Hsiao, "Velocities and Dynamic Moduli of Five EE2 Borehole Samples." This report is a compiliation of velocity data obtained for rocks from the Fenton Hill EE2 borehole under the HDR project. Currently a jointly authored paper is being, written by N. Warren (UCLA) and T. Dey (LANL) which combines both LANL and our data.

2. A paper on the correlation of experimental strain sensitivities to estimated rock porosities.

3. A theoretical/experimental paper on a "rough-crack" model to be authored by H. Fisher (LANL), N. Warren (UCLA) and J.B. Blanton (formerly at UCLA). 
4. A paper on magnetic susceptibility and velocity

correlations between well- $\log$ data and laboratory measurements for Conway granite.

\section{REPORTS/INTRODUCTION}

As stated in the overview, research has been directed to problems of establishing quantitative and predictive relations between rock 'architecturre' and buik properties. In application to Hot Dry Rock technology, these studies bear on the problem of characterizing granitic rock and its response to deep borehole engineering.

We have written our chapters to be free standing reports. In this section we briefly abstract this work and draw some general implications which follow from the combined studies. Reports Listing.

The reports cover results of our work under the PROPOSED EFFORT of our last proposal: I, Petrostructure Analysis; II, Pore Pressure and Pore Fluid Effects; III, Theoretlcal Modelling/Crack Spectra Analysis; and IV, Physical Properties Measurements and Analysis. 
The reports are:

REPORTS/LISTING

I. Petrostructure Analysis.

1. Statistical characterization of complex

crack and petrographic texture: applica-

tion to predicting bulk physical properties.

(reprinted from chapter 14 of Issues in Rock

Mechanics, 23rd U.S. Symposium in rock

mechanics, August 25-27, 1982)

2. Quantitative Petrostructure Analysis

II and III. Pore Fluid Effects and Theoretical

Modelling/Crack Spectra Analysis.

3. Rough crack models and crack compliance around

a borehole

4. Determination of crack porosity from ratios of

static and dynamic bulk moduli

5. Microcrack formation and hysteresis under hydrostatic cycling

IV. Physical Properties Measurements and Anslysis.

6. Relation of well-1og velocities and. magnetic susceptibilities to laboratory value: Conway granites, White

Mountains, New Hampshire

7. Velocities and dynamic moduli of five EE2 borehole samples, technical summary report

8. Elberton granite data compendium 
The Work

In relation to HDR, four main compendiums of data have been generated under the grant. The flrst, "Correlation of permeability, velocity, strain and crack spectra for a suite of seven JASL rock samples" was submitted to DOE and LANL in 1980. The second, "Rock physics characterization of Conway Granite from a DOE borehole, Conway, New Hampshire" was first published in 1979 (LA-8102-MSD) and more recently by CINDAS, The Handbook of Physical Constants for Rock. The remaining two are included here as attachments. The first of these is "Velocities and dynamic moduli of five EE2 borehole samples; technical summary report". It was submitted in original form to LANL in December 1981, and informally to DOE at that time. The version here has an expanded discussion section. This report is becoming incorporated into a joint LANL/UCLA report by T. Dey and N. Warren. The second of these is "Compendium of Elberton granite data", which presents the majority of our studies on "Berkeley Blue granite". This granite has been adopted as a "standard" rock for a number of LANL studies.

In these compendia velocity, strain, and moduli data are emphasized. However, most of these data were obtained in studies that were directed beyond the immediate requirements of rock characterization, and it is this work which is summarized in the other reports. In "Relation of we11-10g velocities and magnetic susceptibilities to laboratory values...", recently obtained we11-1og data from the Conway granite borehole are compared to the earlier obtained laboratory data. A major 
conclusion is that one subset of granites, characterized by grainsize, shows a marked amount of induced microcracking from overcoring and extraction compared to other granites which have almost Identical mineral modes. Generalizing on this concluston, the deviation of laboratory from well-log velocities is strongly effected by details of petrostructure or rock architecture.

The relation of laboratory to large scale properties is further discussed in "Characterization of non-Iinear porous rocks". A model of a "rough-crack" as an elliptical crack with asperities is developed and applied to borehole pressurization experiments on Elberton granite. The model generates very realistic results. A major conclusion is that the basic pore inflation law being inferred is very similar to that obtained In the large scale HDR Fenton Hill tests. Generalizing, it appears that the problem of determining size effects on rock engineering properties can be replaced by a consideration of the ratio of the experiment scale to the flaw scale.

Rough-crack analysis is also expected to have a bearing on the analysis of both mechanical compression and dilatancy of rock. In "Microcrack formation and hysteresis under hydrostatic cycling", although the rough-crack model is not used directiy, it is shown experimentaliy that the frictional properties which effect velocity under compression can explain both compressive hysteresis and the shape of the stable 
dilatancy cycles. This study was based on careful experiments on Elberton granite. This study provides a careful look at the resolvable effects of microstructure on bulk properties.

In a related study, the Inversion of stress-strain data into porosity is considered. This is an important problem, which applies both to laboratory analysis and to borehole and field studies in which the primary data are in the form of velocities on one hand, and/or strain relaxations on the other hand. In "Determination of crack porosities from ratios of static and dynamic bulk moduli", some of the schemes for predicting velocity from stress-strain data are analyzed. The major conclusion is that porosities are not uniquely predicted by these methods, and that the inferred porosity from any one type of experiment appears to be predominately correlated to the strain sensitivity of the experiment used.

These last three studies just discussed can be described as efforts to resolve the microstructure from bulk properties. A major complementary study was conducted under this grant, that is the development of techniques to characterize petrographic and microcrack structure directly. "Quantitative petrostructure analysis" and "Statistical characterization of complex crack..." present the results of the original studies on Conway granite samples. During 1981 Inftial petrographic maps were made on Elberton granite, a1though the end of funding precluded analysis. The original maps are included in the compendium of data for the Elberton granite. 


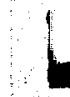

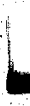

1

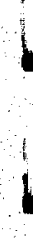

1

b. 


\section{Chapter 14}

STATISTICAL CHARACTERIZATION OF COMPLEX CRACK AND PETROGRAPHIC
TEXTURE: APPLICATION TO PREDICTING BULK PHYSICAL PROPERTIES

Nick Warren

Institute of Geophysics and Planetary Physics

. University of California, Los Angeles, CA 90024

\section{ABSTRACT}

The problem considered is that of predicting rock physical propertles from observations of the structure of the rock. The approach here departs from previous studies in that both the physical properties and structural features are taken as statiscical data and the relations between them are cast as statistical functions. This approach I have termed a "quantitative petrostructure aralysis". This paper deals with two aspects of making such a study; parameterizing patterns of topographic features of rock, and characterizing variables to allow correlation studies to be carried out. The principle of a quantitative petrostructure analysis is outlined and 111ustrated using maps from two samples of Conway granite.

\section{INTRODUCTION}

The Basic Problem

It has long been recognized that correlations exist between observable crack patterns, grain texture or fabrlc and bulk physical properties (examples of emptrical and theoretlcal work on this include Brace, 1969; Tilmann and Bennett, 1973; Simmons, et al., 1974; O'Connell and Budlansky, 1974; and Varren, 1977). However, the problem of being able, in general and for over a large range of rock types, to quanticatively predict the pressure dependence of bulk physlcal properties from observation of rock structure has not been solved. This problem has two causes. The first is in the phenomenology of the problem, the second artses in the theory of the problem. Usual theoretical approaches are basically limited by the requirement of idealizing crack structure. The phenomenological 
approach is limited by the need to measure and quantify a very large set of possibly important petrographic variables.

Approach

The approach taken here is to treat this problem as a problem in statistics. Here then, three classes of varlables are put on equal and quantitative footing. These are the bulk properties (e.g. moduli or resistivity), the compositional (scalar) variables which describe the rack makeup (e.g. mineral modes), and the topographic or geometrical variables (e.g. grain and crack geometries). This puts both the phenomenological and the theoretical approaches into the same frame and allows treatment of a large number of variables. In its broadest sense this approach is an application in pattern recognization and factor analysis (see for example Jareskog et al., 1976).

Feasibility

There are two tasks that wust be accomplished to 1llustrate the feasibility of the approach. First is the demonstration that systematics exist in some class of bulk properties and that these occur at a sufficlent level of resolution to infer that underlying statis$t$ tcal variables can be found. The second task is to Invent a sufficiently general method to economically characterize and parameterize rock structure.

THE STUDY

A pllot study has been made using two samples of Conway granite (syenograntte) from Conway, New Hampshire. In previous work, a technique was developed for grouping the samples based on Modulipressure systematics (Varren and Tiernan, 1981). More recently, a technique for parameterizing and characterizing petrostructure has been developed (Warren, 1982). The study here illustrates this more recent development.

Iodul1-Pressure systematics

The two samples are part of a suite of ten samples from a borehole drilled.by ERDA (now DOE) at an exploration Hot Dry Rock site (Conway, New Hampshire). Using measures of the dependence of ultrasonic velocity on pressure these ten samples were found to form three groups. The two samples used here (381.9 and 704.4 ) are from it single group, being well matched by their moduli-pressure dependence. Thelr similarities are demonstrated in Figures $1 \mathrm{a}$ and $1 \mathrm{~b}$. The figures show "crack spectra" inverted from the velocity data for these two samples. To 1llustrate the difference between these samples and a sample from another group, crack spectra for sample 448.1 


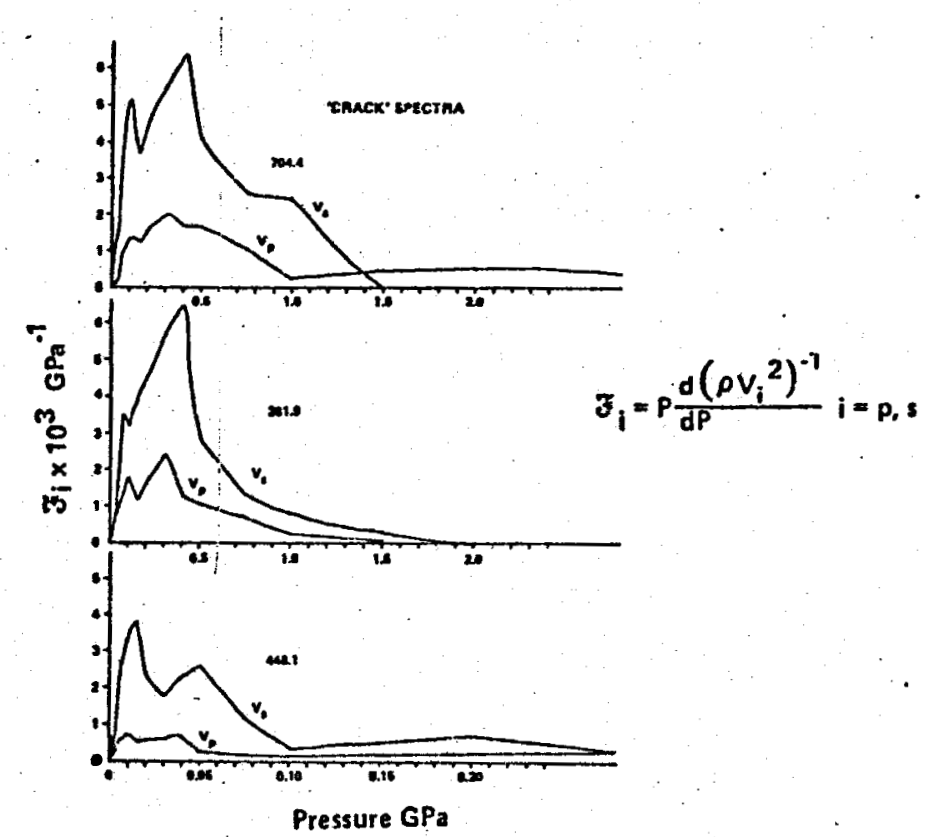

Figure 1. Spectra derived fron velocity data for Conway samples.

are shown In Figure lc. The crack spectra are obtained from the derivative of a spline curve fit to the data. In the inserted equation, $P$ is density, $P$ is pressure and $v_{1}$ is veloctty $(i=p$, and $s$ denotes compressional and shear wave velocity respectively). Although they cone from different depths (they are about 322 meters apart), both 381.9 and 704.4 are fine grained with similar textures. Both the samples and the grouplngs are described in detail in the referenced papers.

\section{Petrostructure Analysis}

Two microphotographs, one from each sample, were used in the second part of this study, the petrostructure analysis. By the term petrostructure is meant a descriptive space spanned by three axes: the mineralogical variables, the petrographic variables, and the incrostructural variables. The variables fall broadly into two classes: 1) topographic and 2) compositional. The compositional varlables (e.g. chemistry and mineralogy) are scalar falrly directly quantiflable. Topographic variables are patterning variables which must be quantified through mapping. They include grain orientation, mineral nearest-nelghbor distances, crack patterns and crack heirarchies. These copographic varlables are evaluated by a mapping 
techalque w'ich proserves the statistics of the geometrical relations in terms of a small fixed set of map parameters. Three parameters are used: 1) sets of coordinate points (pattern nodes), 2) listings of connected points and 3) flag values which specify the nature of connectivity between points, or identify or distinguish a group of points. The values of these three variables are specified through the process of digitizing a map or photo of the network.

In this pllot study, petrostructure was limited to "crack" structure (i.e. those visual features which showed crack-like visual contrast and morphology). The microphotographs were nade at a magnification of $63 \mathrm{X}$, mapped and digitized. The digitized maps are shown in Figure 2. A correlation between the two crack patterns was sought. The maps were selectively decomposed through a series of steps. open networks were broken into length, orlentation, spacing, and connectiveness distributions. Closed networks (e.g. crack boundarles that form grains) were additionally decomposed into area and shape distributions. From these basic distributions a large number of parameters were automatically evaluated using a computer program (SOCIOLOGY) which was developed as part of this analysis effort. The reader is referred to Warren (1982) for details.
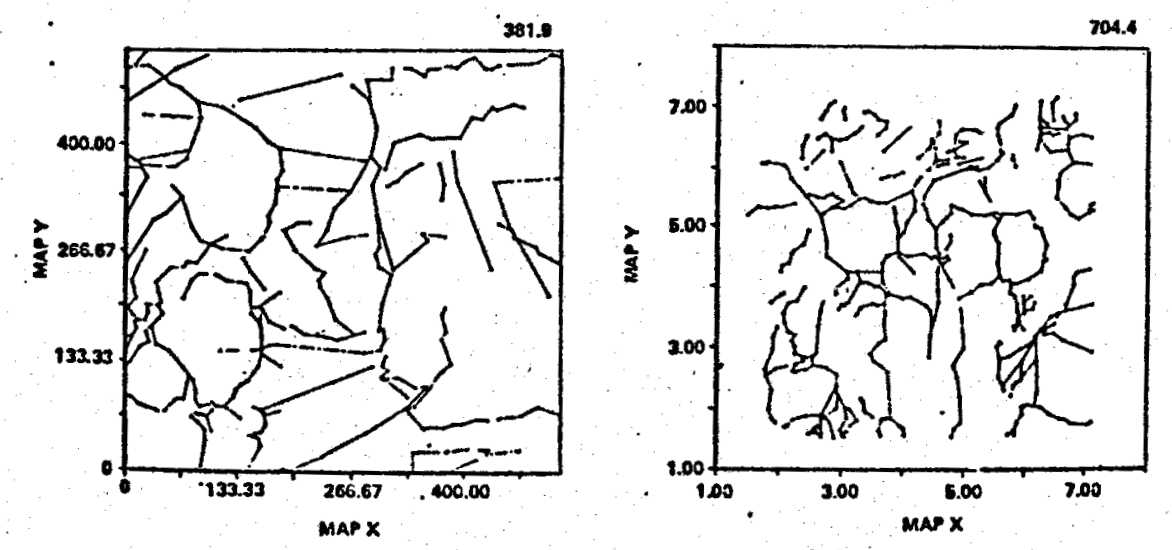

Figure 2. computer generated maps. 


\section{Results}

In this pllot study strong similarities in physical properties were shown to correlate with similarities in petrostructure. Exemplar results are shown in the figures. The first set of histograms (Figure 3) show a strong similarity between the two samples. Three
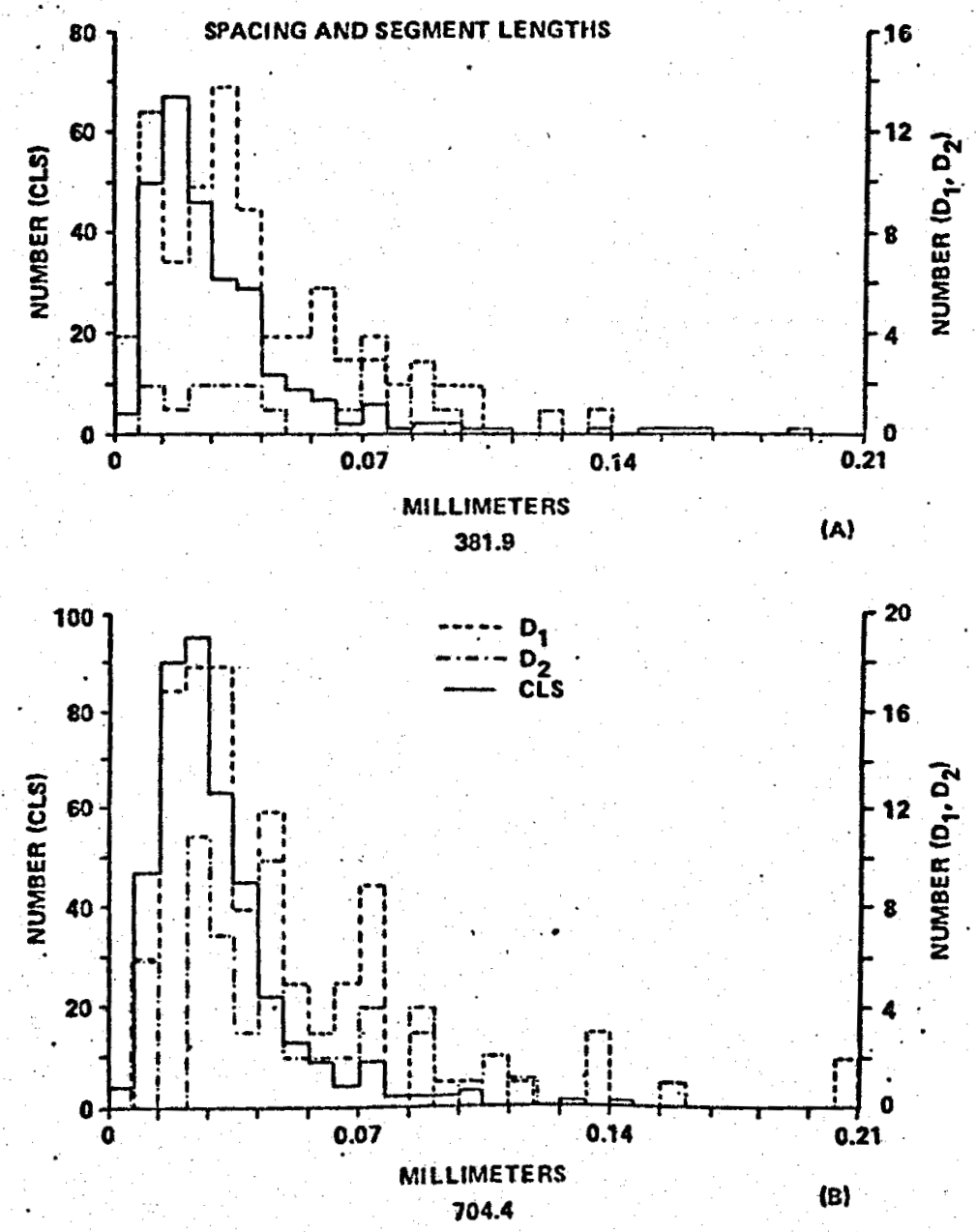

Figure 3. Histograns of crack feature. See text for discussion. 
distributions are shown. These are the distributions of nearestnelghbor distances between crack tips $\left(D_{1}\right)$, the equivalent distributions for crack branch points $\left(D_{2}\right)$, and the directly digitized crack segment lengths ( $C S L$ ). $D_{1}$ way be taken to be a measure of the distribution of a crack-stopping variable; namely et ther low stress regions or barriers. $D_{2}$ is a crack forking varlable indicating the distribution of spactings at which cracks grow together or fork during growth. The CSL may be taken as $a^{\text {. }}$ measure of the mean-free path of crack growth.

The results imply that for these samples the spacial properties of crack-stopping, kinkling, and branching are equal within each rock and between each rock. The first part of this result would not be expected for a highly anisotroplc or schistose rock. The second part, namely that the probability distributions controlling potential crack growth are equivalent in both rocks is in full agreenent with the simllarity predicted by the crack spectra obtained from the velocity data.

In Figure 4 a very striking agreement is found between these results and those of another study designed to deterwine actual crack length distributions in a granite (ladley, 1976). Hadley used 400X SEM of Vesterly granite to directly measure crack lengths and widths. Cracks were "any open flaw of aspect ratio less than 1 which did not change orlentation by more than $20^{\circ}$ over any significant portion of its length...". Her definttion of crack length agrees well with the natural CSL determined for these Conway granite samples.

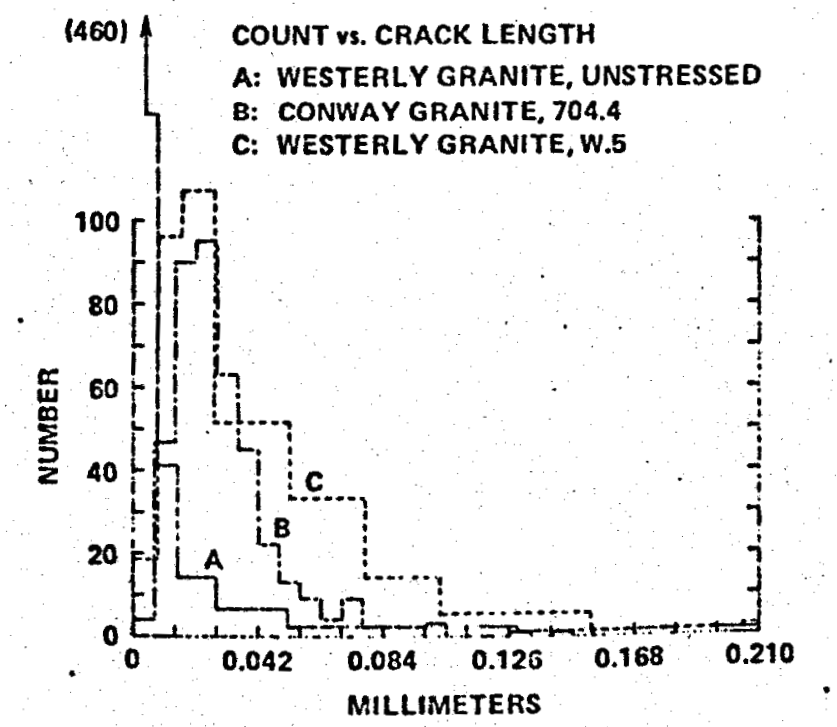

Figure 4. Superpostition of crack length distributions. 
fother varlables discributions wer ilso chacacterlzed lot study. One was an alternative measure of crack length, In the pllot study. On w CSL between crack tips and/or branch namely the cumulated sum of chis measure, as well as $D_{1}, D_{2}$, points: The distribution of this measure, as wecta amplitudes in and CSL, are plotted along with the crack of correlation between the Figure 5. This plot indicates the degree of cor cross plotting the ordinate values of palred curves. If the curves should show a the diagram generated by cross ploteing the clustering along the $45^{\circ}$ diagonal. For twe between them, the Inear structures, but with a scale factor shift between the case of trend of the plot will fall off the 45 dall be seen. Figure 5 Iittle or no correlation, no linear trend. Will be seen. shows the basic similarity of the tro samp all the plotted variables.

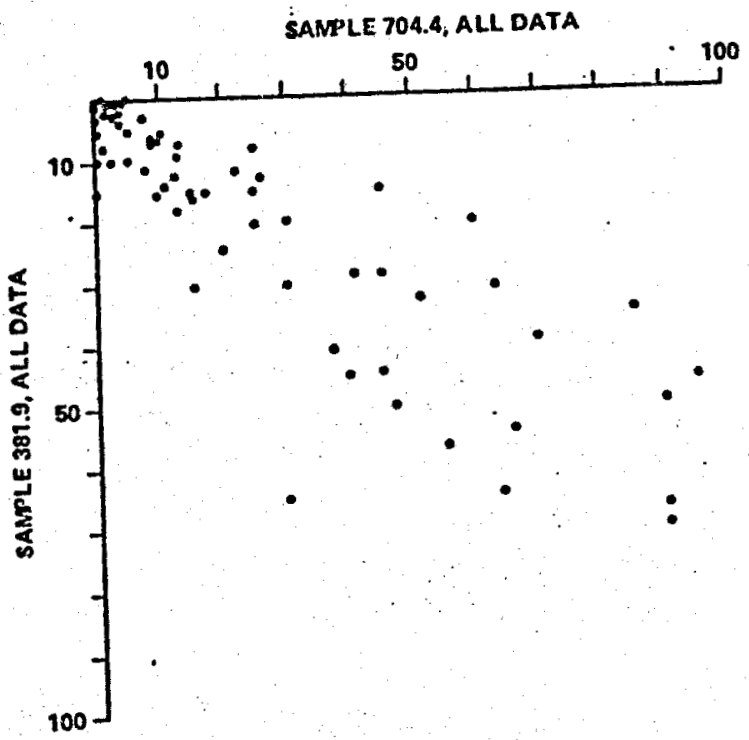

Figure 5. Correlation plot for four varjables. Data are normalized to 100 .

In a true factor analysis, studies of the data such as generated here would be searched for underlying and invisible factors which could serve to reduce the dimensionality of the data and maximize the predictive value of the data. Such techniques can be extremely valuable in rock geophysics. 


\section{ACKNOHLEDGEMENTS}

The Petrostructure Analysis Program has been developed at UCLA under DOE support (DE-ASO3-76FO0034) and in confunction with the Hot Dry Rock Project at Los Alamos Nattonal Laboratory.

UCLA publication no. 2316.

\section{REFERENCES}

Brace, W.F.. 1969, "Micromechanics In Rock Systems", Structure, Solid Mechanics and Englneering Design; The Proceedings of the Southhampton 1969 Civil Engineering Materials Conference, M. Te'eni, ed., Wiley-Intersclence, Pp. 187-204.

Hadley, K., 1976, "Comparison of Calculated and Observed Crack Densities and Selsmic Velocities in Westerly Granite, " Journa 1 of Geophysical Research, Vol. 81, No. 20, July, pp. $348 \overline{4-3493 .}$

Jareskog, K.G., Klovan, J.E., and Reyment, R.A., 1976, Ceologlcal Factor Analysis (Methods in Geomathematics I), Elsevier Scientific Publishing Company, Amsterdam, pp. 174.

O'Connel1, R.J. and Budlansky, B., 1974, "Selsmic Velocltfes in Dry and Saturated Cracked Solids," Journal of Geophystcal Research, Vol. 79, No. 35, Decerber, pp. 5412-5426.

Simmons, G., Slegfrled, R.W. III, and Feves, M., 1974, "Differential Strain Analysis: A New Method for Examining Cracks in Rocks," Journal of Geophysical Research, Vol. 79, No. 29, October, pp. 4383-4385.

TIlman, S.E. and Bennett, H.F., 1973, "A Sonfc Method for Petrographic Analysis," Journal of Geophyslcal Research, Vol. 7B, No. 35, pP. 8463-8469.

Warren, N., 1977, "Characterization of Modulus-Pressure Systematics of Rocks: Dependence on Microstructure," Geophysical Monograph 20, The Earth's Crust, American Geophysical Unlon, Washington, D.C., PP. 119-148.

Warren, N. and Tlernan, M, 1981, "Systematics of Crack Controlled Mechanical Properties for a Sulte of Conway Granites from the White Mountalns, New Hampshire," Tectonophysics, Vol. 73, pp. 295-322.

Warren, N., 1982, "Quant1tative Petrostructure Analysis," Los Alamos Sclentific Laboratory, New Mexico, In press. 


\title{
QUANTITATIVE PETROSTRUCTURE ANALYSIS
}

\author{
by
}

\section{Nick Warren}

\begin{abstract}
Petrostructure may be thought of as a descriptive space spanned by three axes: mineralogical variables, petrographic variables, and microstructural variables. A petrostructure analysis is a study of the correlations among sets of these variables and other experimental quantities (such as moduli-pressure, resistivity-pressure data). This paper deals with two aspects of making such a study: parameterizing patterns of topographic features of rock and characterizing variables to allow correlation studies to be carried out. This is part of a basic study being done in application to the Hot Dry Rock Project at the Los Alamos National Laboratory. In this report the principle of quantitative petrostructure analys is is outlined and illustrated using maps from two samples of Conway granite. A Digital Enhancement technique, available at Los Alamos (DIADS), was used in this study and is evaluated here.
\end{abstract}

\section{INTRODUCTION}

A. The General Research

This report summarizes some recent results of a research effort conducted at the Los Alamos National Laboratory and the University of California at Los Angeles under the Office of Basic Sciences of the Department of Energy.

The general goal of the research is to develop tools for classifying crack structural patterns in rock in order to associate these patterns with, and to predict, bulk physical properties and in situ crustal properties.

The techniques discussed here, however, are not restricted to this application. They are built on a methodology for decomposing complex two-dimensional patterns and as such, can be used for a number of topological 
or morphological pattern analysis tasks. It is hoped that this report may provide notions which may prove useful in other fields as well.

B. General Notions

A large number of interdependent variables relate rock structure to bulk rock properties. With varying success, some physical properties can be predicted by using constitutive relations and a minimum of input parameters. A good example is the prediction of shock Hogoniots of tuff using initial density, water content, and porosity as input parameters (Abey 1981; Butovich 1973). However, the prediction of a large number of other properties depends on knowing explicitly the void structure of the rock. For example, these include all material transport and connectivity properites (such as permeability, resistivity) and elastic deformation and failure properties.

Following Brace (1969), the void structure may be thought of as composed of quasi-equidimensional pores (and/or vugs) and various hierarchies of cracks and microcrack networks. This total void structure is embedded in, and in part controlled by, rock fabric and mineralogy, and it reflects history and conditions of origin and deposition, etc. Therefore, different classes and subclasses of voids correlate to various mineralogical and petrographic parameters such as grain shape, cleavage planes, the spatial distribution of grain boundaries, crystal habit and preferred orientation, etc. Because of this, a general term petrostructure may be defined to denote the combination of mineralogical variables, petrographic variables and microstructure (microcrack variables). The problem of prediciting rock physical properties in terms of basic petrostructure requires a multivariant analysis. In its broadest sense, it is an application in pattern recognition and factor analysis (Joreskog et al. 1976; Davis 1973). The approach discussed in this paper is based on this broad notion.

C. Relation to Other Studies

Partial analysis studies have been done which experimentally correlate observable crack patterns, mineralogy, grain texture (or fabric) and bulk mechanical properties. Among others, Brace (1965), Friedman and Bur (1974), and Hadley (1976) have demonstrated such relationships. However, such work has not been done in a way that generates general mathematical tools which allow prediction of the behavior of pressure-dependent mechanicail and physical properties over a large range of rock types. At the present; most studies relating bulk properties to petrographic description mix quantitative and 
qualitative characterizations. More generalized and moderately economical techniques to quantitatively parameterize rock structure from direct observation are needed.

In other important works, Bennett (1972) and Tilmann and Bennett (1973), have demonstrated that measurements of acoustic properties can be inverted to predict petrostructure. They have developed a sonic method for describing the preferred orientation of crystallographic structure of a polycrystal. Their technique, however, is difficult to apply to the problem of separating out the microstructural and crystallographic effects from each other at low pressure.

The development of theories correlating petrostructure to bulk properties are basically limited by the requirement of idealization. Theoretical approaches include calculating the detailed stress-strain models for various geometric shapes of single isolated cracks (Mavko and Nur 1978; Walsh 1965a, b) and the "inverse problem" approach (0'Connell and Budiansky 1974). However, at the very least, such approaches still assume idealized crack prop- . erties and there are no easy ways to relate the resultant calculated microstructure spectrum to the sample's observed crack pattern.

Another approach to the problem, the approach taken here, is to treat this as a problem in statistics. Both physical properties and rock structure are then to be taken as statistical data, and the relations between these sets of variables are to be statistical functions. This puts both the phenomenological and the theoretical approaches onto the same footing and allows treatment of large numbers of variables.

The rock itself is taken to be describable as a statistical assemblage of directly observable petrostructure variables. In this approach, actual rock mineralogical and morphological features are required to be measured. The general method of mapping and measurement must be both economical and allow various tests to be made easily, such as similarity tests between different rocks and correlation tests to various bulk physical properties.

This report presents a prototypal study based on making two thin section maps from two granitic samples. Based on elastic moduli data, the samples have already been grouped together in an earlier study. In the study here, crack patterns observed in the photographs are characterized. The analysis has two goals:

1. To analyze the problem of how best to map and parameterize patterns in rock; and 
2. To test for and determine the advantages and disadvantages of two different methods of mapping and digitizing microphotographs. The two methods were: low resolution optical and hand techniques available at UCLA, and second, a technique utilizing DIADS (Digital Image Analysis Display System) at the Los. Alamos National Laboratory.

Only one microphotograph of each sample was used. Apparent crack patterns in the microphotographs were mapped as the basic input data for the study. Although limited, these are sufficient to illustrate a petrostructure analysis and to discuss the problem of making a quantitative characterization of microstructure.

An expanded discussion of the basic definitions and notions of a petrostructure analysis are given in Appendix A. Descriptions of the logic of the analysis program itself are given in Appendices $B$ and $C$.

\section{THE TWO GRANITE SAMPLES}

The two samples used in this study are Conway Granite, sample numbers 704.4 and 381.9. Both of these samples are from a bore hole drilled by ERDA in New Hampshire at an exploration Hot Dry Rock site. These two samples are already reported on in Warren and Tiernan (1981) and LOS Alamos report LA 8102-MS. These previous studies describe systematics in the elastic properties of a suite of ten Conway Granites. The samples were found to form three groups. Within each group the samples showed qualitative similarities in textures and grain size distributions.

Samples 704.4 and 381.9 are from a single group and are fine grained. Their similarities are demonstrated in Figs. la and $1 b$. This figure shows "crack spectra" inverted from the velocity data from these two samples. These spectra are not dependent on the exact physics of cracks but are a measure of the microstructure of the samples. The crack spectra are labeled compressional and shear spectra depending on whether they were formed from compressional velocity data or shear velocity data. - The strong similarities between the compressional and shear spectra for each sample indicate that the fine structure of the velocity data is a measure of underlying microstructure. The crack spectra are obtained from the derivative of a spline curve fit to the (velocity) data. The technique follows from simmmons et al.. (1974) and is given in Eq. 1. 


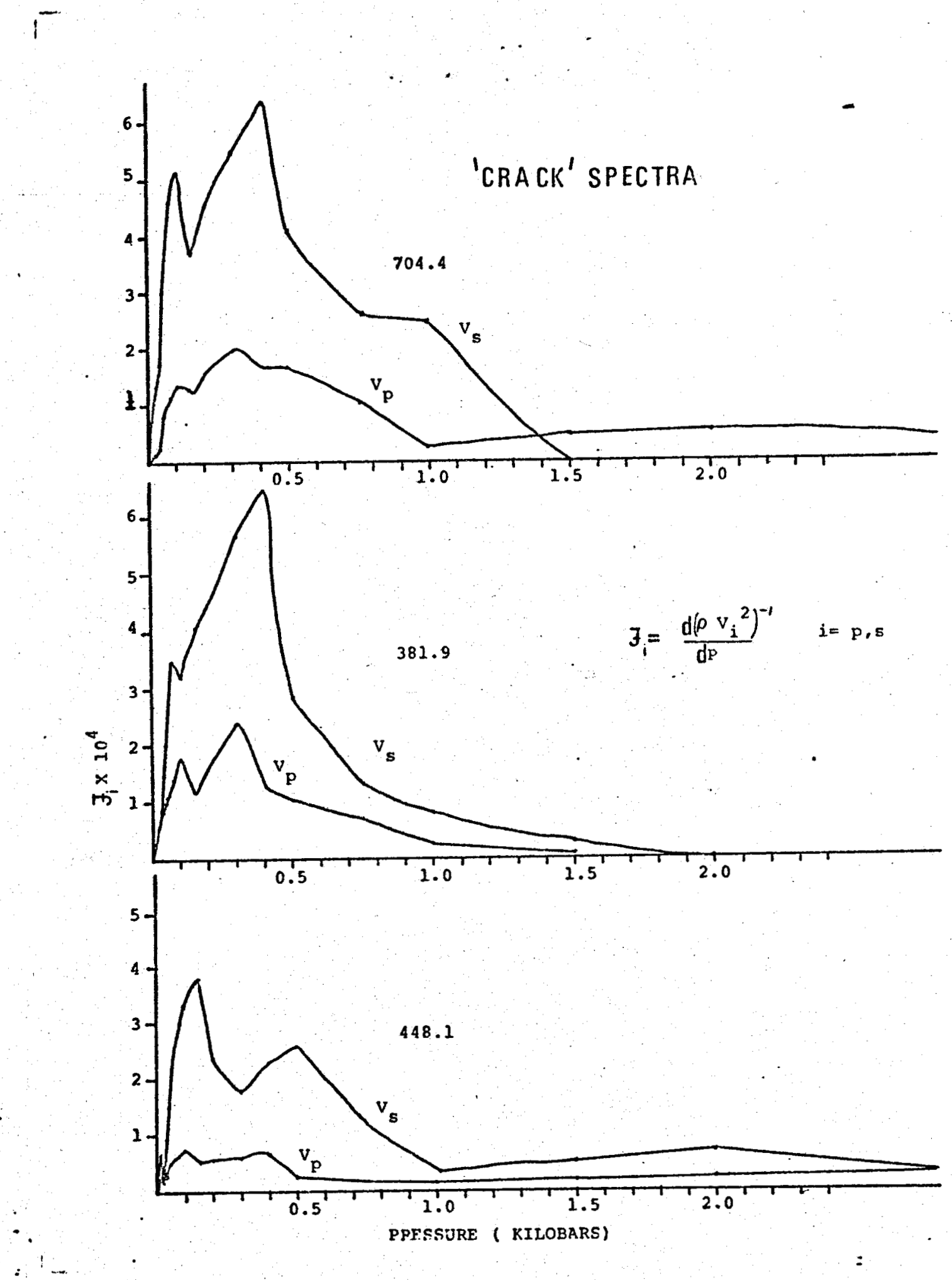

Fig. 1.

"Crack" spectra of Conway samples. Crack spectra are properly derived from strain or compressibility data. Here, however, spectra are. derived from velocity data directly to show consistency of their forms. Curves labeled $V_{0}$ are from compressional wave velocities. Curves labeled $V_{s}$ are from shear wave velocity data. 


$$
F_{i}=P \cdot \frac{d\left(\rho V^{2}\right)^{-1}}{d P} \quad i=p, s
$$

Pressure is denoted by $P, \rho$ is density, $V_{i}$ is either compressional velocity ( $i=p$ or shear velocity $i=s$ ). The quantity $F_{i}$ is a measure of the derivative of compliance with pressure and is proportional to the zero pressure crack porosity, which is pinned closed at a pressure $P$ to $P+d P$. This result is clear if the acoustic moduli are combined into the volumetric bulk modulus. To illustrate the difference between these two samples and a sample from another group, crack spectra for sample 448.1 is shown in Fig. 1c.

In these studies, a simple statistical measure also was made of a crack density which brings out the similarities between these two samples. Counts were made of the number of cracks intersected by standard circles which were placed on photographs taken at magnifications $32 x$ to $600 x$. The results for samples 381.9 and 704.4 are shown in Fig. 2. Both of these samples are denoted by a single hierarchy of cracks which is the only one counted at all magnifications.

These two samples were, therefore, picked for the petrostructure study here because they showed strong similarities and provide a basis to illustrate the technique of establishing the measure of correlation between the petrostructure of two distinct but similar rocks.

\section{MAPPED DATA}

In this study petrostructure was limited to "crack" structure. The term "crack" here is qualified in that no attempt was made to dope or mark open cracks to distinguish them from other features which showed similar visual contrast and morphology. The two reflection microphotographs used are shown in Fig. 3. Portions of the crack patterns seen in the microphotographs were digitized as described in Appendix A. The computer regenerated crack patterns are shown in Fig. 4. The microphotographs were made at a magnification of 63x. Each microphotograph was analyzed separately. One microphotograph was digitized at UCLA, the other one at Los Alamos.

The three goals in this part of the study were:

1. To determine the efficiencies and qualities of different mapping techniques;

2. From this, to develop an efficient technique; and 


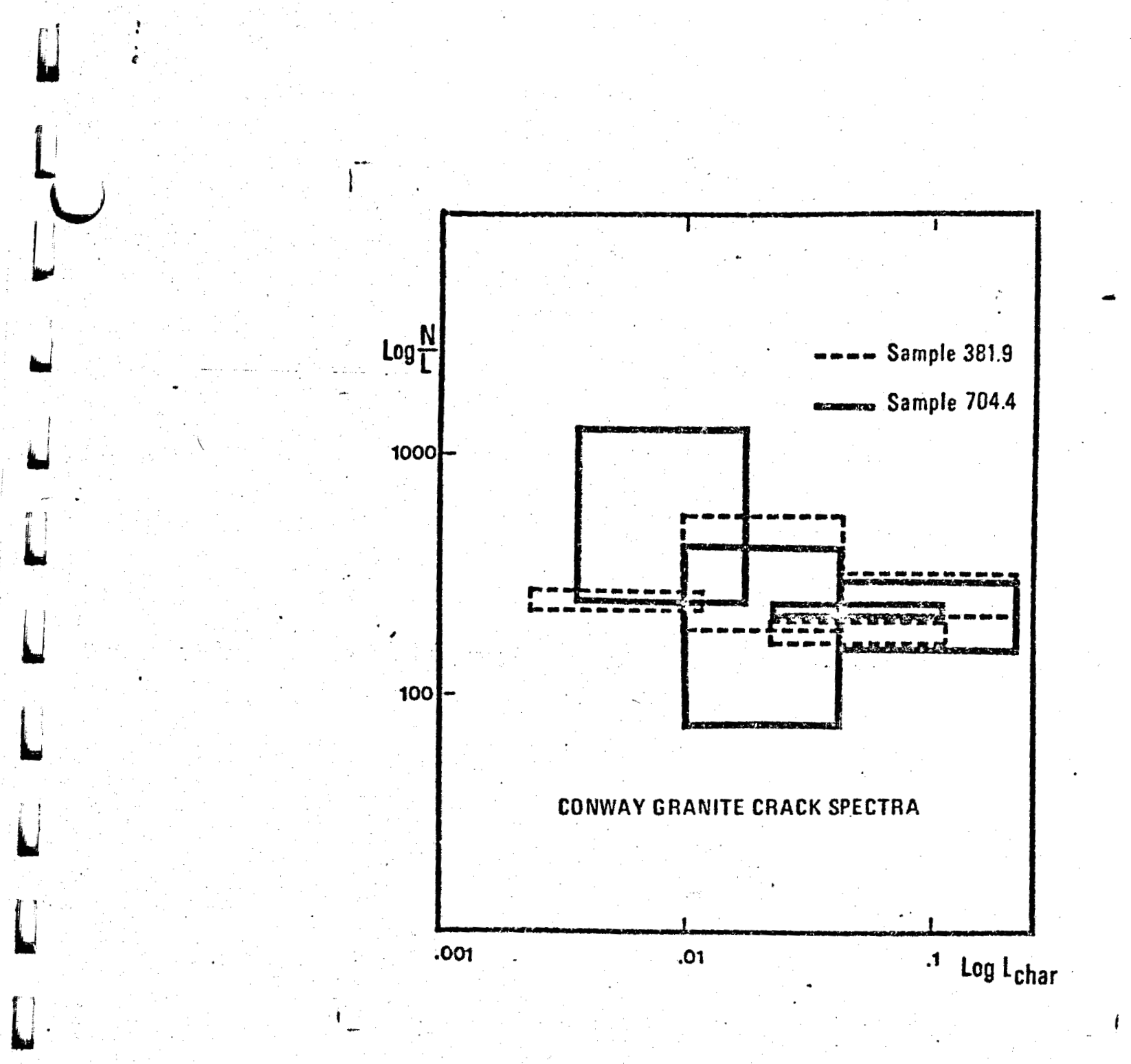

Fig. 2.

Logarithmic plot of cracks intersected by standard circles. The characteristic length ( $L_{c h}$ ) is the circle circumference corrected for magnification. The number density $(N / L)$ is sensitive to crack length and crack spacing. The vertical height of each box corresponds to the range of spacings that were measured using a number of photographs.

3. To determine operator effects, that is, the effects of the skill and experience of the operator in making subjective judgements on the data.

Digitization at UCLA was done on SAC graph-pen digitizer tied to a - Hewlett-Packard 1000 minicomputer.

The second technique involved using a microdensitometer to scan the microphotograph and then digitizing the data using image enhancement techniques (DIADS) (Breedlove, 1979, and personal communication). There were a number of differences in handling the two microphotographs. These included resolution and density of mapping. 


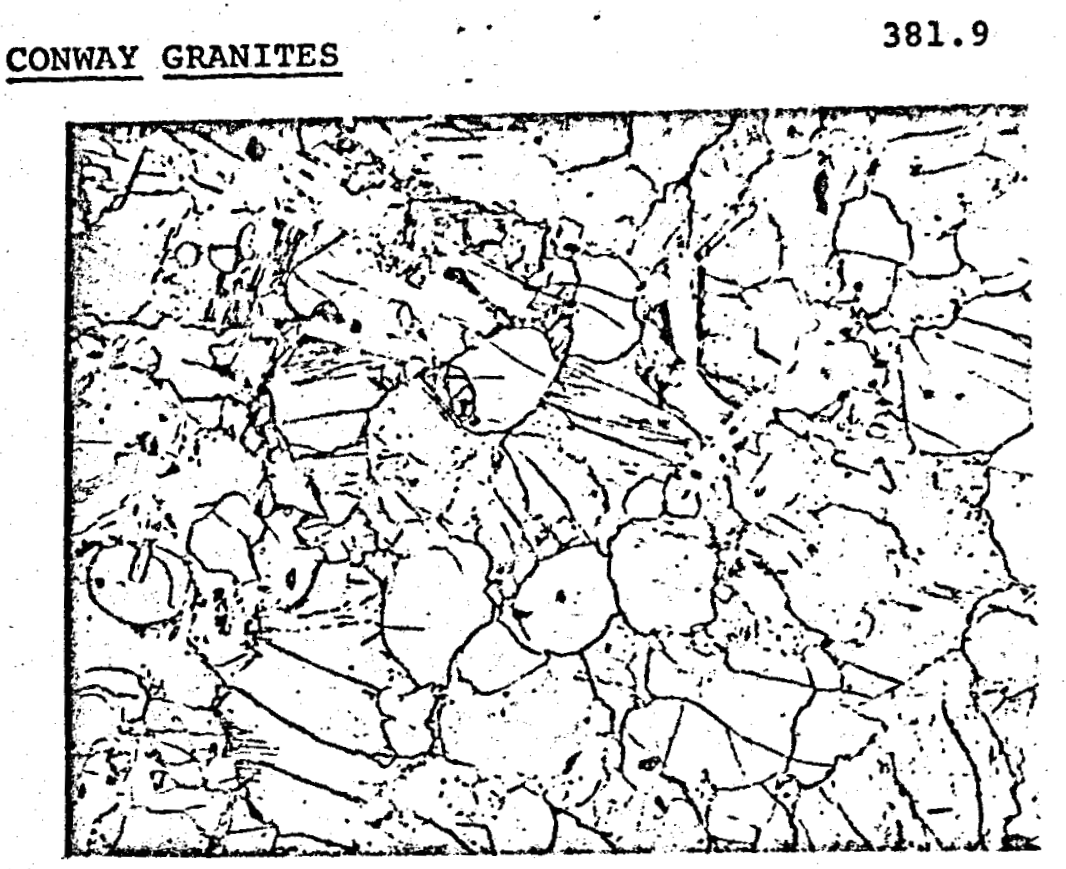

* 3-63-10-18-77
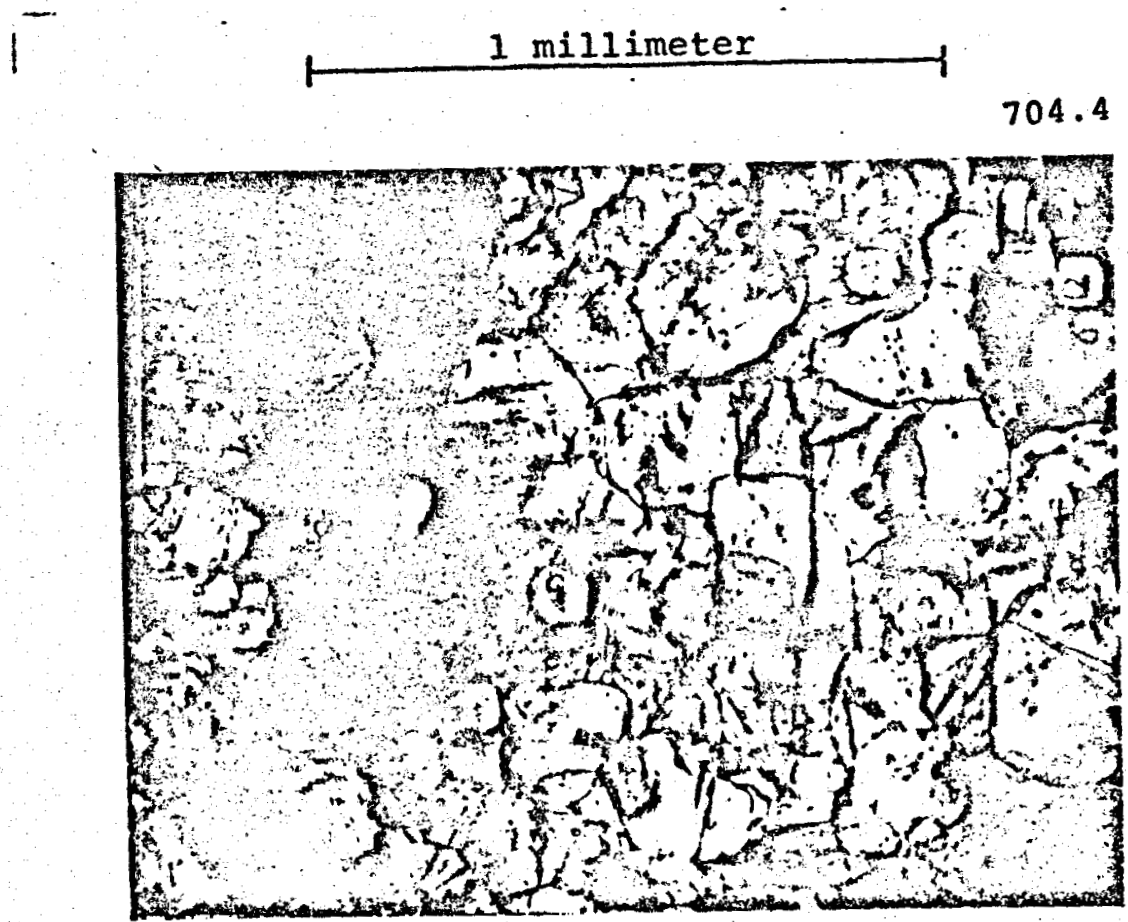

( $6-63-2-16-78$

Fig. 3. Microphotographs used in the study here. 
L
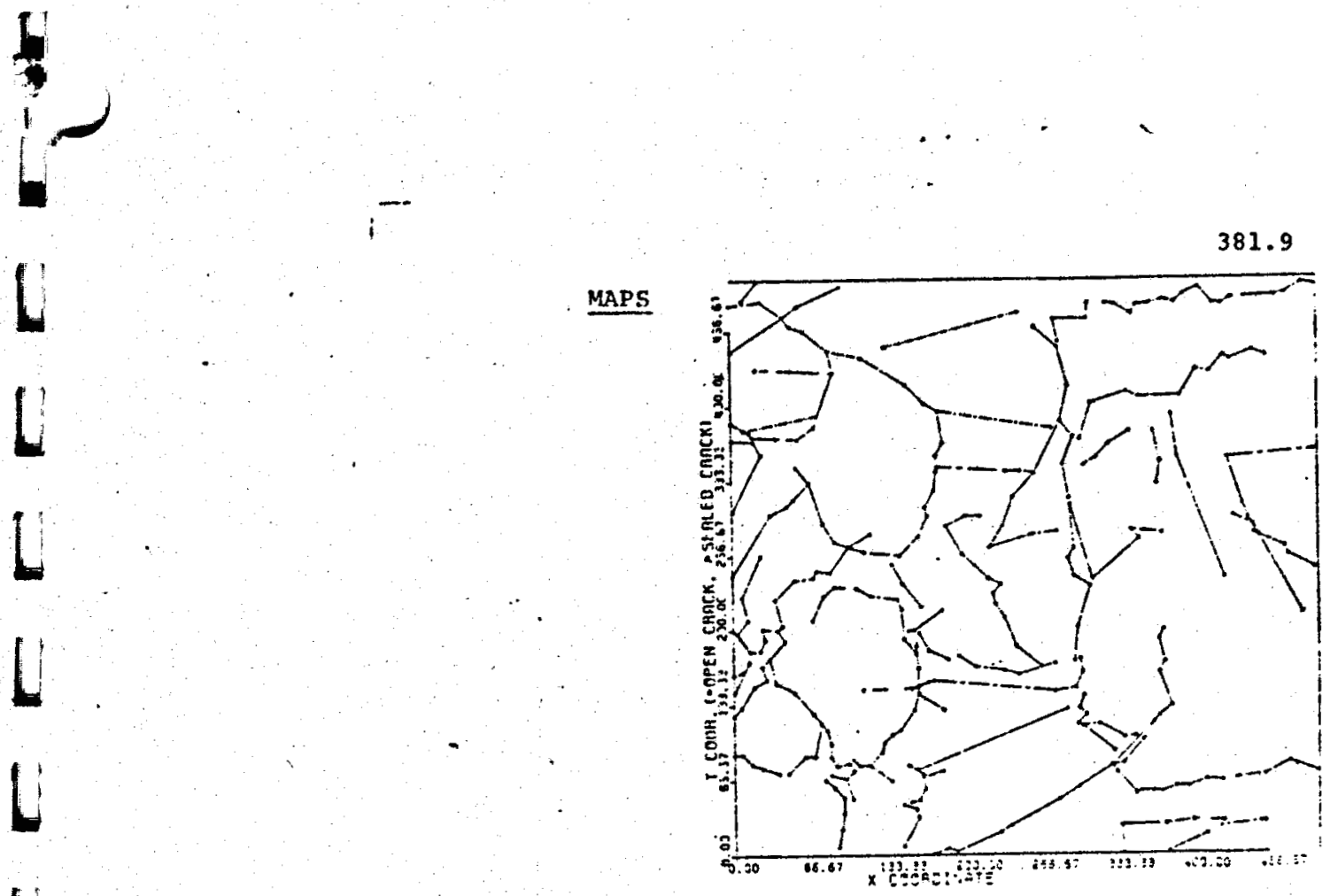

+ $3-63-1 n-18-77$

4

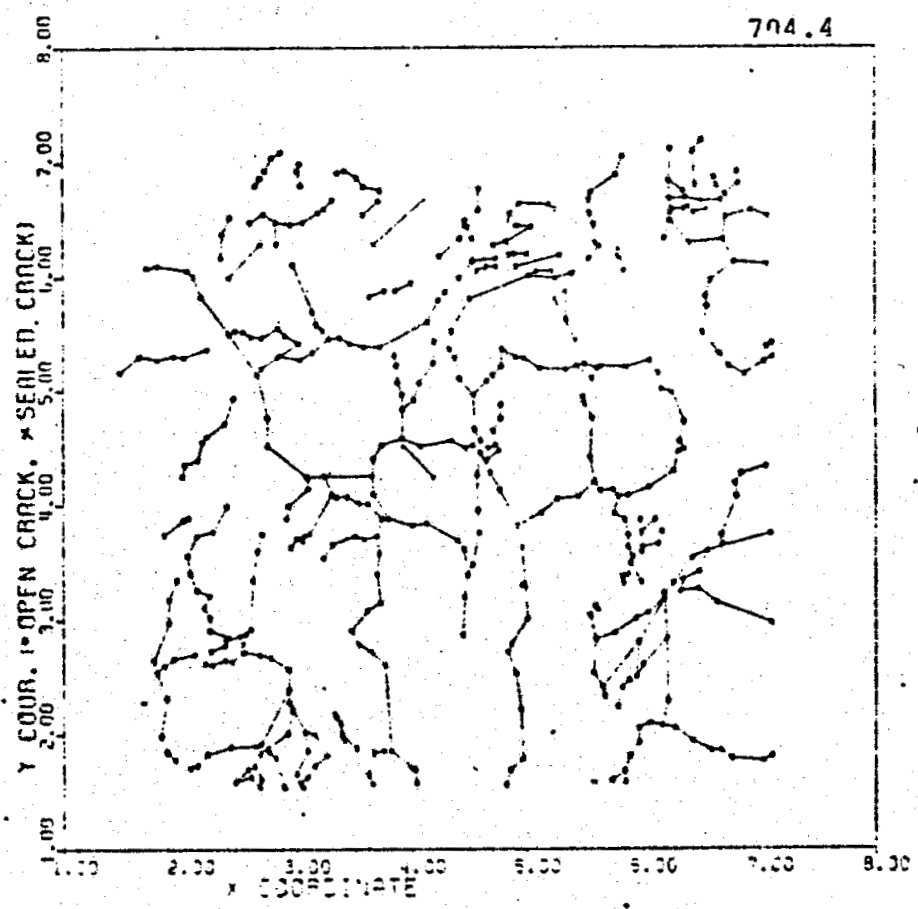

- 6-63-2-16-78

Fig. 4.

Computer generated patterns from the microphotographs shown in Fig. 3 . 
At UCLA a pixel grid was overlaid on the microphotographs and features traced onto the grid. The pixel spacing was $1 / 16$ in. The traced map made from the thin section was then enlarged and digitized directly. In this mapping, features smaller than pixel distances were not traced and features

- that were traced were located to about $1 / 4$ of a pixel spacing unit. The digitizing table was good to $\pm 0.01 \mathrm{in}$.

Under DIADS at Los Alamos, no grid was superimposed so the operator was free to decide on the level of resolution. Digitization was made on a television image of the original photograph and resolution on the scan corresponded to \pm 0.004 in.

B. Differences in Density of Mapping

At UCLA essentially all of the crack-like features were digitized that were on the scale of resolution at which the maps were made. At Los Alamos not all the features on the microphotographs were mapped. The operator made a prototypical mapping only, which included the major features. The operator. also tended to judge whether a crack-like feature constituted a real open crack or a healed or sealed feature. Only those that were judged open were digitized. Neither map was oriented.

Another procedural difference was that no standard instruction was given for digitizing along crack-like features. Only general guidelines were given:

1. That enough points be digitized to resolve crack trends with fair accuracy and with the minimum number of points necessary to do this.

2. That if a crack-like segment seemed to be straight and then kink, the kinked point should be digitized if that segment was on the order of or greater than that of the resolving grid unit.

\section{Comparison}

In summary, the difference in the two approaches are the following: at Los Alamos the photo image was worked with directly. The display was much more readable and the image quality was much higher. However, the operator tended to.digitize just a fraction or portion of the features which included mainly, but not all, apparently open cracks. At UCLA the digitized map was allready of lower resolution but all mapped features were digitized.

These differences showed themselves in comparison of the statistics of the two maps. Relative to the Los Alamos map, the UCLA map contained a larger crack density. That is, a greater number of data points were taken at UCLA. 
In the Los Alamos data, very few cracks were judged to join other cracks. That is, the number of actual forks or intersections was smaller than the number mapped in the UCLA section. Also, fewer crack grains (that is regions closed by a continuous crack) were digitized on the Los Alamos microphotograph.

The digitized data from both microphotographs were carefully checked for errors (repeated points, etc.). In the UCLA data the crack-grains that were mapped were augmented by closing almost closed or grain-like crack features.

This was done in order to generate a small but definite population of grain-like features for the demonstration in this report.

D. Relative Advantages of DIADS vs Other Digitization Techniques

The much higher resolving power at the same magnification and the ability to digitize the resolved differences indicate the importance of using DIADS. The ability to scan and judge the photo directly during digitization greatiy enhances objectivity. Neither technique resolves the problem of marking or doping cracks for positive identification of open features or crack networks. It can be suggested here that for some studies positive identification of cracks is not necessary. Statistical correlation of the patterns proceeds much more efficiently than the finding of actual or real open cracks. It is expected that actual cracks will be directly reflected in the statistical pattern. In this approach we also emphasize mapping these features at relatively low magnifications (that is, 32 power to 600 power) well below usual (Scanning Electron Microscopy) SEM magnifications used in crack studies. This is done for the same reason just noted.

\section{ANALYSIS}

A number of variables were chosen that could serve to characterize the mapped crack patterns and have physical significance. The analysis was done using a computer program developed explicitly for this type of study. The program is simply named SOCIOLOGY, in order to emphasize that the analysis it

- performs is one of pattern decomposition and parameterization devoid of modeling theory (see the Appendices for program description). In brief, through SOCIOLOGY, the mapped pattern is decomposed into tables of segment length, angle orientations, and connectivity, and then from these tables, distributions and characteristic parameters are generated which: quantify the 
description of the mapped pattern. The variables chosen, and their significances are given in Table 1. The mathematical definitions of key variables are given in Appendix $B$.

\section{RESULTS}

A. Crack Lengths

The first sets of histograms (Fig. 5) show a strong similarity between the two samples. The similarity is demonstrated to be real; that is, to be independent of techniques of digitization and of the persons doing the digitization. Three distributions are shown. These are the distributions of nearestneighbor distances between crack tips $D(J=1, k=1)$, the equivalent distributions for crack branch and fork points $D\left(J=3^{+}, K=-1\right)$, and the directly digitized crack segment lengths (CLS). The nearest neighbor distributions give the spacing between nodes of degrees 1 and $3^{+}$, independent of their connectivity. The CLS distribution gives the distances between adjacent connected nodes independent of degree. The physical significance of the $(J=1, K=1)$ and the $J=3^{+}, K=1$ ) distributions is indicated in Table 1 .

Three implications are directly apparent from the histograms. First, for either sample, the spatial probabilities of crack stopping or branching are equal (i.e., the distributions $D(J=1, K=1)$ and $D\left(J=3^{+}, K=1\right.$ ) are commensurate). This would not be expected for a highiy anisotrophic or schistose rock. [The problem with $\left(J=3^{+}, K=1\right)$ population for 381.9 may arise from the low count of intersections and forks as discussed in the first part of this section.]

Second, for either sample, the segment length distributions are commensurate with the nearest-neighbor distributions. This has a two-fold significance. First, it implies that crack segments are straight features between kink points. There is no a priori reason for a segment length distribution to have a physical significance, since $J=2$ nodes can be picked subjectively to give sufficient resolution of a curved line. Only the crack tip $(J=1)$ and branch point $(\mathrm{J}=3)$ distributions may be expected to be a priorily significant. However, if the crack between its ends and branch points is formed of straight segments between kink points then the tendency of the person doing the digitizing would be to only digitize kink points. The segment length distribution would then be a measure of the shortest distances along a crack between kink points. In Figure 5 the fact that for each sample all three 
TABLE I

SOCIOLOGICAL VARIABLES

(See Appendices $A$ and $B$ for nomenclature)

Variable

Type

Node

Node

Linear

Segment lengths between connected neighbors.
Linear $\quad C L(1,1)$

crack lengths of nonforking cracks.

\section{Significance}

This is a spatial distribution of crack tips in a cross section. This may be taken to be a measure of the distribution of a crack-stopping variable; namely, either low stress regions or barriers (high $k_{C}$ ).

This is the spatial distribution of a crack forking variable (either low stress regions into which cracks "sink," or higher K regions at which cracks may fork if they are growing in region II. The super-script $(+)$ simply denotes that the degree of the node is equal to or greater than 3 .

The similarity or difference of these two distributions is a measure of whether the (spatial) probability for a crack to stop is the same as for a crack to fork, and hence, it gives an inference as to whether the same material properties control both probabilities.

This variable may be taken as a measure of the mean-free-path of crack growth. Kink points can be mapped either where an apparently straight crack segment kinks (small change in angle), or can be mapped as a point needed to resolve the curvature of a crack. That is kink-points $(J=2)$ are not as uniquely specifiable between operators as are nodes $\mathrm{J}=1$ or $\mathrm{J}=3^{+}$. However, IN A WELL PLANNED MAPPING STUDY this distribution can become a measure of the probable distance a crack may grow without meeting any barrrier. THIS BECOMES A MEASURE OF THE SCALE OF HOMOGENEITY.

These are crack lengths for cracks defined by strings of connected nodes $(J=1,1)$ and $(J=1,2 \ldots .2,1)$ only. These distances can be taken as crack-diffusion-distances.

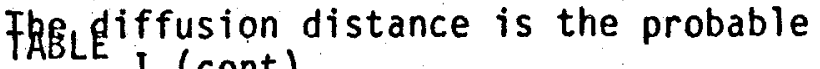


TABLE I (cont.)

$\begin{gathered}\text { Variable } \\ \text { Type }\end{gathered}$
Linear $\quad \begin{gathered}\text { Variable } \\ \text { Description/Name }\left(1,3^{+}\right)\end{gathered}$

Angle $\frac{\text { Segment angle }}{\text { orientation of }}$ CLS.

This is a direct measure of preferred orientation. The orientation distribution is determined by stress field, crystallographic, and mineralogical variables.

\section{Linear/ CLS length versus Angle angle. \\ Angle Max., min. branch angles that is the Targest and smallest inter- angles at a branch point.}

Closure Crack-grain area and shape. Angle $\frac{\text { Grain.principal }}{\text { direction. }}$

:

Node
Nearest-neighbor distances between crack grains.
Characterizes the degree of isotropy of the crack growth mean-free-path.

This gives a measure of interaction of stress fields and the relations to crystallographic and mineralogical control.

Area and shape (flatness and aspect ratio) are defined in Appendix B. A cross-plot of these two variables shows size-shape clustering of crack grains, indicating for example; mosaic fitting of cracks due to crystallographic control.

This is the direction of the principal axis of a grain, and characterizes preferred orientation of crack grains (stress freed regions).

A crack grain indicates a stress-freed region. The spatial distribution of such regions is a measure of the distribution of stress concentrations. 

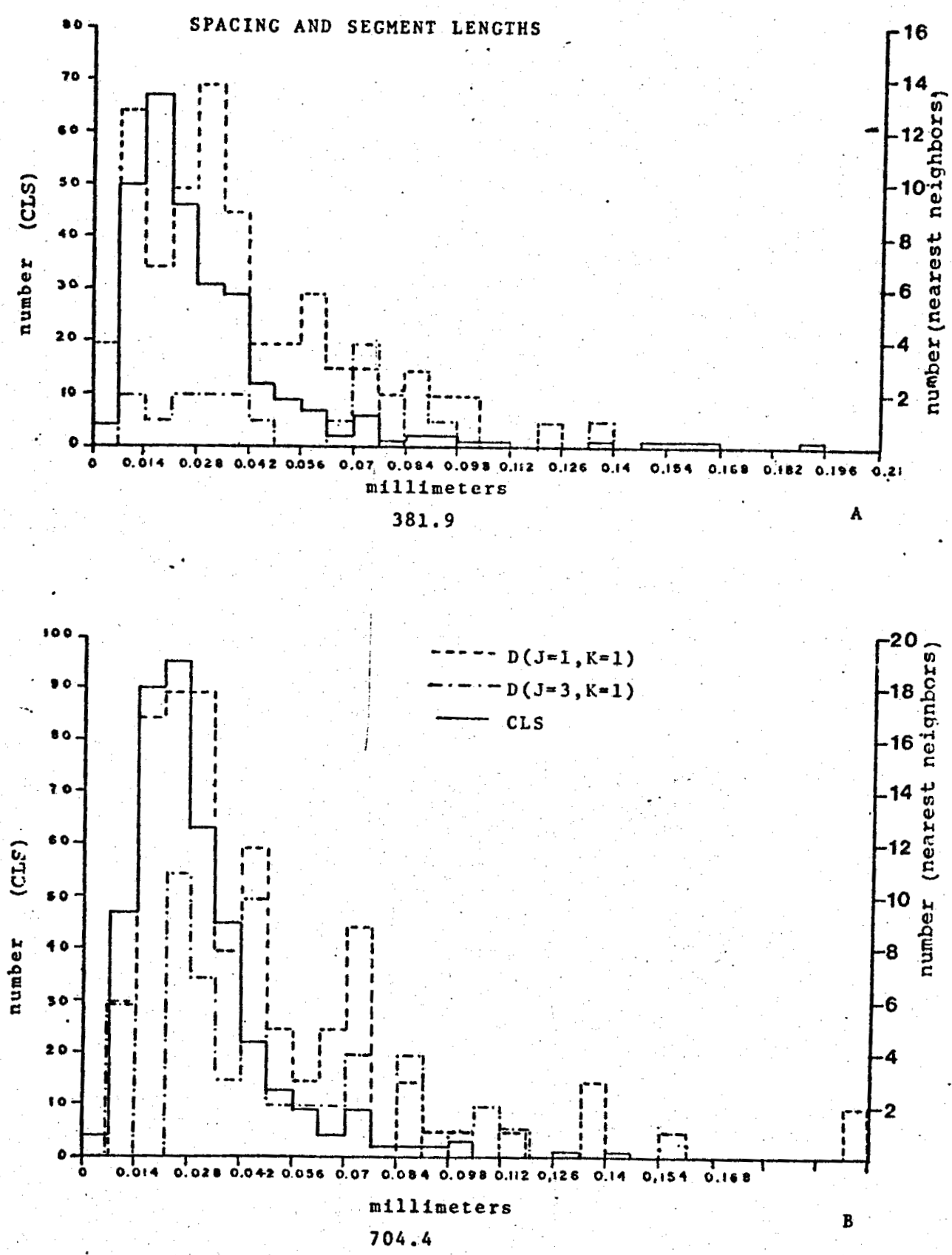

Fig. 5 .

Histograms of nearest-neighbor distances between crack tips $[D(J=1, K=1)]$, between crack forks $\left[D\left(J=3^{+}, K=1\right)\right]$, and the segment lengths of continuous crack segments (CLS).

distributions are commensurate demonstrates that the spatial probability distributions for a crack to stop, to kink, or to branch are equal. The samples can, therefore, be modeled as having to first order uniform dijstributions of crack-growth-barriers; the spatial probabilities of a crack stopping, kinking, or branching being equal. 
Third, the fact that the probability distributions controlling potential crack growth are to first order equivalent in both rocks is in full agreement with the similarity predicted by the crack spectra obtained from the velocity data.

Although these distributions are not direct measures of the actual microstructure or fine cracks which control elastic modudli, a very striking agreement is found for these results and those of other studies designed to determine actual crack length distributions. (The problem of measuring true crack length distributions is discussed in Appendix D.) An important effort was made by Hadley (1976). She used 400x SEM microphotographs of westerly granite for which she directly measured crack lengths and widths. She defined a single crack to be "any open flaw of aspect ratio less than I which did not change orientation by more than $20^{\circ}$ over any significant portion of its lenth and which was either continuously open or bridged by material of exposed thickness no more than three crack width or one tenth of the total crack length, whichever was less."

Figure 6 is a superposition of her crack length distributions for two samples of westerly granite along with the CLS distribution for 704.4. The lowest curve is for unstressed granite, and the uppermost curve is for prestressed granite W.5, (which was cyclyed to 0.68 GP differential stress at 0.08 GP confining pressure). None of the sets of data are normalized to each. other, however, Hadley's micrograph covered "about $1 \mathrm{~mm}^{2}$," and the areas covered in our mapping of 704.4 was almost exactly $1 \mathrm{~mm}^{2}$. It is stricking that the crack length ranges plotted for the three samples in the figure, are very similar. Hadley's definition of crack length agrees well with the natural CLS determined for the Conway granite sample. In this case, the CLS can be taken as a measure of the probable distance a crack may grow without meeting a significant barrier. That is, the mean CLS can be interpreted as a measure of the mean-free-path of crack growth.

Although samples 381.9 and 704.4 can be said to have to first order uniform distributions of crack-growth-barriers, there are anisotropic components in the distribution of the CLS, or more appropriately the crack growth-free-paths. For the mapped area of sample 704.4, the mean lengths of the free-paths and the probability of crack growth are not independent of direction. This is shown in Figs. $7 a$ and $b$, which contour the crack-segment frequency as functions of segment length and angle. The $90^{\circ}$ direction is 


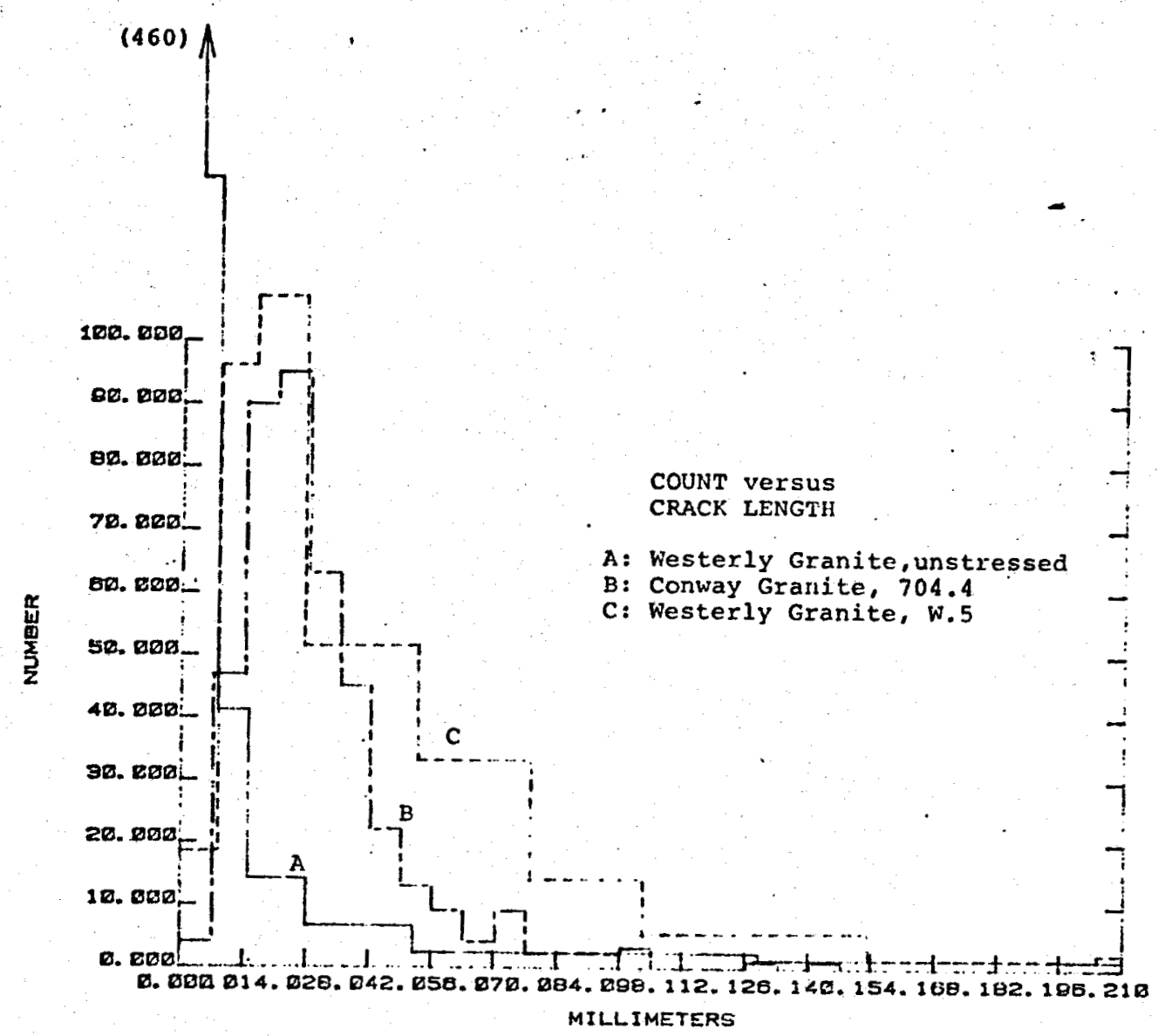

Fig. 6.

Superposition of crack length distribution from Hadley (1976) and the CLS. distribution for 704.4 shown in Fig. 5.

arbitrarily chosen as the vertical in the image plane. Peaks appear in the $0^{\circ}-180^{\circ}$ line, and in the $90^{\circ}-270^{\circ}$ direction. The effect of this orthogonal gridding shows itself in the control of crack-grain formation which is discussed later. The map for 381.9 (Figs. $7 \mathrm{c}$ and $d$ ) shows a main horizontal girdle. There may be secondary (nonorthogonal) griddings at $40^{\circ}$ and $120^{\circ}$.

The second set of histograms ( $F i g .8$ ) give distributions of cumulated crack-segment lengths, or more simple, the 'crack-length' distributions CL(1, 1), $\mathrm{CL}\left(1,3^{+}\right)$, and $\mathrm{CL}\left(3^{+}, 3^{+}\right)$. Obviously, here cracks are now defined to go from a tip to another tip, or to a branch point, or between two branch points. $A-c r a c k$ defined this way is not necessarily straight but as defined in the table, may be called a "diffusion distance."

The data here are biased by two effects: First, for 381.9 the number of free ends may be skewed with respect to the number of branch points since fewer branch points were mapped in comparison to the data for 704.4. Second, 


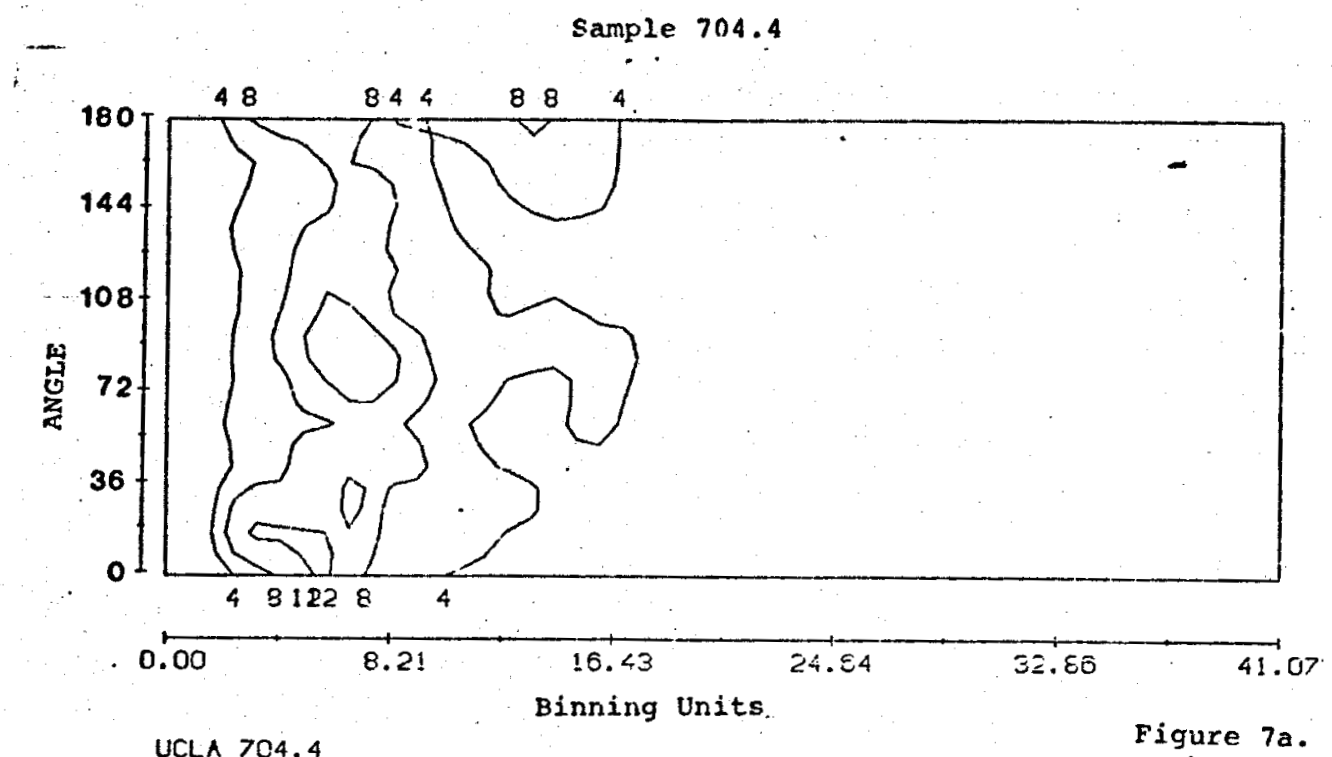

i

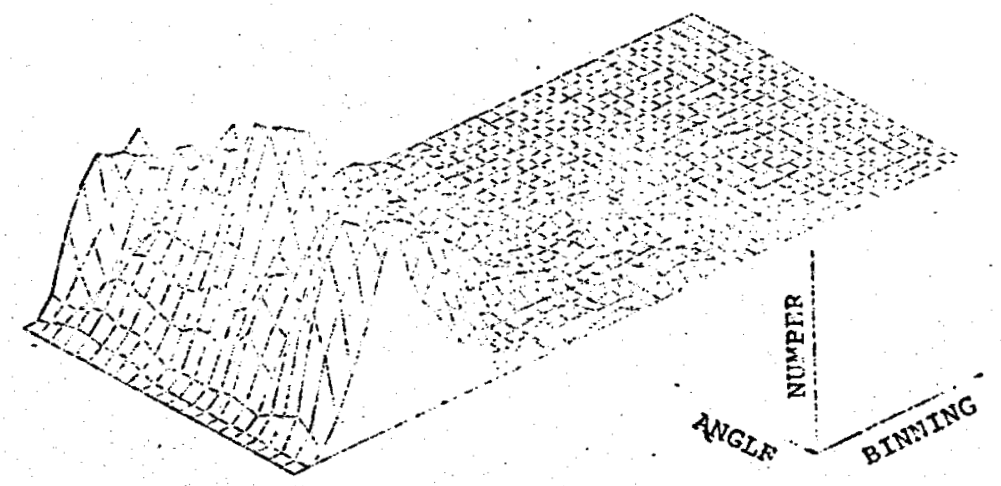

UCLA $704.4^{\circ}$

AZIMUTH 225.00 DEGREES

ELEVATION 30.00 DEGREES

figure $7 b$.

Fig. 7.

The crack segment length-angle distributions. Figures $7 a$ and $c$ show contour plots. Figures $b$ and $d$ show the three-dimensional display of the same data.

the data include artificial augmentations of the $C L(1,1)$ and $C L\left(1,3^{+}\right)$populations. Any crack that cuts the boundary of the map area generates a $\mathrm{J}=1$ node on the map boundary. This subpopulation was not removed for the demonstration study here. The result, nevertheless, is that for either rock, crack diffusion distances are about the same for all three types of crack populations (although the distributions may be flatter for sample 381.9). This is consistent with the results in fig. 5.

Figure 9 shows the dominant crack branching angles for the two samples. If at a branch point, all angles are equal, then they are equal to $120^{\circ}$. If a 

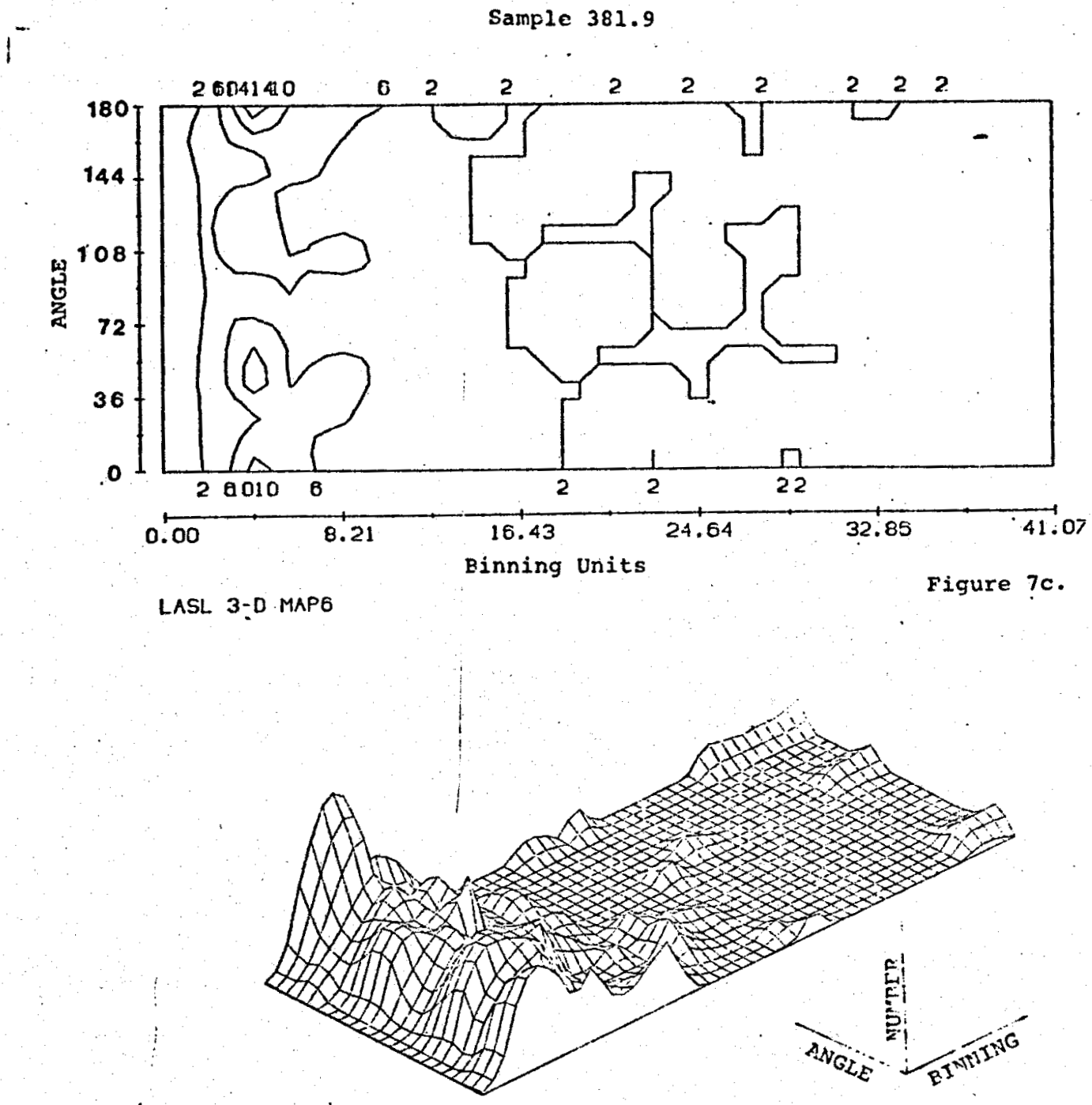

LASL $3-0$

AZIMUTH 225.00 DEGREES

ELEVATION 30.00 DEGREES

Figure $7 d$.

Fig. 7 (cont).

crack branch grows off (or into) a straight crack, then the maximum interangle is $180^{\circ}$ and the minimum intercrack angle is equal to or less than $90^{\circ}$. Both samples show tendericies to form this latter form of crack pattern. Peaks are observable in the data for preferred interangles. These are especially clear in the distribution for 704.4 .

B. Crack-Grains

As discussed earlier, the crack pattern for 704.4 tended to form closed areas or grain-like regions bounded by cracks. These closed areas were characterized using the subroutine of SOCIOLOGY named BORDER. The crack-grain 
CRACK LENGTHS

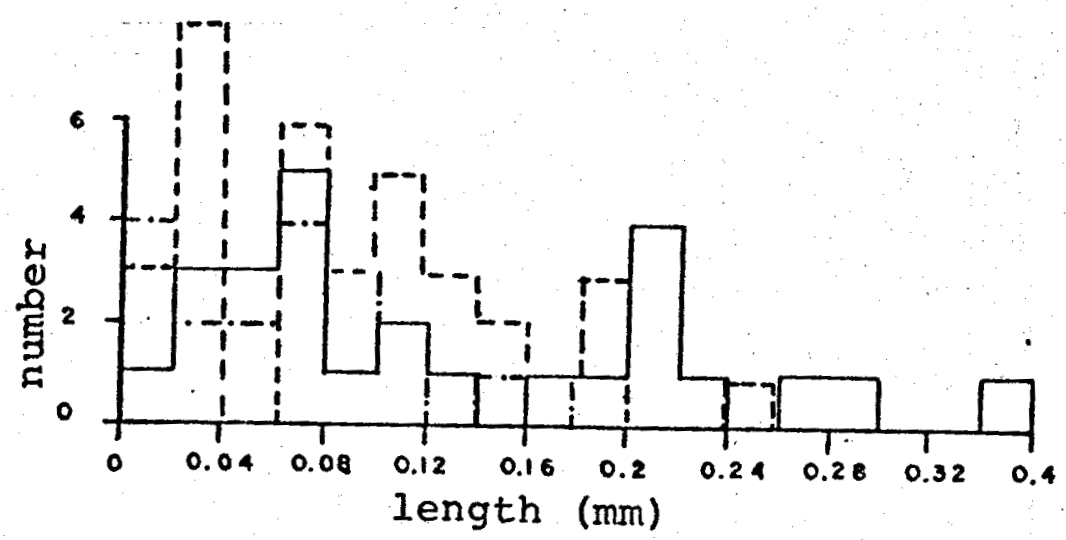

381.9

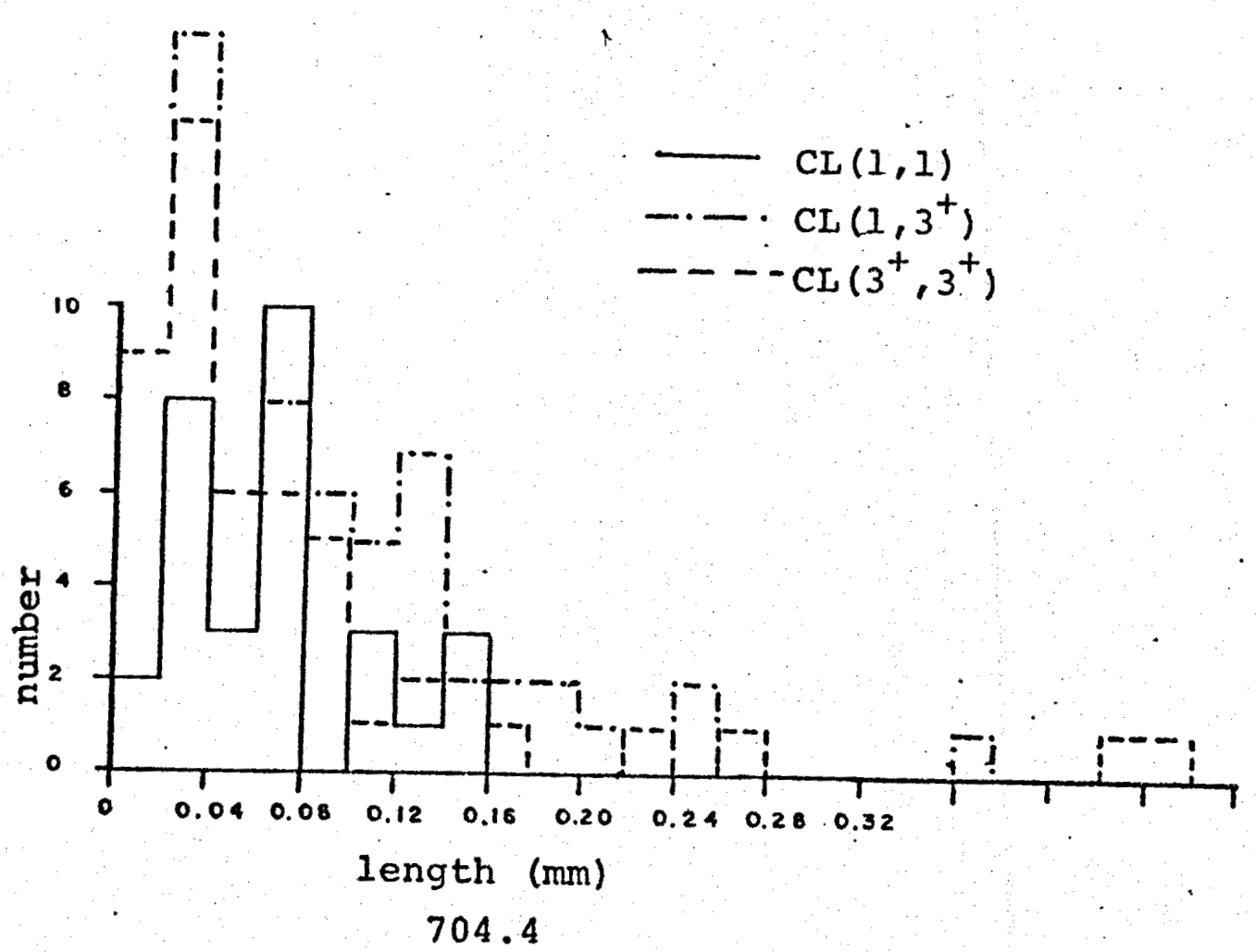

Fig. 8.

Cumulated crack-segment lengths. The three distributions are for cracks which do not fork $[\mathrm{CL}(1,1)]$, for cracks which start from a crack tip and run to a crack fork $\left[\mathrm{CL}_{2}\left(1,3^{+}\right)\right]$, and for cracks which run from a crack fork to a crack fork $\left[\mathrm{CL}\left(3^{+}, 3^{+}\right)\right]$. 

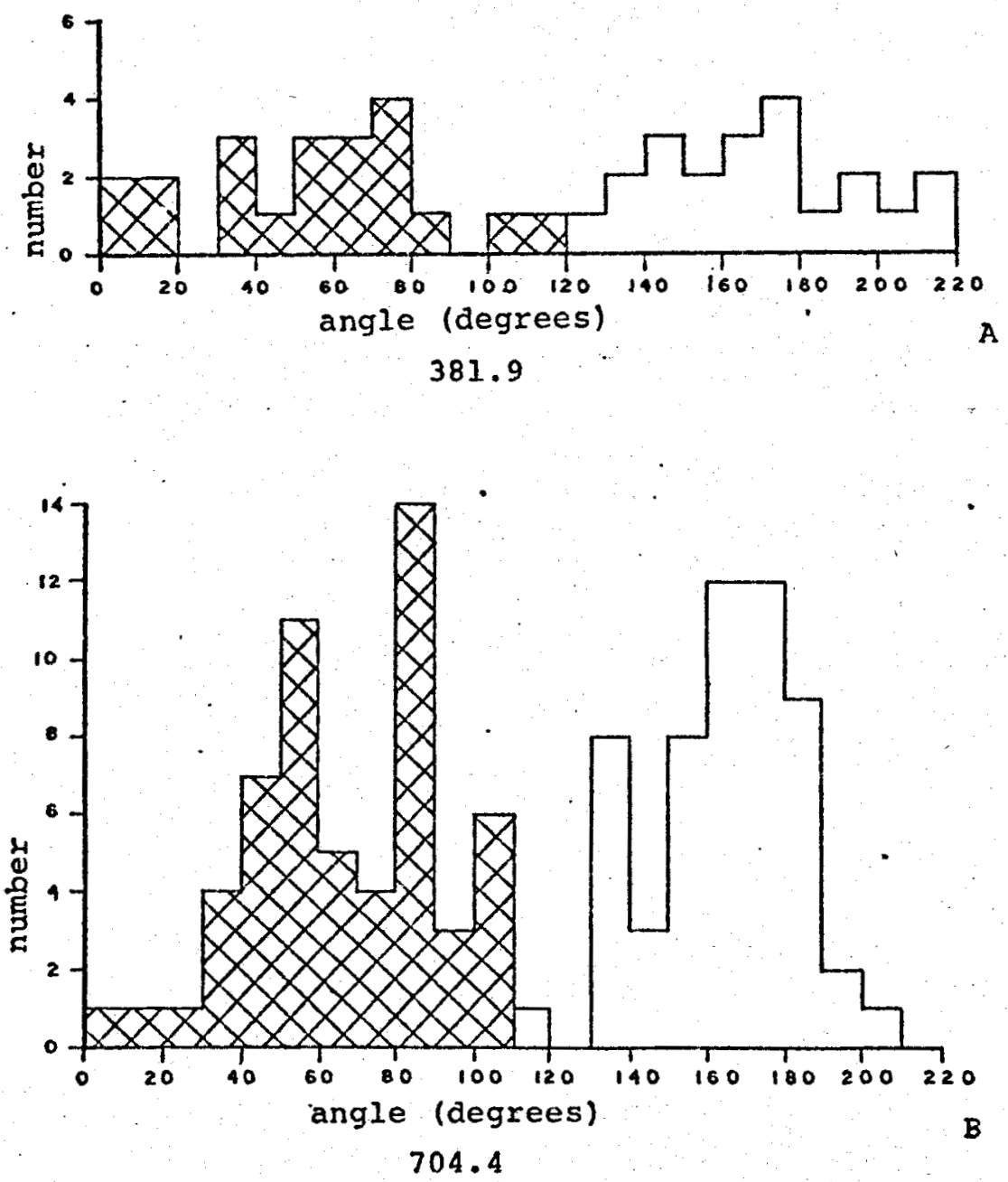

smallest angle $\bigotimes$

maximum angle

Fig. 9.

- Distribütions of maximum and minimum interangles at crack branch points.

size distribution tends to be bimodal. There are a number of small crackgrains and fewer larger grains. These two populations are also separated by differences in shape and preferred orientation. 
Figure 10 is a plot of grain area versus flatness. The larger grains tend to be equidimensional; that is, to have flatness near 1.0 to 1.5 . The smaller crack-grains have a greater range of flatiesses with the grain shapes varying from almost round to very flat.

Small crack-grains have an unique orientation distribution (Fig. 11). The major axes of the grains tend to form an orthogonal grid which is rotated by $45^{\circ}$ about the dominant orientation of the large crack grains. Therefore, the two sets of crack grains each generate their own sets of cracks with: preferred orientation. Large grains align with the dominant crack trends in the mapped sample, and form the major mosaic of the fracture pattern. The small grains are set in corners of this dominant pattern.

Figure 12 shows the spatial distributions of these two populations. In the figure are plotted the nearest neighbor and second nearest neighbor distances for the grains marked by their centers-of-mass. Large grains, being aligned with the dominant crack pattern, can form contiguous groups. On the other hand, there are seldom more than two small grains contiguous with each other. Therefore, as seen in the figure, the nearest neighbor spacings of the grains are almost equal to the mean grain dimensions (given by the squareroots of the averaged grain area) but the spacings to the second nearest neighbors are very different for the two populations.

\section{DISCUSSION}

A large volume of data has been generated from the two maps. The basic data reduction was done very efficiently on the UCLA 3033 IBM computer. The running times for SOCIOLOGY (Prune and Border) were less than six seconds for either the 452 node map of 704.4 or the 303 node map of 381.9. Therefore, multi-map large studies are economically feasible.

At present the software system for making a full study is not completed. That is, we do not yet have interactive capacity and direct integration of output from SOCIOLOGY with various statistical factor analysis packages. However, such a fully interactive system can be developed using, for example, a - Hewlett-Packard IMAGE Data Base Management System Package.

A. What Can Be Learned From Such Studies

Even in the extremely limited study here, enough consistency appears in the reduced data to suggest that some of the results are significant, in 


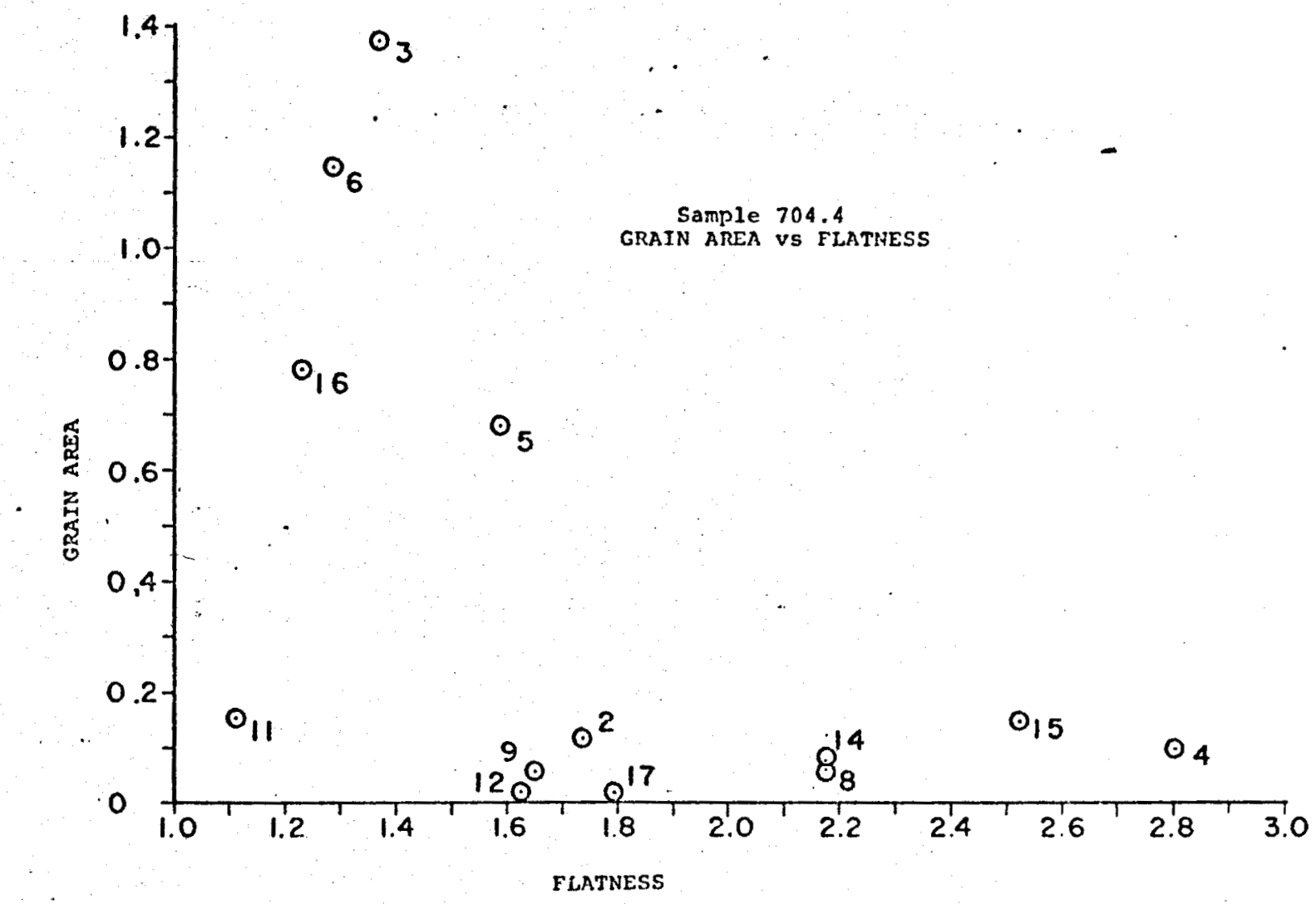

Grain area vs flatness. Area units are in map units (not corverted to $\mathrm{mm}^{2}$ ).

particular the match between the distributions of CLS and Hadley's crack measurements. The similarity of the distributions for both conway granite samples is satisfying in light of the similarity of the velocity spectra obtained earlier. The mean-free-path and diffusion distances appear as imediately interesting physical quantities.

The ability to readily establish such parameters has several implications. These can be seen by considering a few points. First, the established measures are statistical parameters. Therefore, one can phrase problems of crack growth in the frame of statistics. Probability distributions of crack lengths can be established without needing to make a complete identification of all cracks. Such probability distributions of length can be, for example, convolved with the perferred crack spectra to yield most probable distributions of crack-aspect ratios or widths, etc. In this way probability distributions can be used to model the medium in which cracks may grow. That is, they may constrain models of materials in crack growth studies. In relation to such studies, data generated by SOCIOLOGY can be used to provide 


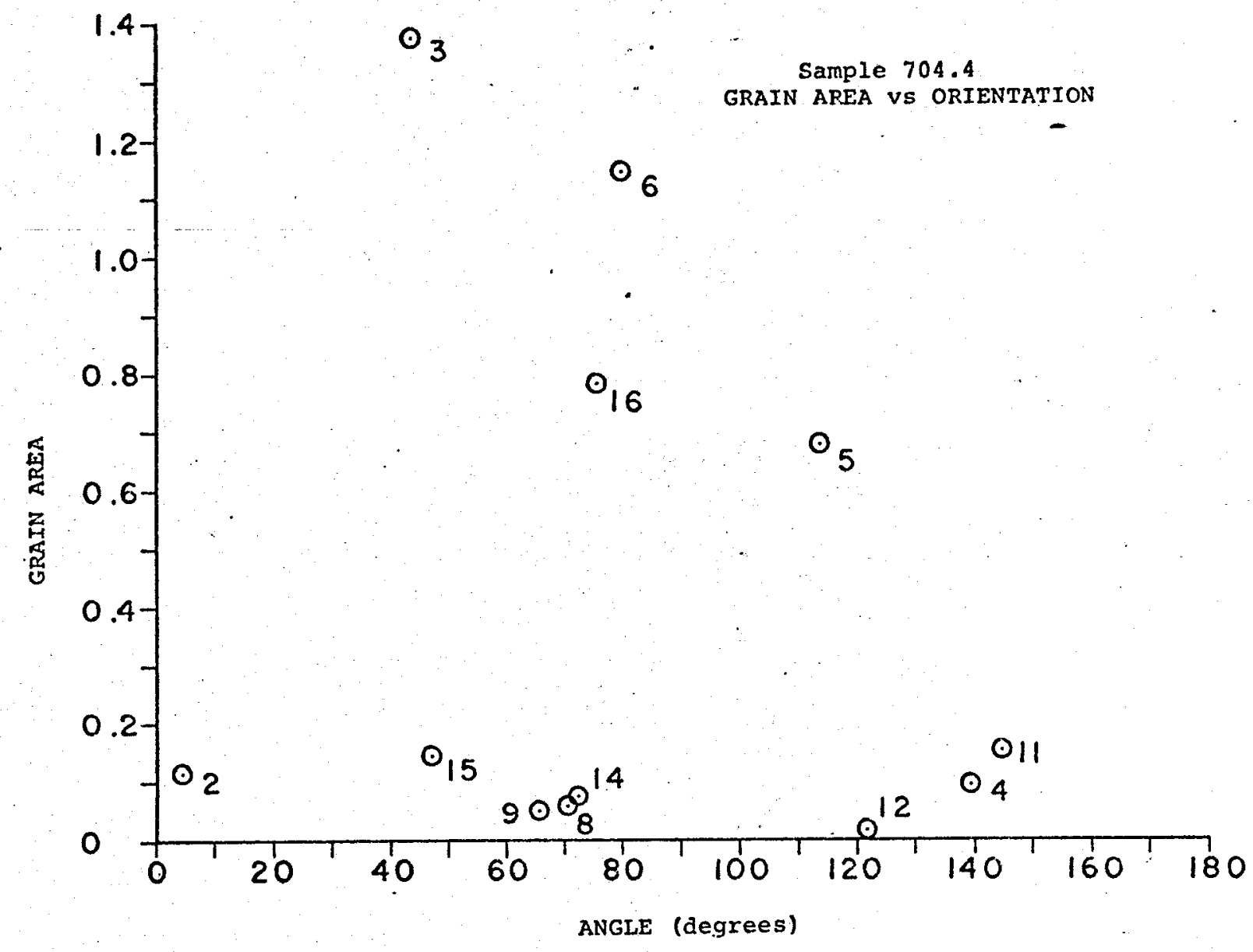

Fig. 11.

Grain area vs grain orientation.

quantitative definitions of other material properties. Although not done here, a measure of tortuosity can be defined as well as measures of crack connectivity, which enter directly into modelling, permeability, resistivity etc.

A second point concerns the problem of how such data as generated here can be correlated to, or summarized to describe rock structure in a way as to generate predictions of other types of rock-properties. Although a formal treatment of this task is not carried out here, a simple demonstration follows in order to show here how the data presented in the last section can be synthesized in a form suitable for this task.

In doing this, two analytic questions are very apparent and of immediate interest. The first concerns similarity, the second concerns predication. 

similar based on the similarities in their petrostructure. At the second level, the absolute behavior of the physical property is to be predicted.

The first level of prediction is based on the assumption that there is a strong correlation between petrostructural variables and physical properties. As an example, Fig. 13 shows that the correlation of the crack spectra of 381.9 and 704.4 is on the same order as the correlation between the measured petrostructural variables in the preceding section. The figure can be interpreted as being analog to a correlation matrix of the data presented in the last section. The figure has been generated in the following way. For any pair or set of data, such as that for the segment length distributions shown in Fig. 5, the ordinate values of any two pairs of graphs can be plotted against each other. Irrespective of the scate or unit of the abscissa of the cross-plotted graphs, if the curves are similar, then the diagram generated by cross plotting the $y$ values should show a clustering along the $45^{\circ}$ diagonal. For two samples with similar structures, but with a scale factor shift between them, the linear trend of the plot will fall off the $45^{\circ}$ diagonal. In the case of little or no correlation, no linear trend will be seen. This technique can be used for many pairs of variables to generate both correiation and cross-correlation graphs:

In Fig. 13a the data for CLS are plotted for 381.9 against those for 704.4. Figure 13b shows a similar crossplot for a crack spectra obtained from the velocity data. The measured correlation in the moduli are seen to have the same order or correlation as the segment lengths.

The use of such plots as a measure of the similarities of two objects indicates the form of prediction at the first level; namely, the use of a measure of the tightness of grouping within one set of variables to predict the level of significance of tightness within a second set of variables.

Figure 14 shows four variables plotted against each other. The basic similarity of the two samples is established over all the variables.

In a true factor analysis, studies of -the data such as generated here would be searched for underlying and invisible factors which would serve to reduce the dimensionality of the data and maximize the predictive value of the data. such techniques can be extremely valuable in rock geophysics. There is a great power in being able to apply statistical methods to problems in rock mechanics. 


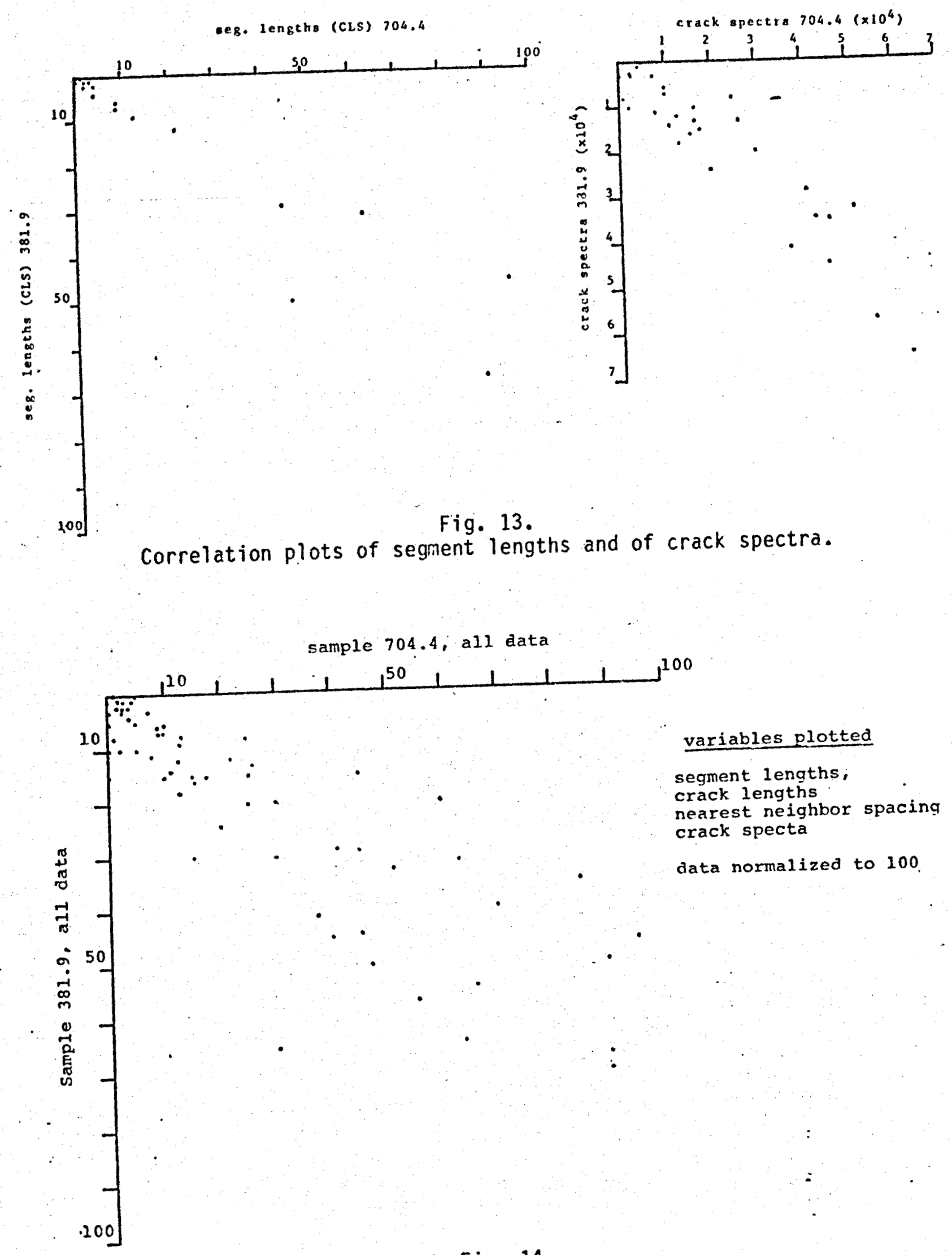

Fig. 14.

Correlation plot for four variables. 


\section{ACKNOWLEDGMENTS}

The Petrostructure Analysis Program has been developed at UCLA under DOE support (DE-AS03-76SF 00034, PA\# DE-ATO3-76ER70224) in condjunction with G-4 and $G-5$ at Los Alamos Scientific Laboratory. At Los Alamos, I wish to thank Dr. J. Breedlove for his help on DIADS, and Drs. T. Dey and T. Shankland for criticaliy reviewing the original manuscript and making a number of important suggestions. At UCLA, I wish to give special recognition to Mr. J. Haggerty and Mrs. Man Cheng for programming and running SOCIOLOGY.

\section{REFERENCES}

1. Abey, A. E., "A Computer Model for Stress-Volume Relationships of Porous Rocks with Various Saturations," Rock Mechanics 13, no. 4, 235-244, March (1981).

2. Bennett, H. F., "A Simple Seismic Model for Determining Principal Anisotropic Direction," J. Geophys. Res. 77, 3078-3080 (1972).

3. Brace, W. F., "Relation of Elastic Properties of Rocks to Fabric," J. Geophys. Res. 70, 5657-5668 (1965).

4. Brace, W. F., "Micromechanics in Rock Systems" in Structure, Solid Mechanics and Engineering Design: The Proceedings of the Southhampton 1969 Civil Engineering Materials Conference, Ed. M. Te'eni, Wiley-Interscience,

5. Breedlove, J., "Mini Computer Based Interactive Image Processing" in Proceedings of the First Micro and Mini Computer Canference, November 1978, Houston (1978).

6. Butkovich, T. R., "A Technique for Generating Pressure-Volume Relationships and Failure Envelopes for Rocks," Manuseript No. UCRL-51411, Livermore, California: Lawrence Livermore Laboratory (1973).

7. Davis, J. C., Statistics and Data Analysis in Geology, John wiley and Sons, Inc., New York, 550 pp. (1973).

8. Friedman, M., and Bur, T. R.,. "Investigations of the Relations Among Residual Strain, Fabric, Fracture, and UItrasonic Attenuation and Velocity in Rocks," International Journal of Rock Mechanies and Mining Sciences 11 , 221-234 (1974).

9. Hadley, K. "Comparison of Calculated and Obsenwed Crack Densities and Seismic Velocities in Westerly Granite," J. Geophys. Res. 81, no. 20, 3484-3493, July (1976).

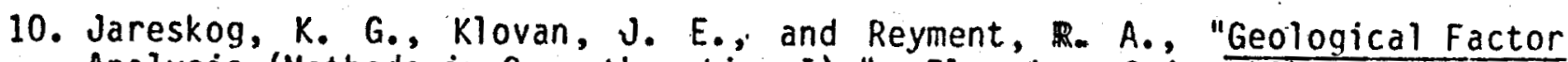
Analysis (Methods in Geomathematics I), "Elsevier Scientific Publishing Company, Amsterdam, 174 pp. (1976). 
11. Mavko, G. M., and A. Nur, "The Effect of Nonelliptical Cracks on the Compressibility of Rocks," J. Geophys. Res. 83, 4459-4468 (1978).

12. O'Connell, R. J. and B. Budiansky, "Seismic Velocities in Dry and Saturated Cracked Solids," J. Geophys. Res. 79, no. 35, 5412-5426 (1974).

13. Simmons, B., Siegfried, R. W., and Feves, M., "A New Method for Examining Cracks in Rocks," J. Geophys. Res. 19 , 4383-4385 (1974).

14. Tilmann, S. E. and Hugh F. Bennett, "A Sonic Method for Petrographic Analysis," J. Geophys. Res. 78 , no. 35, 8463-8469 (1973).

15. Walsh, J. B., "The Effect of Cracks on the Compressibility of Rock," J. Geophys. Res., 70 381-389 (1965a)..

16. Walsh, J. B.:."The Effect of Cracks on the Uniaxial Elastic Compression of Rocks," J. Geophys. Res. 70, 399-411 (1965b).

17. Warren, N., "Rock Physics Characterization of Conway Granite fron a DOE Borehole, Conway, New Hampshire," Los Alamos Sci. Lab. Rpt. LA-8102-MS, Los Alamos Scientific Laboratory, New Mexico (1979).

18. Warren, N., and M. Tiernan, "Systematics of Crack Controlled Mechanical Properties for a Suite of Conway Granites from the White Mountains, New Hampshire," Tectonophysics 73, 295-322 (1981).

\section{APPENDIX A \\ PETROSTRUCTURE ANALYSIS \\ PHILOSOPHY AND LOGIC}

\section{GENERAL COMMENTS}

In the approach taken in this study, both physical properties and petrostructure are to be taken as statistical data. This approach necessitates the demonstration that statistical systematics exist in some class of rock properties. Such systematics must occur at a sufficient level of resolution to infer that underlying.variables can be found. The systematics in one class of properties must be of a type to reasonabiy imply correlated systematics and predictable systematics among other variables.

\section{A. Moduli Systematics}

In a study which addressed this problem, Warren and Trice $(1975,1977)$ showed that over a large spectrum of rock types, from competent granites to porous sandstones and breccias, the functional forms of velocity-pressure data 
exhibit predictable behavioral regularities (i.e., systematics) which are characteristic of the texture and fabric of that specific rock type.

Continuing this work in a more quantitative vein, warren (1977) further showed that such regularities can be represented in terms of a fairly general theoretical model of crack and pore behavior. Warren and Tiernan (1981) extended the concept of the preceding work to rocks within one class of similar fabric and texture. The study demonstrated that the much smaller texture and fabric differences between rocks with essentially the same mineralogy and geologic history are reflected in the systematics of pressure-dependence of the mechanical properties. We have, therefore, established that correlations between bulk properties and observable rock structure do exist at the proper level of significance. The detailed functional forms of static strains (Simmons et al., 1974) and velocity-pressure data give proper measures of the average microstructure in the rocks. However, these measures are not yet sufficient to determine the related microstructures.

B. Structure Systematics

A second aspect is necessary in the approach. The second task is to invent a sufficiently broad and general method to economically characterize and parameterize rock structure itself and to do so in such a way that similarity tests can be made between different rocks and in correlation to such physical properties as those mentioned above.

There are three parts to this task. These are:

1. Obtaining input data from rock thin sections.

2. Sorting and binning the values of the variables generated from the input data.

3. Developing statistically meaningful tests.

There are four requirements on such an analysis. The parameterization must:

1. Allow one to group rocks together based on their microstructure and textural patterns;

2. Provide a characterization of the crack networks and fabric sufficient to qualitatively associate network features with various mechanical properties;

3. Establish quantitative relations between measurable petrographic features and details of bulk properties.

The methodology of petrostructure analysis is being developed to meet these tasks: 
11. BASIC DEFINITIONS AND NOTIONS OF A PETROSTRUCTURE ANALYSIS

A. Definition of Petrostructure

Petrostructure may be thought of as a modelling space spanned by three axes: - the mineralolgical, the petrographic, and the microstructure (microcrack) variables. It is into this space that bulk physical and mechanical properties are to be correlated onto classes of allowed petrostructure.

Petrostructure variables fall broadly into two groups:

\section{(1) Topographic \\ (2) Compositional}

The compositional variables (e.g. chemistry and mineralogy) are fairiy directly quantifiable. Topographic variables are patterning variables which must be quantified through mapping. Every topographic pattern is composed of some combination of line element networks with at least one free end and/or closed networks, that is, line patterns having no free ends. These two classes of patterns are decomposed by a mapping technique which preserves the statistics of the pattern geometry.

Mapping variables fall into four classes. These are:

- Nodal variables: which describe point relations such as those for crack end-points and crack branch-points.

- Linear variables: which describe line features such as lengths along crack segments and accumulated crack distances.

- Angle variables: which describe orientations of cracks and crackrelated fratures, such as the major axes of crack-grains.

- closure variables: which describe closed features such as crackgrains by their areas and shapes.

B. Requirements for the Mapping Technique

1. Be both time and cost efficient, allowing one to study a large sample base for statistical analyses.

2. Allow decomposition of a wide range of possible (mappable) networks.

3. Allow possible tests for the completeness of characterization. In particular, allow inverse modelling; i.e., the generation of statistically equivalent networks on the scale of the original resolution of the network pattern.

4. Be scale invariant. That is, the resolution of the technique is to be limited only by the resolution of the original map or microphotograph. 
C. Mapping and Analysis

For the mapping of thin sections, three sets of map parameters have been chosen.

1. Sets of coordinate points (pattern nodes) $(x, y)$.

2. Listings of connected points $\left(n_{1} n_{2} n_{3} n_{4} \ldots n_{j}\right)$.

3. Flag values $\left(F_{j}\right)$ which specify the nature of connectivity between points, or identify, or distinguish a group of points.

The value of these three variables are specified in the process of digitizing a map or photo of the network.

The ideal digitization process produces, in the shortest possible time, the smallest possible output set which corresponds with exactly one pattern.

D. The Network Form

In the digitized pattern every node has some identity, that is, some flag value and connectiveness to its neighbor(s). The degree $(n)$ of a node is equal to its number of immediate connected neighbors, which is denoted by the number $\mathrm{J}=\underline{n}$. The evaluated map parameters are arranged (by computer program) into a table of points, distances, and angles between any one point and up to six of its connected neighbors. The tabulated network is operated on by a number of statistical analysis routines using three specially written major subroutines. These subroutines are based on the intrinsic nature of any network mapped in Input format.

E. Major Subroutines

SOCIOLOGY consists of three major subroutines, which operate on the network table. The subroutines are PRUNE, BORDER, AND PSUEDOCLOSURE.

1. PRUNE: This subroutine decomposes any open line network in a step-wise process, and in the process, characterizes the open network by resultant length and angle distributions.

Output from PRUNE includes distributions of the node distances, the line segment lengths, cumulative line length per unit area, the angle distributions of the segments, and a distribution of segment length versus angle.

2. BORDER: This subroutine decomposes any remaining network of closed paths. The output consists of grain areas, roundness, aspect ratio, principal axes direction. 
3. PSUEDOCLOSURE: This subroutine generates a measure of crack pattern closure. Line segments are extended from the free ends $(J=1)$ to test for intersection with other local line segments. The output of this subroutine is a distribution (length and angle) of new (virtual) line segments.

Additional subroutines, used in conjunction with the three above are:

TORT: A measure of "tortuosity." This is the distribution of the summed line segments between specified node-types (e.g. $J=1$, $J=3$, etc.) divided by the distance between the endpoints of the summed line segments.

KNEIGH: The calculated distributions of distances between nodes. The nodes need not be connected. The node population can be freely specified and requested ( $K=1$ implies nearest neighbor, etc.).

JLENG: Gives the distributions of the cumulative line lengths of specifiable subpopulations of the network pattern (e.g. lengths of tine segments terminated by two free ends, or by one free end and a forkpoint, etc.).

INANG: Calculates the interangles of line segments radiating from branch points.

F. Statistical Analysis

Output from SOCIOLOGY is applicable to various levels of statistical analysis. On the first level, the output is an analysis itself in terms of mean values, first variations, and distributions or histograms.

On the next level the data is applicable to Abstract Factor Analysis programs.

\section{APPENDIX B}

\section{SUBROUTINE ALGORITHMS}

The following summarizes the major algorithms and funtional definitions used in the various subroutines of SOCIOLOGY.

A. Definitions:

1. distance: $d_{i j}=\sqrt{\left(x_{i}-x_{j}\right)^{2}+\left(y_{i}-y_{j}\right)^{2}}$ 
2. angle: $\phi=\tan ^{-1}\left(x_{i}-x_{j}\right) /\left(y_{i}-y_{j}\right)$

where $\left(x_{i}, y_{i}\right)$ and $\left(x_{j}, y_{j}\right)$ are two node points in the mapped pattern.

3. crack density: $C D=$ cummulated line length/mapped area.

$$
C D=\sum_{i j} d_{i j} / 2 \cdot a r e a
$$

4. grain area: GAREA $=\oint x d y$ where the integration is done using a trapezoidal rule in which the steps are given by $\Delta x_{i}=$ $x_{i}-x_{i-1}$, and $\Delta y_{i}=y_{i}-y_{i-1}$.

5. grain shape (roundness):

$$
R=4 \pi \cdot \frac{\text { GAREA }}{(G P)^{2}}
$$

where GP is the grain perimeter which for an $\underline{n}$ node grain is given by

$$
G P=\sum_{i}^{n} \sqrt{\Delta x_{i}^{2}+\Delta y_{j}^{2}}+\sqrt{\left(x_{n}-x_{1}\right)^{2}+\left(y_{n}-y_{1}\right)^{2}}
$$

5a. flatness (inverse roundness):

$$
F=(G P)^{2} / 4_{\pi} G A R E A
$$

5b. aspect ratio: This is an alternate definition for flateness, not illustrated in this report. To define aspect ratio, first define DTEST

$$
\text { DTEST }=\sqrt{\left(X C G-X_{f}\right)^{2}+\left(Y C G-Y_{f}\right)^{2}}
$$

where XCG, YCG, $X_{f}, Y_{f}$ are defined under $\underline{6}$ and $\underline{7}$. 


$$
\begin{aligned}
& \text { then ASPECT RATIO } \equiv A R \\
& A R=\pi D^{2} E S T^{2} / \text { GAREA }
\end{aligned}
$$

\section{Comparison of Flatness to Aspect Ratio}

Square

$F=1.273$

$A R=1.571$

$$
\begin{aligned}
& \text { Circle } \\
& F=1.0 \\
& A R=1.0
\end{aligned}
$$

Ellipse $F=\frac{1}{2} \frac{a}{b}\left(1+b^{2} / a^{2}\right)$ $A R \cong a / b$

where $a$ and $b$ are the major and minor semiaxes respectively.

6. grain center of gravity: $x C G=\frac{1}{\text { GAREA }} \oint x y d x$

$$
Y C G=\frac{1}{\text { GAREA }} \oint x y d y
$$

7. principle grain direction:

$$
\theta=\operatorname{TAN}^{-1} \frac{X C G-x_{f}}{Y C G-y_{f}}
$$

where $\left(X_{f}, Y_{f}\right)$ is the coordinate of the node furthest from the center of gravity. 
APPENDIX C

SUBROUTINE FLOW DIAGRAMS

1. Typical

SOC IOLOGICAL;

Flow Path

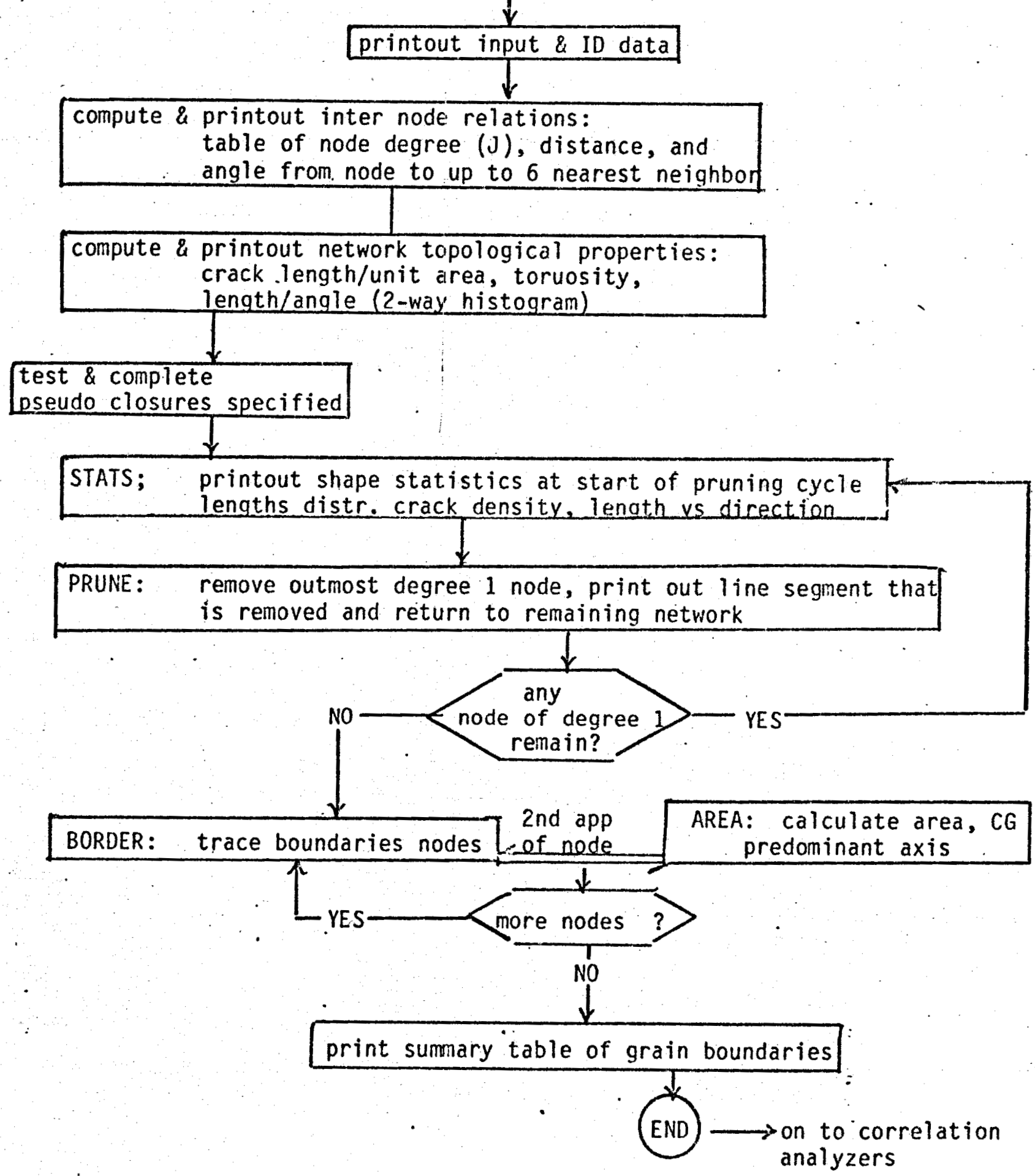


II. PRUNE

subroutine "PRUNE"

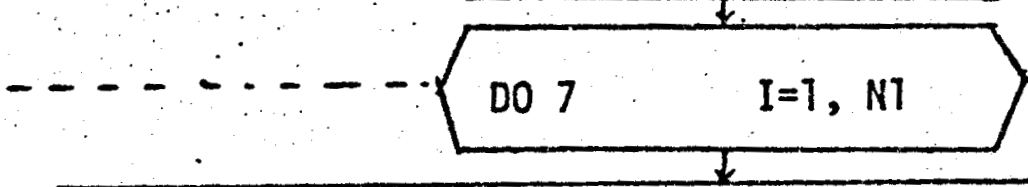

preset degree of node (JDEGR)

allowing for degree to change for each cycle of prune

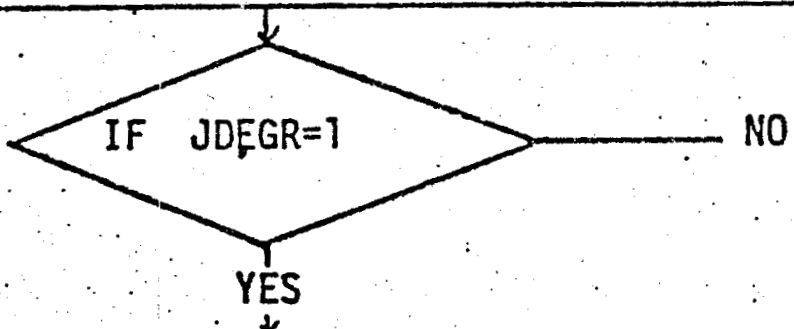

search for positive 7 ag on real neighbor (NBR)

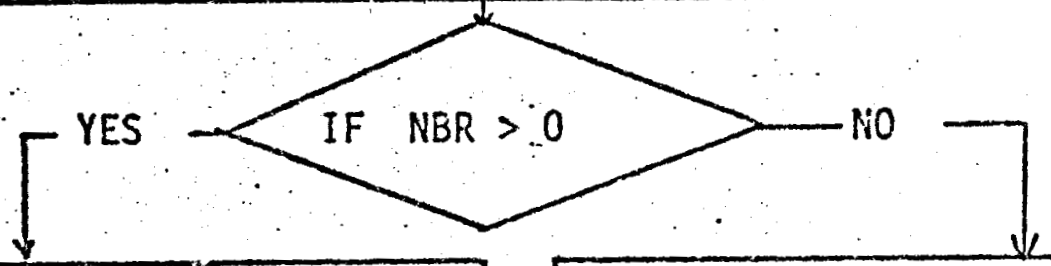

flag the node,

print out the line, segment, re

moved (XNDIST);

remaining segment length(XCUMD

skip around pruned linkage

flag NBR number, find its co-link

1 and also flag it

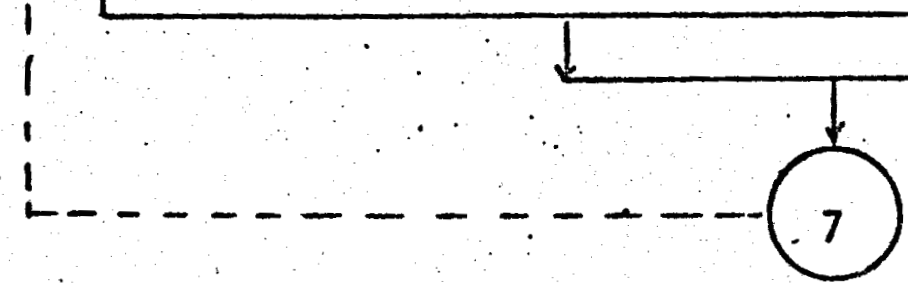


III. BORDER

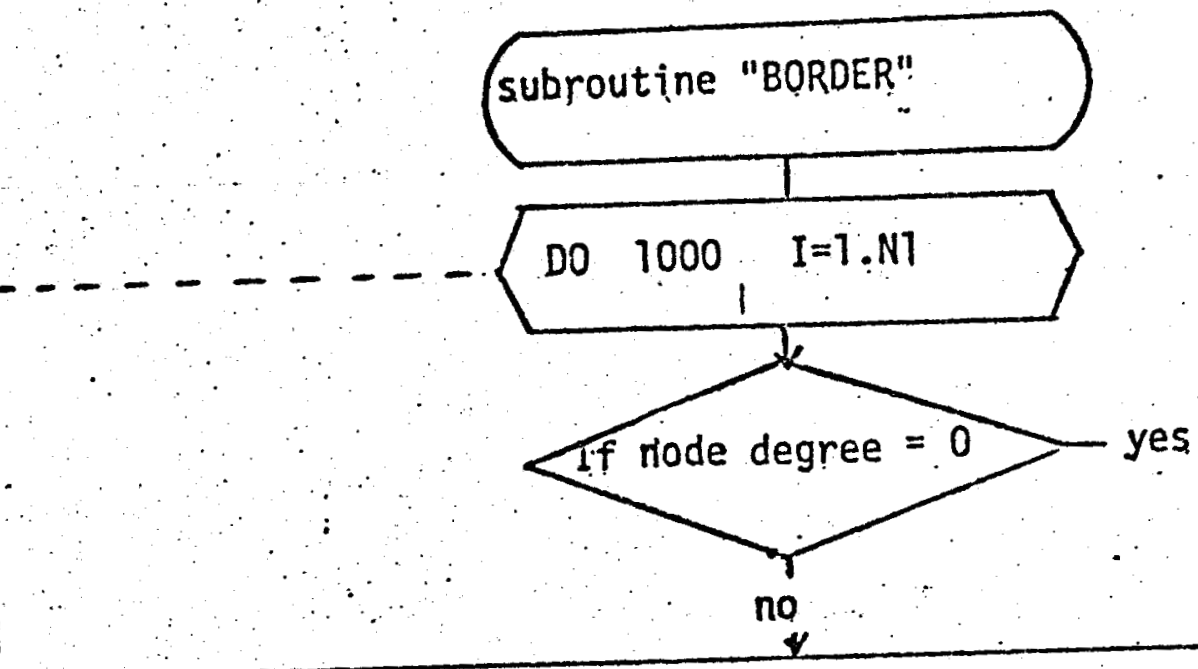

gather angles for selecting which is proper branch, in clockwise direction (RH R)

choose node by RHR, flag the node and move around the border

calculate the area bounded by the route, and find the center of the grain

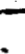

reset initial conditions for new grain boundary tour

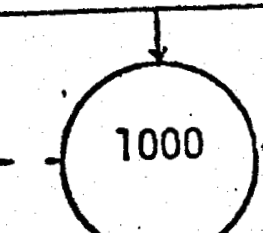


APPENDIX D

THE PROBLEM OF CHARAĆTTERIZING MICROSTRUCTURE

A. Modeling Variables

Typically a minimum number of parameters are used to specify the microstructure of a rock in a theoretical modeling of rock properties.

A crack is specified by its shape, its length, and its width, or an equivalent set of variables. A crack may also be replaced by a model distribution of asperities. Crack-crack interactions are either ignored or calculated in an extreme sense by using global approximations such as selfconsistent models. The first assumption is equivalent to assuming a very low density of cracks (the stress fields do not interact). The global approximations tend to yield maximum estimates of stress interactions. Asperity models are not porosity sensitive.

B. Correlation of Model to Real Cracks

The correlation between model cracks and real, observable microstructure is not known. In particular, the closure of a model crack with pressure depends explicitly on its initial shape, length and width; however, for a crack with some kinks, and roughness and bridges, observed only in a cross section which randomly slices through the crack; any demonstration that the correct shape, length and width can be specified proceeds, at best, on a crack-to-crack basis.

c. Petrostructure Characterization of Microstructure

The intent in a petrostructure analysis is to generate the statistics of the patterns formed by the crack-like features. It is of interest to consider the relation of such a characterization to the model variables discussed above. In a petrostructure study usual model variables may be accounted for, or replaced by the following:

Crack shape: 'There is no direct measurement of individual crack morphology. Observable classes of crack pattern morphology in combination with velocity-pressure data can in theory be used to : infer average closure laws for comparison to theoretical closure laws. given by the specification of crack shapes. 
Length: Distributions of crack segment lengths and cumulative crack lengths are measured directly. Segment lengths can be determined as a function of resolution for comparison to theoretical crack length distributions.

Width: No direct measurement of crack width is made. However, planar area can be mapped, so, in practice, any resolvable open crack or pore feature can be mapped and analyzed as a "grainlike" feature. "For very narrow cracks this is neither practical nor economical. Inferred width distributios can be calculated to be self consistent with the best average closure laws and length distributions. The self-consistent set of variables are testable against observed bulk rock properties.

Porosity: There is no direct measurement of crack-porosity in map parameterization. Any finite density of cracks can be mapped and parameterized. Averages of pore-pore interaction effects are theoretically derivable from the statistics of the crack patterns and the generated best model distributions.

\section{Mapping Cracks}

Crack structure is a function both of scale and of resolution. That is, hiearchy is a fundamental aspect of crack patterns which must be accounted for in petrostructure studies. Different distributions describing microstructure may be expected to be measured at different levels of magnification. Therefore, in any study the resolution must be picked as a free parameter. This can be done by making analysis on microphotographs as a function of scale. scale-dependent properties can be characterized by fractals (Mandelbrot, 1979).

\section{REFERENCES TO APPENDICES}

1. Mandelbrot, B. B., Fractals: Form, Chance, and Dimension, W. H. Freeman, revised translation, pp 365 (1977).

2. Trice, R. and N. Warren, "Preliminary Study on the Correlation of Acoustic Velocity and Permeability in Two Granodiorites from the LASL Fenton Hill Deep Borehole, GT-2, Near the Valles Caldera, New Mexico," Los Alamos Sci. Lab. Informal Rpt. LA-6851-MS, Los Alamos, New Mexico (1977). 
3. Warren, N. and Trice, R., "Correlation of Elastic Moduli Systematics with Texture in Lunar Material,: Proc. 6th Lunar Sci. Conference, Suppl. 6, Geochimica Et Cosmochimica Acta 3, 3255-3268 (1975).

4. Warren, N., "Characterization of Modulus-Pressure Systematics of Rocks: Dependence on Microstructure," Geophyusical Monograph 20, Amer. Geophys. Union, The Earth's Crust, 119-148 (1977). 
A ROUGH-CRACK MODEL FOR

PORE COMPRESSIBILITY: APPLICATION

TO DATA FOR CRACK COMPLIANCE

AROUND A BOREHOLE

(Summary of Paper in Progress)

by

H. Fisher ${ }^{1}$

iN. Warren ${ }^{2}$

J. Blanton ${ }^{2}$

\section{SUMMARY}

It is we11 known that rocks are non-linear in that the compliances and stiffness matrices are non-linear functions of applied stress and internal pore pressure. Numbers of general solutions to this problem are available in the literature. However, even though they incorporate different underlying assumptions, in final effect not all the theories can be separated. At the level of data comparison they become equivalent n-parameter non-linear fitting functions. The

\footnotetext{
1 Los Alamos National Laboratory

2 University of California, Los Angeles
} 
question of model goodness, therefore, becomes a question of fit and of extrapolative and interpolative power.

After reviewing a number of the available theories, we have developed a rough-crack model which combines the features of flat open cracks (Walsh, 1965a, b) and asperities (Gangi, 1978, 1981) This combination casts the stress-strain relation into an equation of state which yields average measures of crack properties. The final form becomes that of a "stiffened gas", which has been used successfully in analyzing the results of large scale pressurization experiments at Fenton Hill under the Hot Dry Rock project at Los Alamos (Fisher and Tester, 1980).

In our study here, the rough-crack theory is directly tested by fitting laboratory data for crack compliances around a borehole in a thick-walled cylinder of Elberton granite. In the experiments the cylinder was subjected to varying bore-hole pressures over a matrix of axial and confining stresses. Crack compliances were determined from the axial and circumferential strain. In both the laboratory experiments, and in the field, only certain average or effective compliances are obtained directly. These compliances are themselves functions of the full (and stress-dependent) rock compliance matrix. As part of our analysis, therefore, it became necessary to explore the limits of inferring the compliance matrix from the effective moduli. This is the problem of articulating the limits of modelling theories in terms of various sets of effective parameters. This is done in the case of the rough-crack model. 
Much of the original experiment description and qualitative discussions have been given in earlier reports. Two descriptive memos are reattached as Appendix 1 and 2 here. The experimental results are summarized in a condensed form in Figures 1 and 2 . These plots show the dependencies of axial $\left(\Delta \varepsilon_{11}\right)$ and circumferential $\left(\Delta \varepsilon_{L}\right)$ strains on the effective pore pressure: The basic pore inflation law being inferred here is very similar to that obtained in the large scale Fenton Hill tests, indicating tentatively that scaling to and from laboratory results is possible within the form of the law. In addition to this result, by using the theoretical development here mean crack lengths and widths as functions of stress can be inverted from such data. Such mean-value parameters may sufficiently characterize a rock system for many applications. 


\section{References}

1. Walsh, J.B., "The effect of cracks on the compressibility of rock," Journal of Geophysical Research, Vol. 70, pp. 381-389, (1965a).

2. Walsh, J.B., "The effect of cracks on the uniaxial elastic compression of rocks," Journal of Geophysical Research, Vo1. 70 , pp. 399-411, (1965b).

3. Gangi, A.F., "Variation of whole and fractured rock permeabilitywith confining pressure", International Journal of Rock Mechanics Science of Geomechanics, 15, 1978.

4. Gangi, A.F., "Variation of mechanical and transport properties of cracked rock with pressure" in 22nd U.S. Symposium on Rock Mechanics, 1981.

5. Fisher, H.N., and J.W. Tester, "The pressure transient testing of a manmade fractured geothermal reservoir: An examination of fracture versus matrix dominated flow effects", Los Alamos National Laboratory Informal Report No. LA-8535-MS, September 1980. 
b
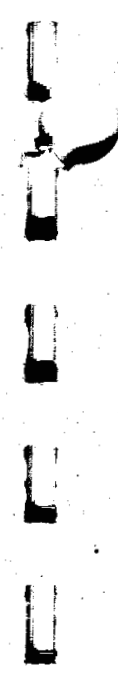

1

1

1

$1 !$

1

1

1

1

1

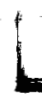

3.0

$\epsilon_{0}=4.7$

$\beta=0.5$

$P_{c}=70$

$$
E=\epsilon_{0}\left(1-P / P_{e}\right)^{-\beta}
$$
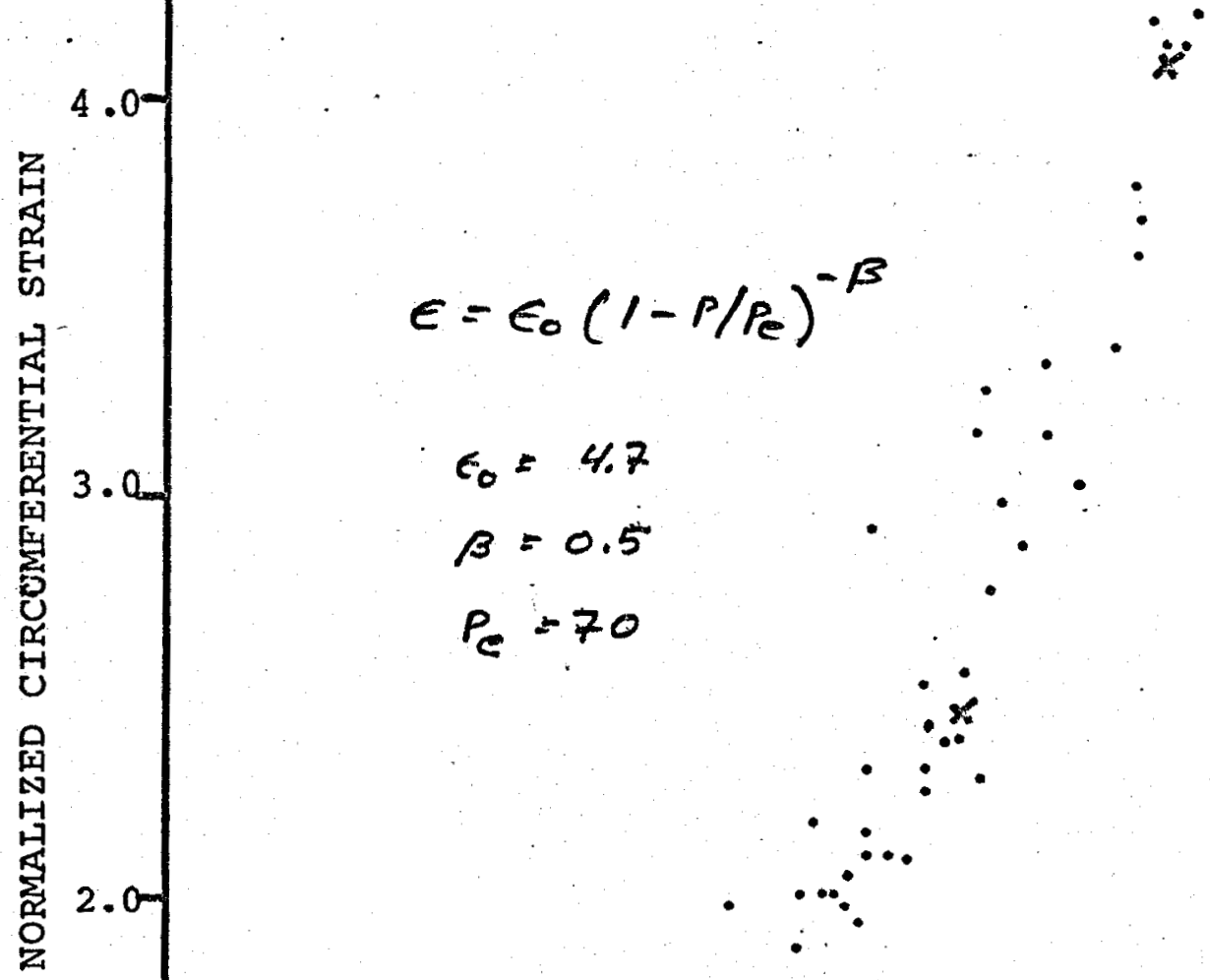

2
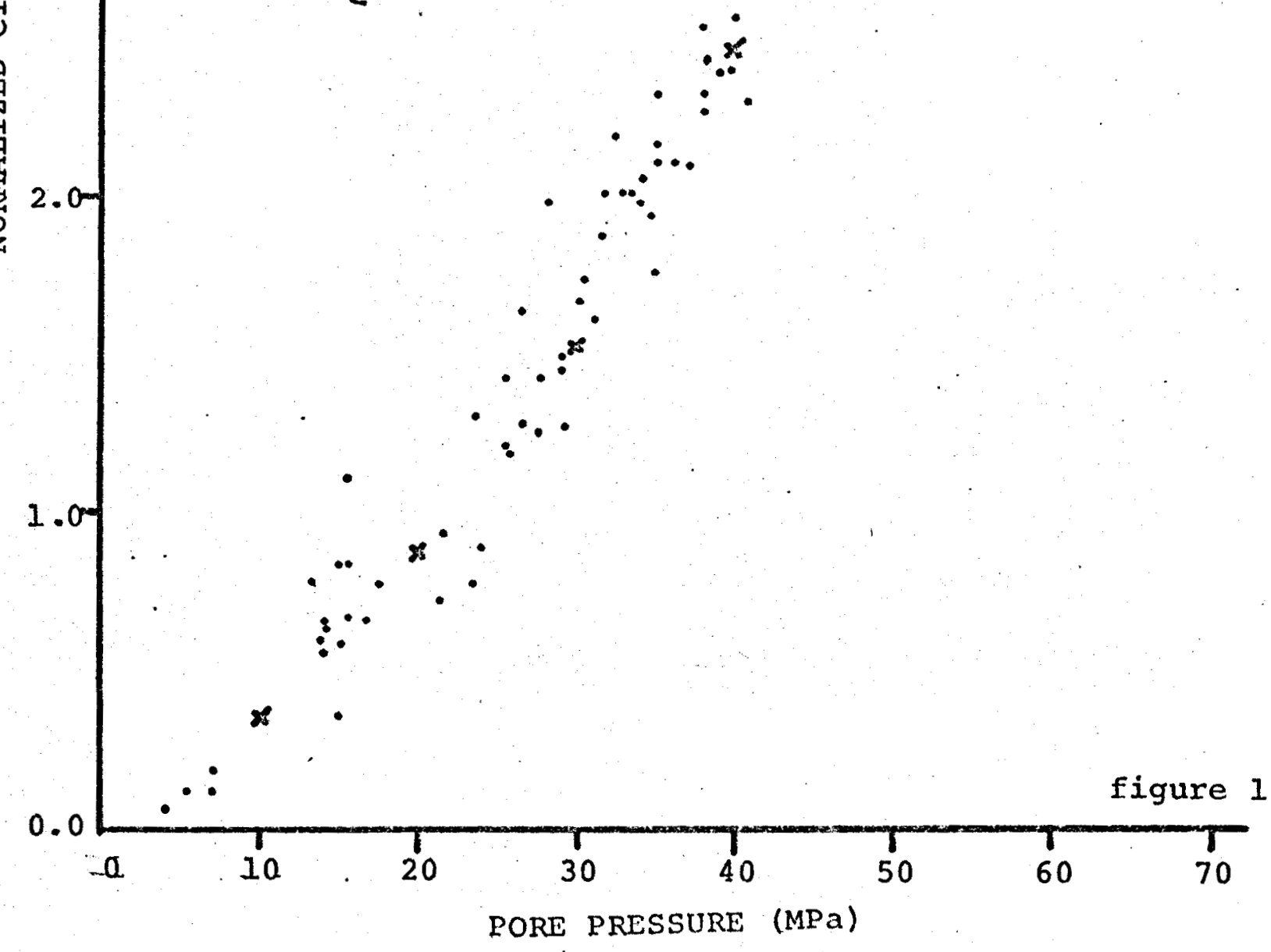

1 


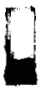

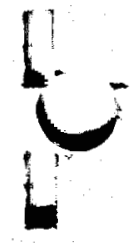

4

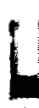

疍

$\epsilon=\epsilon_{0}\left(1-P / p_{e}\right)^{-\beta}$

$\epsilon_{0}=0.71$

$\beta=0.5$

$P_{e}=80$

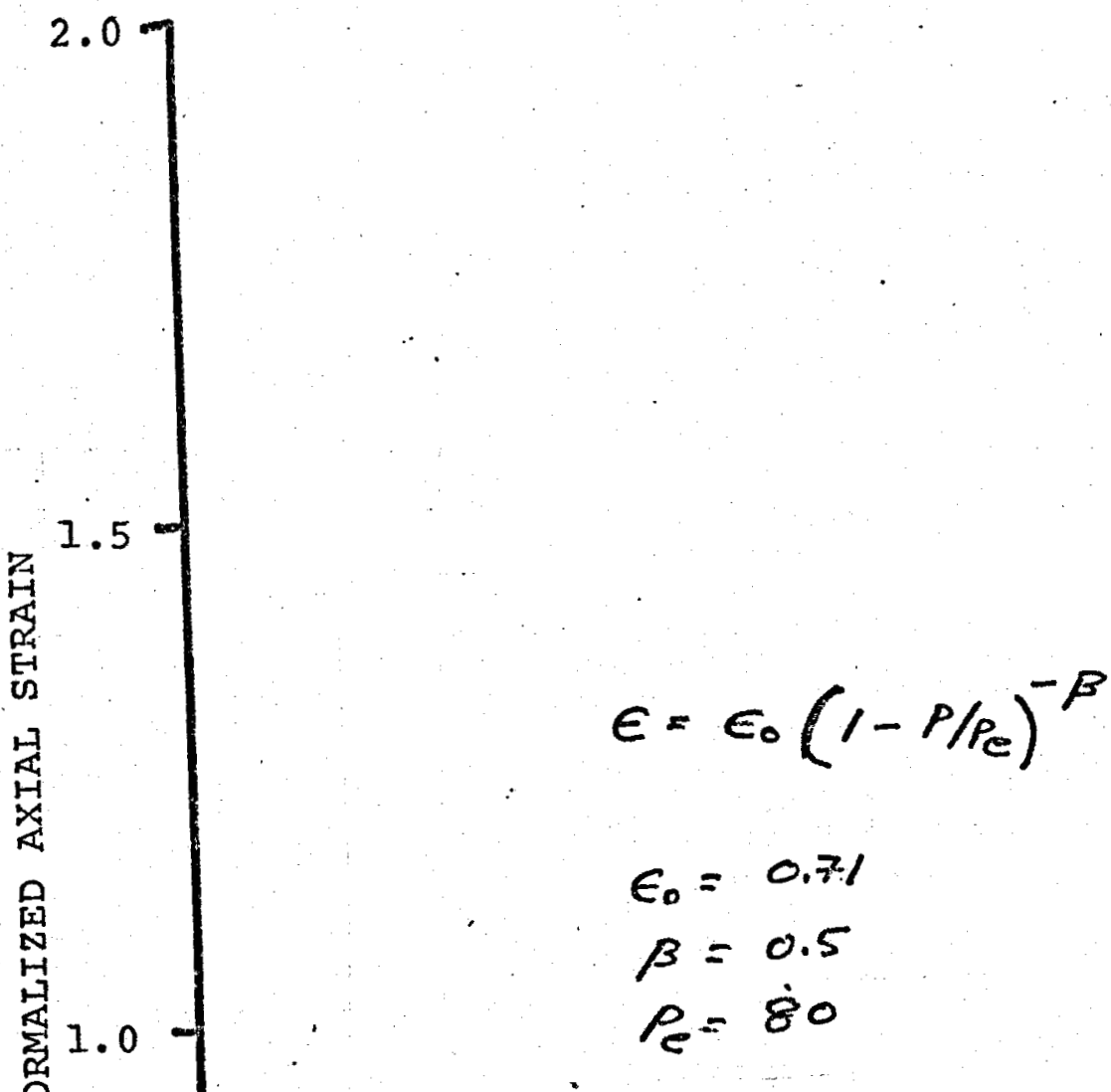

figure 2

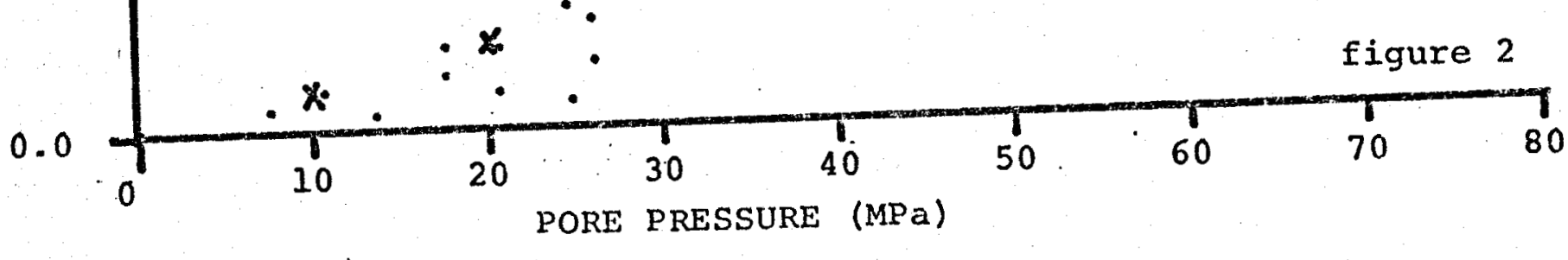


APPENDIX 1

OFFICE MEMORANDUM
LOE ALARSO SCIENTIFICLIBOKATORT

UNIVERSITY OF CALIFOHNIA LOS ALAMAS, NEW ME XICO $87: 45$

Teiephone Ext:

To : Distribution

DATE: JUTY 10, 1980

FROM : Nick Warren

SUBSECT :

STRAINS OF A THICK-WALLED CYLINDER OF BERKELEY UNDER TRIAXIAL LOADING DUE TO BOREHOLE PRESSURIZATION

SYMBOL :

MAIL STOP:

\section{INTRODUCTION}

A first series of experiments have been completed at UCLA which have been designed to measure the strains of thick-walled cylinders of rock as functions of borehole pressure and confining and axial stresses. The attached is a compilation of data plots for a series of experiments on Berkeley Blue Granite. Three forms of experiments were run: an axial loading at zero confining pressure, and low borehole pressure (127 psi); cycling in confining pressuring starting from a uniaxial state of load, and cycling borehole pressure at fixed axial and confining stresses.

The equipment used, and the experimental technique have been discussed in earlier memos and reports. Figure 1 shows the sample configuration, with the nominal dimensions for the Berkeley Granite sample.

Figure 2 shows the experiment set up. During each experiment the prime data recorded were:

time (approximately $1 / 2 \mathrm{hr}$ relaxation between data points)

$S A(m v)$ : recording of oil pressure generating axial load

$S B(m v)$ : recording of borehole pressure

$S C(m v)$ : recording of confining nressure

ram extension: Three independent axially mounted strain gauges on the ram extension allow correction for hystersis between $S A(m v)$ and axial load.

Load cell: internal to vessel

Sample strains: Three horizontal and three vertical gauges spaced uniformaly around equator of sample.

LVDT: 'displacement of lower ram/vessel in load frame during experiment

Point \#: number assigned to each setting ( $S A, S B, S C$ ) 


\section{EXPERIMENTAL SEQUENCE}

The sequence of experiments compiled here are:

\# 1) an uniaxial run to a maximum stress of 430 bars,

\#2) an uniaxial run followed by cycling confining pressure, followed by an uniaxial run,

\# 3) thru 14) runs in which borehole pressure was cycled over a matrix of fixed axial and confining stresses. Figure 3 is a plot of the stress matrix. Each cluster of crosses corresponds to one experiment. As the differential stress acting on the sample (axial minus confining) decreases, the clusters of points fall increasingly to the right. As the total stress (axial plus confining) on the sample increases the clusters fall lower on the plot. 

$-4-$

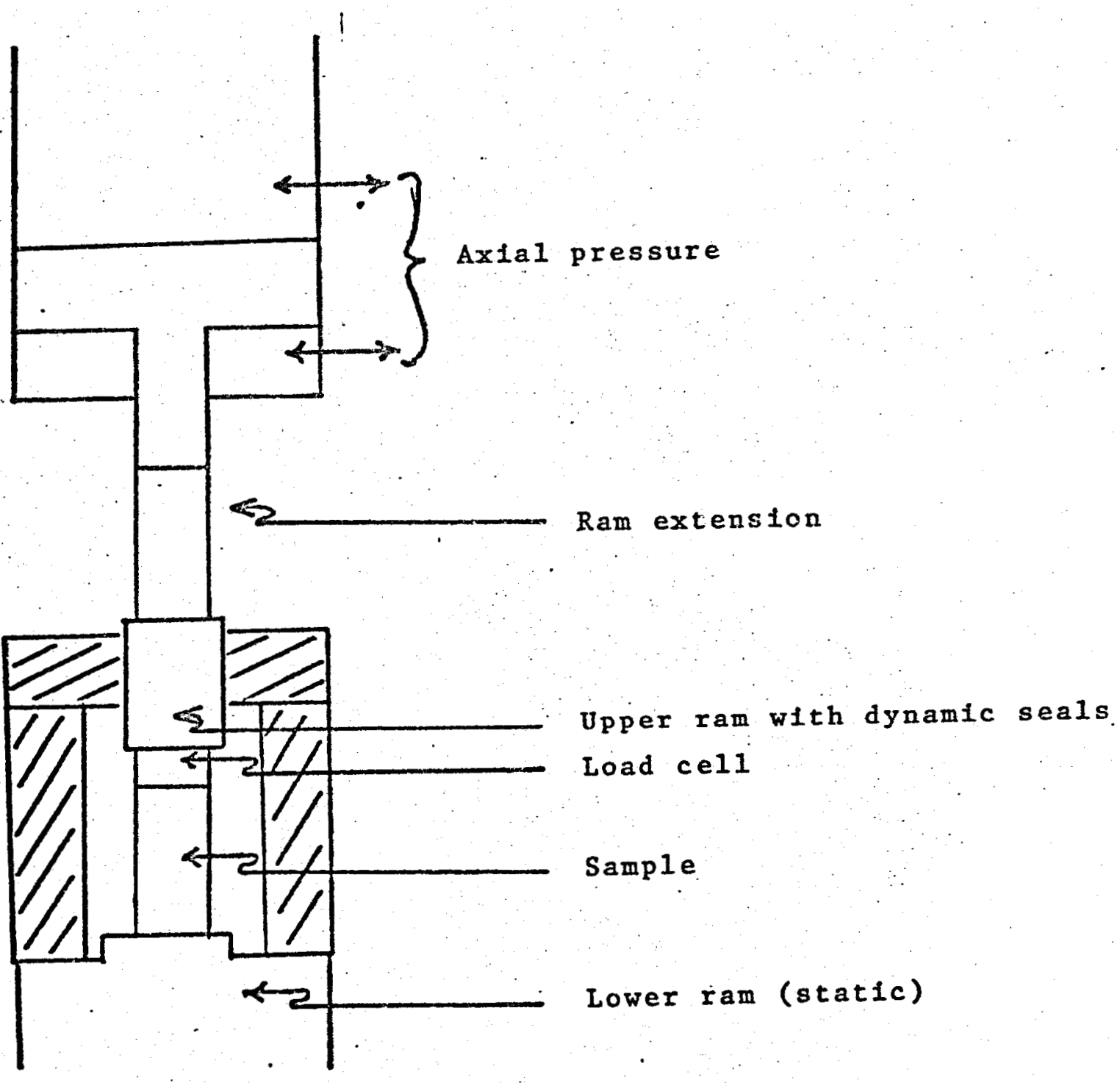

Configuration of loading system.

Fig. 2 
THE NOMINAL STRESS MATRIX IS

Pt. numbers

32-38

75-81

99-105

$39-45$

68-74

91-98

24-31

60-67

$\left(\begin{array}{c}84-90 \\ 90-83\end{array}\right)$

53-59

82-89.
Axtal (bars)

280

410

580

290

410

670

230

390

550

390

550 $\frac{\text { Confining (bars) }}{250} \quad \frac{\text { Borehole (max) }}{240}$

380

362

550

535

220

214

345

345

530

535

110

103

.250

235

420

421

170

.158

460

317 


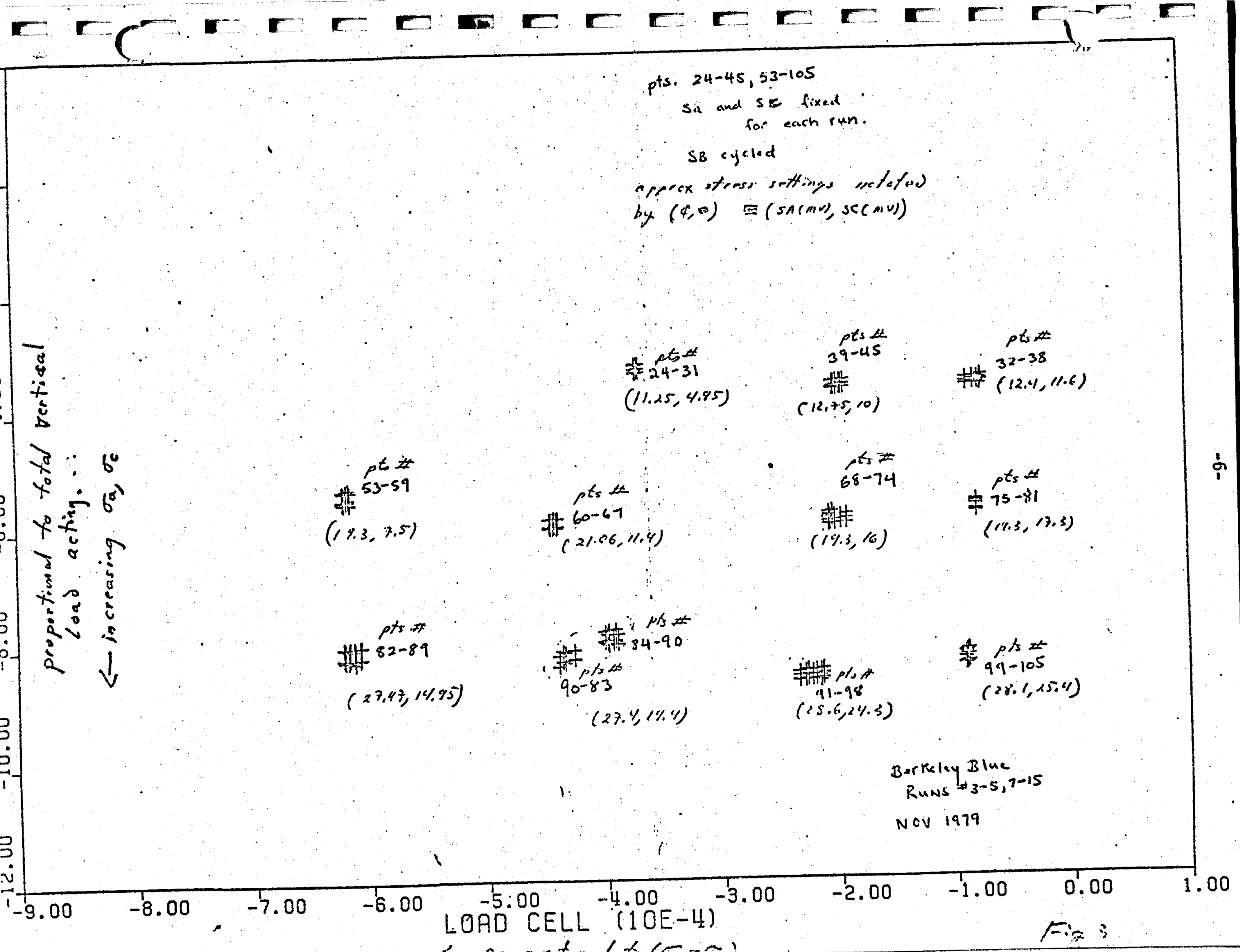




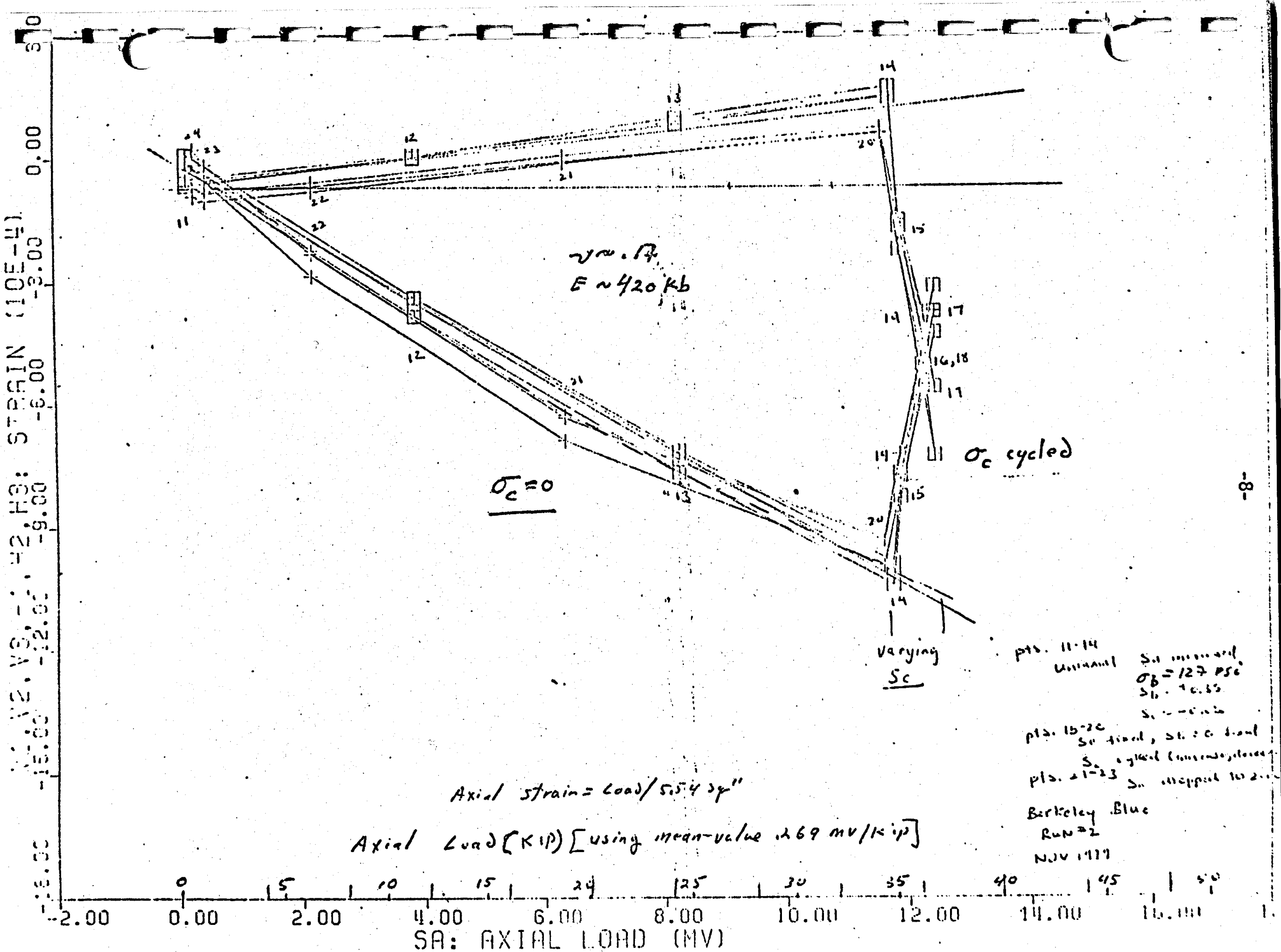




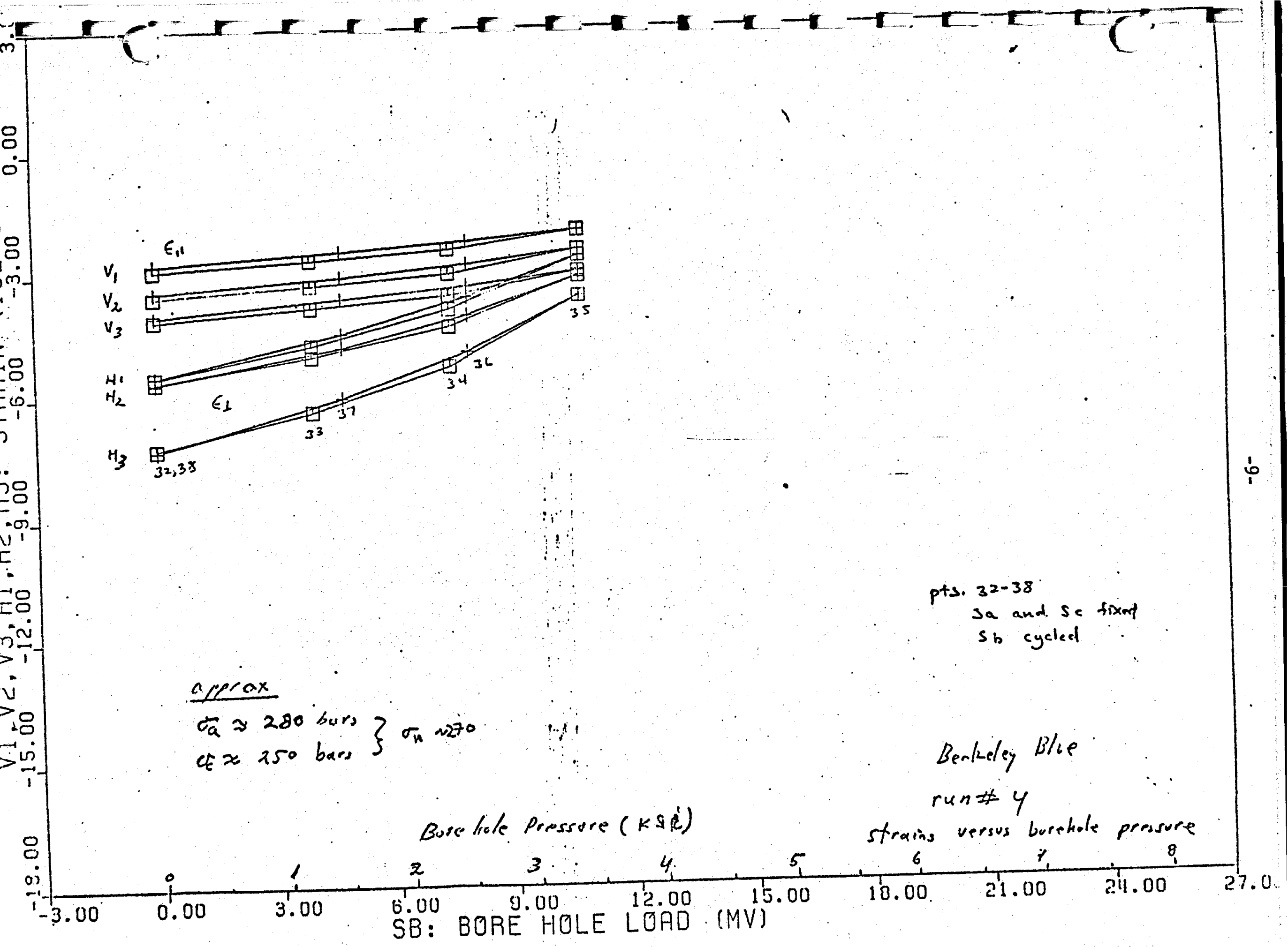

$3 a$ and $S c$ fixorf

sb cycled

Merax

$\left.\begin{array}{l}\sigma_{a} \approx 280 \text { burs } \\ \epsilon_{t} \approx 250 \text { bars }\end{array}\right\} \sigma_{n} \times 270$

Buscliole Pressore (KSi)

run $y$

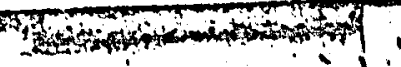




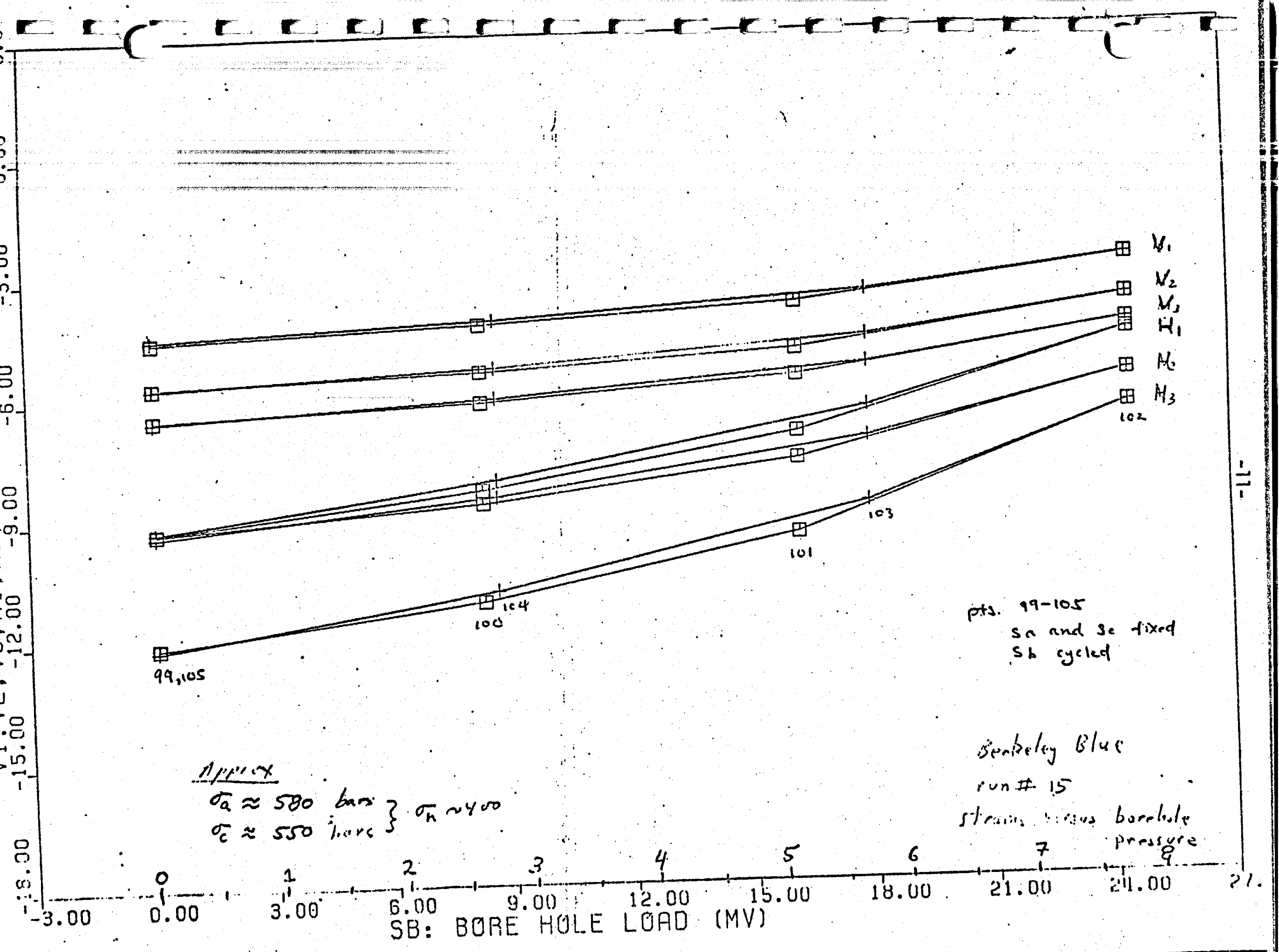




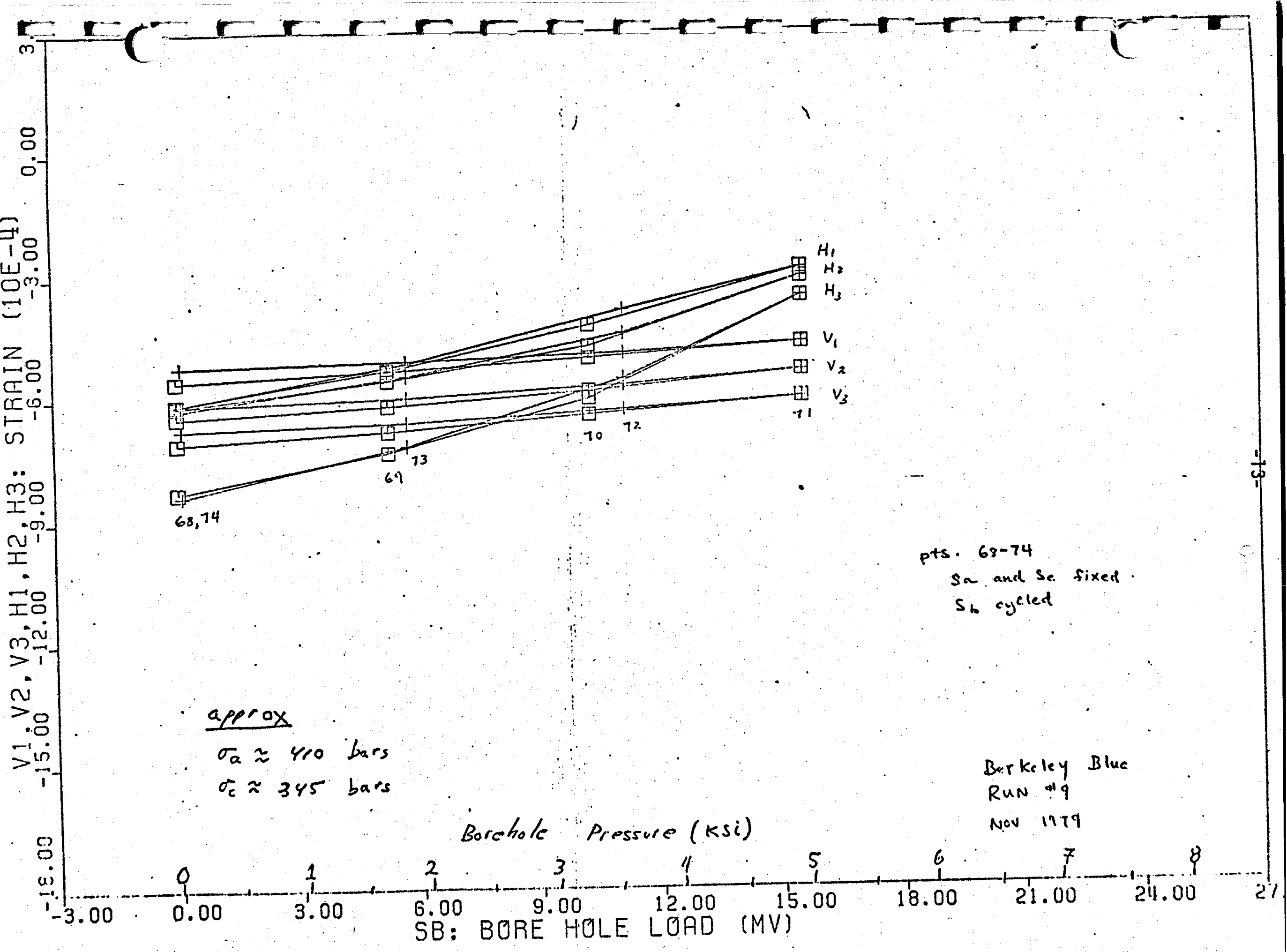




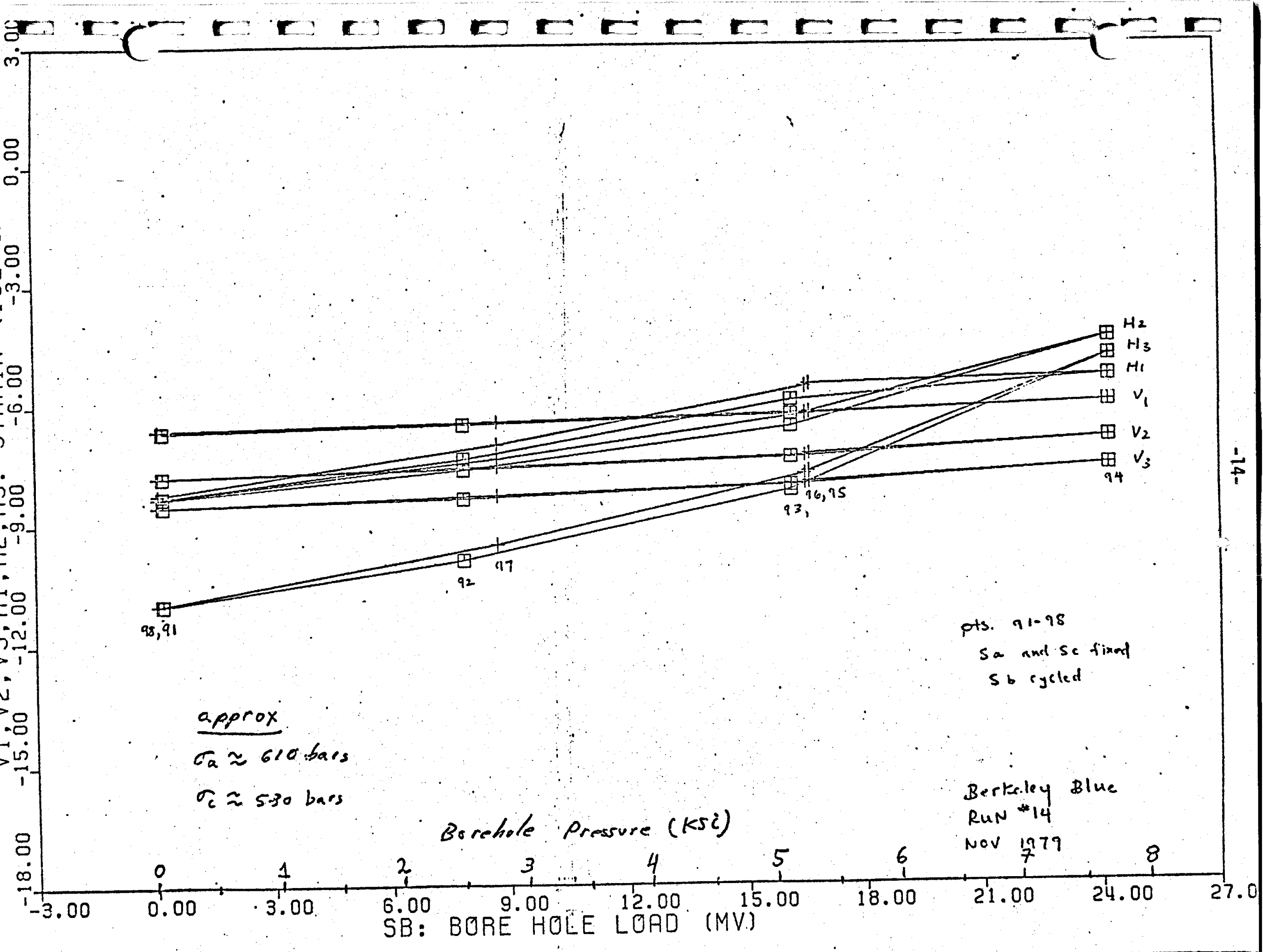




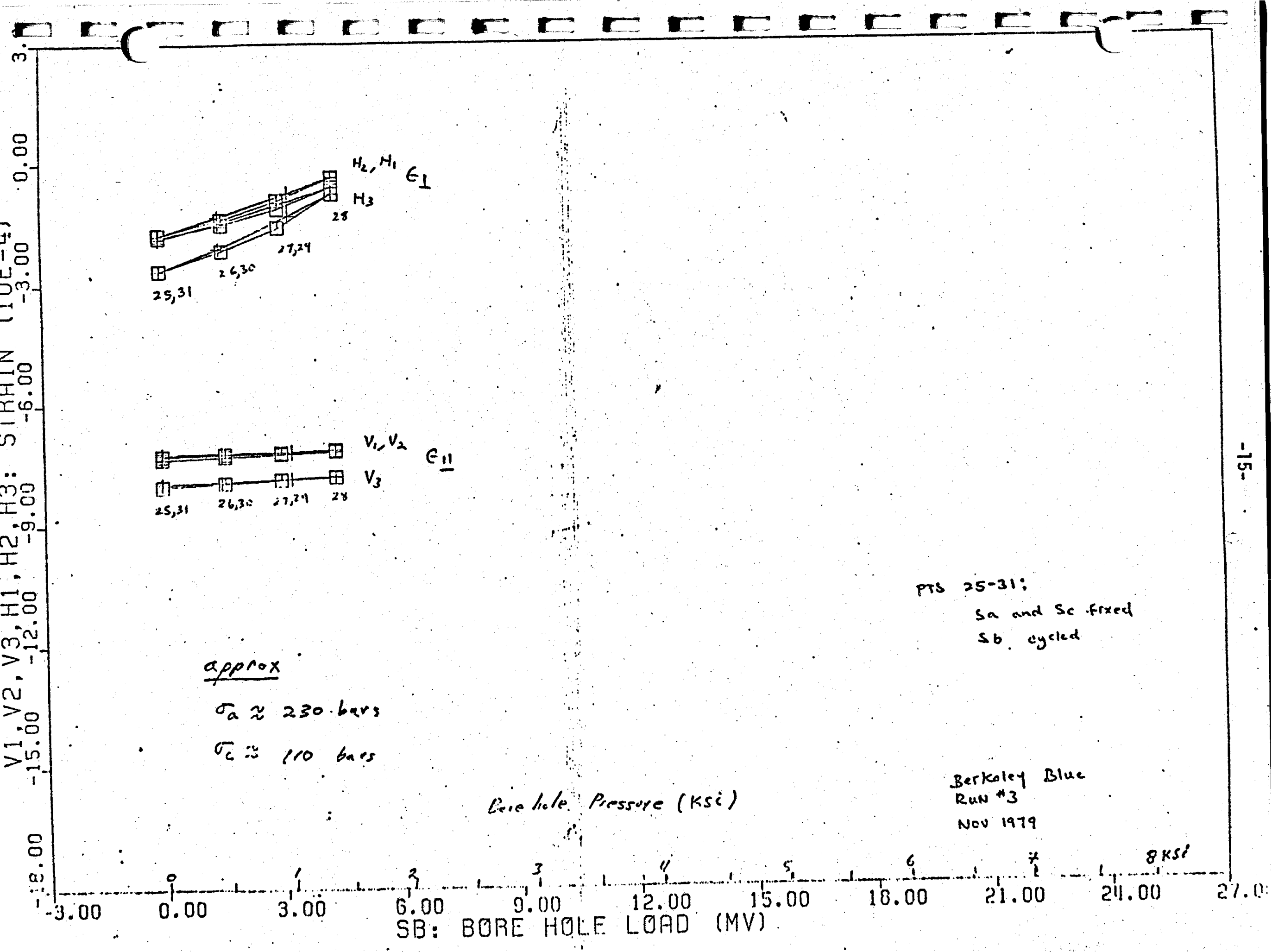




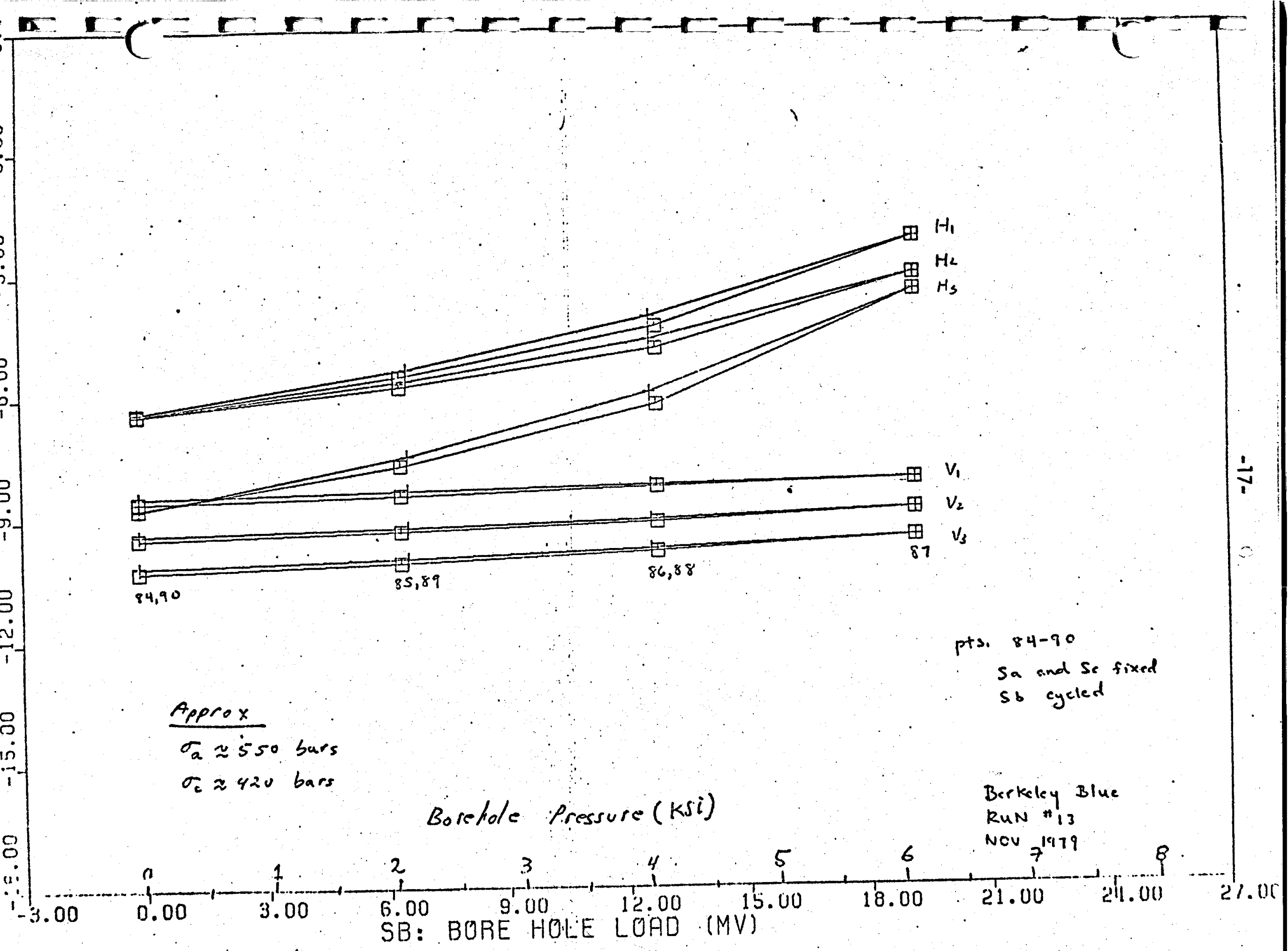

Sa and Se fixed

$S b$ cyeled 


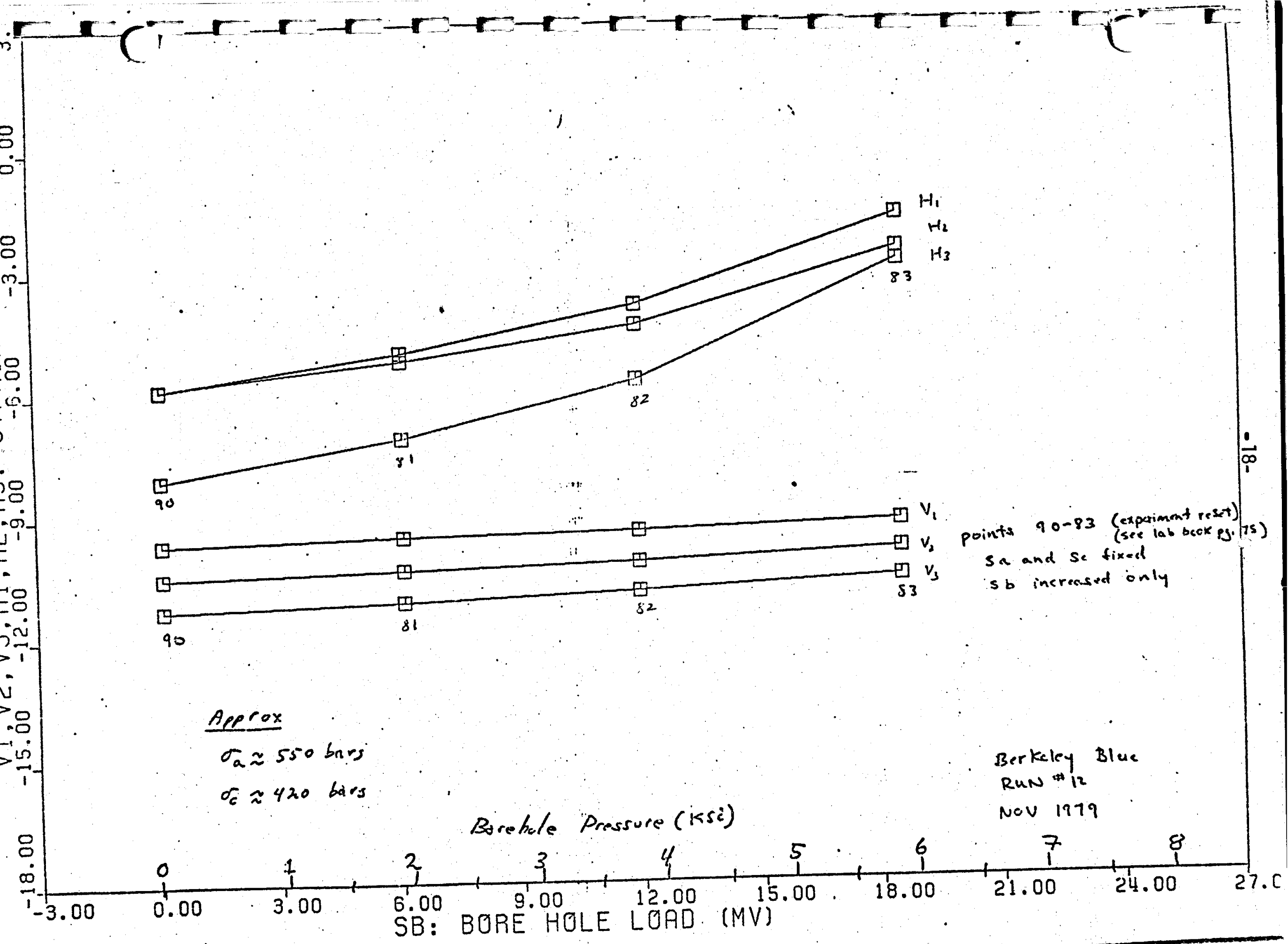




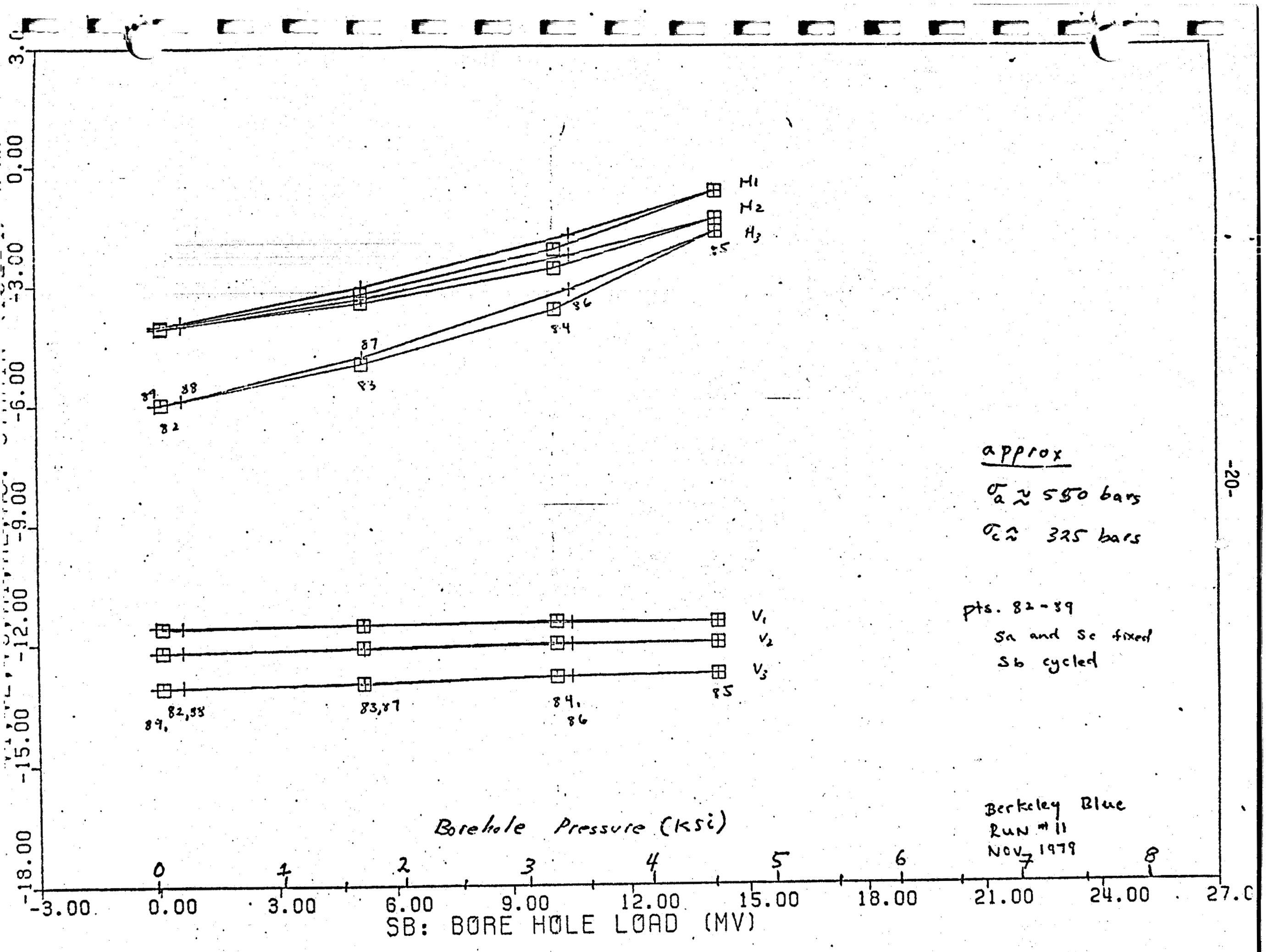


APPENDIX 2

OFFICE NENIORANDUM

Distribution

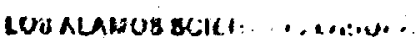

UNIVERSITY OF CALIFGIINIA

LOS MLAHOS. NEW NEXICO G7GAS Teleptione Ext:

DATE: JuTY 11, 1980

: Nick Warren

QUALITIVE MODELLING OF THE STRAINS OF THICK-WALLED GRANITIC CYLINDERS TO BOREHOLE PRESSURE AND DEVIATORIC STRESS

SYMBOL

MAIL STOP:

Rock strains (axial and radial) have been measured on a suite of thick-walled cylindrical granitic rocks under varying borehole (and pore) pressure at fixed axial and confining stress levels.

Nominal data reduction has been done for two samples of Barrē granite and one sample of Berkeley Blue granite.

The slopes of the strains to borehole pressure have been estimated by simple linear approximations to the strain data (which are actually non-linear), and the siopes have been plotted against the deviatoric stress (axial minus confining). Figures for the samples are attached.

For all three samples, the data show similar functional forms. The slopes of the axial strains to borehole pressure are, to first order. a function of the deviatoric stress. The slopes of the radial strains to borehole pressure are, to first order, dependent on the confining stress directly (independent of the value of the deviatoric stress) and dependent on the axial stress as a function of the deviatoric stress (that is $\left.\Delta \epsilon_{-} / \Delta \sigma_{c_{b}}\right)_{b_{a}}=f\left(\sigma_{a}-\sigma_{c}\right)$ and $\left.\Delta \epsilon_{\perp} / \Delta \sigma_{\beta}\right)_{\sigma_{c}}=$ constant $\left(\sigma_{c}\right)$ ).

This leads to the following initial suggested modelling. The deviatoric stress $\left(\sigma_{a}-\sigma_{c}\right)$ closes down the horizontal planar cracks, and opens up the vertical cracks. $\Delta \epsilon_{n} / \Delta \sigma_{b}$ is controlled predorinantely by the extent to which the borehole fluid can migrate into the horizontal planar cracks out into the cylindrical field under the deviatoric loading.

The quantity $\Delta e_{+} / \Delta \sigma_{b}$ is controlled by the ease to which the pore fluids can flow through the vertically oriented cracks. These cracks are pinched down in a uniform manner by increasing $\sigma_{c}$ at any $\sigma_{a}$, and opened by increasing the stress $\sigma_{a}-\sigma_{c}$.

To very approximate first order, the results of the experiments are consistent with the hypothesis that flow outward from the borehole (and hence the bulk rock strains) can be modelled by assuming two mechanically independent crack networks, of horizontal and vertical orientation which may then be handled by a superpositioning for moduli and flow calculations.

The volume of the flow channels (and hence $\langle\Delta t\rangle / \Delta \sigma_{b}$ may be increased from a minimum either by increasing the deviator, stress (opening vertical 



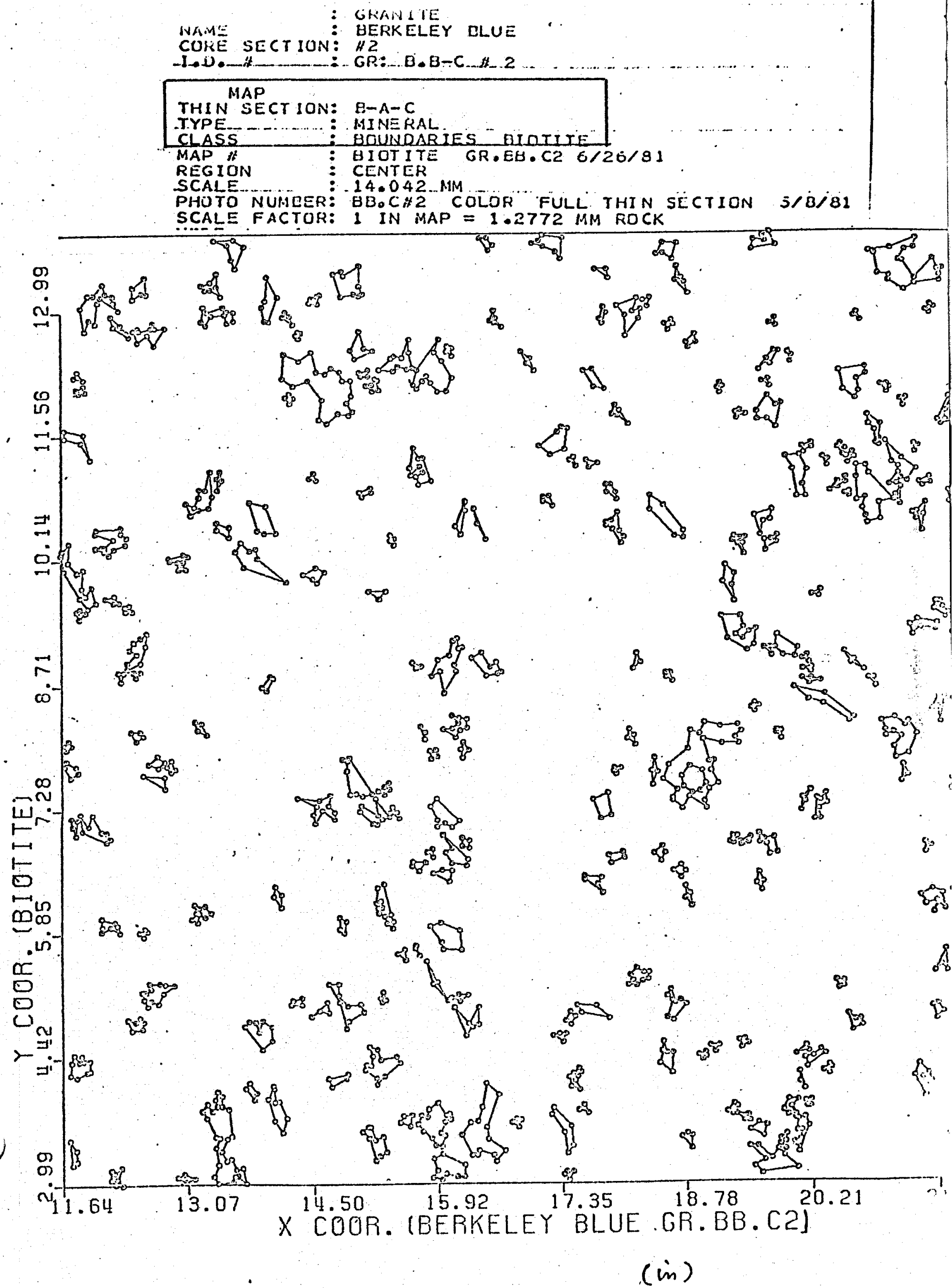




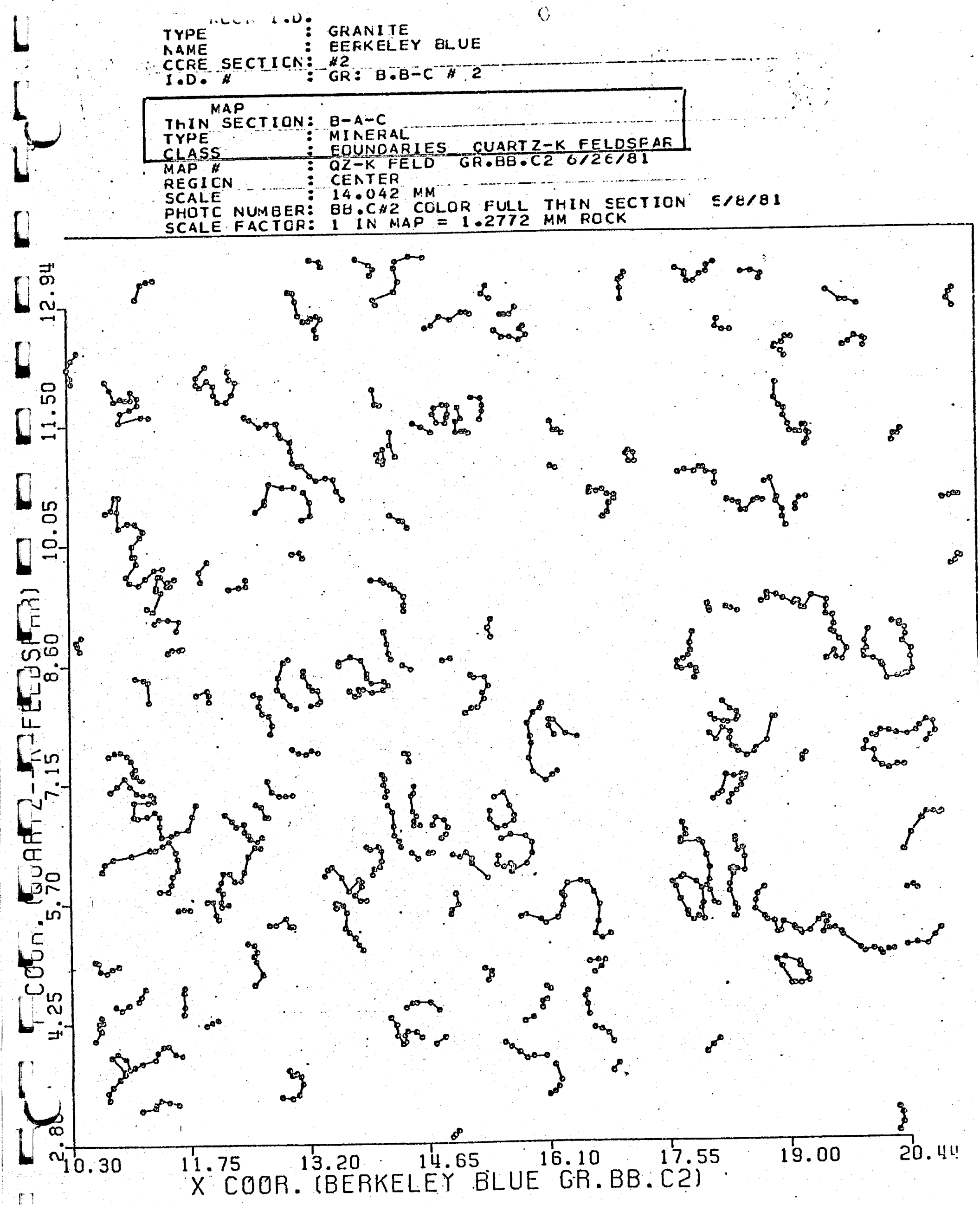


NAME _..._. BERKELEY BLUE

CURE SECTIUN: $\# 2$

Z $G R B B C-2$

1.D. H : GR: B.H-C*2

THIN SECTION: B-A-C

TYPE : MINERAL

CLASS BOUNDARIES PLAG-OUARTZ

MAP H

REGIUN : CENTEK

SCALE $14.042 \mathrm{MMM}$

PHOTO NUMGER: BB.CAZ2 CULOR FULL THIN SECTION $5 / 8 / 81$

SCALE FACTOR: I IN MAP $=1.2772$ MM ROCK.

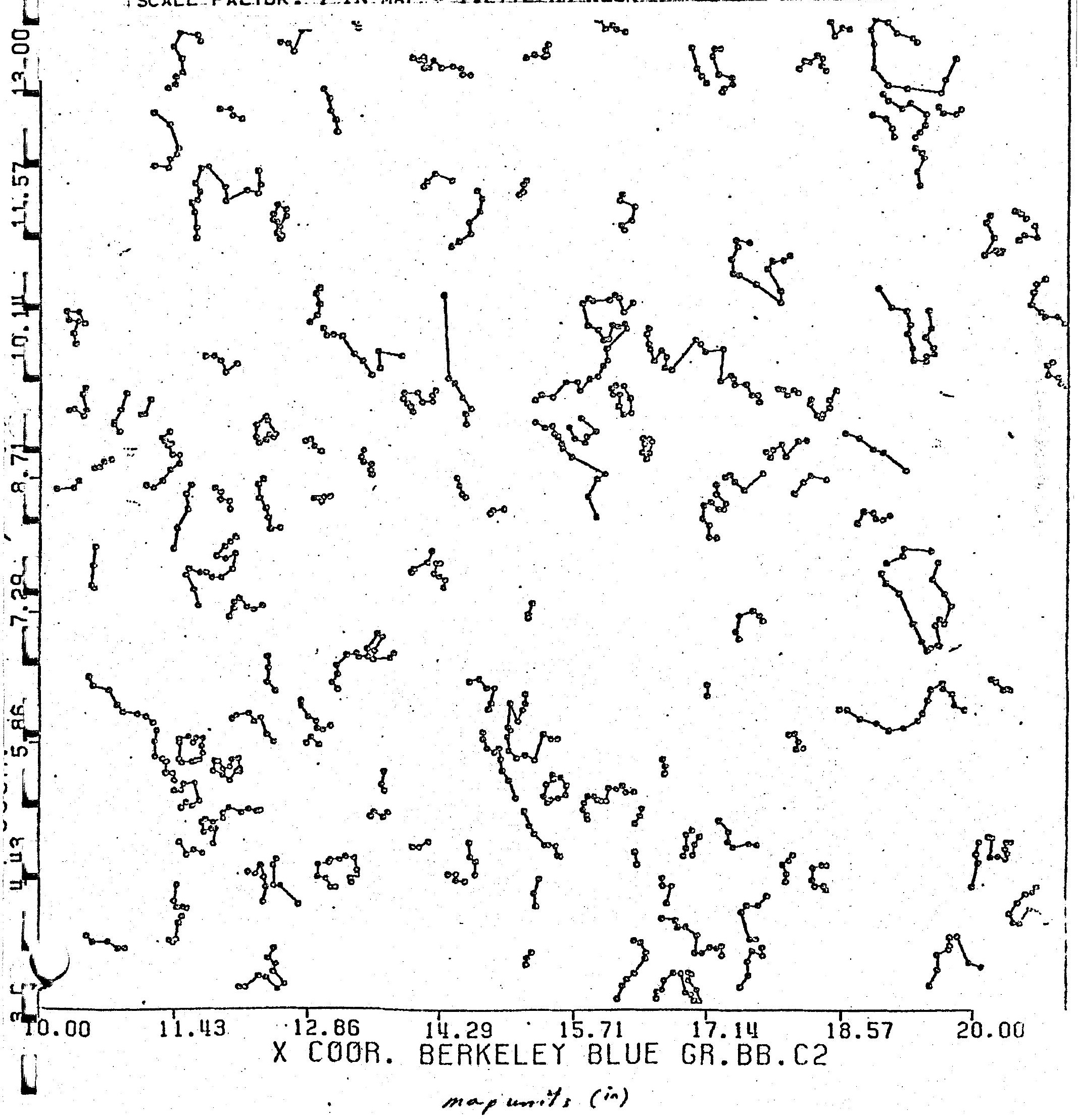




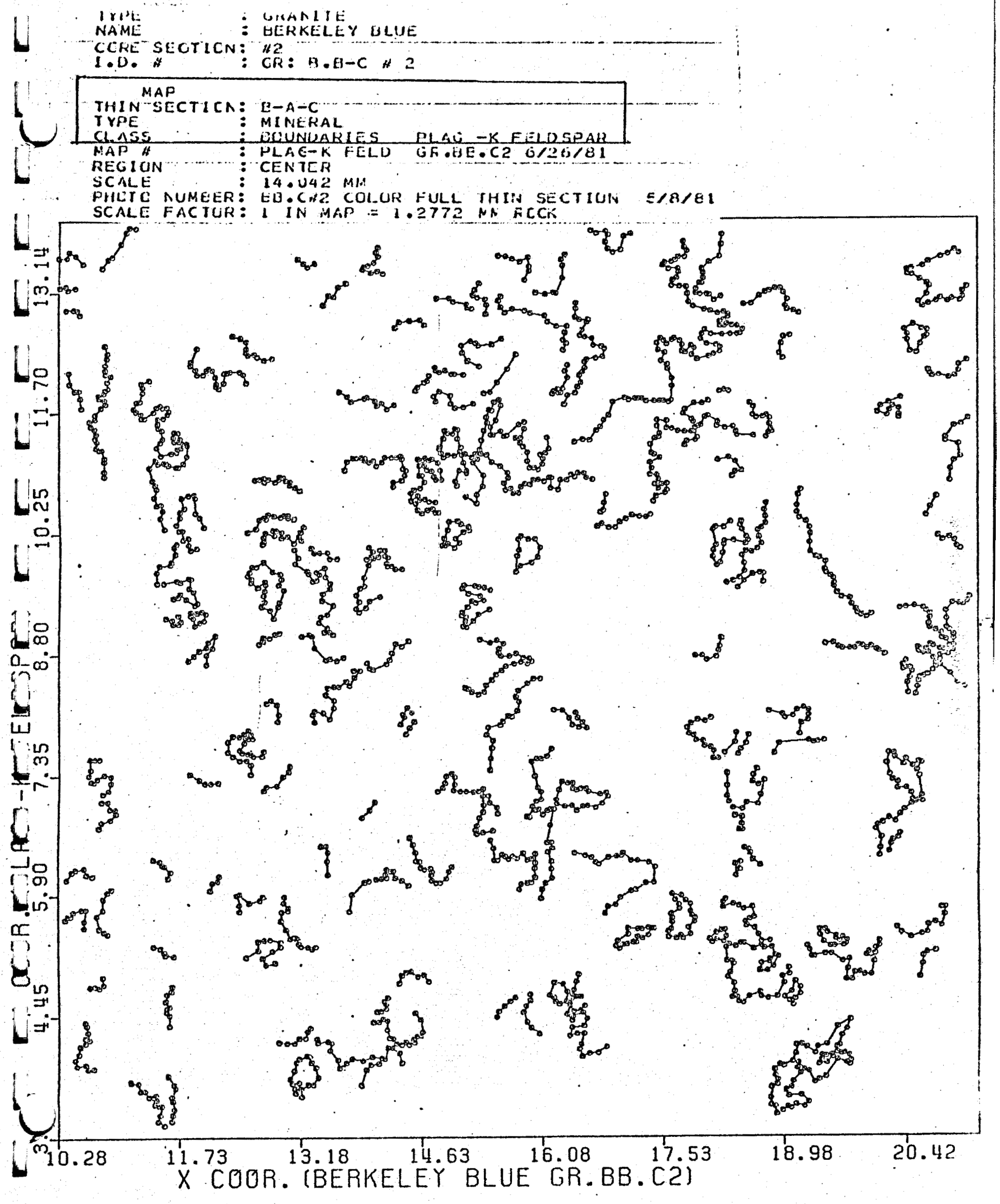




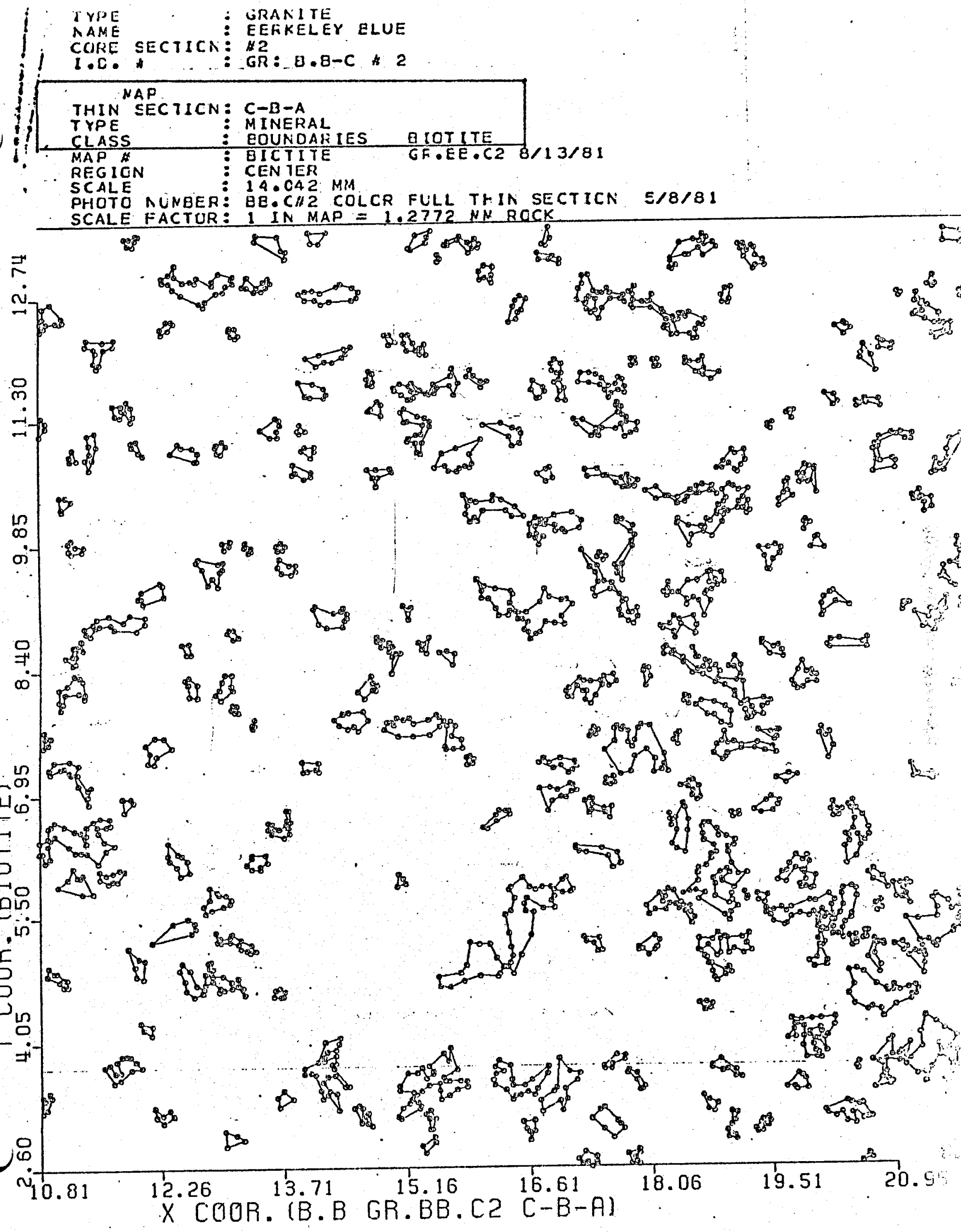




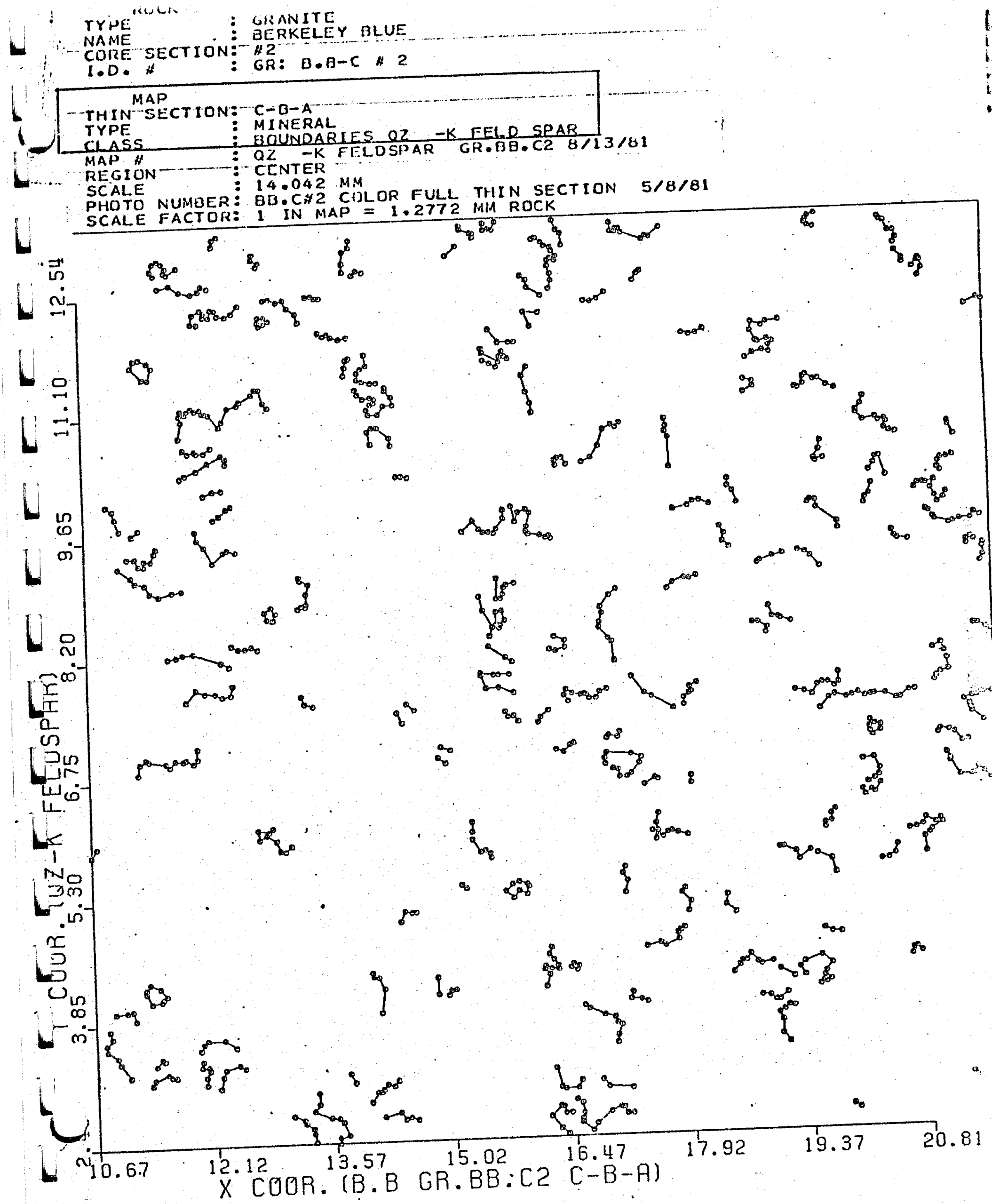




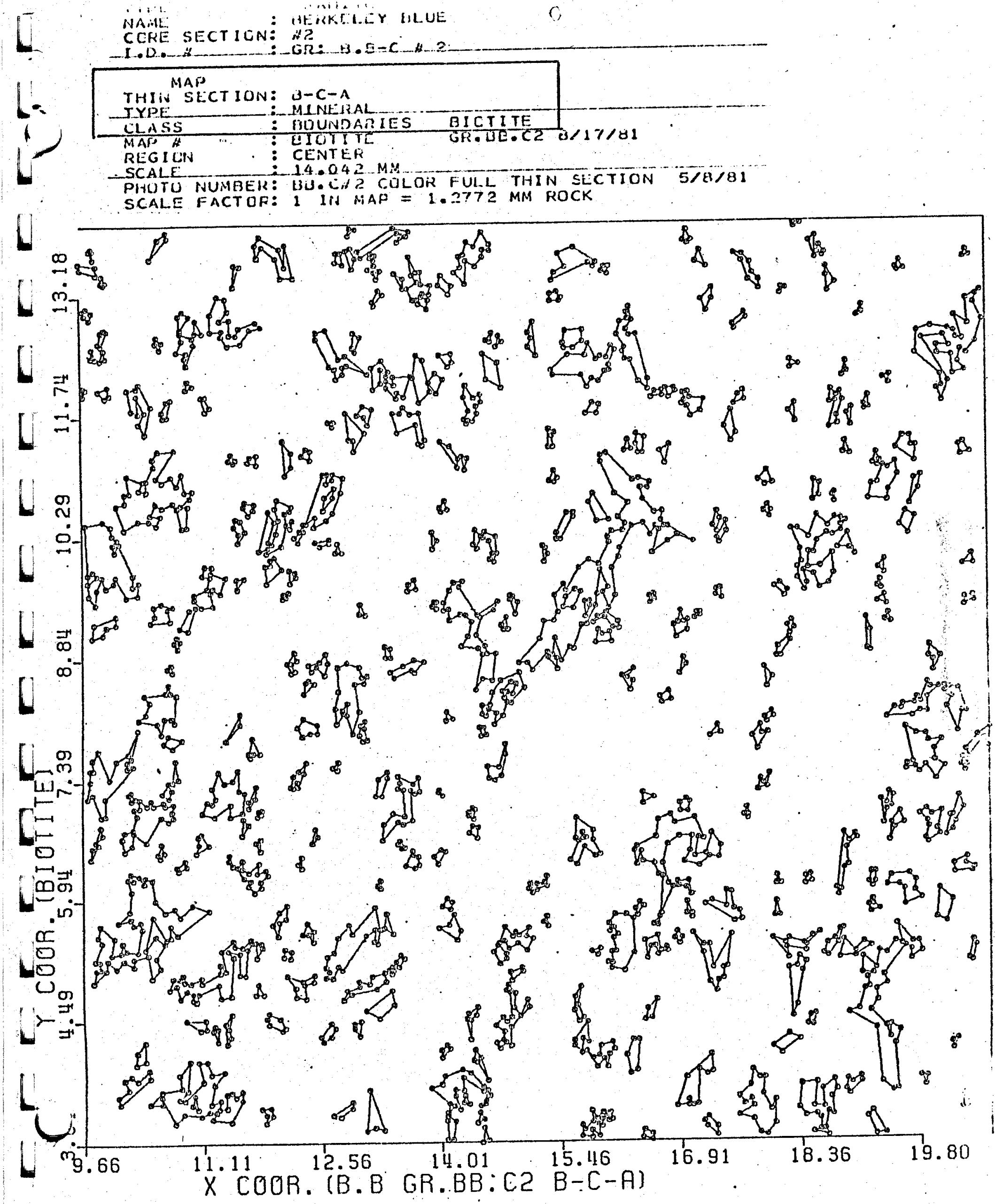




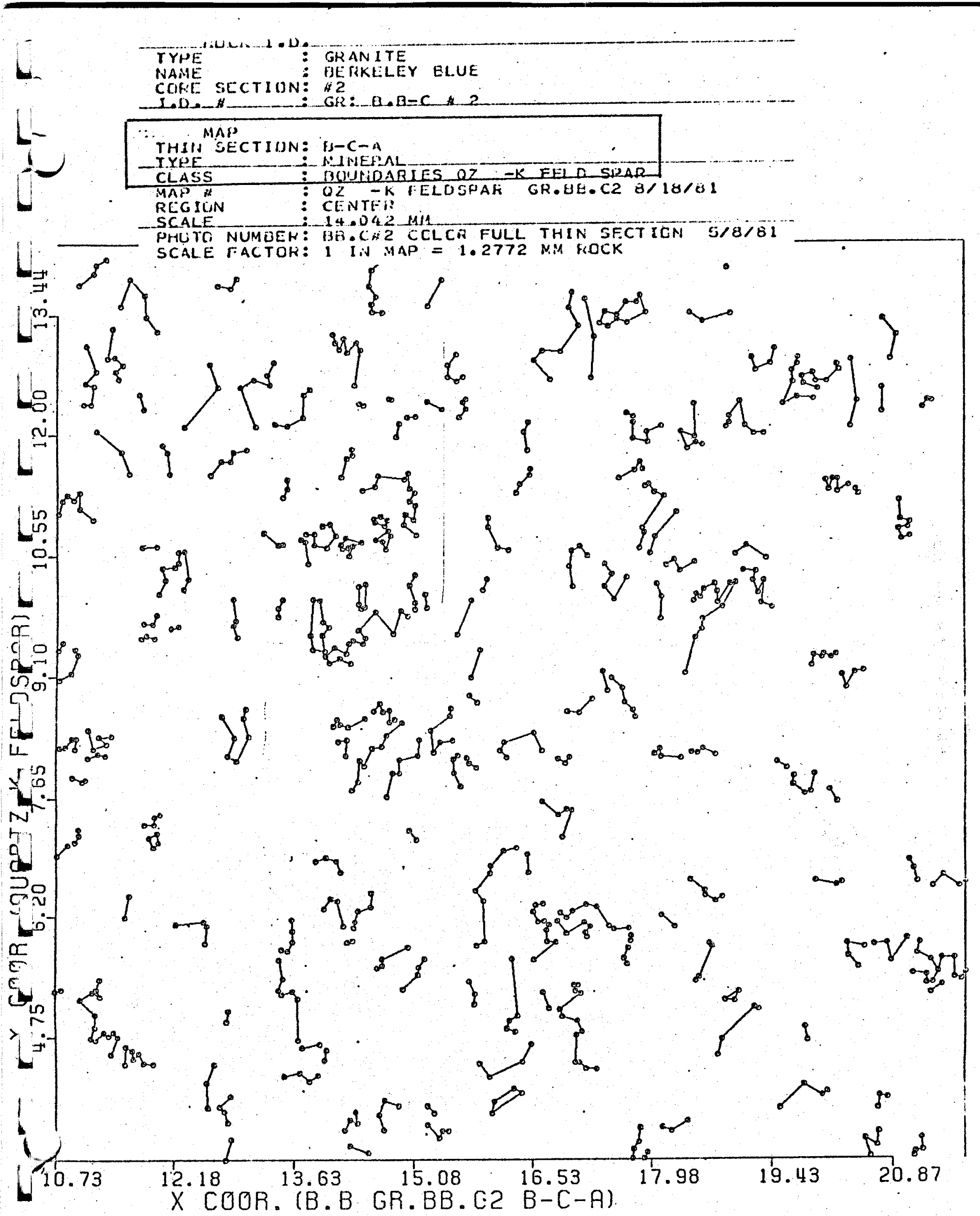




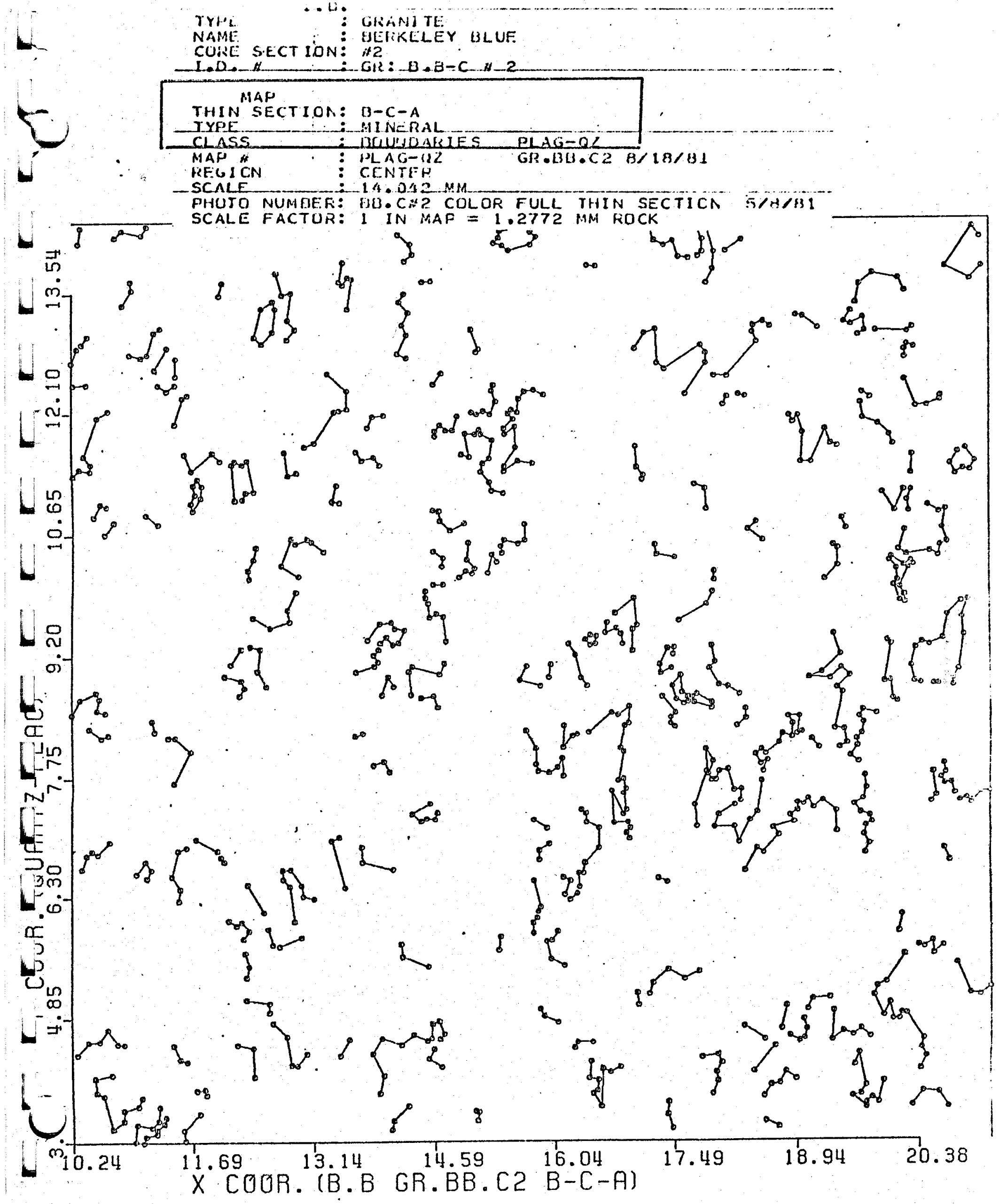




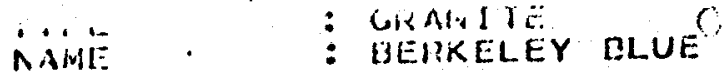

COHE SECTION: \#2

- I.D. A
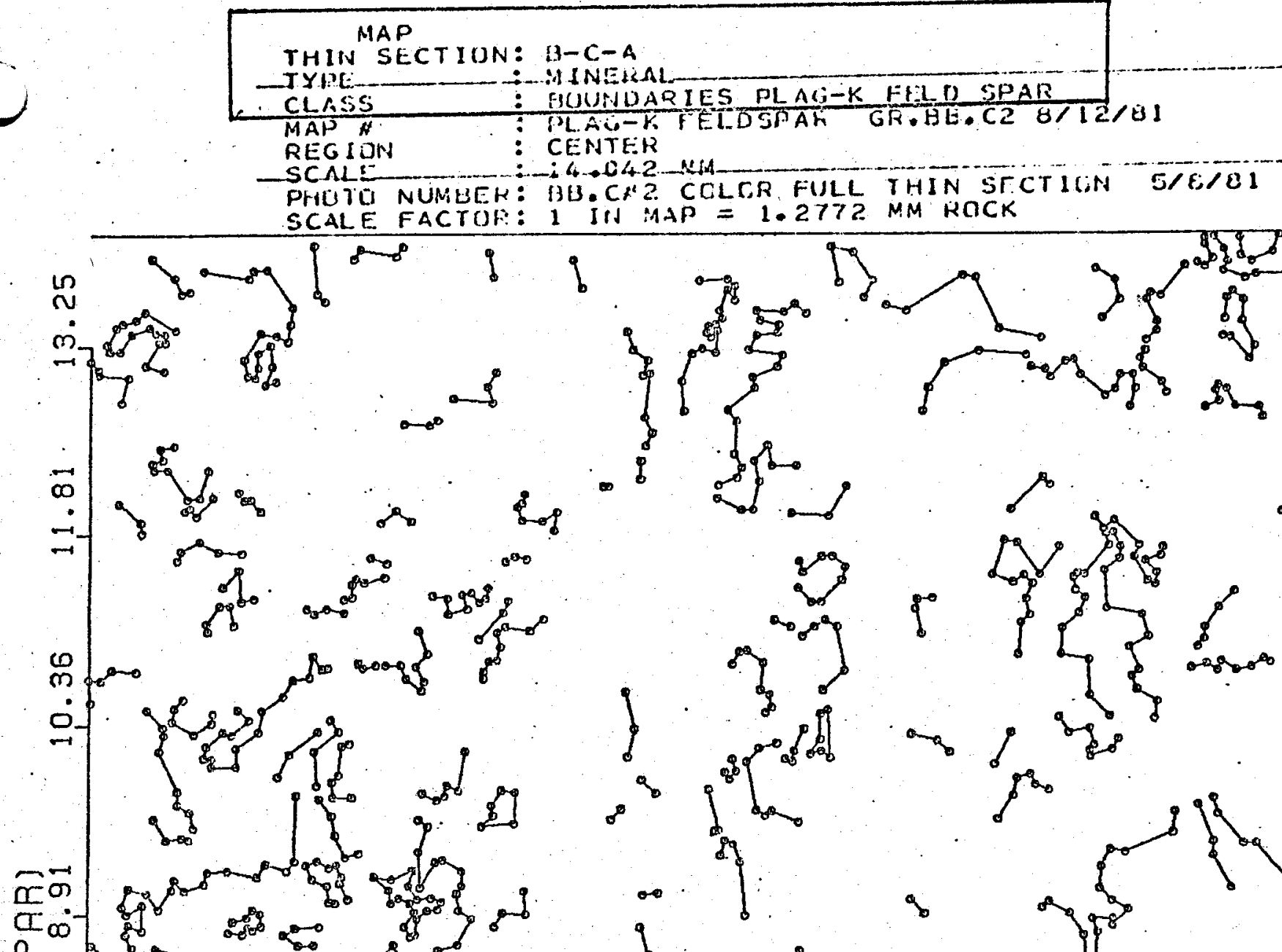

更

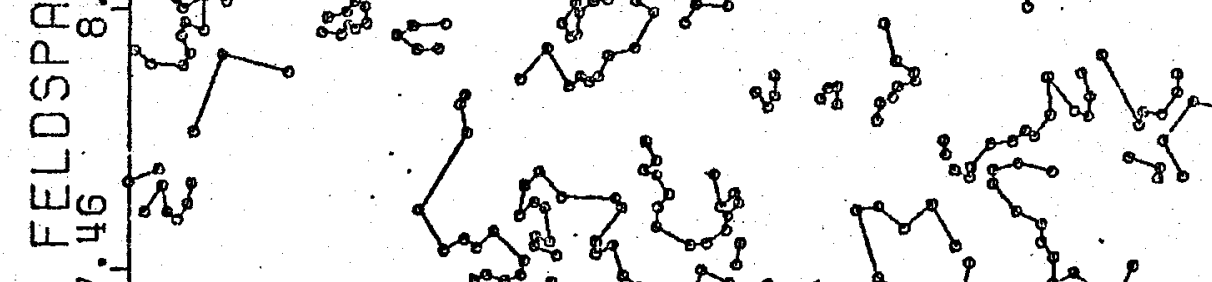

$\frac{x}{1}$

뭉

.6-

$\infty$

0

$\omega_{0}$

$>-1$

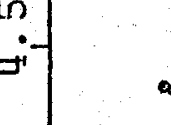

$=$

i-
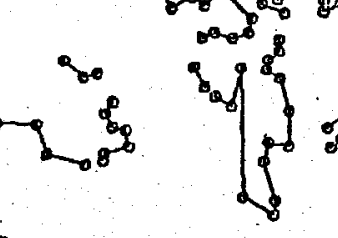
$\log _{0}$

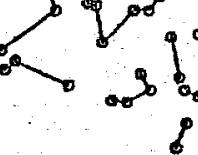

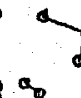

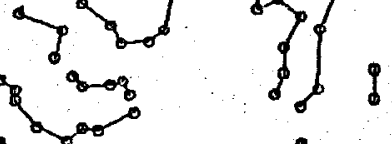

?.

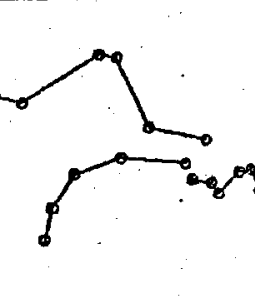

s

का

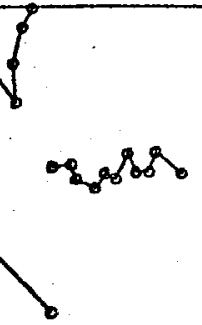




\section{RELATION OF WELL-LOG VELOCITIES AND \\ MAGNETIC SUSCEPTIBILITIES TO \\ LABORATORY VALUE: CONWAY \\ GRANITES, WHITE MOUNTAINS, NEW HAMPSHIRE}

by

Nick Warren

Mike Tiernan

Nick Coffey

Institute of Geophysics and Planetary Physics University of California

Los Angeles, California 90024

\section{REPORT}

\section{Introduction}

Through DOE grant "The Relationship of Rock Physics to Geothermal Energy. Technology," a series of studies were conducted on core samples from an ERDA borehole in the Conway granite of White Mountains, New Kampshire. $(1,2,3,4,5)$.

Here we present the correlation of well $\log$ velocities and magnetic susceptibilities to laboratory values for these same samples.

We11-log data was obtained from the United States

Geological Survey (Denver) through the courtesy of Dr. Fredrick L. Paillet (Borehole Geophysics Research Project). Velocities, Summary

Well log velocities were generated from acoustic travel time between two logging tool receivers located two and three feet respectively uphole from a relatively narrow band transmitter of approximately $34 \mathrm{kHz}$. Laboratory velocities 
were obtained as functions of pressure on dry samples at frequencies of 1 to $3 \mathrm{Mhz}$. In the previous laboratory studies 10 samples were sorted into 3 classes based on grouping in the velocity-pressure functions $(1,2)$. More recently data for four additional samples were obtained, extending the membership in one of the velocity classes ${ }^{(6)}$. Our first finding is that each class shows a separate correlation to the well-log data. Velocity, Data and Results

The table lists the Conway sample by depth (in meters), their grouping (I, II, III), corresponding lithostatic pressure (using the average bulk rock density of $2.62 \mathrm{gm} / \mathrm{cm}^{3}$ ), well log velocities at corresponding depth, dry sample velocities at corresponding pressure, and crack-free velocities for the sample (nominally at $0.4 \mathrm{GPa}$ ). The last column, volume magnetic susceptibility, is discussed in a separate section.

Figures 1, 2, and 3 show the dry rock sample velocities plotted on the velocity log. Two points are immediately apparent. First, the Group I and III samples correlate with the $\log$ data (figures 1 and 3 ). (The anamolous low velocity sample 537.4 is from a low velocity region in the bore hole, indicating that this sample is from a highly fractured zone.) Second, the group II samples do not correlate with the $10 \mathrm{~g}$ velocities (figure 2).

There are no gross mineralogical differences between $I$ and II samples. However I samples are coarser grained and also exhibit less uniform distributions of dark 'clots' (opaques 
plus biotite plus chlorite?). It appears that petrotexture controls the marked differences in the $I$ and II responses to coring.

The lower velocities of the lamprophyre samples (III) are mineralogically controlled, and it is felt that the intrusion of these dikes may have effected the local fracture densitites, accounting for the low velocity of the granitic sample 537.4 . Magnetic Data and Summaries

Magnetic susceptibilities for the Conway samples were measured at the University of California at Santa Barbara, by courtesy of Prof. B. Luyendyk.

Figure 4 shows that there is a weak separation of classes I and II based on magnetic susceptibility. The mean value of $\underline{k}$ for group II is higher than that for $I$, but the variance of either group is too large for separation. The lamprophyre rock has $\underline{k}$ values which are one to two orders of magnitude greater than those of the granitic samples. The granitic samples show a possible correlation of $\underline{\mathrm{k}}$ with grain size, however, the magnetic susceptibility is not as strong a factor as the velocity contrary to what was first suspected. The laboratory k, nevertheless, is in good agreement with the well log data. Figure 5 presents the lab data plotted on the well log. Porosity

From figure 2, the crack porosities of group II are expected to be larger than those of group $I$. This is true for 
crack porosities inferred from the total change in velocities with pressure. The inferred crack porosities are about $2 \cdot x$ $10^{-4}$ for group II and $1 \times 10^{-4}$ for group I. (3) However, static strain measurements yield much larger estimates of crack porosities. These later estimates do not clearly separate the I and II groups. Crack porosities inferred from strain are about $12 \times 10^{-4}$, which is felt to be a reasonable estimate for this granite body. For comparison Westerly granite has a crack porosity of about $20 \times 10^{-4}$ and grandiorites and monzogranites from Fenton Hill, Valle Grande Caldera, New Mexico which appear quite similar to these Conway granite have porosities of $2 \times 10^{-4}$ to $10 \times 10^{-4}(7,8)$

The lamprophyre dike rocks have porosities of less than $6 \times$ $10^{-4}$ as determined from either velocity or strain data. 

1.
2.
3.
4.
5.
6. 7 .
8.

\begin{tabular}{llllllll}
\hline 197.2 & I,A & G & 5.07 & 6.01 & 5.66 & 6.55 & 0.246 \\
301.8 & I & MG & 7.76 & 5.81 & 5.83 & 6.36 & 0.105 \\
335.0 & II & MG & 8.61 & 5.81 & 5.02 & 6.23 & 4.91 \\
381.9 & II & SYG & 9.81 & 6.28 & 5.19 & 6.10 & $8.87,8.67 \mathrm{~d}$ \\
419.0 & I & G & 10.77 & 5.92 & 5.73 & 6.41 & 1.13 \\
448.1 & I & SYG & 11.52 & 5.81 & 5.94 & 6.41 & 0.238 \\
502.3 & III & LAMP & 12.91 & 5.49 & 5.26 & 5.67 & 70.4 \\
515.7 & I,A & G & 13.25 & 5.70 & 5.93 & 6.84 & 0.219 \\
523.3 & I & SYG & 13.45 & 4.69 & 5.51 & 6.18 & 4.49 \\
537.4 & I,A & G & 13.81 & 4.50 & 4.88 & 5.48 & 0.147 \\
610.2 & III & LAMP & 15.68 & 5.37 & 5.09 & 5.60 & 87.1 \\
704.4 & II & SYG & 18.10 & 6.10 & 5.43 & 6.33 & 1.90 \\
715.7 & I & G & 18.39 & 5.83 & 5.64 & 6.31 & 0.164 \\
771.1 & I,A & G & 19.82 & 5.81 & 6.11 & 6.47 & $0.93,1.01 \mathrm{~d}$
\end{tabular}

Column:

1 = Sample group ID in meter depth.

2 - Group number ${ }^{a}$

$3=$ Lithologyc

4 = Lithostatic pressure (MPa)

$5=$ Well-log $\mathrm{V}_{\mathrm{p}}(\mathrm{km} / \mathrm{sec})$

6 = Sample velocity $(\mathrm{Km} / \mathrm{sec})$

7 = Crack-free velocity $(\mathrm{km} / \mathrm{sec})$

8 = Magnetic susceptibility (CGS $\times 10^{4}$ )

AVERAGED VELOCITY DIFFERENCES ( $\mathrm{km} / \mathrm{sec})$

\begin{tabular}{|c|c|c|}
\hline Class & $\begin{array}{l}\text { Crack } \\
\text { free- } \\
\text { vel1 } \\
\text { log } \\
\text { velocit } \\
(7-5)\end{array}$ & $\begin{array}{l}\text { Crack } \\
\text { free- } \\
\text { sample } \\
\text { velocity } \\
(7-6)\end{array}$ \\
\hline
\end{tabular}

I-IA $+0.77+0.64$

II $+0.16+1.01$

III $+0.21+0.46$

a reference $1,2,3$

b group I,A refers to new samples ldentifled as members of group I

c MG = monzogranite, $S Y G=$ syenogranite, LAMP = Lamprophyre,

d $\mathbf{G}=$ granitic (mode not determined)

d measured against two standards 


\section{REFERENCES}

1. Warren, N. "Rock physics characterization of Conway granite from DOE borehole, Conway, New Hampshire", LANL Report \#LA-8102-MS, Los Alamos National Laboratory, New Mexico, 1979.

2. Warren, N. and M. Tiernan, "Systematics of crack-controlled mechanical properties for a suite of Conway granites from the thite Mountains, New Hampshire", Tectonophysics, 73, 295-322, 1981.

3. Warren, N., M. Tiernan, and N. Coffey, "Determination of crack porosity from ratios of static and dynamic bulk moduli", report to Department of Energy, 1982.

4. Warren, N., "Quantitative petrostructure analysis", LANL report, in press, 1982.

5. Warren, N., "Statistical characterization of complex crack and petrographic texture: Application to predicting bulk mechanical properties" in Issues in Rock Mechanics: 23 U.S. Symposium on Rock Mechanics, Berkeley, CA, Aug . 25-27, 1982.

6. Tiernan, M. "Progress report to Department of Energy on 'The Relationship of rock physics to geothermal energy technology'" for the period February 1, 1980-October 31, 1980.

7. Simmons, G. and H. Cooper, "DSA of the microcracks in GT-2 core: Interpretation and implications," submitted to Los Alamos National Laboratory, 20 November 1976. 
8. Simmons, G. and H. Cooper, "Final technical report--DSA of the microcracks in wore GT-2 core: interpretation and implications," submitted to Los Alamos National Laboratory, 16 November 1977. 



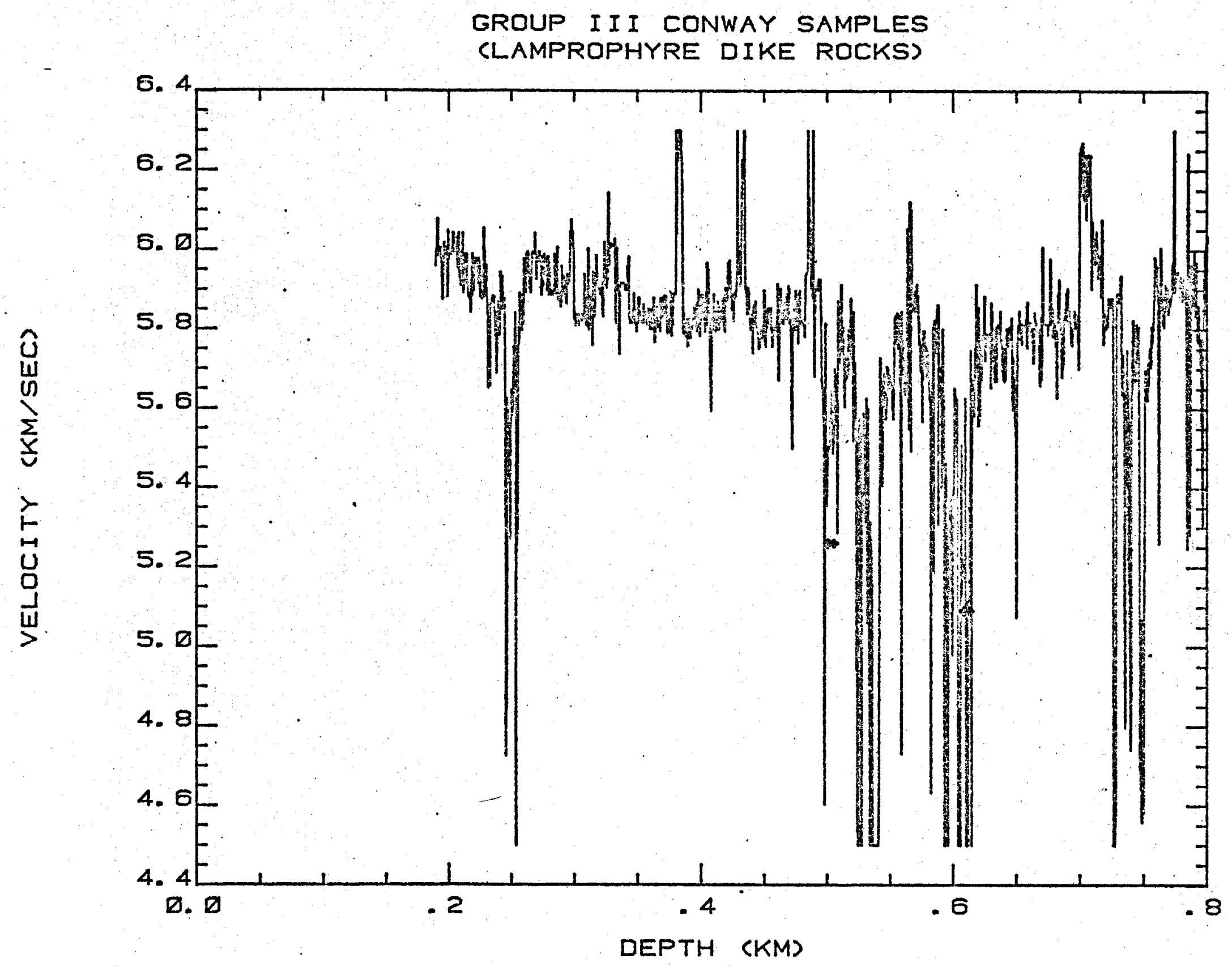


MAGNETIC SUSCEPTIBILITY : MICROCGS

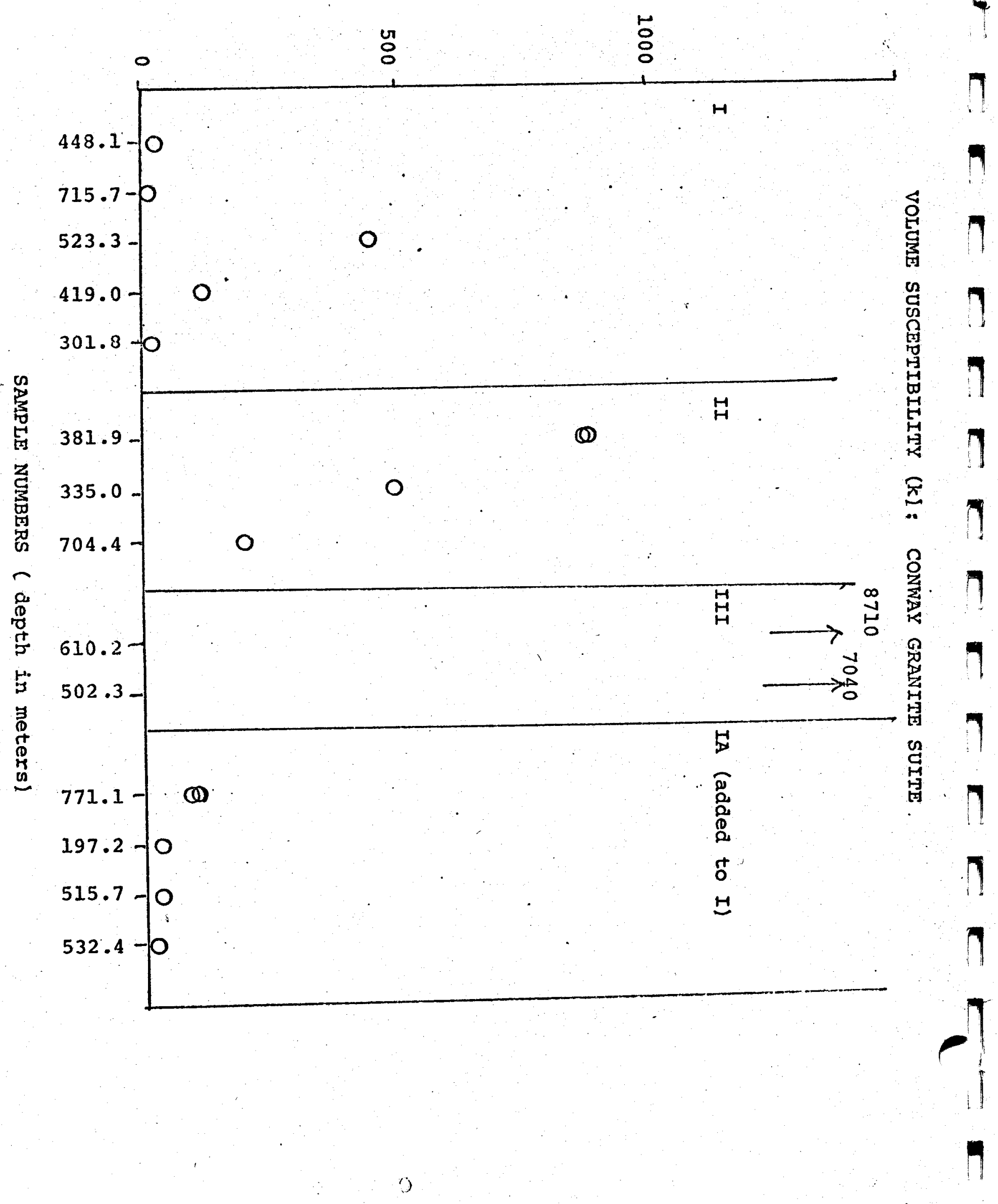



VELOCITIES AND DYNAMIC MODULI OF FIVE EE2 BOREHOLE SAMPLES
TECHNICAL SUMMARY REPORT

\author{
by \\ Nick Warren \\ Nick Coffey \\ Chou Hsiao
}

Institute of Geophysics and Planetary Physics

University of California, Los Angeles

\title{
Summary
}

Velocity and dynamic moduli data are compiled here for five EE2 minicore samples from four depths. They are 11739-6B $12851-5 B, 13461-2 B$, and $13962-1 B$ and 1C. Measurements were made under hydrostatic pressure to about $0.2 \mathrm{GP}$. Transducer frequencies were $1 \mathrm{MHz}$ and $3 \mathrm{MHz}$. The suite includes fine grained, Intermediate grained and coarse grained granitic samples, and one basaltic sample. The locations within the well from which the minicores were taken were chosen to be adjacent to, or near locations of minicores characterized at LANL within the Geoscience group ESS-3.

At UCLA under DOE support (DE-AS03-76SF-00034, PAll DE-A003-76ER70224) in conjunction with $G-5$ and $G-4$ at Los Alamos Scientific Laboratory. 


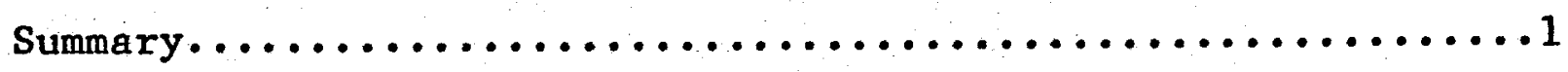

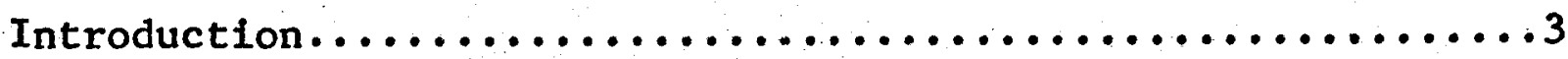
EE2 Velocity Measurement at UCLA..................

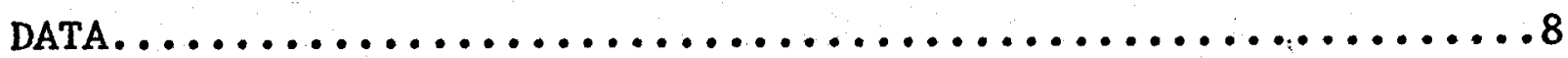

Velocity Moduli Data......................... 8

Organization of Appendices.....................11

Comparison to Uniaxial Static Data.................11 Comparison of Dynamic and Static Moduli

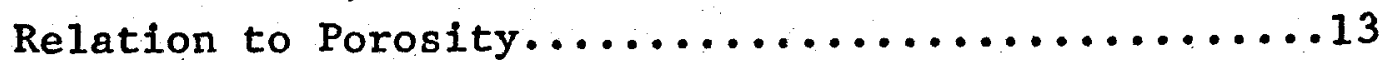

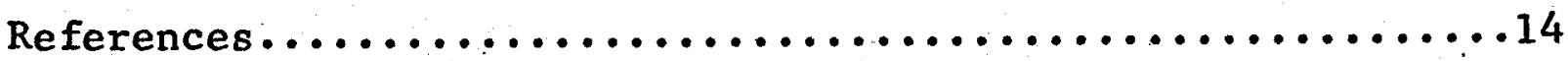
Appendices

Section I - Velocities and Dynamic

Moduli, Tables and Plots..................... 16-52

Section II - Static and Dynamic

Moduli Graphs......................... 53-68 


\section{INTRODUCTION}

Under the Hot Dry Rock (HDR) Geotherma1 program at Los Alamos National Laboratory, an HDR geothermal system is being developed at Fenton Hill, near the western edge of the Valles. Caldera in the Jemez mountains near Los Alamos. ${ }^{1}$

The latest and deepest borehole is designated EE2 and was drilled to attain a bottom hole temperature of about $300^{\circ} \mathrm{C}$. - Recovered cores from depths of $11,739 \mathrm{ft}$. to $13,962 \mathrm{ft}$. were sampled for laboratory acoustic and mechanical measurements. This report presents the acoustic data obtained at University of California, Los Angeles along with static strain measurements taken at Los Alamos Nation Laboratory by Tom Dey. The experiments at UCLA were performed with hydrostatic pressure. At LANL static strains were measured as a function of uniaxially applied stress. There are two sections in the Data Appendix. The first contains the acoustic velocity and resulting dynamic moduli data. The second compares these moduli to the static moduli obtained for similar samples under uniaxial testing at Los Alamos.

The two sets of samples were:

LANL

UCLA.

11739-6A, 6B

$11739-6 \mathrm{~B}$

$12850-4 A, 4 B$

$12851-5 B$

$13461-3 A, 3 B$

13461-2B

i $3958-4 \mathrm{~A}, 4 \mathrm{~B}$

13962-1A, 1B

$13962-1 B, 1 C$ 
The minicores were taken from larger $E E-2$ cores. With the exception of sample 13962-1B all of the UCLA samples were cut parallel to the core direction. Sample 13962-12B was cut orthogonal to the original core direction. Sample 11739-6B is a coarse-grained biotite-granodiorite gneiss. Sample 12851-5B is a fine grained metavolcanic rock. It is generally equigranular and is mostly comprised of biotite, plagioclase, quartz and. opaques. Epidote and sphene are also abundant in this rock. Sample 13461-2B is medium grained blotite-granodiorite with appreciable quantities of epidote and sphene. Samples 13962-1B \& C are a fine grained biotite monzogranite composed primarily of $\mathrm{K}$-feldspar, plagioclase, quartz and blotite.

In addition to the EE-2 experiments a 'standard' granite (Elberton Granite or Berkeley Blue Granite) was measured. The Elberton Granite is a fine grained biotite-muscovite granite. It is the hardest granite in the suite and serves to give a measurement of the variation in moduli that may be expected from the different techniques employed at the two facilities. 


\section{EE2 VELOCITY MEASUREMENT}

\section{AT UCLA}

\section{Experimenta1:}

The EE2 rock samples were nominally $30-45 \mathrm{~mm}$ in length and $16.58 \mathrm{~mm}$ in diameter. The flat faces were ground parallel to a tolerance of $\pm 0.01 \mathrm{~mm}$; usually better than $\pm 0.005 \mathrm{~mm}$.

Both shear velocity and compressional velocity measurements were made. In both cases, $0.625 \mathrm{in}$. diameter PZT transducers were glued directly to the rock. For the compressional velocity measurements, $3 \mathrm{MHz}$ compressional mode transducers were used and for the shear velocity measurements, $1 \mathrm{MHz}$ shear mode transducer were installed. The samples were jacketed in an elastic material which kept them dry but freely transmitted hydrostatic pressure to them.

A $4 \mathrm{~Kb}$ pressure vessel, with kerosene as the pressure medium, was used for these experiments. The pressure apparatus was fitted with three gauges: two Heise gauges and a pressure transducer.

Figure 1 shows a schematic of the configuration used in the travel time determination. Three pulse generators (PG), an amplifier (AMP), and an oscilloscope with three independent vertical input channels were used. These pulse generators supply a fiducial mark for the pulse travel time, generate an input pulse to the sample, and provide a movable marker to measure the time delay between the fiduclal mark and the first arrival of the acoustic signal. 
PGl supplies two outputs. First, it generates a trigger pulse which triggers both the oscilloscope horizontal sweep and PG2; second, PGI gives an output pulse which is fed into one of the oscilloscope's vertical channels. The output signal from the sample is put through an amplifier and then goes to a second vertical channel on the oscilloscope. Note that with the sample taken out of the configuration, the output pulse from PGI can be set at the position of the output pulse from PG2 as seen on the oscilloscope. This pulse then serves as a $t$ $=0$ marker because it has calibrated out all the delays in the configuration due to the electronic components and cables. PG3 generates a second marker pulse which is triggered by the variable delay trigger on the oscilloscope. Using this marker on the third vertical input channel of the oscilloscope, the time delay between the $t=0$ marker of $P G 1$ and the acoustic arrival from the sample was determined by a Hewellet Packerd 5300B Measuring System.

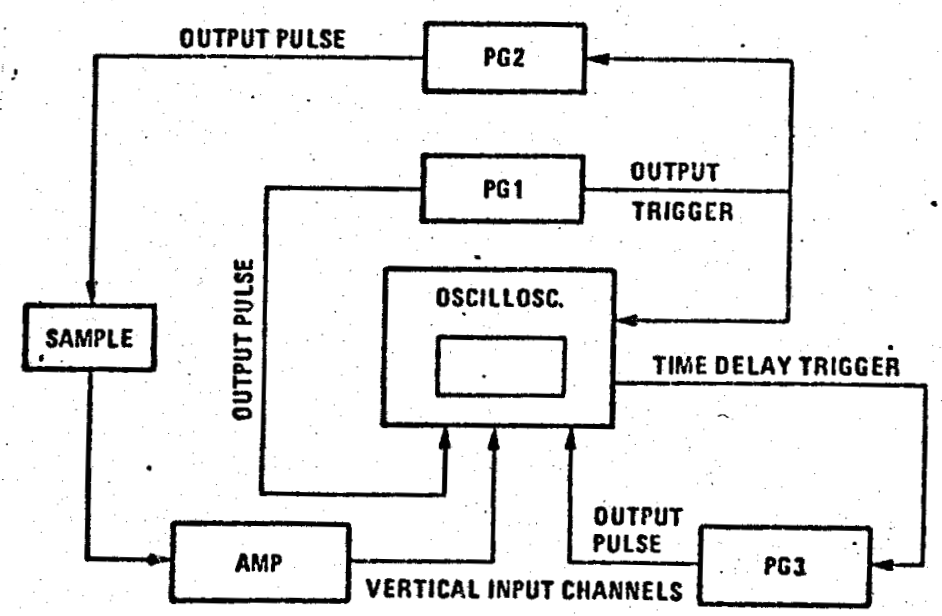

Fig. 1.

Pulse transmission electronic systems. See text for discussion. 
This arrangement allows us to eliminate uncertainties on our travel-time measurements due to the electronics, and we achieve reproducibility of a few nanoseconds and an overall absolute uncertainty of about $1 \%$ for our travel-time determinations through any given sample.

Prior to each pressure run, the apparatus, with the sample installed and connected to the electronics, was pressurized to $3,000 \mathrm{psi}$ and returned to ambient pressure. This was done to insure proper seating of all the seals before the experiment was started.

All of the experiments were conducted at room temperature over a pressure interval that ranged from zero to approximately $2.2 \mathrm{~kg} \mathrm{-}^{-2}$, with ambient pressure taken as zero. In every case the most closely spaced data were taken in the first 500 bars of the run.

In the first 500 bars of each run, data were taken about every 20-30 bars. As the experiment proceeded to higher pressures, these data points were gradually spread out so that, approaching the top of the run, velocity measurements were made at intervals of 125-150 bars. In most cases, down run data were taken with a corresponding procedure, just the reverse of the above. 


\section{DATA}

\section{Velocity Moduli Data}

The table below presents this new laboratory velocity up run data at pressures corresponding to depths from which samples were taken. Blair, Tester and Mortenson ${ }^{2}$ present laboratory velocities for GT-2 samples in comparison to we11-log measurements. These are represented in the table below to establish the velocity profile for the upper portion of the Fenton Hill pluton and the overlying metamorphic complex. No we11-log data have been obtained for the EE2 borehole. We have therefore calculated predicted in situ velocities based on our lab measurements and the work of Blair, et a1.

The expected in situ values are based upon a mean increase In compressional velocity of $0.34 \mathrm{~km} / \mathrm{sec}$ with a standard deviation of 0.23 for in situ vs. laboratory conditions. For shear velocity values a mean increase of $0.07 \mathrm{~km} / \mathrm{sec}$ with a standard deviation of 0.07 was used. The velocity increase may be due to saturation effects, overcoring effects, thermal effects or combined effects. Thermal effects cannot be fairly established at this time. Estimated temperature at the depth of 11,000 to 14,000 are around $250^{\circ} \mathrm{C} .{ }^{3}$. Laboratory room temperature velocities will be lowered by open, cool, dry cracks. However we see no trend in the GT2 data which Indicates a definite thermal effect which can be extrapolated from the data based upon in situ porosity and saturation. 
Simmons and Cooper ${ }^{4}$ have reported a correction to in situ velocity for GT-2 samples by ignoring thermal effects and basing the correction on removal of the effects of cracks which close below in situ pressure. Their results suggest that cracks induced by coring the sample and bringing the sample up from depth can account for the velocity differences. Warren and Coffey, in the report "Conway-Borehole Logs" (DOE Final Grant Report, 1982), show that for granitic rocks, the effects of overcoring can selectively effect rocks of a particular grain size and petrostructure. It has also been shown (Nur and Simmons ${ }^{5}$ ) that a $5 \%$ increase in in situ velocity over lab velocity can be accounted for by saturation effects. Based on the data available we feel that the predicted velocity ranges we have established bracket the realistic values to be expected. 
A.

\section{COMPARISON OF LABORATORY AND FIELD ACOUSTIC VELOCITY MEASUREMENTS}

$\underline{\text { Sample Number }}^{\mathrm{a}}$

$2580-6$
$2580-5$
$2600-4$
$2600-3$
$2844-6$
$2844-4$
$2857-7$
$2857-5$
$3151-5$
$3151-7$
$3464-8$
$3697-1$
$4279-1$

4894-1

4915-2

4916-1

$5234-1$
$\frac{V_{p}(\mathrm{~km} / \mathrm{s})}{\underline{\text { Lab }} \quad \text { Fie1d }}$

5.82

5.92

5.94

5.93

5.83

5.90

5.98

5.80

4.98

4.97

5.66

5.86

5.88

5.77

5.90

5.92

5.82

5.88

5.64

5.42

5.90

\subsection{5}

6.05

6.00

6.00

6.31

6.31

6.34

6.34

5.78

5.78

6.02

5.86

5.99

5.93

5.98

5.98

6.03
$\frac{V_{s}(\mathrm{~km} / \mathrm{s})}{\text { Lab }}$

3.39

3.44

$3.46 \quad 3.44$

$3.44 \quad 3.42$

$3.43 \quad 3.42$

$3.48 \quad 3.48$

$3.44 \quad 3.48$

$3.51 \quad 3.55$

$3.46 \quad 3.55$

$2.87 \quad 2.97$

$2.95 \quad 2.97$

$3.19 \quad 3.43$

3.52

3.46

3.35

3.51

3.42

3.43

3.50

3.41

3.37

3.42

3.51

3.49

3.52

3.54

3.54

3.56

a First four digits refer to depths in feet.

B.

LABORATORY ACOUSTIC VELOCITIES AT PRESSURES CORRESPONDING TO SAMPLE DEPTH AND EXPECTED RANGE OF IN SITU VALUES

\begin{tabular}{llllll}
$\begin{array}{l}\text { Sample } \\
\text { Number* }\end{array}$ & $\begin{array}{l}\text { Pressure } \\
(\mathrm{MPa})\end{array}$ & $\begin{array}{l}\mathrm{Vp} \mathrm{Lab} \\
(\mathrm{Km} / \mathrm{s})\end{array}$ & $\begin{array}{l}\mathrm{Vs} \text { Lab } \\
(\mathrm{Km} / \mathrm{s})\end{array}$ & $\begin{array}{l}\text { Predicted } \mathrm{Vp} \\
\text { field range }\end{array}$ & $\begin{array}{l}\text { Predicted Vs } \\
\text { field range }\end{array}$ \\
\cline { 1 - 5 } $11739-6 \mathrm{~B}$ & 947 & 6.03 & 2.96 & $6.14-6.60$ & $2.96-3.10$ \\
$12851-5 \mathrm{~B}$ & 103.6 & 5.71 & 3.17 & $5.82-6.28$ & $3.17-3.31$ \\
$13461-2 \mathrm{~B}$ & 108.6 & 6.00 & 3.32 & $6.11-6.57$ & $3.32-3.46$ \\
$13962-1 \mathrm{~B}$ & 112.6 & 5.94 & 3.19 & $6.05-6.51$ & $3.19-3.33$ \\
$13962-1 \mathrm{C}$ & 112.6 & 6.05 & 3.16 & $6.16-6.62$ & $3.16-3.30$ \\
*first four digits refer to depths in feet.
\end{tabular}




\section{Organization of Appendices.}

In the Appendix the data sets are arranged by increasing sample number. The velocity data are presented in two forms: first the raw pressure and velocity values are 1 isted, and second, interpolated velocity values at standard pressure are given. The method of interpolation is given in Warren and Tiernan ${ }^{6}$. These interpolated values are used to calculate the tabled dynamic moduli. Comparison to Uniaxial Static Data

For the purpose of making direct comparisons between the hydrostatic data $\left(K_{s}\right)$ and uniaxial measurements $\left(K_{d}\right)$, as listed in the appendices, it is necessary to apply a conversion factor. To produce an equivalent strain in a given direction greater hydrostatic pressure than uniaxial must be applied. A pressure mean relationship suggests that to obtain equivalent strains the pressure exerted in a uniaxial experiment $\left(P_{L}\right)$ is $1 / 3$ the pressure in the hydrostatic case $\left(P_{H}\right)$. On the other hand Warren and others ${ }^{7}$ (March 8, 1973) show that the relationship between hydrostatic pressure and uniaxial loading is:

$$
P_{H}=\left(\frac{1}{1-2 \sigma}\right) P_{L}
$$

where $\sigma$ is the Poisson's ratio. In the limit where $\sigma \rightarrow 0$ the pressures exerted to produce equal strain are the same.

If we can assume that velocities measured in a chosen direction are controlled by the strain in that direction, then the correspondence between equivalent hydrostatic and uniaxial stress-states are given by equation 1 . 
This means that in an uniaxial experiment cracks perpendicular to the loading close at stresses much lower than under hydrostatic stress. If these cracks control velocity then higher hydrostatic pressures are needed than uniaxial stress to reach the same equivalent strain.

In the figures in Appendix B the abscissa are to be read as uniaxial stress for the uniaxial data and hydrostatic stress for the dynamic data. The effects of the conversion between the two types of loading can be estimated from the tabulated data in Appendix A. In general the greatest effect is on Young's modulus and is on the order of $20 \%$ or less at $20 \mathrm{MPa}$.

Two types of static strain transducers were used in the LANL studies, namely strain gauges and LVDT's. Axial and circumfrential strains were measured under uniaxial loading and the data converted into Young's moduli, Poisson's ratio, and volume compressibility. Strain gauge measurements were made away from through-going cracks, while the LVDT measures across all such cracks. In general, the LVDT data translate into lower stiffness than do the strain gauge data. The dynamic moduli are stiffest. Comparison is shown for Elberton granite in the first set of graphs. The strain gauge and LVDT are from LANL office memorand1. In the memos $T$. Dey notes that "data for the Berkeley granite show how much agreement between the two methods can be expected when no fractures are present. The axial strain shows good agreement." In each of the following graphs, we have simply. plotted our data directly onto the LANL graphs from the G-7 memos (presently ESS-3) of May, June, and July $1980.8,9,10$ 
The relationship between $\mathrm{K}_{\mathrm{S}}$ and $\mathrm{K}_{\mathrm{d}}$ values for $\mathrm{EE}-2$ samples are consistent with the findings of a broader study (Warren, Tiernan \& Coffey ${ }^{11}$ ) in which $\mathrm{k}_{\mathrm{s}} / \mathrm{K}_{\mathrm{d}}$ were found to reflect the grain size and homogeneity of the measured samples. The $K_{s}$ and $K_{d}$ values can be used to estimate down hole moduli and fracture regimes. In situ velocities are equivalent to laboratory velocities and thus predict moduli of similar values. The $K_{d}$ values indicate the stiffest behavior or the best rock condition. The $\mathrm{K}_{\mathrm{s}}$ values fall closer to in situ moduli inferred from hydrostatic experiments.

\section{COMPARISON OF DYNAMIC AND STATIC MODULI}

RELATION TO POROSITY

To first order, the gap between dynamic and static bulk moduli is a direct function of crack porosity. The ratio between the moduli, for the EE2 rocks here, is basically compatible to that observed fro a similar suite of granitic rocks from an ERDA borehole in the Conway granites, New Hampsire ${ }^{6}$ Since the static compressibilities used in this report are mostly from LVDT data, the ratios indicated by the graphs (1.e. Ks/Kd $\leq 0.5$ to 0.3 ) are probably maximal, and if so, suggest crack porosities are strictly less than about $0.5 \%$. This value corresponds to about the upper estimate of crack porosities for granitic rocks. The most probable porosity range (taking into account the effect of the LVDT on $k_{d}$ is $2 \times 10^{-4}$ to $10 \times 10^{-4}$. 


\section{REFERENCES}

1 G.M. Cremer, R. B. Duffield, M. C. Smith, M. G. Wilson, "Hot Dry Rock Geothermal Energy Development Program", Los Alamos Scientific Laboratory report, LA-8280-HDR, (August 1980).

2 Blair, A.G., Tester, J.W., and Mortensen, J.J., "LASL Hot Dry Rock Geothermal Project: July 11975 - June 30, $1976^{11}$ LANLReport number LA-6525-PR issued October 1976.

3 Pettit, Roland A., "Environmental Monitoring for the Hot Dry Rock Geotherma1 Energy Development Project: Annual Report for the period July 1975 - June 1976," LANL report number LA-6504-SR, issued September 1976.

Cooper, H., and G. Simmons, "Final Technical Report: DSA of the microcracks in more GT-2 core: interpretation and implication, submitted to LANL November 1977.

5 Nur, A. and G. Simmons, "Earth and Planetary Science Letters I, 183-193, 1969.

N. Warren, M. Tiernan, "Systematics of Crack Controlled Mechanical Properties for a Suite of Conway Granites From the White Mountains, New Hampshire", University of California; Los Angeles (August 1980).

7 Warren, N., R. Trice, N. Soga, and O.L. Anderson "Rock Physics Properties of some Lunar Samples" in Proceedings of the Fourth Lunar Science Conference, Geochimice Cosmochimica Acta, supplement 4, 1973. 
8 Office Memorandum to Jeff Tester (G-5), from Toll Dey (G-7) through Jim Albright (G-7), Subject: HDR Rock Mechanics; April 1980 (May 5, 1980).

9 Office Memo to Jeff Tester (G-5) from Tom Dey/Phil Halleck/Al Kumnick through Jim Albright (G-7), Subject: May Progress Report - HDR.Rock Mechanics (June 5, 1980).

10 Office Memorandum to Jeff Tester (G-5), from Tom Dey (G-7) through Jim Albright (G-7), Subject: Progress Report - HDR Rock Mechanics (July 2, 1.980).

11 N. Warren, M. Tiernan, N. Coffey, "Relation of Well-Log Velocities and Magnetic Susceptibilities to Laboratory Value: Conway Granites, White Mountains, New Hampshire", University of California, Los Angeles (October 1982). 


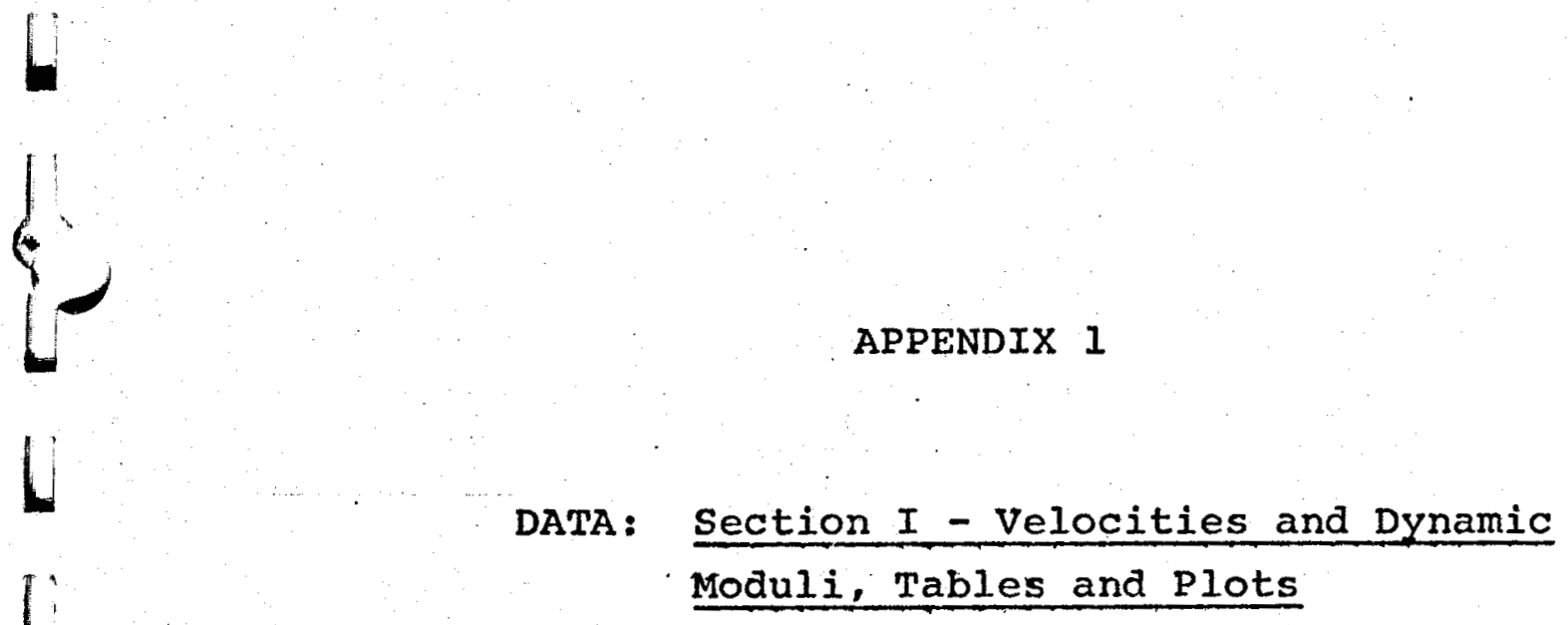

.

b

h

$\phi$

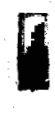

a

A

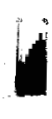

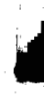

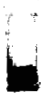

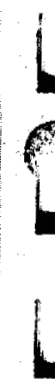


EL2-11739-6B

VELOCTRTES AND RRESSURES

I measured compressional velocity with increasing pressure B interpolated velocity with pressure

$\lambda$

$\begin{array}{ll}1.7490 & 3.708 \\ 1.0415 & 3.972 \\ 6.0121 & 4.167 \\ 13.5262 & 5.400 \\ 18.911 & 5.025 \\ 28.530 & 5.238 \\ 39.570 & 5.517 \\ 47.659 & 5.614 \\ 60.553 & 5.733 \\ 74.276 & 5.944 \\ 86.023 & 5.954 \\ 99.621 & 6.095 \\ 119.310 & 6.162 \\ 136.759 & 6.164 \\ 156.946 & 6.213 \\ 182.793 & 6.260 \\ 201.662 & 6.270\end{array}$

$\mathbf{B}$

pressure

MP velocity

$\mathrm{Hm} / \mathrm{sec}$

2.0000

4.0000

6.0000

8.0000

10.000

15.000

20.000

25.000

30.000

40.000

50.000

60.000

70.000

80.000

90.000

100.00

110.00

120.00

130.00

140.00

150.00

160.00

170.00

180.00

190.00

200.00
3.7339

3.91348

4. 1748

4.3593

4.52 .27

4.9690

5.0520

$5.18 \% .3$

5.27 .0

5.524 .6

5.6381

5. 74.11

5.8361

6.0013

5.9776

6.0970

$6.14,96$

6.1620

$6.171 \%$

6.1212

6.1936

6.21 .99

6.2424

6.2650

6.2015

6.3002 
A measured compressional velocity with decreasing pressure B interpolated velocity with pressure

A

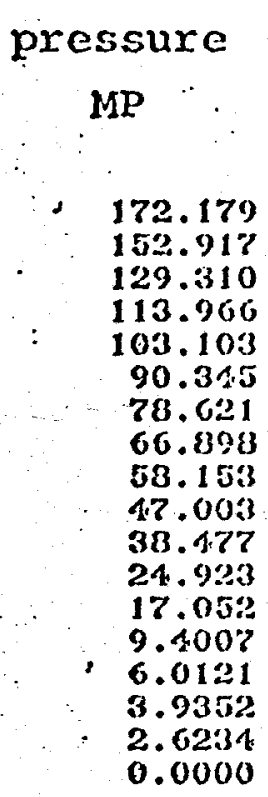

velocity
$\mathrm{km} / \mathrm{sec}$

6.235

6.235

6.183

6. 1913

6.148

0.098

5.991

5.036

5.921

5.280

5.652

5.305

5.010

4.658

4.1 .10

4.170

$3.75 \%$

3.167
B velocity $\mathrm{km} / \mathrm{sec}$

\begin{tabular}{|c|c|}
\hline $\begin{array}{l}0.0000 \\
2.0000 \\
4.0000 \\
6.0000 \\
10.000 \\
15.000 \\
20.000 \\
25.000 \\
30.000 \\
40.000 \\
50.000 \\
60.000 \\
70.000 \\
80.000 \\
90.000 \\
100.00 \\
110.00 \\
130.00 \\
150.00 \\
170.00\end{array}$ & 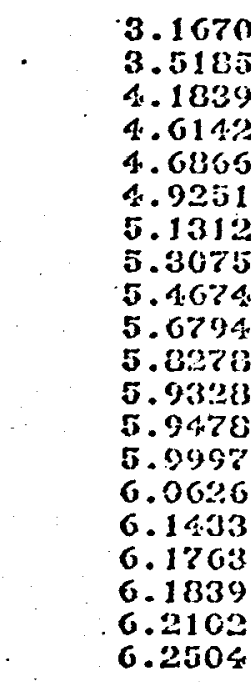 \\
\hline
\end{tabular}


Best estimated values of shcar velocity at standard pressuresa

pressuxe
MP.

$$
\begin{aligned}
& 2.0000 \\
& 4.0000 \\
& 6.0000 \\
& 8.0000 \\
& 10.009 \\
& 15.000 \\
& 20.000 \\
& 25.000 \\
& 30.000 \\
& 40.000 \\
& 50.000 \\
& 60.000 \\
& 70.000 \\
& 80.000 \\
& 90.000 \\
& 100.00 \\
& 110.00 \\
& 120.00 \\
& 130.00 \\
& 140.00 \\
& 150.00 \\
& 160.00 \\
& 170.00 \\
& 180.00 \\
& 190.00 \\
& 200.00 \\
& 1
\end{aligned}
$$

velocity
$\mathrm{km} / \mathrm{sec}$

2.1703

2.3039

2.3937

2.4 .412

2.1 .973

2. 60283

2.6208

2.6568

2. 68037

2.7536

2.8202

$2.870: 2$

2.9091

2.9301

2.9517

2.9671

2.9306

2.9942

.3 .0039

3.0147

3.0200

3.0274

$.3 .031 \%$

3.0378

3.0451

.3 .0518

a. In the original experimonts, wave-forms well after the first. Shear encrgy arrival wore the ones actually recordcred. The shear velocity as a function of pressure was estimated using these data and the lab book sketches of the total wave form. I feel that the actual shear velocity is slightly higher than could be established from the drawings of the wave forms. That is, the ture shear wave velocities are slightily higher than those given 
SARTE: ET2-11730-60

DENSITY: $2.725:($ (n) $/ \mathrm{CC})$

DYNAMIC NODUII CaICulated at standard pressures

A fron velocity with increasing pressure

B from velocity with decreasing pressure iulk shear press moculus modulus ??

GD
$\mathrm{E}(=I / K)$ modulus ratio

$\cdot I / G P$ buik press $M P$

\section{modulus}

GP shear.

ôulus $B(=1 / K)$

GP

I/GP

young's poissca moduius Iatio

GP

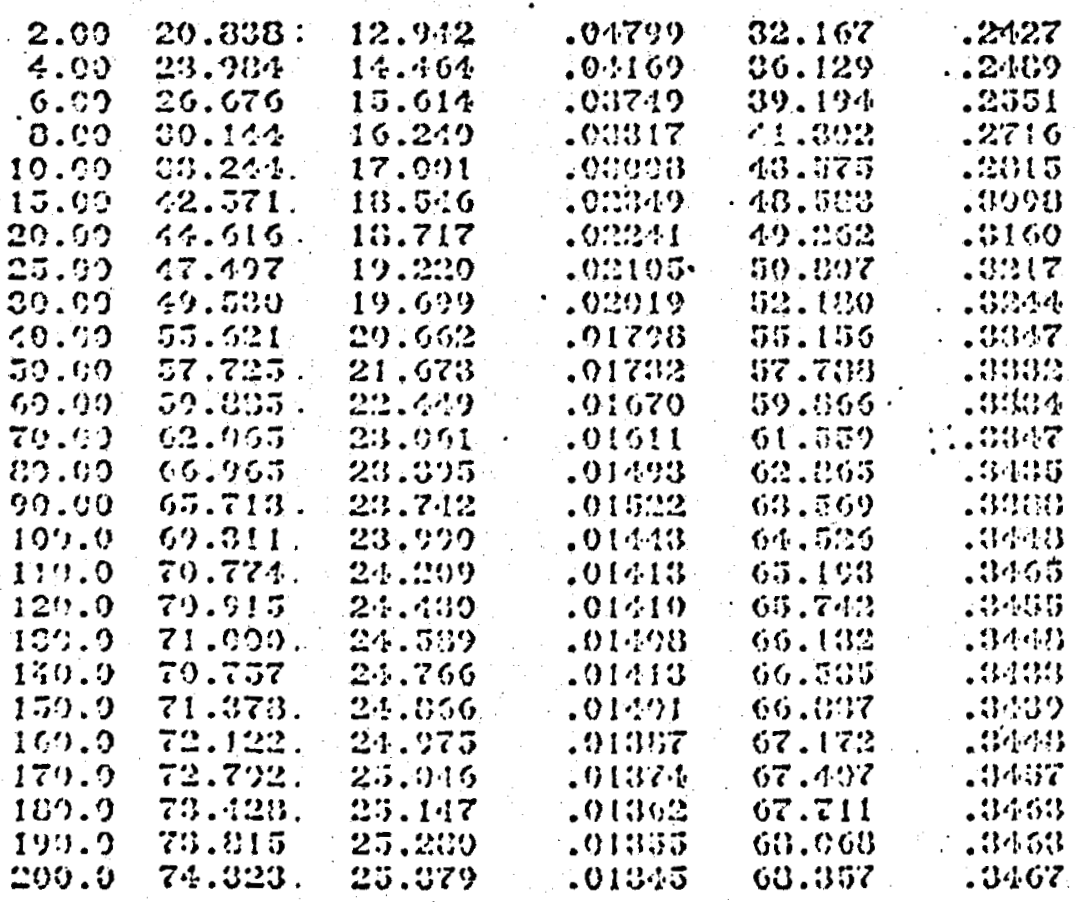

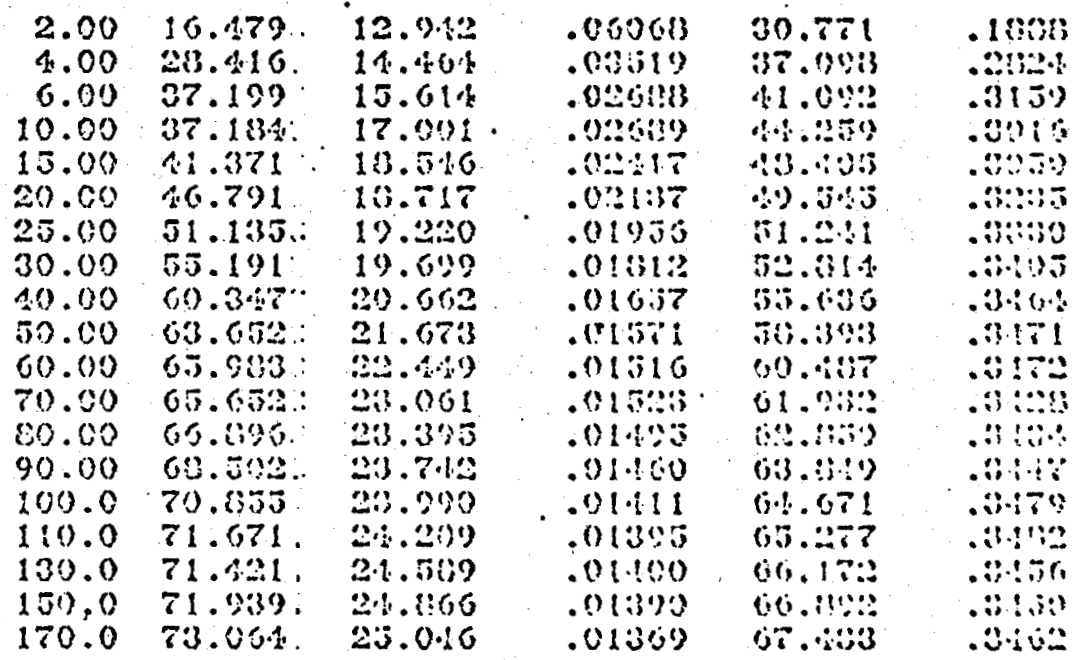




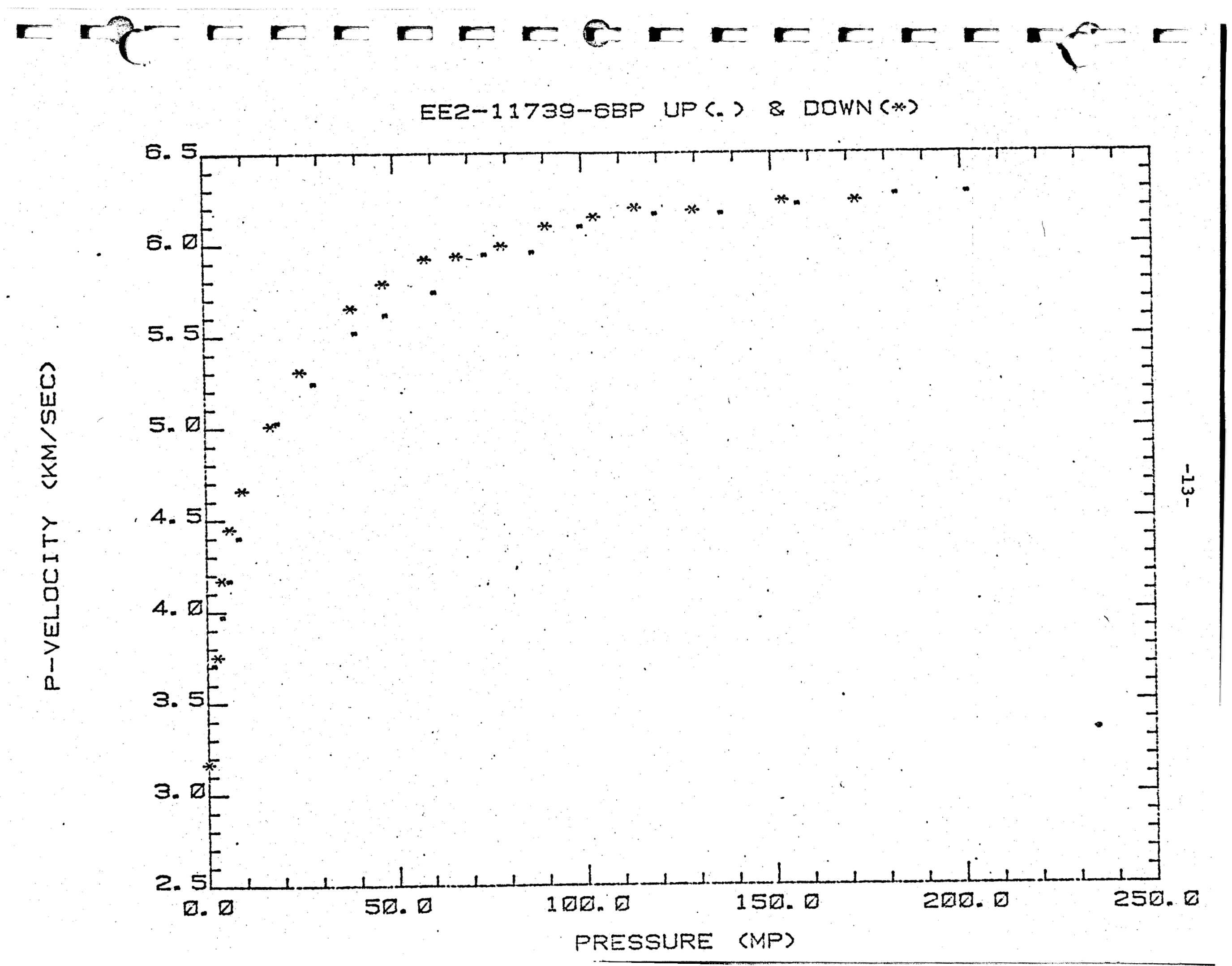


EEZ-11739-EBS UP(.) \& DOWN (*)

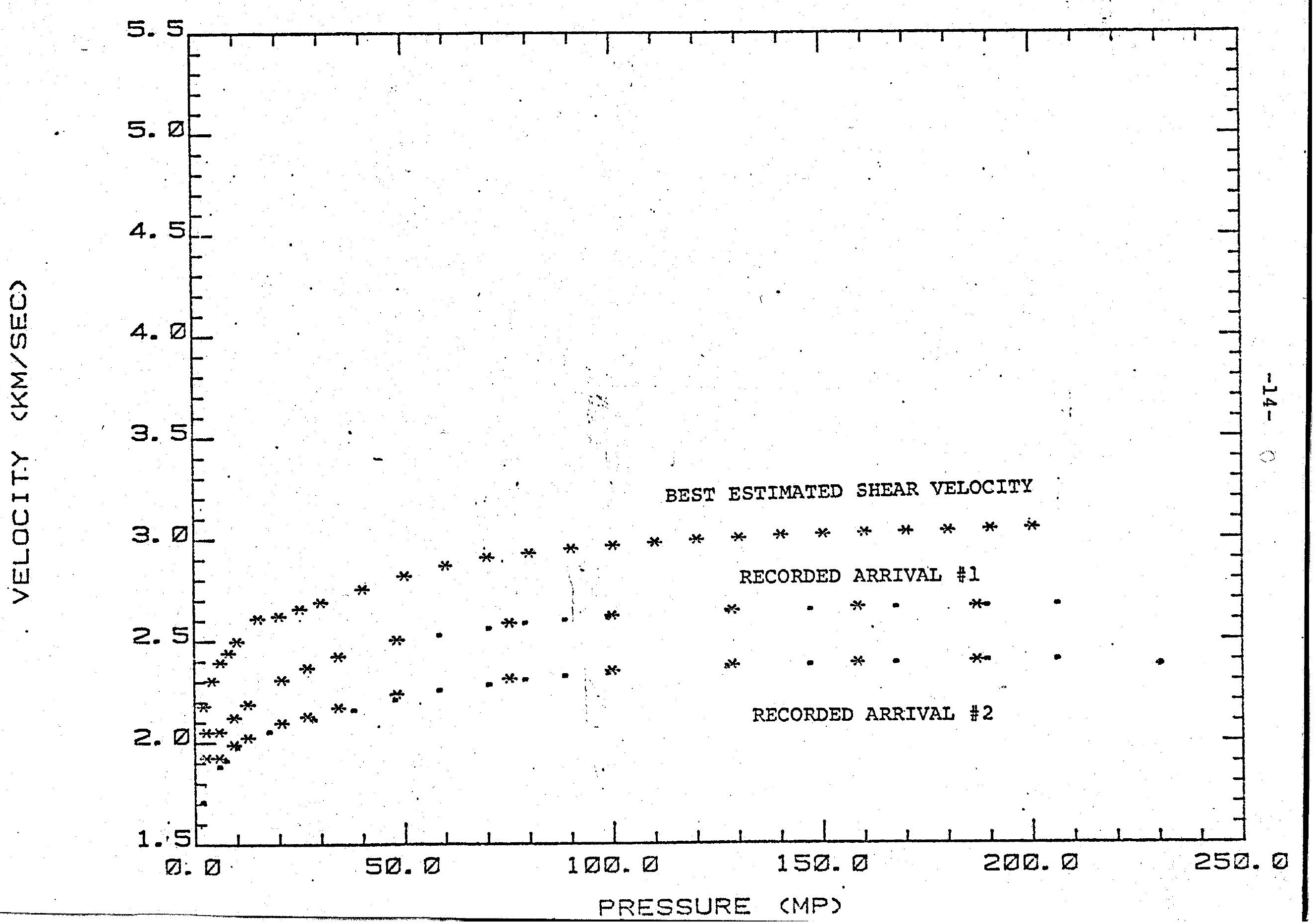


A measuxed compressional velocity with increasing pressure. B interpolated velocity with pressure

A

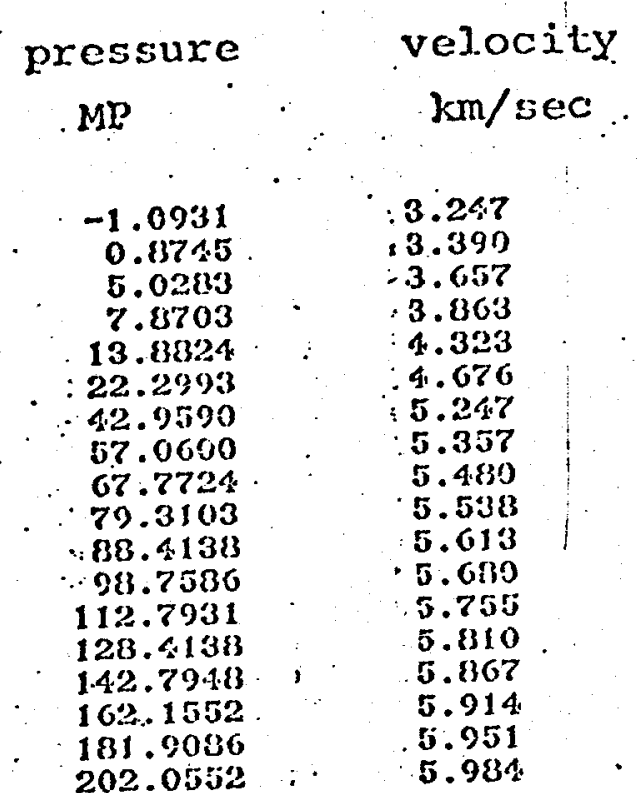

5. 984 pressure

MI'

2.0000
4.0000
6.0000
1.0000
10.000
15.000
20.000
25.000
30.000
35.000
10.000
45.060
50.000
50.000
60.000
65.000
70.000
80.000
90.000
100.00
110.00
120.00
130.00
140.00
150.00
160.00
170.00
180.00
200.00

2.0000

15.000

20.000

35.000

40.000

50.000

$\therefore \quad \therefore$

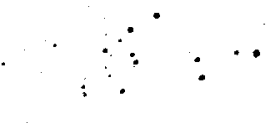

vel.ocity

$\mathrm{Inn} / \mathrm{sec}$

:3. 4670

3.6039

3.7249

3.11?2:

4.0190

4.4001

.4 .74 .48

$\because 4.7047$

.4 .2290

$: 5.0932$

5.2575

5.2712

$: 5.3305$

: 5.3398

5.3331

5.51610

$: 5.4 .979$

5.54 .32

5.6240

$.5 .6\{373$

.5 .7465

.5 .7311

.5 .8160

.5 .8536

.5 .6006

.5 .9235

.5 .9293

$.5 .9+137$

.5 .9819 


\section{VETOCTRIES MND RRESSURES}

A measured compressional velocity with decreasing pressuxe $\underline{B}$ interpolated velocity with pressure

I

pressure MP.

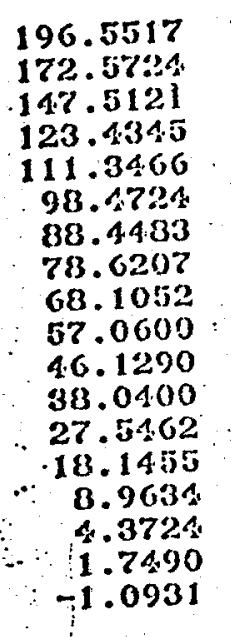

$$
\begin{gathered}
\text { velocity } \\
\mathrm{km} / \mathrm{sec}
\end{gathered}
$$

5.996

5.950

5.923

5.795

5.771

5.726

5.671

5.630

5.567

5.4 .90

5.411

.5 .322

5.078

4.625

3.939

3.798

3.412

3.213

\section{pressure \\ MP}

velocity
$\mathrm{lm} / \mathrm{sec}$

3. 4.303

3.65:0

3.9115

4.0310

.40560

4.3793

4.7329

5.0.23!

5.1571

5.3133

5.3468

.5 .4136

$5.4,409$

5.4757

5.5105

5.0453

5.5302

5.6151

5.61 .43

5.6733

5.7327

5.726 .4

5.7903

5.8133

5. 34.24

5.92613

5.94 .61

5.9654 
$\Lambda$ : measured shoar velocity with increasing pressure B . interpolated velocity with pressure

A.

$$
\begin{gathered}
\text { pressure } \\
\text { MP }
\end{gathered}
$$

\author{
velocity \\ $\mathrm{km} / \mathrm{sec}$
}

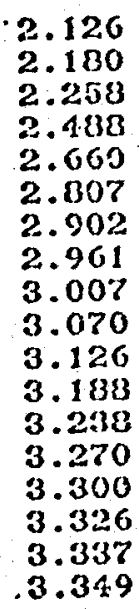

B
MP pressure velocity.

$\mathrm{Km} / \mathrm{sec}$

$\begin{array}{ll}1.7490 & 2.126 \\ 4.3724 & 2.180 \\ 6.7772 & 2.258 \\ 17.703 & 2.480 \\ 27.765 & 2.060 \\ 37.384 & 2.807 \\ 46.348 & 2.902 \\ 57.279 & 2.961 \\ 66.679 & 3.007 \\ 60.511 & 3.070 \\ 92.759 & 3.126 \\ 107.794 & 3.1838 \\ 122.097 & 3.230 \\ 136.8397 & 3.270 \\ 150.559 & 3.300 \\ 167.069 & 3.326 \\ 182.203 & 3.337 \\ 203.431 & .3 .349\end{array}$

2.0000

1.0000

6.0000

8.0000

10.000 .

15.000

20.000

25.000

30.000

35.000

40.000

$\because \quad \because \quad 45.000$

50.000

55.000

60.000

65.000

70.000

80.000

90.000

100.00

110.00

120.00

130.00

140.00

150.00

160.00

170.00

180.00

200.00

2.1297

2.1590

$2.2 ! 35$

2.21372

2.3350

2.454

2.5264

2.6167

2.6964

2.7272

2.8638

2.9141

2.9236

2.9331

2.974 .4

2.9990

3.0223

3.0085

3.1135

3.1587

3.1969

$3.235 ?$

3.2549

3.2769

3.2902

3.3202

3.32136

3.337?

3.3475 
Ex:2-1.2851-513

VELOCTTTES AND PRESSURES

A measured shear velocity with decreasing pressure B interpolated velocity with pressure

A

pressure

MP.

171.983

148.397

124.483

98.502.

04.483

67.772

51.376

38. 477

24.704 .

10.712

2.2955

$\because 1.0931$ velocity:

$\mathrm{km} / \mathrm{sec}$

3.320

3.305

3.253

3.173

3.121

3.051

2.958

2.1367

2.674

2.323

2.192

2.192
B

pressure

MP

2.0000

4.0000

6.0000

8.0000

10.006

15.000

20.000

25.000

30.000

35.000

40.000

.45 .000

50.000

55.000

60.000

65.000

20.000

75.000

80.000

90.000

100.00

110.00

120.00

130.00

140.00

150.00

160.00

170.00 velocity $\mathrm{km} / \mathrm{sec}$

2. 1850

2.2085

2.2270

2.2 .71

2.2604

2.4136

2.5192

2. 6795

2.7730

2.8604

2.8739

2.9181

2.9572

2.9794

3.0090

3.0336

3.0612

3.0341

3.1670

3.1424

3.1779

3.2118

3.2457

3.2651

3.2924

3.3050

3.3265

.3 .3451 
DYNAMIC MODUII Calculated at stanaard pressures

Eron velocity with increasing pressure buik buif $\because ?$ G? shear GP

young's poisson modulus ratio I/GP GP
B from velocity with decreasing pressure

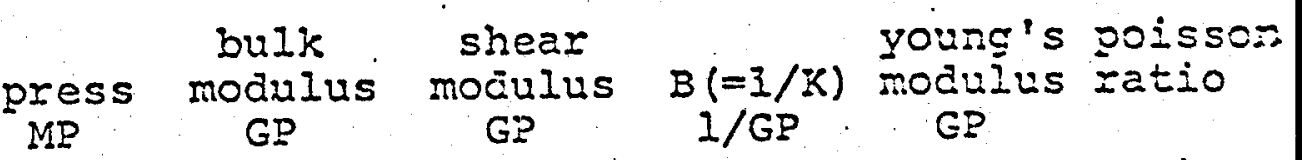

\section{$.05 \% 63$}

.052059

(c) 200

$.04+19$

.09113

obil (30)

$.025: 11$

.0925

- aring

.02200

.00117

- (a:26is

.0:av?

$.0 \times 13$

.0:80:06

.01977

.19.9

.01063

01879

$.01 i: 40$

.01011

\begin{tabular}{|c|c|}
\hline 0.425 & .1970 \\
\hline 11. 471 & avol \\
\hline 33.090 & 2232 \\
\hline 36.1232 & .2421 \\
\hline 48.042 & .2462 \\
\hline 1:3.014 & . $27+4$ \\
\hline 0.0 .34 & .3018 \\
\hline 19.272 & $\therefore: 1$ \\
\hline 13.416 & . \\
\hline ii: & . $2 ! !$ \\
\hline .60 & . $20 \%$ \\
\hline 60.91 & $.20 \% 0$ \\
\hline (51. & anto \\
\hline (6a. & 2845 \\
\hline 63.803 & - aness \\
\hline $6: 6$ & $\therefore A ? 14$ \\
\hline 65.609 & $\therefore 8 \div 45$ \\
\hline 67.482 & וסדים. \\
\hline 69.493 & 2600 \\
\hline 31.403 & .2780 \\
\hline 283.675 & 2853 \\
\hline 34.600 & 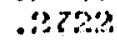 \\
\hline 73.67 & $\therefore 8$ \\
\hline 86.59 & $\therefore 81$ \\
\hline 77.035 & $\therefore 71$ \\
\hline 36.51 & $\therefore 610$ \\
\hline 73.6! & -26oses \\
\hline 79.36 & 23!" \\
\hline 79.030 & 2720 \\
\hline
\end{tabular}

$.91: 312$

\begin{tabular}{|c|c|}
\hline 4.00 & $\begin{array}{l}15.298 \\
19.14 .8\end{array}$ \\
\hline 3.00 & 24.020 \\
\hline-9.00 & 27.118 \\
\hline 10.00 & 25.906 \\
\hline $\begin{array}{l}15.00 \\
20.00\end{array}$ & 31.965 \\
\hline 25.00 & $43.095:$ \\
\hline 30.00 & 45.793 \\
\hline 35.00 & 4.037 \\
\hline 40.00 & 47.170 \\
\hline 43.00 & 50.395 \\
\hline 50.00 & 50.277 \\
\hline 55.00 & 30.449 \\
\hline 60.90 & 51.253 \\
\hline 60.00 & 51.603 \\
\hline 70.00 & 62.241 \\
\hline 75.00 & 620.310 \\
\hline 130.00 & 53.201 \\
\hline 90.07 & $0: 3.450$ \\
\hline 100.0 & 54.354 \\
\hline 110.0 & $54.25 \%$ \\
\hline 120.0 & 54.783 \\
\hline 150.0 & $5 \% 3 \% 9$ \\
\hline 110.0 & 56.153 \\
\hline 150.0 & $57: 564$ \\
\hline 100.0 & $37.7 \div 8$ \\
\hline 170.0 & 37.907 \\
\hline
\end{tabular}

. 1709

(4) 1793

. n!?

. Cis?3

.01712

$17.1 \% \div 7.215$

3: $: 3: 5$

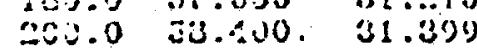

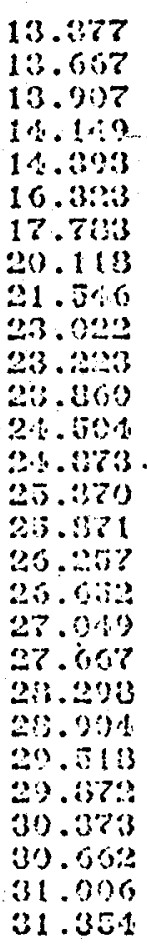

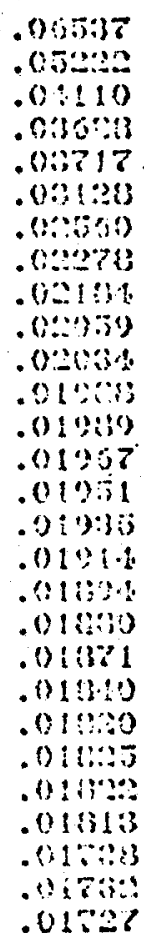

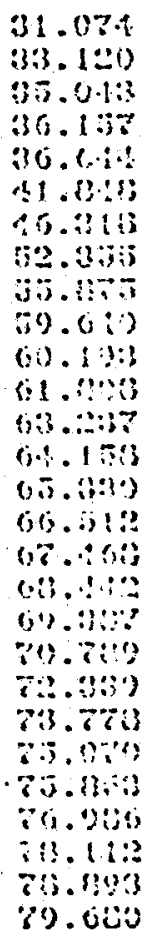

$161:$

$2 \div 17$

$\therefore 529$

ara

a?

-..en?

a1:3i;

$\because: 12$

ans

ariso

a․

$\therefore:-4$

- $29 \cdot 7$

$\because 30$

$\because . . . .1$

…:

$\because \cdots$

$\therefore$. $\because 4)_{3}$

aris

arito

$2 \div 1$

.?in

$\therefore$ 워

atis

at 


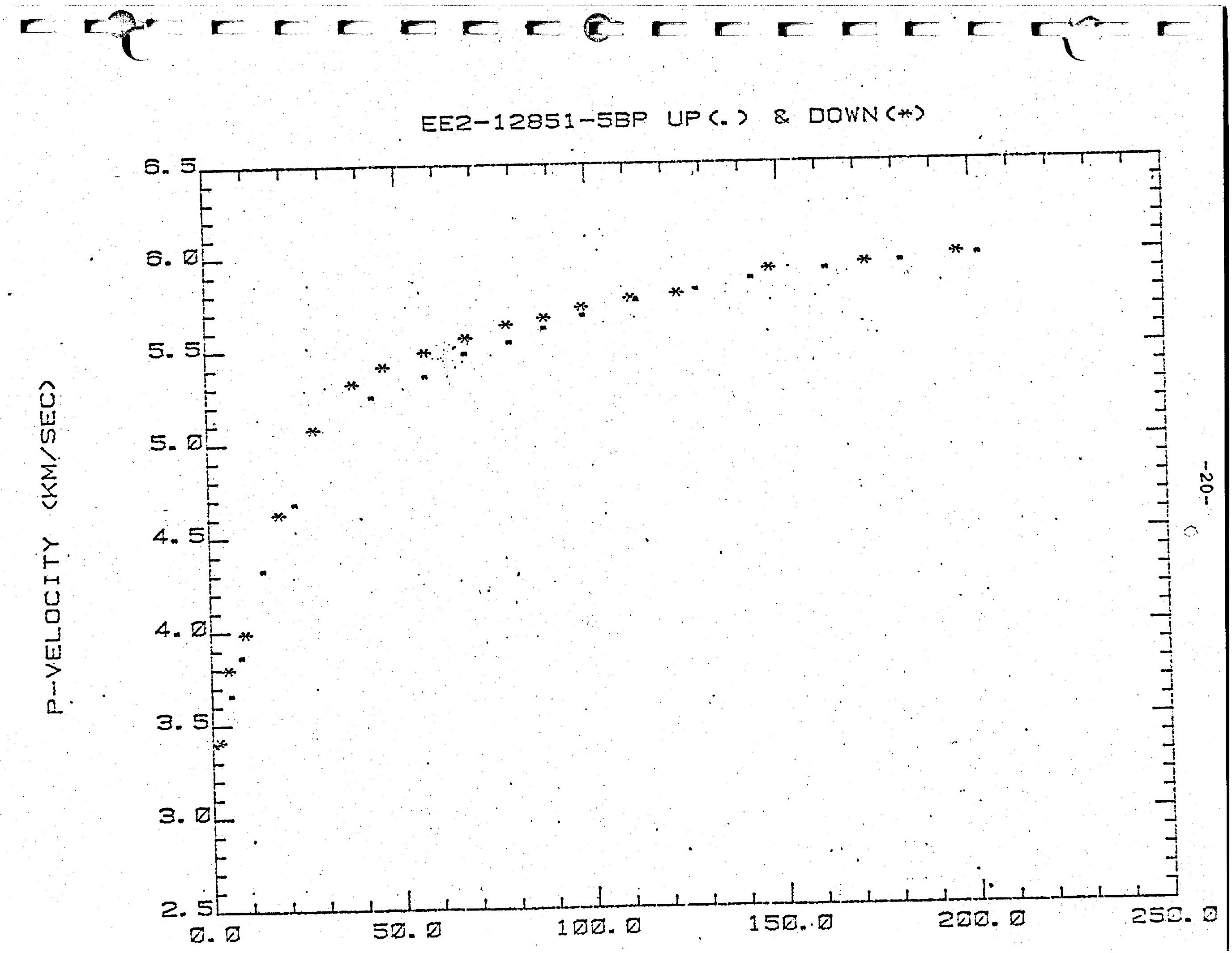




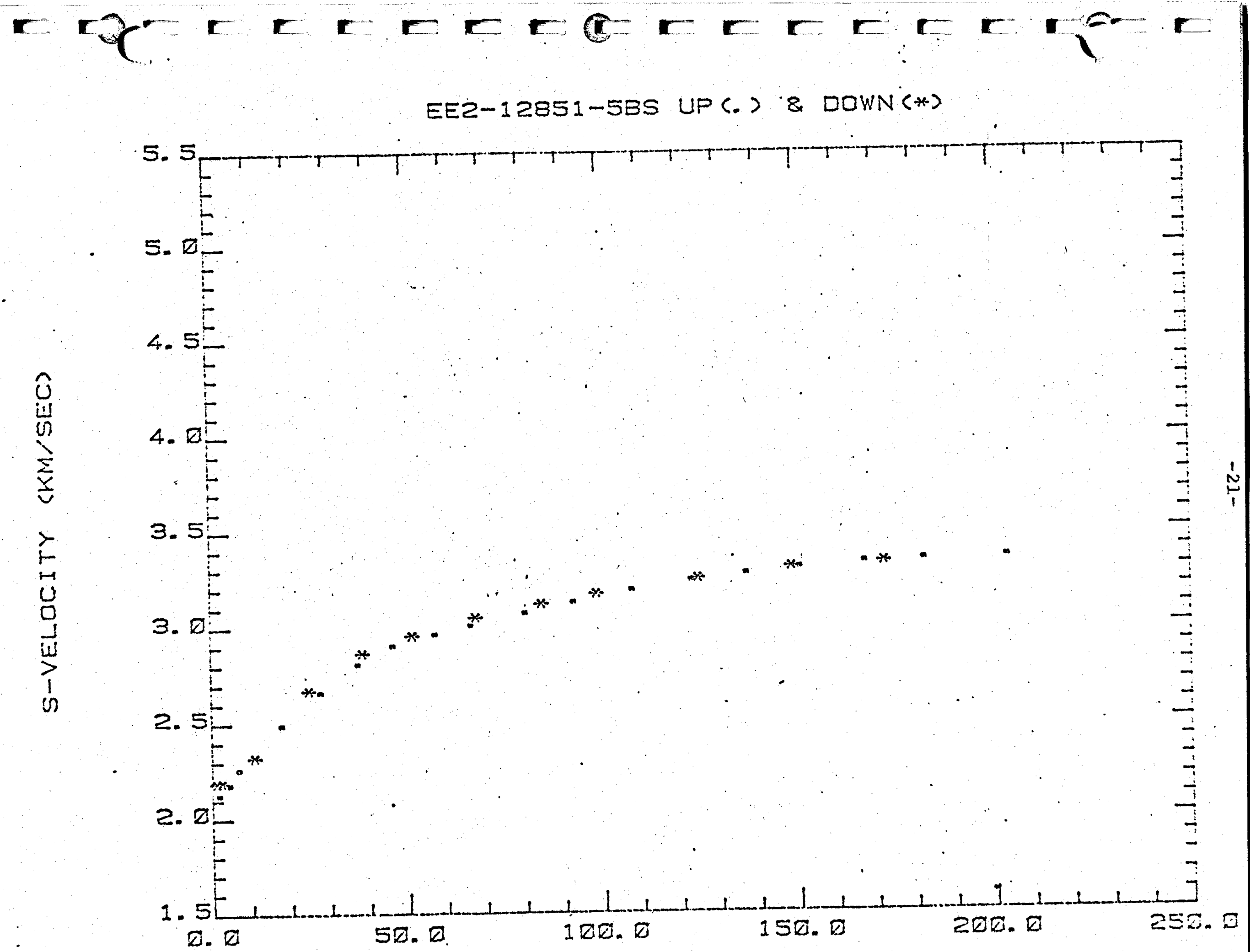


$\triangle$ measured compressional velocity with increasing pressure $\underline{B}$ interpolated velocity with pressure

A

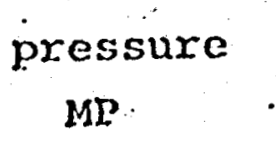

$-0.984$.

0.000

2.100

4.482.

6.559

8.963

18.255

27.54 .6

47.878

58.372

63.793

73.828

88.276

98.552

$108: 414$

129.965

137.506

154.784

171.283

191.638

201.465

velocity
$\mathrm{km} / \mathrm{sec}$


2.960
3.315
3.624
3.852
3.925
6.235
1.795
5.042
5.168
5.635
5.751
5.817
5.894
5.955
5.998
6.071
6.134
6.160
6.105
6.263
6.263
6

B

pressurt:

MP

2.0000
4.0090
6.0000
10.000
15.000
20.000
25.000
30.000
35.000
40.000
15.000
50.060
55.000
60.000
65.000
70.000
60.000
90.000
100.00
110.00
130.00
140.00
150.00
160.00
170.00
100.00
200.00

velocity

$\mathrm{ru} / \mathrm{sec}$ ,$\cdots$

3.6030

3.13134

3.9029

1.3560

4. 7060

$4.2 \cdot 53$

4.904

5.0435

5. 20.7

$5.313 i$

$5.4 \% 26$

$5.506 \%$

5.5973

6.6568

5.7238

5.7603

5.6?59

5.9061

5.9020

6.0043

6.0711

6.1378

6.1533

6.1677

6.1424

6.1969

6.:u6r 
[EE 2-1346]-2D

VELOCITIES AND PRESSURES

A measured compressional veloejty with decreasing pressure B interpolated velocity with pressure

A

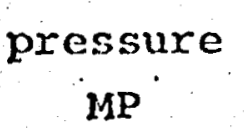

196.060

$17: 572$

152.524

131.034

109.65

98.621

84.690

75.586

58.590

48.921

39.133

$26.45 i 3$

12.461

2.733

2.069 velocity

$\mathrm{km} / \mathrm{sec}$
$\mathbf{B}$
$\because$ pressure
MP

130.00

140.00

150.00

160.00

170.00 velocity

$\mathrm{km} / \mathrm{sec}^{\circ}$

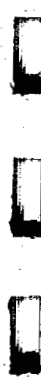

.6 .249

0.136

$\therefore 6.148$

0.059

$: 0.018$

$\therefore 5.945$

$: 5.874$

5.707

5.569

15.4.02

.5 .114

.4 .479

$\because 3.824$

$: 3.327$

.6 .1382

.6 .1801

.6 .2158

.6 .2037

.6 .2273 
I: measured shear velocity with increasing pxessure B : interpolated velocity with pressure

\section{$\pi$}

pressure MP

1.0931

2.1862

5.3562

7.4331

9.1021

18.471

27.983

37.821

17.222

57.716

.66 .023

79.310

89.517

94.759

113.310

137.193

157.241

181.516

.201 .859 velocity.

$\mathrm{km} / \mathrm{sec}$

2.136

2.31 .3

2.463

2.560

2.619

2.876

2.999

3.063

3.132

3.182

3.229

3.261

3.286

3.306

3.357

3.354

3.3835

3.390

3.403

B

pressure

MP

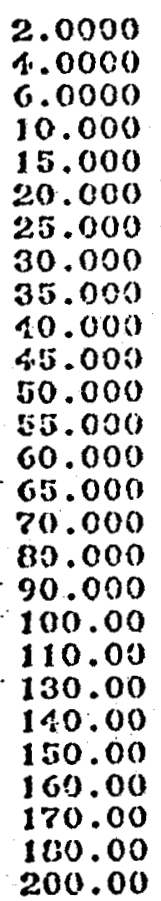

2.0000

1.0000

6.0000

10.000

.000

25.000

30.000

.000

45.000

50.000

.000

65.000

70.000

90.000

100.00

110.01

140.00

150.00

169.00

180.00

200.00 velocity.

$\mathrm{Km} / \mathrm{sec}$

2.3763

2.4209

2.4 .926

2.6413

2.79837

2.9073

3.0099

3.0128

3.0471

3.0785

3.1110

3. 1489

3.1794

3.1938

.3 .2196

3.2391

3.2627

3.28371

3.3087

3.3303

3.3716

3.3572

3.3636

$3.33 u ́ l$

3.3935

3. 4001

3.3999 


$$
\begin{gathered}
-25- \\
E E 2-1.3161-2 B
\end{gathered}
$$

\section{VETOCITTES AND PRESSUIES}

$\triangle$ measured shear velocity with decreasing pressure

B interpolated velocity with pressure

A

\section{pressure.}

MP

172.572

148.003

123.759 velocity

$\mathrm{km} / \mathrm{sec}$

3.371

3.362

3.34 .2

B

pressure

MP

130.00

140.00

150.00

160.00

170.00 velocity $\mathrm{km} / \mathrm{sec}$.

$3.3 \% 20$

$3.34 \geqslant 0$

3.3620

3.3620

3.3620 
DYNavic MODUII calculated at standara pressures

Eron velocity with increasing pressure

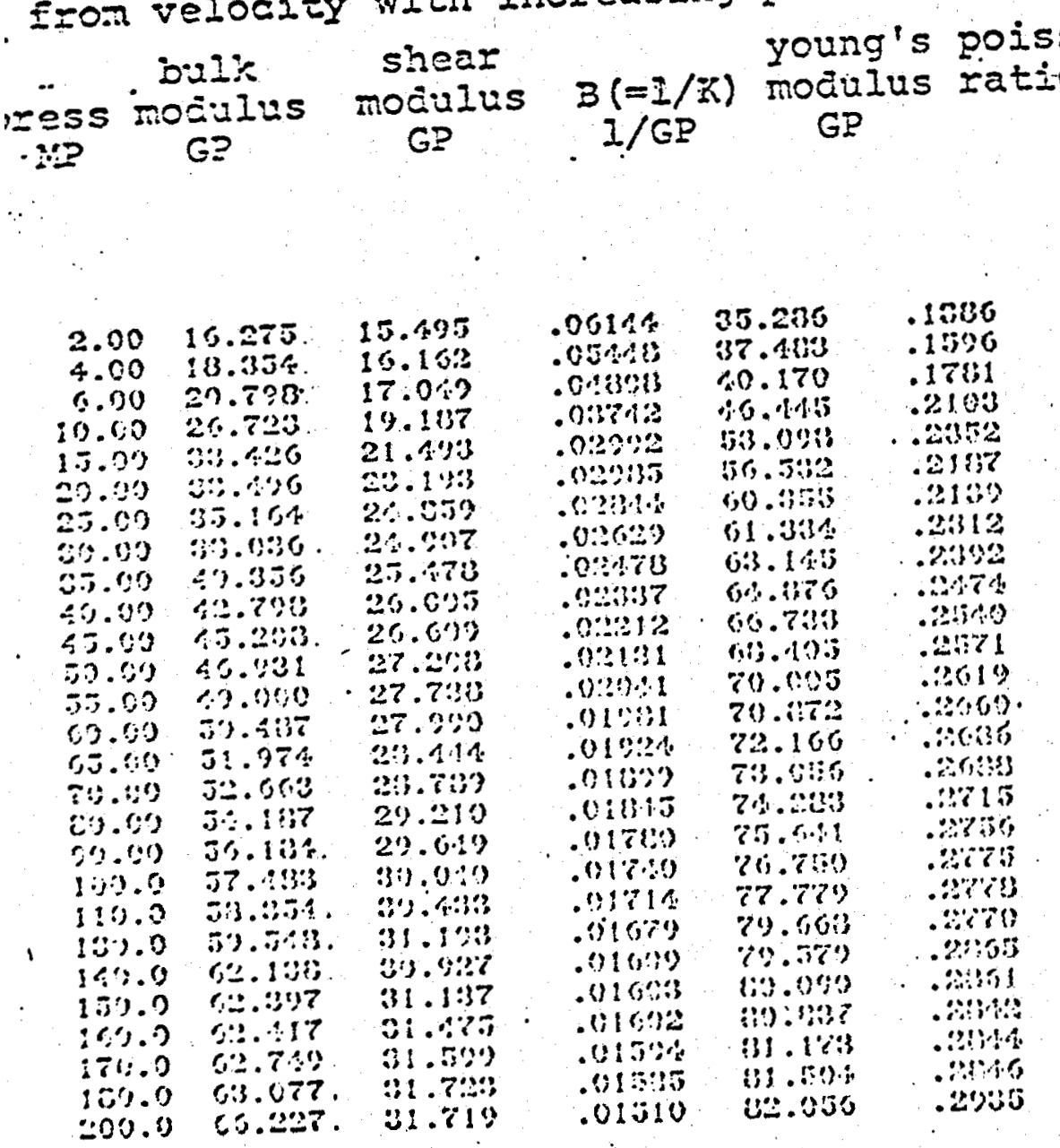

B from velocity with decreasing pressure

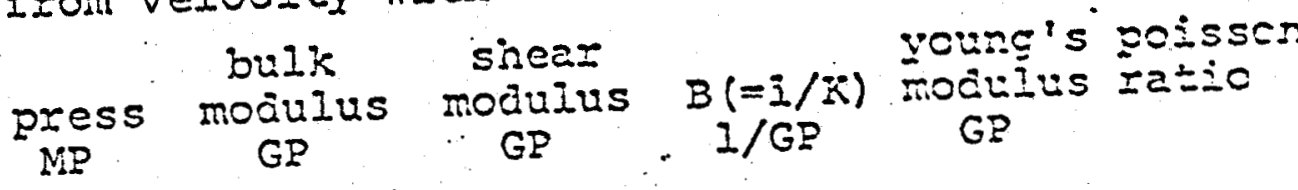

\begin{tabular}{|c|c|c|c|c|c|}
\hline $\begin{array}{l}130.0 \\
140.0 \\
150.0 \\
150.0 \\
170.0\end{array}$ & $\begin{array}{l}62.524 . \\
63.240 . \\
01.604 . \\
64.251 \\
65.036 .\end{array}$ & $\begin{array}{l}30.0413 \\
30.048 \\
31.015 \\
31.016 \\
31.016\end{array}$ & $\begin{array}{l}.0159 ? \\
.0150 \% \\
.015 \cdot 16 \\
.015 .56 \\
.01507\end{array}$ & $\begin{array}{l}72.030 \\
79.277 \\
30.22 ! \\
13 ! 1.159 \\
00.283\end{array}$ & 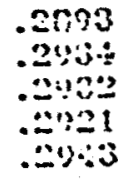 \\
\hline
\end{tabular}



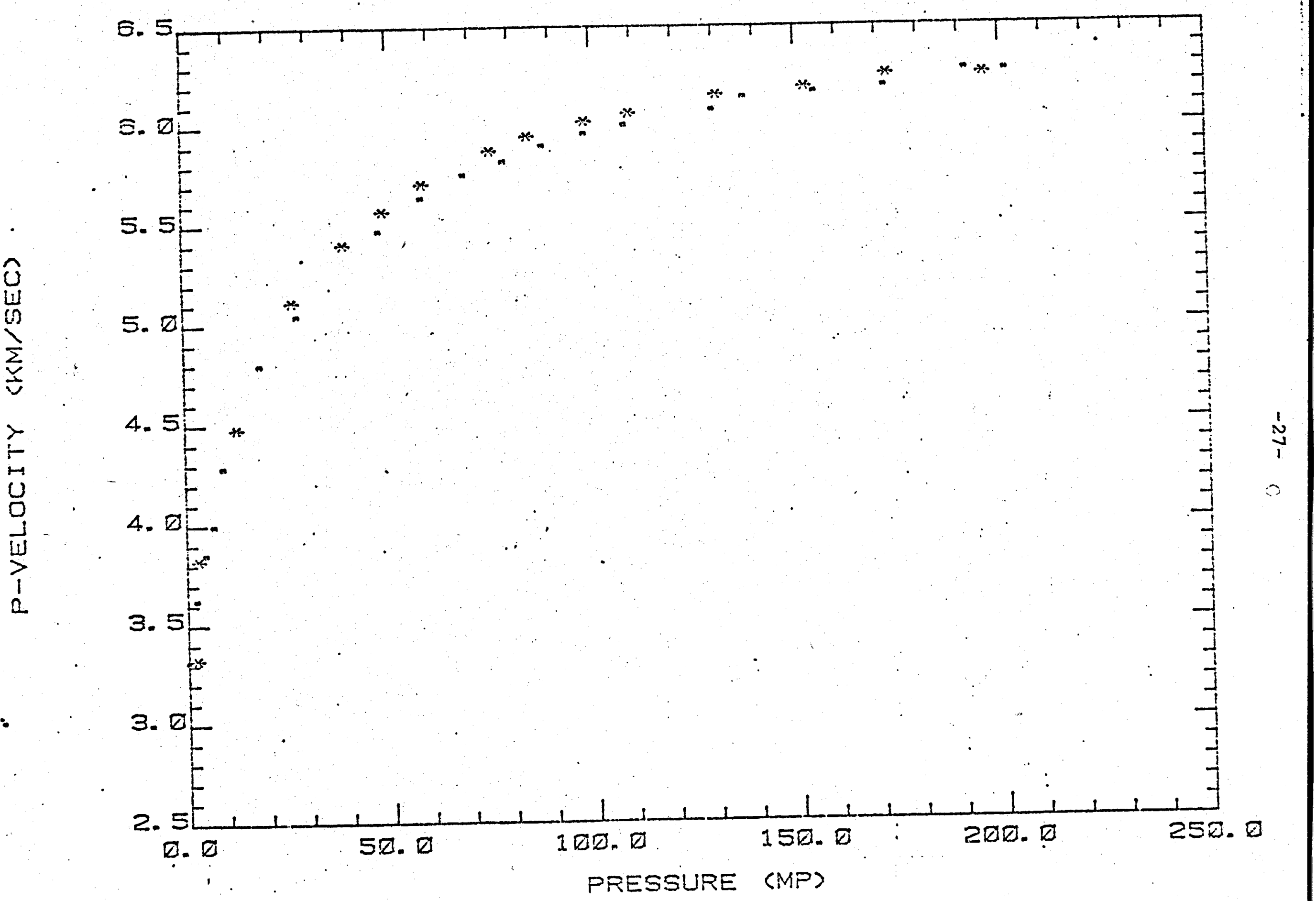


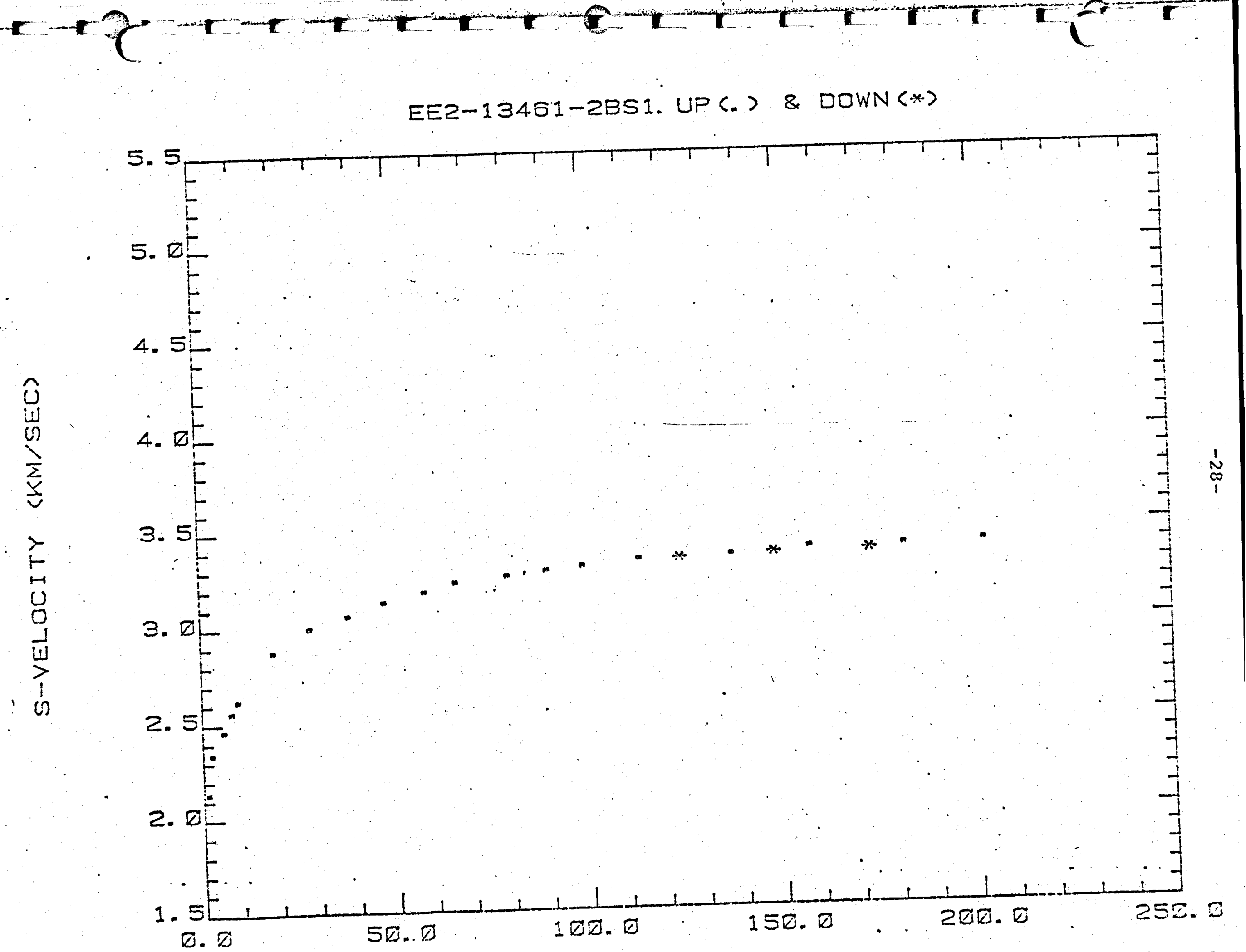


$212-13962 \div 1.3$

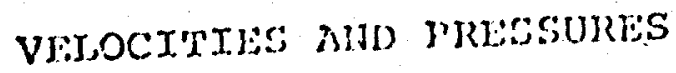

2. measured comprcssional velocity with jucreasing prossuxe $\underline{B}$ interpolated velocity with pressure

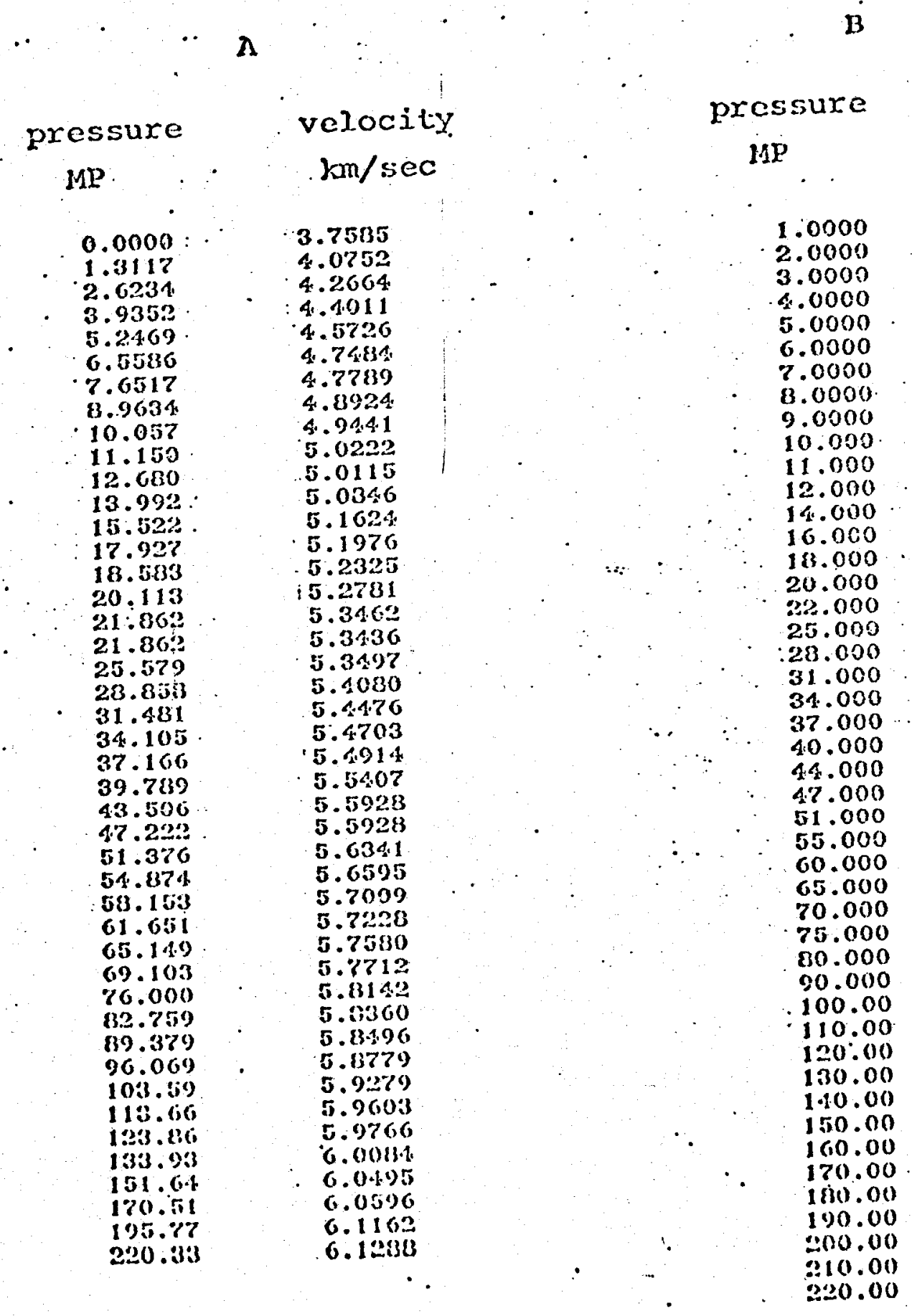

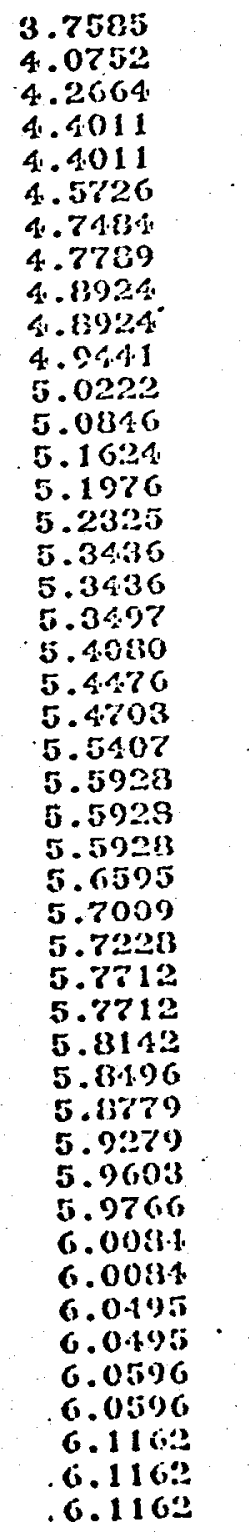


EE2-13962-2B

\section{VELOCITIES AND IRESSURES}

1. mcasured compressional velocity with decreasing prosisure B intcrpolated velocity with pressuie

A

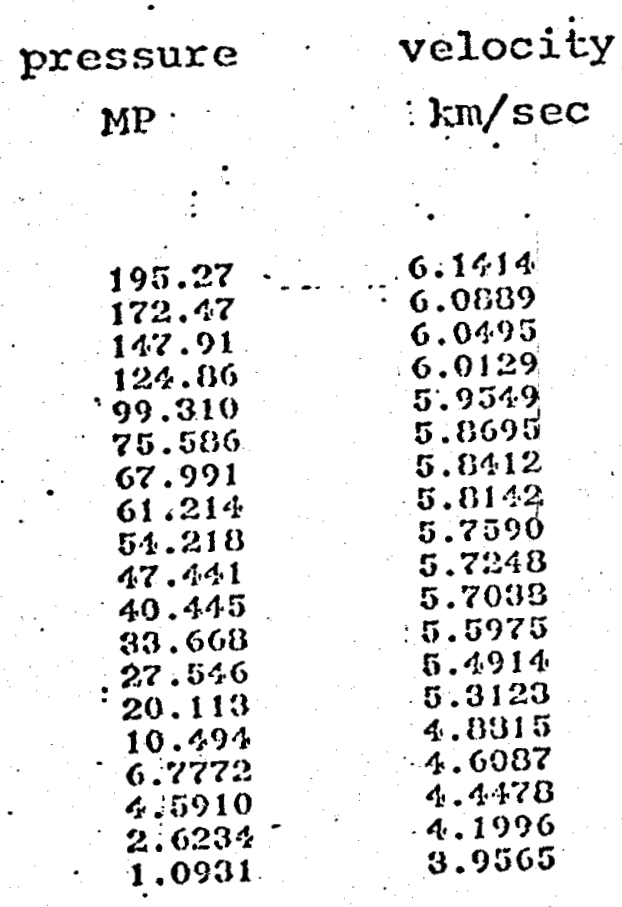

2.6234

6.0030

5.9549

5.7013
$\mathbf{B}$ pressure

MP. velocity $\mathrm{km} / \mathrm{sec}$

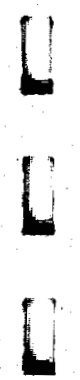

3

(

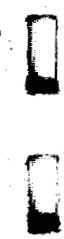

4.0000

6.0000

8.0000

10.000

15.009

20.000

25.000

30.000

35.00 i)

40.000

45.000

50.000

55.000

60.000

65.000

70.000

75.000

80.000

90.000

100.00

125.00

150.00

170.00

195.00

4.1156

4. 4.011

4. . 53320

4.6965

4. 84.5 .5

5.2 .111

5. 576 ?

5. 4.434

$5.535: 2$

5.6190

5.2036

5.7295

5.7363

5.7637

5.7934

5.8305

5.34.87

$5.86 \%$

5.0359

5.9209

5.9472

0.0131

6.05 .3

6.0048

0.1254 
I: measured shear velocity with increasing pressure B interpolated velocity with pressure

A

$\underset{M P}{\operatorname{pressure}} \quad$ velocity

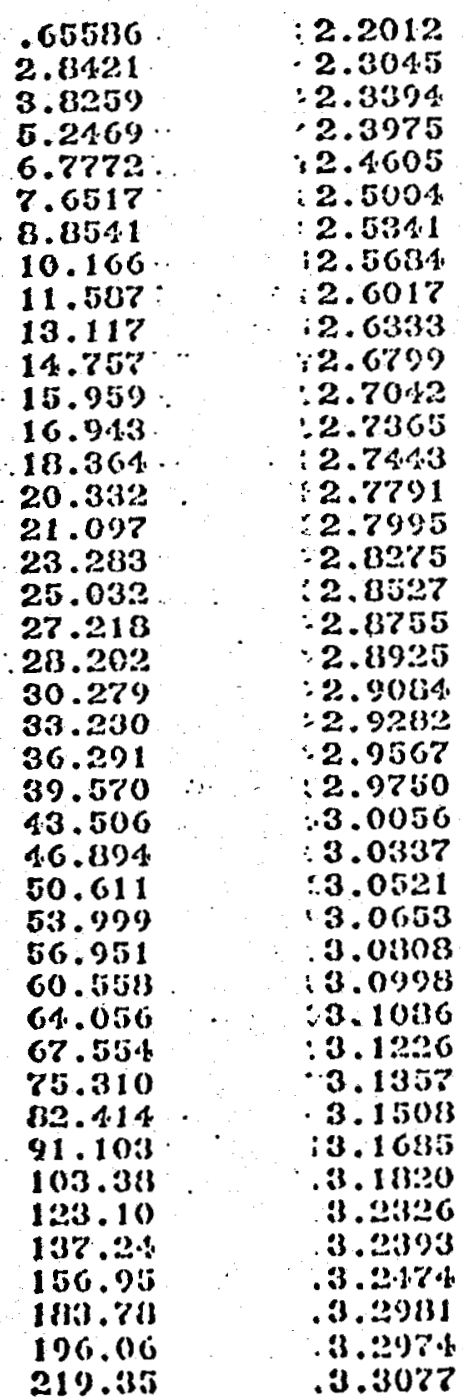

B pressure MP velocity. : $\mathrm{Km} / \mathrm{sec}$

$: 2.2195$ 2.2726 .2 .3107 2.3465 $\div 2.3373$ 2.4233 2.4 .693 2.5120 2.5330 2.564 .3 $: 2.51393$ 2.6111 $: 2.6534$ 2.7052 $2.75 \%$ $\therefore 2.7683$ 2.13130 $: 2.8516$ 2.8355 $: 2.9134$ $: 2.93313$ $: 2.9619$ :.9782 $\mathbf{3 . 0 0 9 5}$ $\because 3.0345$ 3.0537

.3 .0705 3.0968 3.1117 3.1210 3.1391 3.1456 3. 1667 .1.11861 3.10:23 .3 .2070 3.2:165 3.2405 . 0.24 .49 . 3.:2.1138 . 3 . 25133-1. .3 .2570 3. 1100) a. $\because 913$ a) alll::1 .3.30isl 
EE2-13962-13

\section{VELOCTRIES AND PRESSURES}

$\AA$ measured shear velocity with decreasing pressure

$B$ interpolated velocity with pressure

$\lambda$

pressure

MP .

196.135

163.25

148.59

100.69

86.586

$75.80 \%$

64.602

46.1 .29

32.3834

29.404

23.2633

16,39?

9. 6379

5.9028

2. $8.2: 1$

.98379 velocity.

$\mathrm{km} / \mathrm{sec}$

3.2004

3.2695

3.2707

3.2145

3.1830

3. 16838

3.1393

.3 .0149

3.0253

2.9511

2.9033

2.7959

2.0306

2.4027

2.3233

2.1995

B

pressure

$M P$

2.0000

2.0000

0.0000

8.0000

$10: 000$

15.000

$20.00 !$

25.000

30.000

35.000

40.000

45.000

50.000

55.000

60.000

65.000

70.000

75.000

80.050

90.000

100.00

125.00

150.00

170.00

195.00 velocity

$\mathrm{km} / \mathrm{sec}$

2.27 .16

2.3914

2.4872

2.5793

2.6135

2.79\%

2.362

2.9192

2. 90.1

$3.0011)$

3.0477

3.0907

3.0960

3.1150

$3.15 n 0$

$3,140.4$

$3.15 \% 9$

3. 167.1

3.1762

3. 1892

3. .2075

a.2.:?

3.2720

3.2909

3.3103 


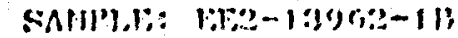

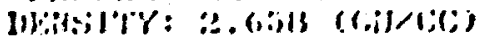

DYNFRJC MODULI calculated at standard pressures

I from velocity with increasing pressure

bulk shear

- press modulus molulus $B(=1 / K)$ moculus ratio

$\because \mathrm{NP} G P \mathrm{GP} \quad \mathrm{G} / \mathrm{GP} \mathrm{GP}$.

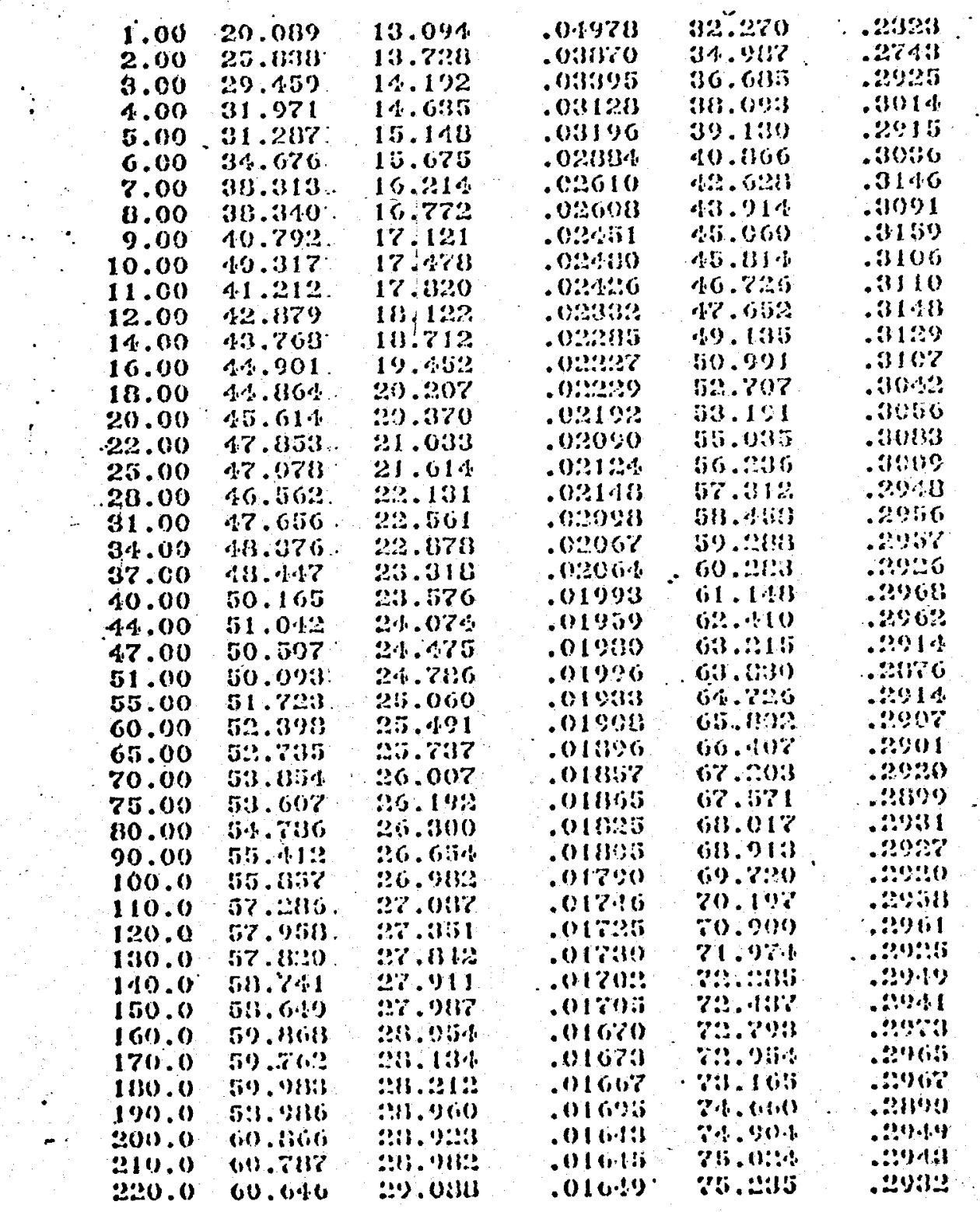




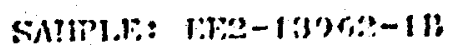

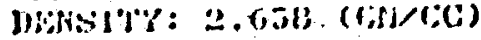

DYNAMIC MODULI calculated at standaxd pressures

B from velocity with decreasing pressure

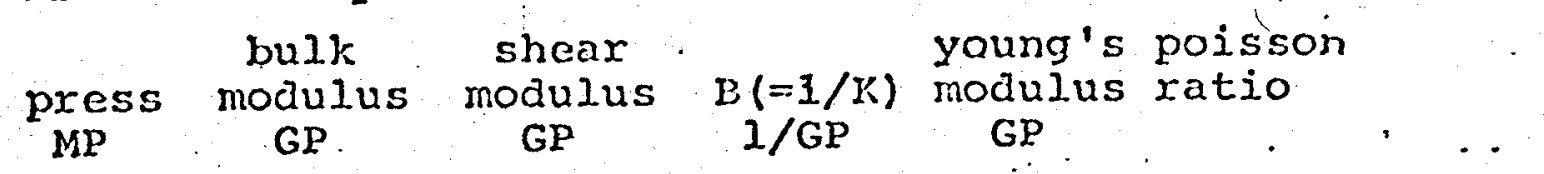

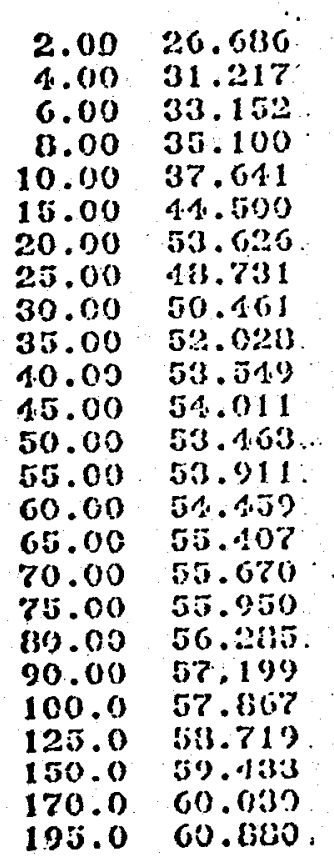

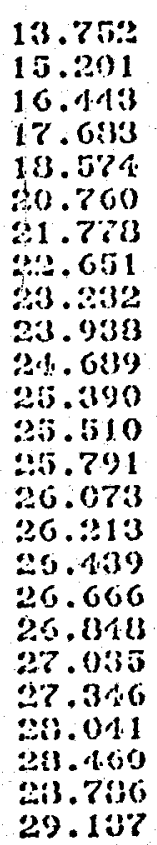

.037478

$.0: 33: 33$

.03016

.021199

$.0 \% 657$

.02847

.01665

$.020 ! 3: 3$

.019132

.019 .92

.011167

.011131

.018170

.011355

.01836

.01805

.01726

.017378

01678.

.017 a

.017213

.01203

orgua

.01606

.01643

$$
\begin{aligned}
& .2001 \\
& .29015 \\
& \text {.317\%: } \\
& \text { - 2aktas } \\
& \text { asues } \\
& \text { - ziser } \\
& \text {. 3:1.8. } \\
& \text {-2s\{lis } \\
& .3004 \\
& \text {.3005 } \\
& \text {.309? } \\
& \text { - 205a } \\
& \text {.2018 } \\
& \text {. anat? } \\
& \text {.2016 } \\
& \text { astir } \\
& \therefore \because 900 \\
& .2914 \\
& \text {.89.13 } \\
& \text {.213 5iu } \\
& \text {.:3) } \\
& .2010 \\
& \text {.80:15 } \\
& \text {.:?03:3 } \\
& .2936
\end{aligned}
$$





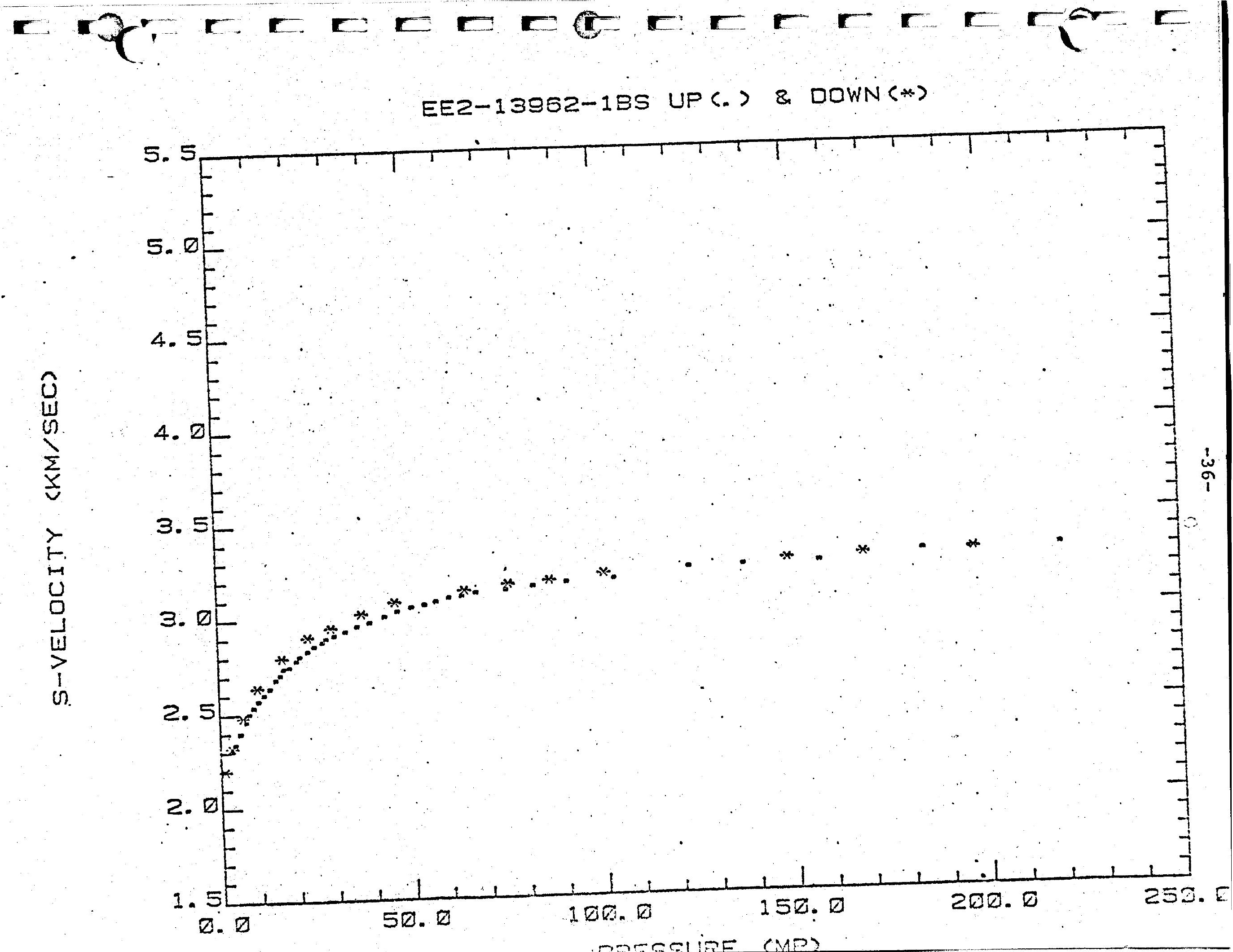


A measured compressional velocity with incrcasing pressure B. interpolated velocity with pressure

A pressure
MP

\author{
velocity. \\ $\mathrm{km} / \mathrm{sec}$.
}

2.6850

2.9726

3.31318

3.6708

4.1197

4.24283

4.3096

4.3060

1. 5494

4.6731

4.7776

4.9036

5.0557

5.1817

5.2445

5.3090

.5 .3953

:5.4380

5.53:24

5.6389

5.7151

5.7170

$5.76 \%$

5.784 .8

5.8171

5. B14.

5.0937

5.9255

5.9608

5.9091

0.0163

6.04 .65

G.0063

0.1167

0.1598

0.1573

6.2095
$\mathbf{B}$

pressure

MP

1.0000

.2 .0000

3.0000

4.0000

5.0000

6.0000

7.0020

8. $0000^{\circ}$

9.0000

10.000

11.000

12.000

$1 \% .000$

16.000

13.000

20.000

22.000

23.000

23.000

31.000

34.000

37.000

40.000

44.000

4.000

51.000

55.000

60.000

65.000

70.000

$.75,000$

80.000

90.000

100.00

110.00

120.00

130.00

140.60

150.00

160.00

iro.n!)

180.00

100.00

200.00

.210 .00 velocity

$\mathrm{Km} / \mathrm{sec}$
2.9279

3.1760

3.4231

3. 6.269

3.9097

1.2342

4.2771

4.3251

4.4217

4.5197

4. 6273

4.74837

$4 . .3607$

5.0530

5.1995

5.2910

5.39083

5.4553

5.5920

5.6402

5. 0993

5.7565

5.7398

5.7873

5.83055

5.8145?

5.17752

5.9210

5.9561

5.93 .10

$5.95 \%$

5.90310

6.0051

6.0 .250

6. (3.473)

6.0700

.0 .1071

0.1265

o.12á

$0.13 \%)$

0.1507

G.12uis

G.11130

0.1613

$0.1 \% 01$ 


\section{VELOCJTYES MIJD PRESSURIS}

I measured compressional velocity with decreasing prossure B interpolated velocity with pressure

A

pressure

ISP .. velocity

$\mathrm{km} / \mathrm{sec}$

.6 .1440

. $6.13: 34$

.0 .0973

$\because 6.0646$

i5.9094

$: 5.9789$

$-5.9613$

$\therefore 5.2200$

¿5.rial1

$: 5.7943$

$\because 0.0323$

$\therefore 5.3961$

4. 9727

$: 4.2470$

3.2415

3.6114

$\therefore 3.0840$
$\mathfrak{B}$

pressure

IPP

2.0000

4.0000

7.0000

10.000

15.000

20.000

25.000

30.060

35.000

.40 .000

4.5 .0110

50.000

55.000

60.000

70.000

09.000

90.000

100.00

125.00

150.00

175.00 velocity

$\mathrm{km} / \mathrm{sec}$

$: 3.2845$

3.7530

4.21359

4.8094

:5.1001

5.4005

5.602s

$\therefore 5.7127$

$\because 5.0258$

$\therefore$. 8632

.5 .9110

$-5.9353$

5.9637

$\therefore 5.9 \% 59$

6.0003

6.0230

$\therefore 6.0516$

.6 .0771

.6 .0990

.0 .1229

$.6 .14 a 8$ 


\section{VELOCTIIES AID PIRSSURES}

A: measurcd shcar vclocjty with increasing pressure B interpolated velocity with pressure

\section{A}

pressure

MP

0.0000

1.5172

2.2955

1.04.45

5.5748

6.6629

7.7610

9.072 .3

10.603

12.243

13.336

14.538

1

1

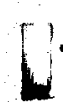

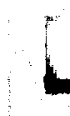

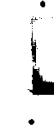

15.959

17.300

$10: 129$

20.222

21.425

23.174

24.595

25.907

27.000

28.311

29.623

31 . 044

32.574

34.433

35.74 .4

36.8313

38.368

39.789

41.64 .7

12.710

A1.27 1

45.2301

47.4 .1

48.643

4.0. $95: 3$

51.011:

5i3. 2315

5!..8(1):

(ic. 051

59.137

$\left(1.97^{9}\right)$

65. 0.14)

(ill. 100

75.5131

(II. 6 (6)

(II) .978

$97 .(1): 1$

117.45

1:1+. (1:3

$1+17.1: 2$

(7). (7)

196. .j:5

$$
\text { velocity }
$$

$\mathrm{km} / \mathrm{sec}$

1.0302

1.7733

1.9157

2.0441

2.1276

2.184 .8

2.2393

2.3073

2.3034

2.4321

2. 4755

2.5150

2.5540

2.5996

2.6340

2. 6639

2.6975

2.7292

2.7574

2.7825

2.7939

2.8236

2.81.61

2.11673

2.8328

2.9096

:2.9251

2. 94.8

2.9591

.2 .98116

.2 .9067

3.0053

-3.0209

3.0.3iso

3.0273

0.04.65

3.00 .17

3.0708

3.0734

3.01451

3.0910

$: 3.094: 3$

3. $10: 30$

$: 3.1000$

:3.1135

$3.119 \%$

:3.10685

3.1364

$\therefore 1.1+100$

a. 1 ! i. 1

a. Iitill

3. 1135

3. 101):
B

pressure

IIP

velocity

$\mathrm{km} / \mathrm{sec}$

1.0000

2.0000

3.0000

4.0000

5.0000

6.0000

7.0000

u. 0000

9.0000

.10 .000

11.000

12.000

14.000

16.000

in. 000

20.000

22.090

$\therefore \quad 25.000$

20.000

31.000

34.000

37.000

40.000

44.000

4.000

51.000

55.000

60.000

65.000

70.000

75.000

80.000

90.000

100.00

110.00

120.00

$130 .(10)$

140.00

150.00

160.00

170.00

1110.010

$190 . n 0$

:00.00

210.00
1. 6322

1.8613

.1 .9773

2.0660

2.0965

2.1500

2.2017

2.2513

2.3015

2.35113

2.3797

2. 4.207

.2 .4991

2.5552

2.6165

2.6574

$2.711 \%$

2.7054

2.8160

2.8691

2.9012

2.9471

2.9863

3.0204

: 3.0347

3.0708

3.0363

3.0963

3.1082

3.1105

3.1244

3.1354

:3.1372

3.1.176

3.15623

3. 16.48

3.1743

3. 161:-

3. 11175

3. 1931)

3. :00:3

3.2(1) 1.5

a. 2111

3. $2: 136$

3. 2051 


\section{VELOCI'TES MND PRYSSURES}

A measured shear velocity with decreasing pressure $B$ interpolated velocity with pressure

\section{$\lambda$}

\section{pressure}

MP

186.23

14.8 .10

101.00

74.130

A7.4A1

27.000

0.9959

2.6234

.07448 velocity

$\mathrm{km} / \mathrm{sec}$

3.2177

3.2263

3.1910

3.17083

3.1377

2.9251

2.3992

2.1385

1.9797

B

pressure

$M P$ velocity

$\mathrm{km} / \mathrm{sec}$

2.0995

2.24:26

2.3294

2.5120

2.6907

2.03374

3.0731

2.9606

3.0357

3. 1048

3.1240

3.1416

3.1491

3.1567

3.1713

3.175

3. 16.27

3. 1303

3.2090

3.2277

3.24 .64 


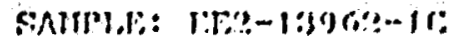

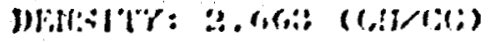

DYNAMIC MODULI calculated at standard pressures

$\therefore$

A from velocity with increasing pressure

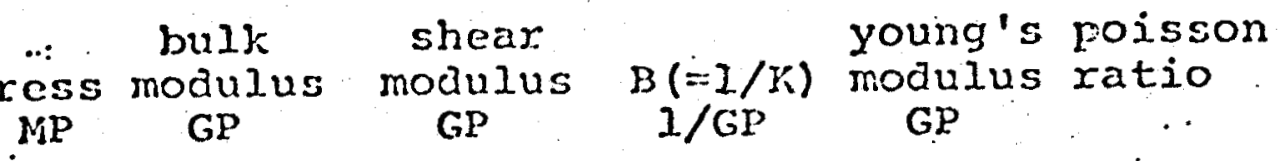

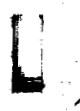

\begin{tabular}{|c|c|c|c|}
\hline & 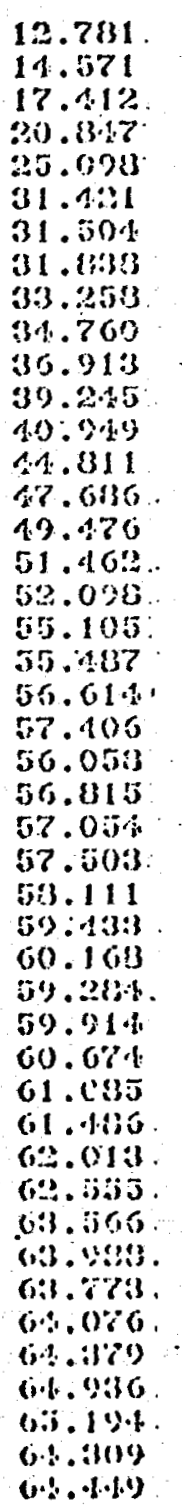 & 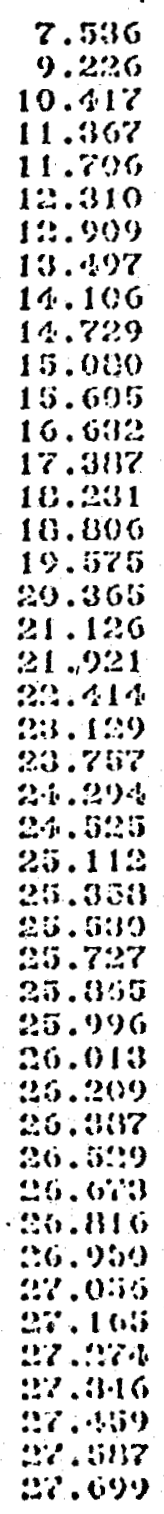 & 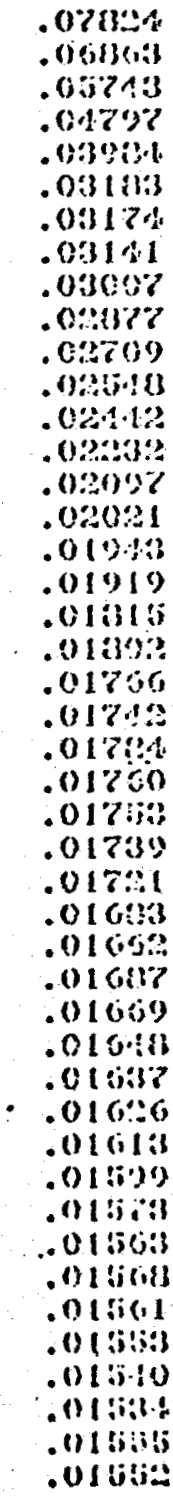 \\
\hline
\end{tabular}

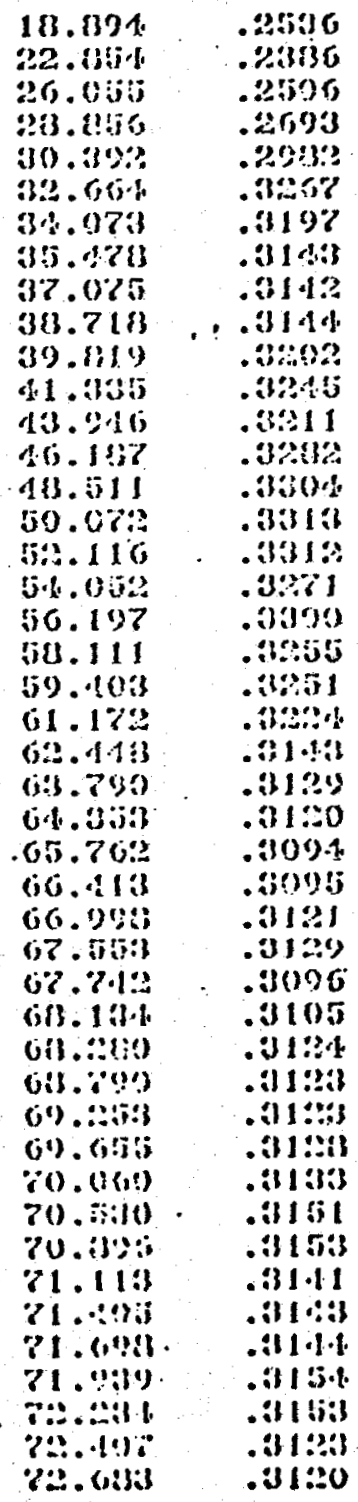

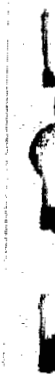
litio: anch 


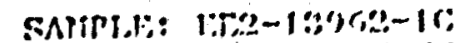

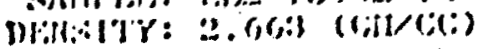

DYNAMIC MODULI calculated at standard pressures

B from velocity with decreasing pressure

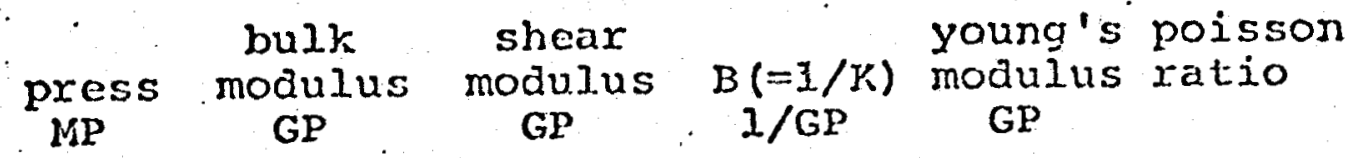

\begin{tabular}{|c|c|}
\hline $\begin{array}{l}2.00 \\
1.00 \\
7.00 \\
10.00 \\
15.00 \\
20.00 \\
25.00 \\
00.00 \\
35.00 \\
10.00 \\
15.00 \\
50.09 \\
50.00 \\
60.00 \\
70.00 \\
30.00 \\
90.00 \\
100.0 \\
1.05 .0 \\
150.0 \\
175.0\end{array}$ & 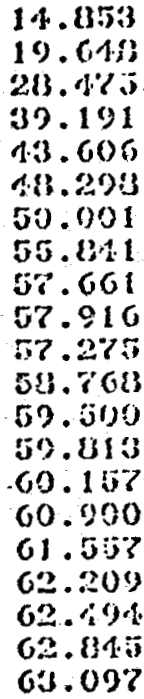 \\
\hline
\end{tabular}

11 . 73 in

13.305

15.311

16.0 .09

19. 109

2a. . 202

$23.18 \%$

30.206

24.611

23.671

$26.83: 33$

25.2113

20.109

26.536

20.791

20.1383

2.0 .975

$27.10 \%$

26.423

37.749

28.060

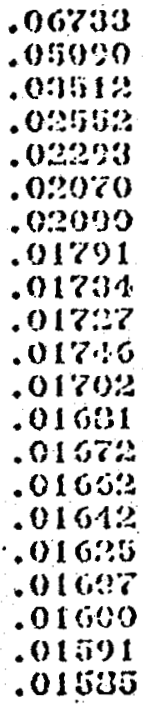

$97.072 \quad .1073$

$3: 3.2135$

34.9y:5 . .2013

44. 1 (143 .113:.4

50.701 .8002

$177.755 \quad .3007$

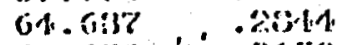

61. (53) . . 3159

$64.965 \quad .3136$

is.09\% .3356\%

69.61. .2074

6:3.619 .9051

(9).015 . .196?

(0).315\% .9057

(0).9i13 .3351

$70.2 .250 \quad .3458$

70.611 .8504s

(1.0.011 .035011

$71.770 \quad .09196$

$72.5 i 5 i l \quad .1060$

$t_{1}$

73.325

.3003

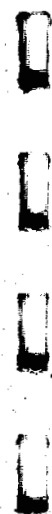




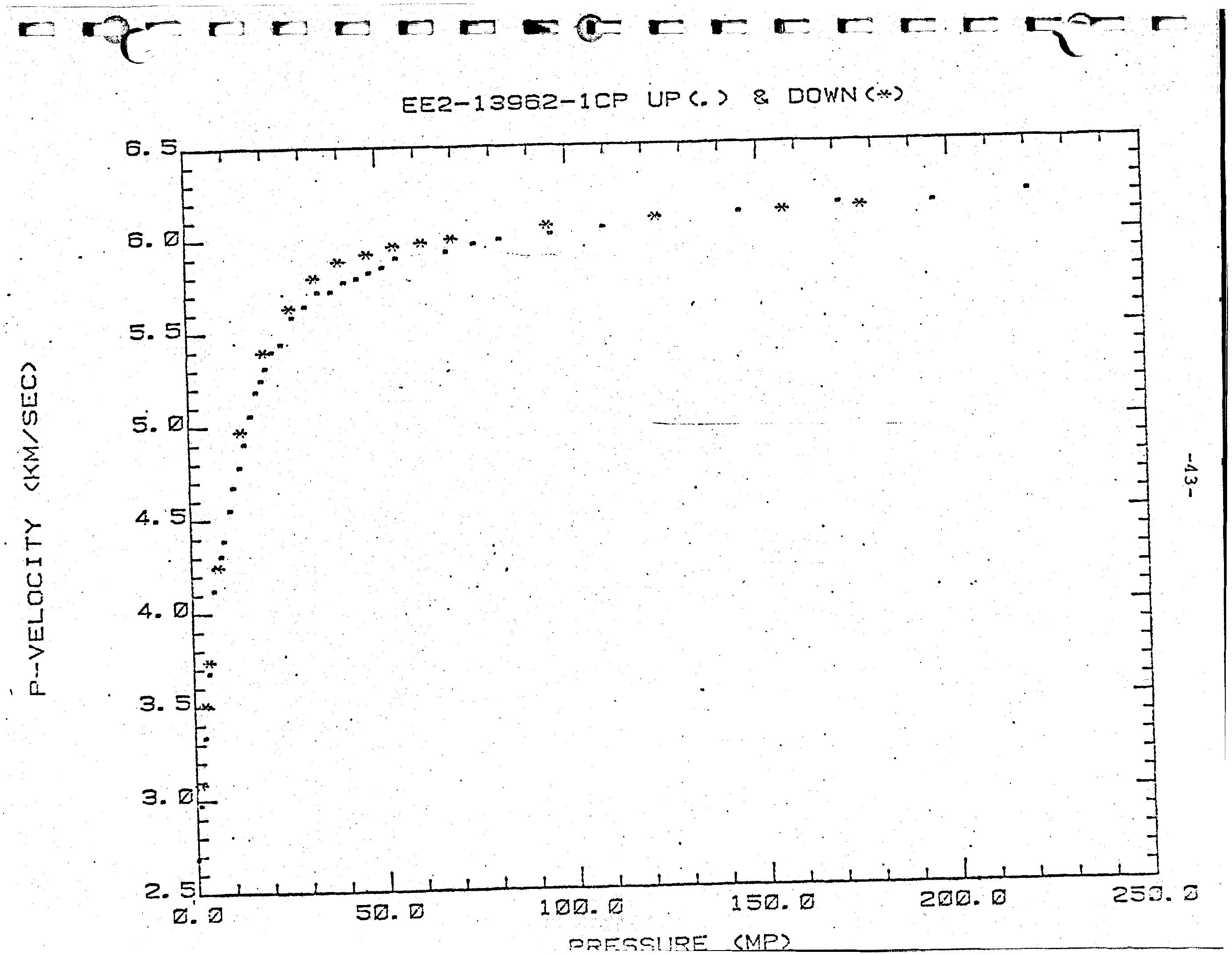




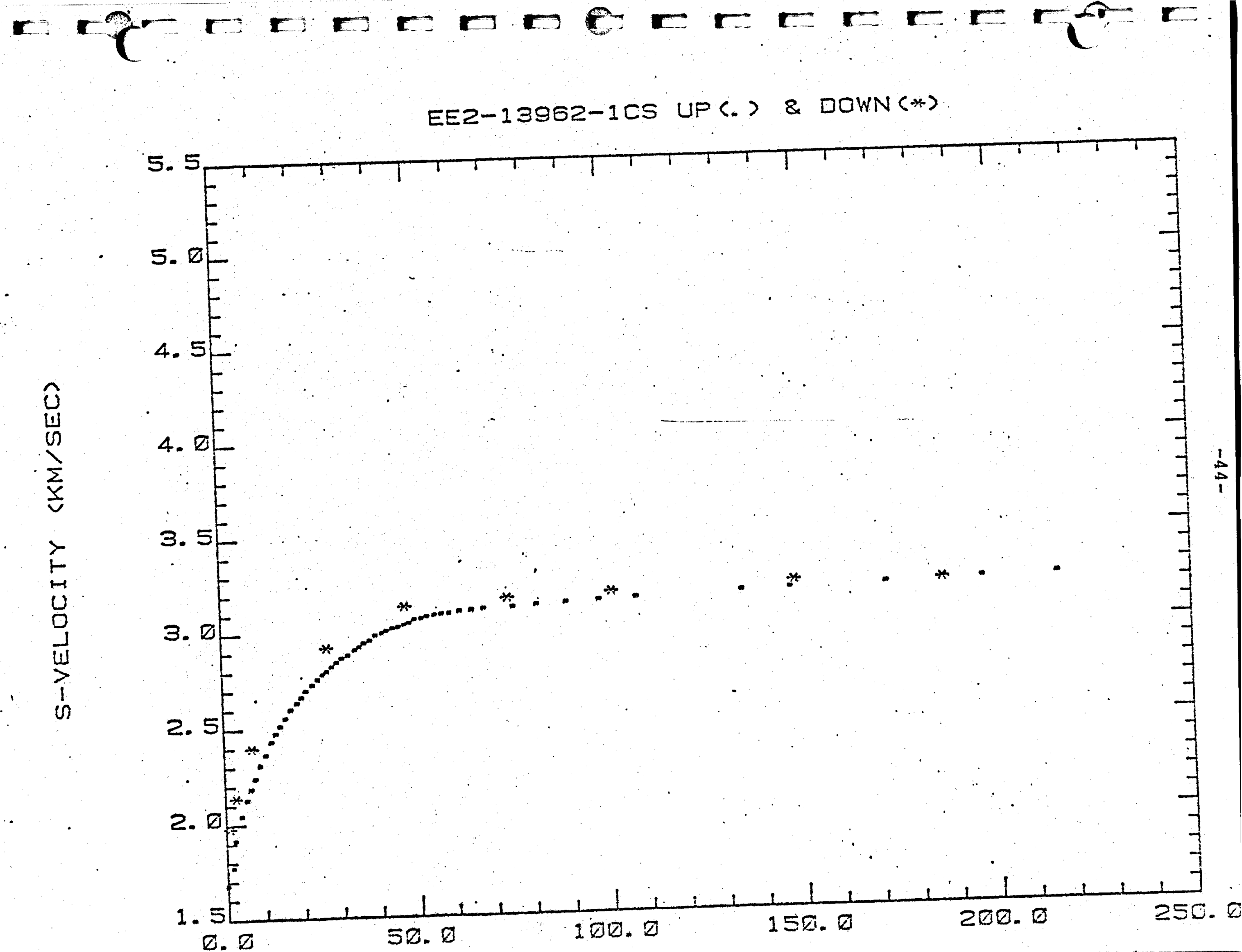


1

$$
-45-C
$$

APPENDIX 2

\section{DATA: Section II - Static and Dynamic} Moduli Graphs

if

in

1

1

$F$

1

1

1

1

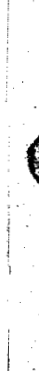

6. 


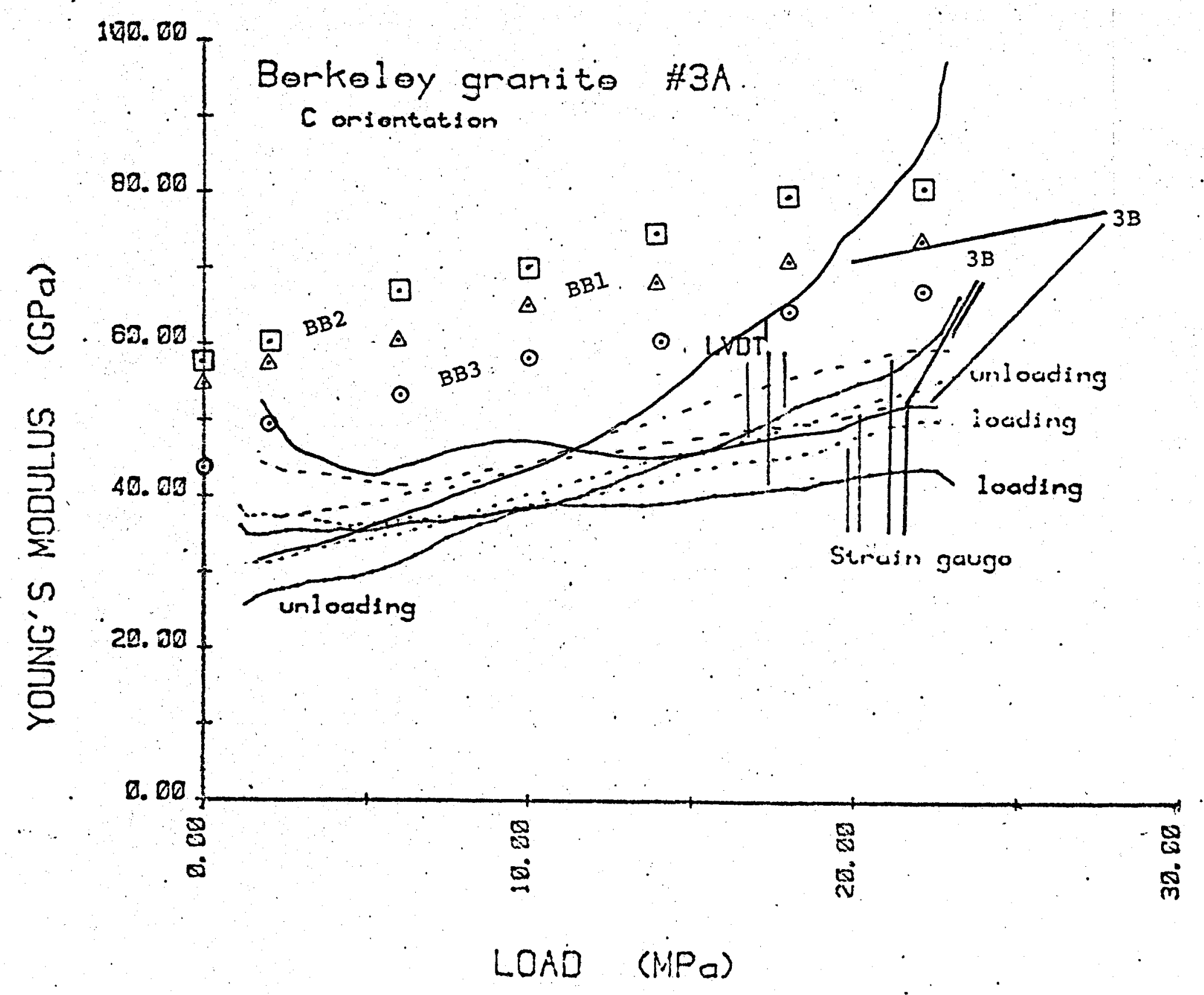




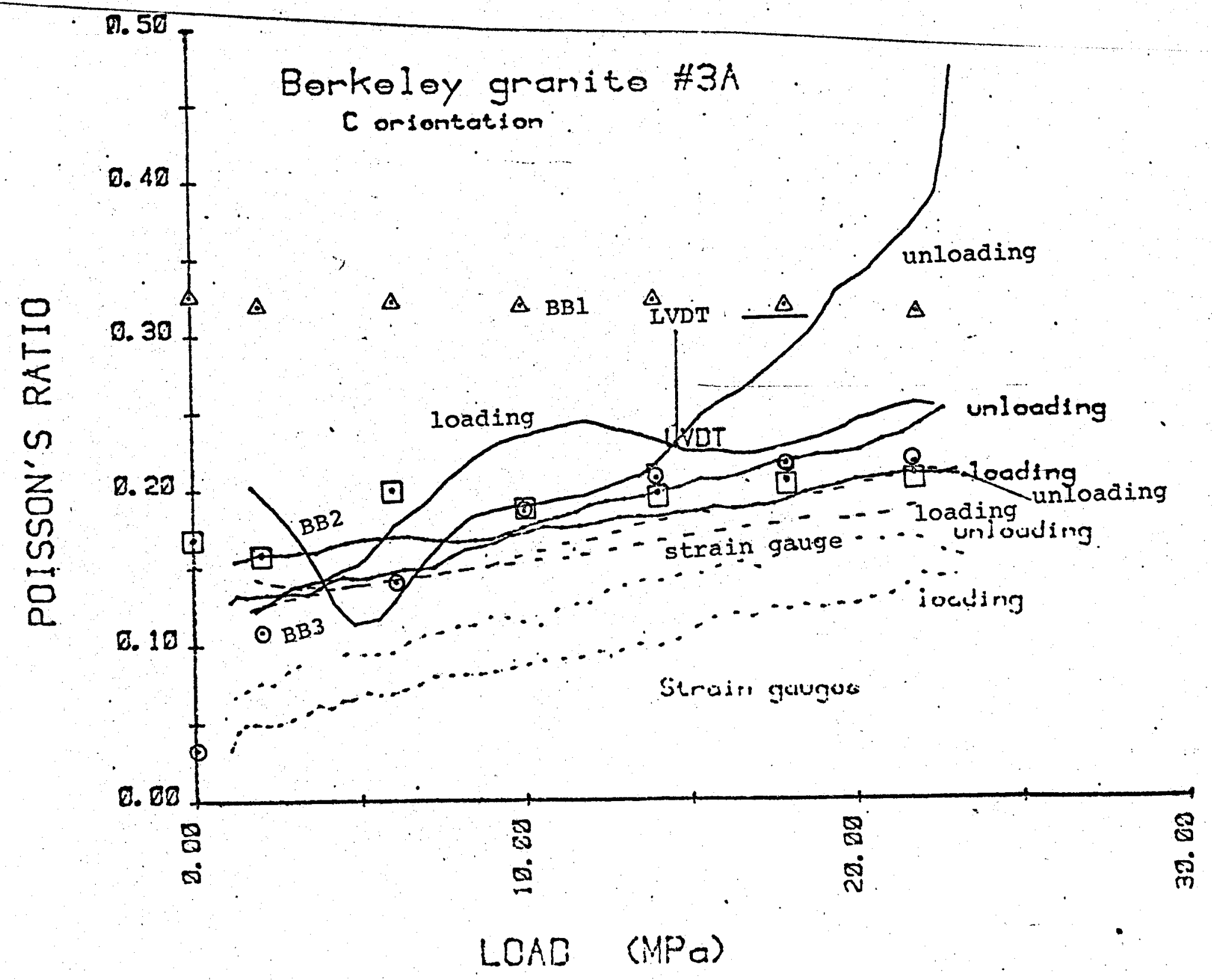






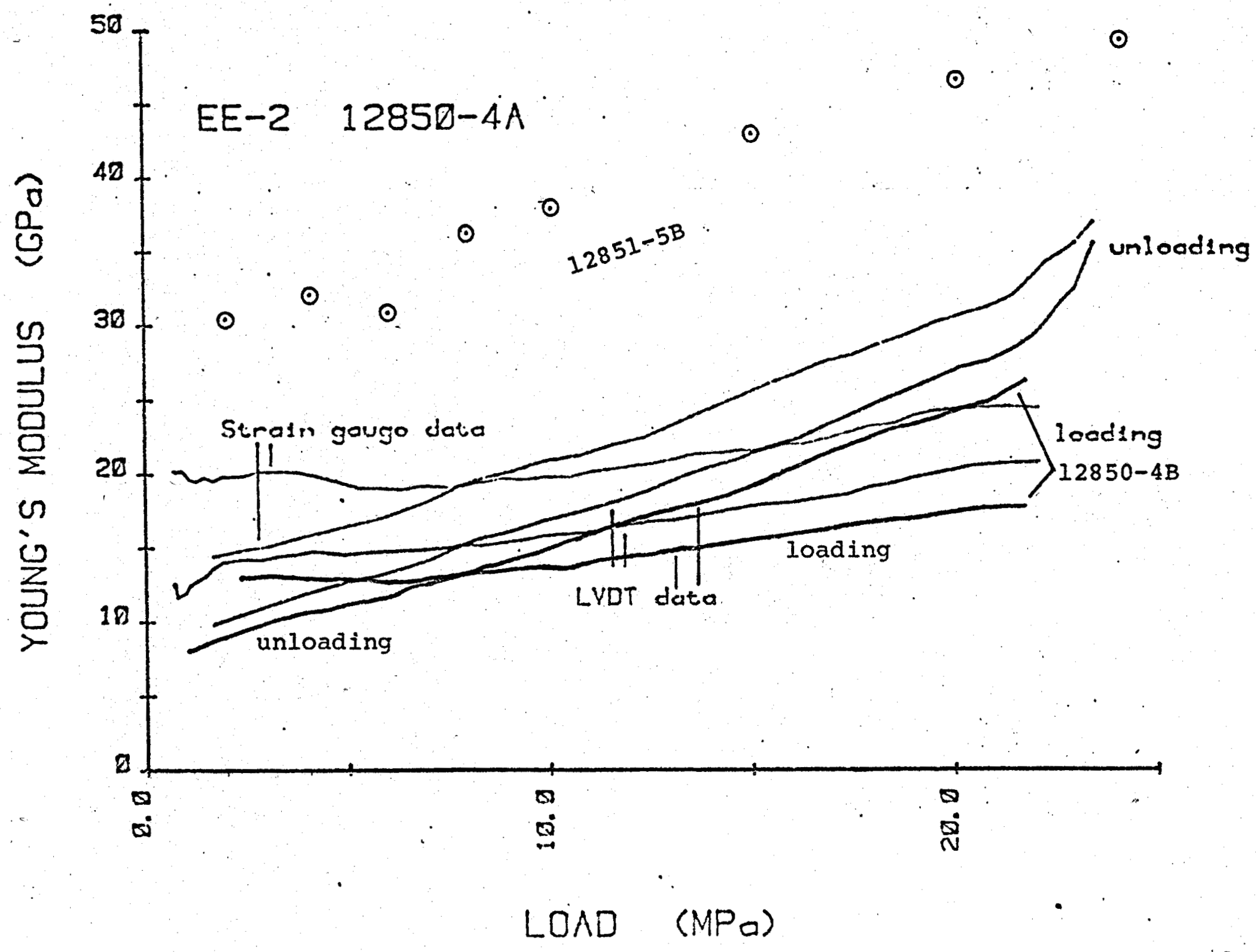







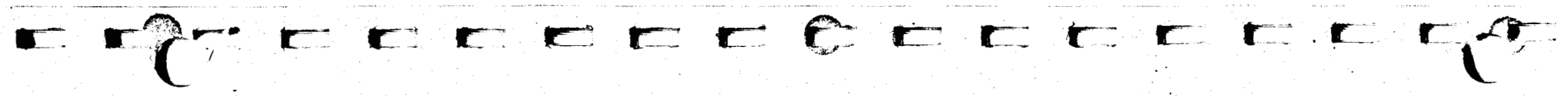

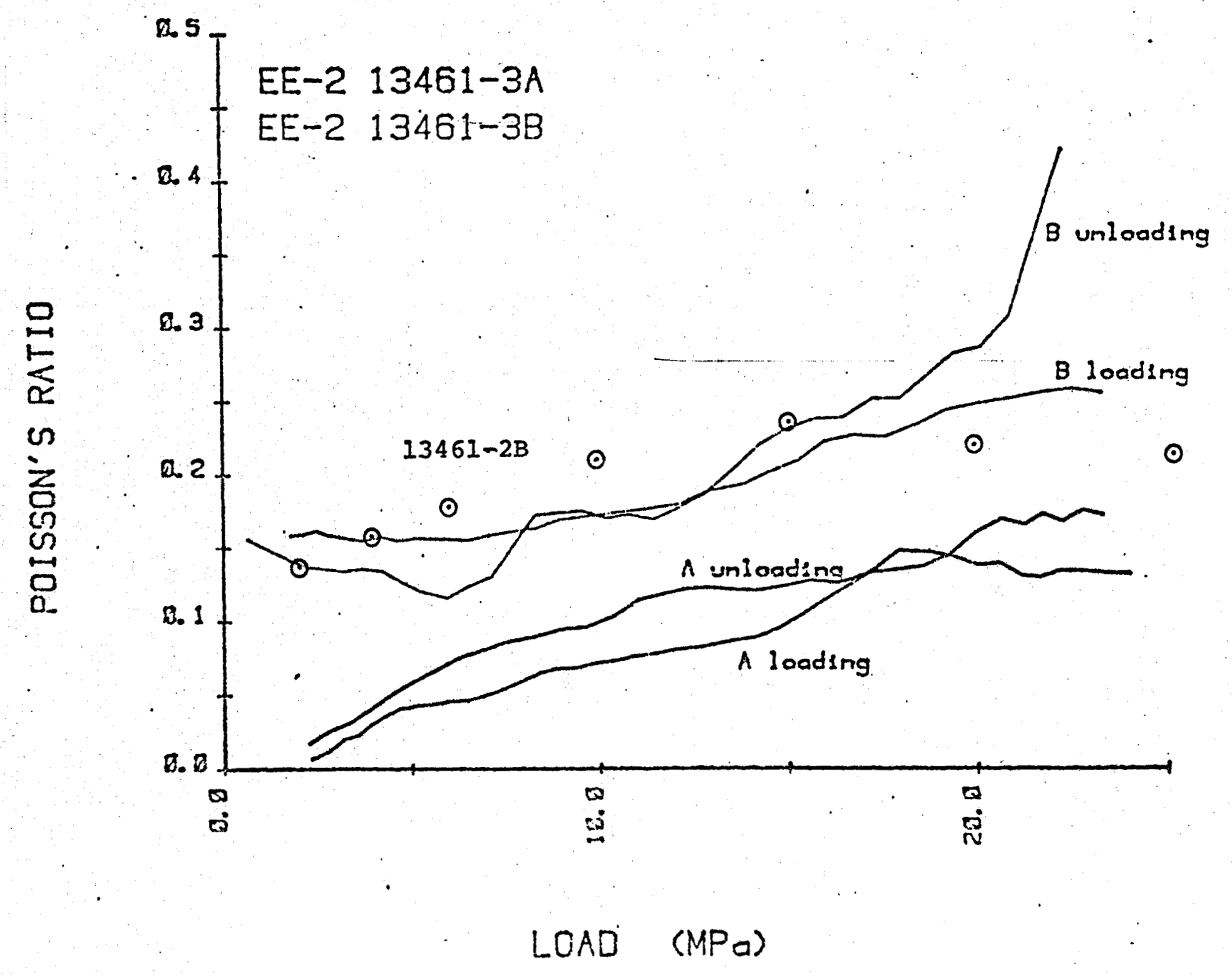




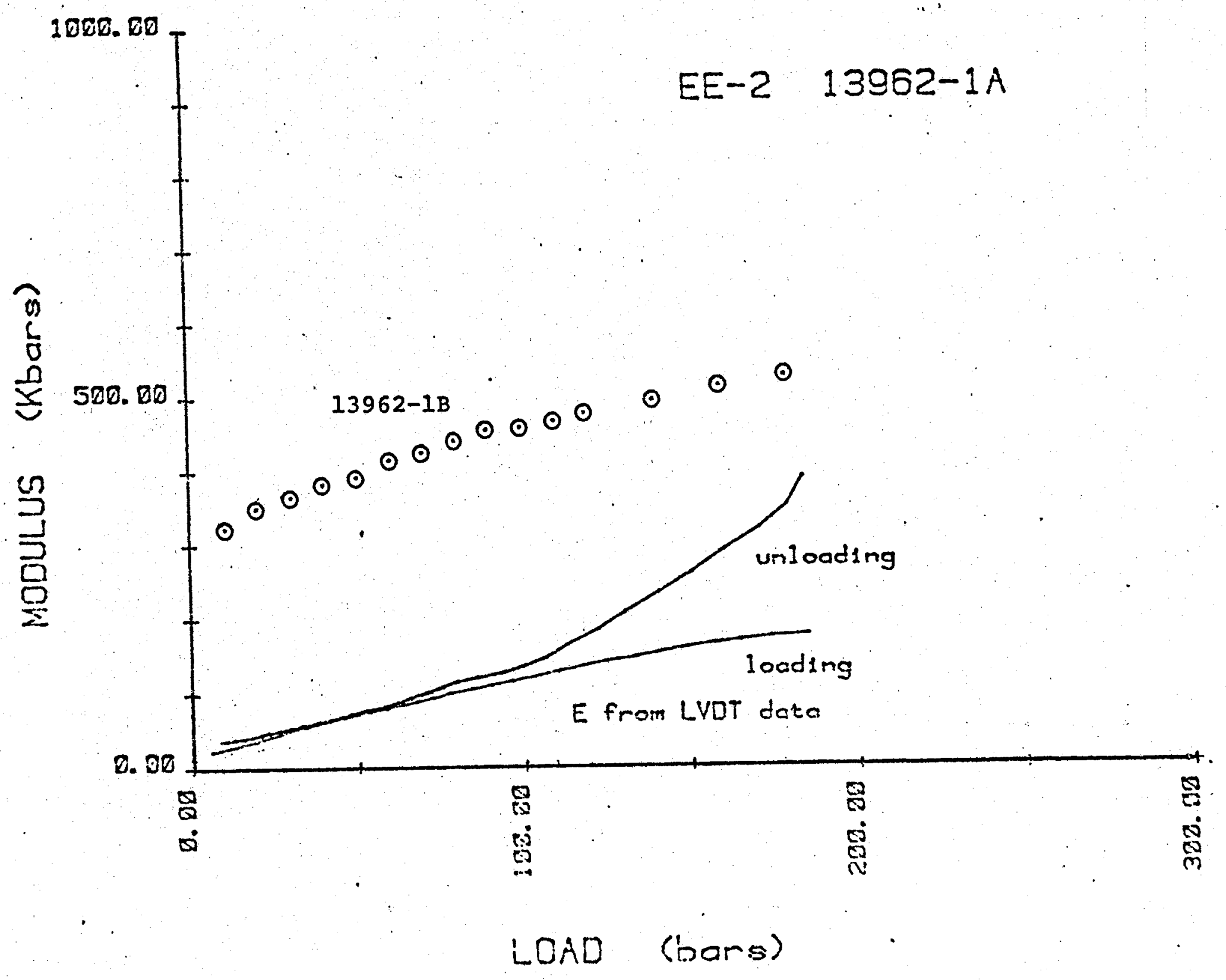





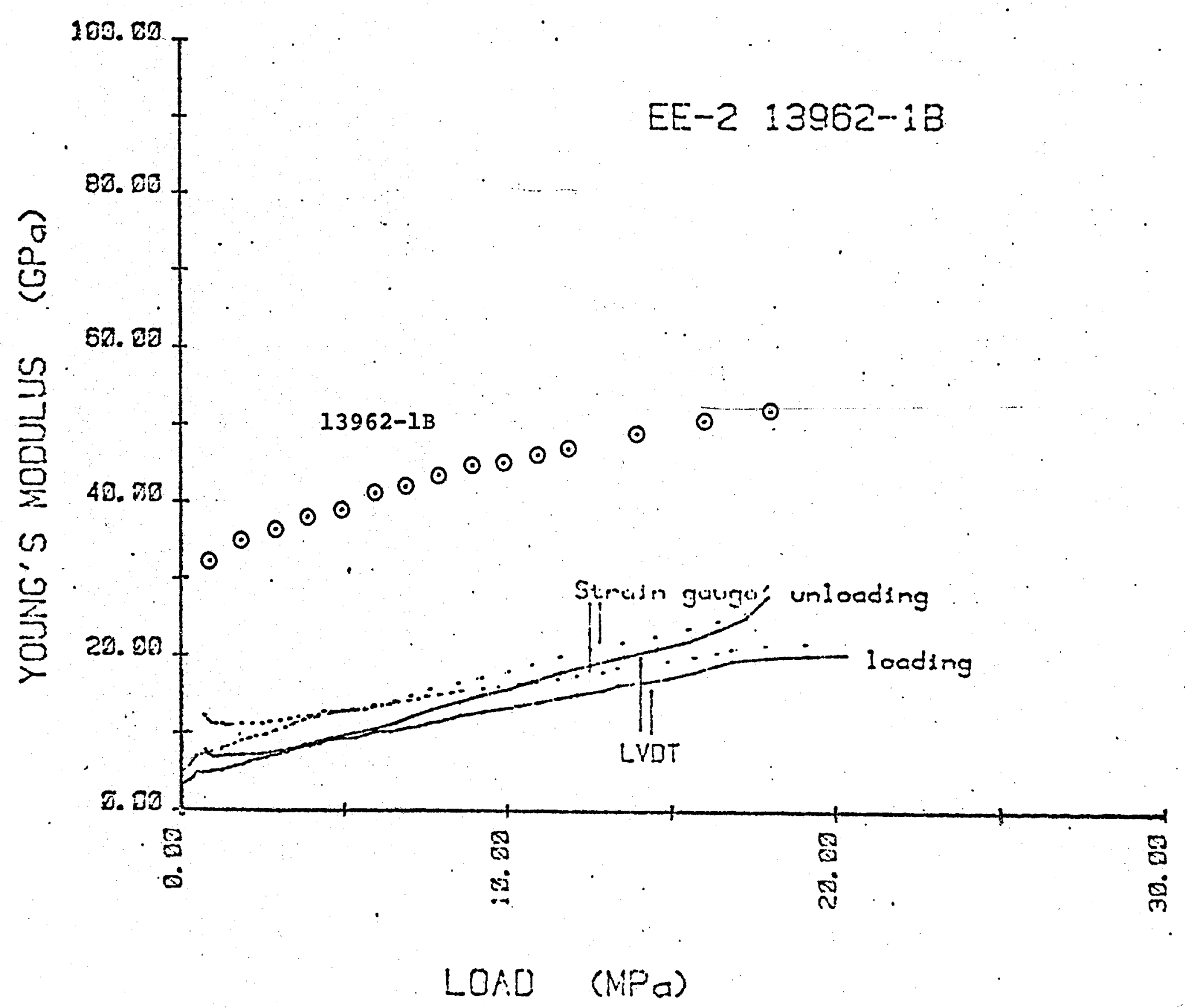





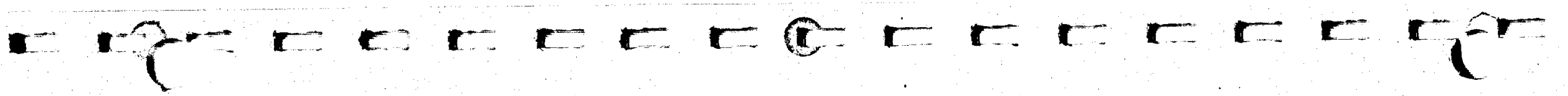

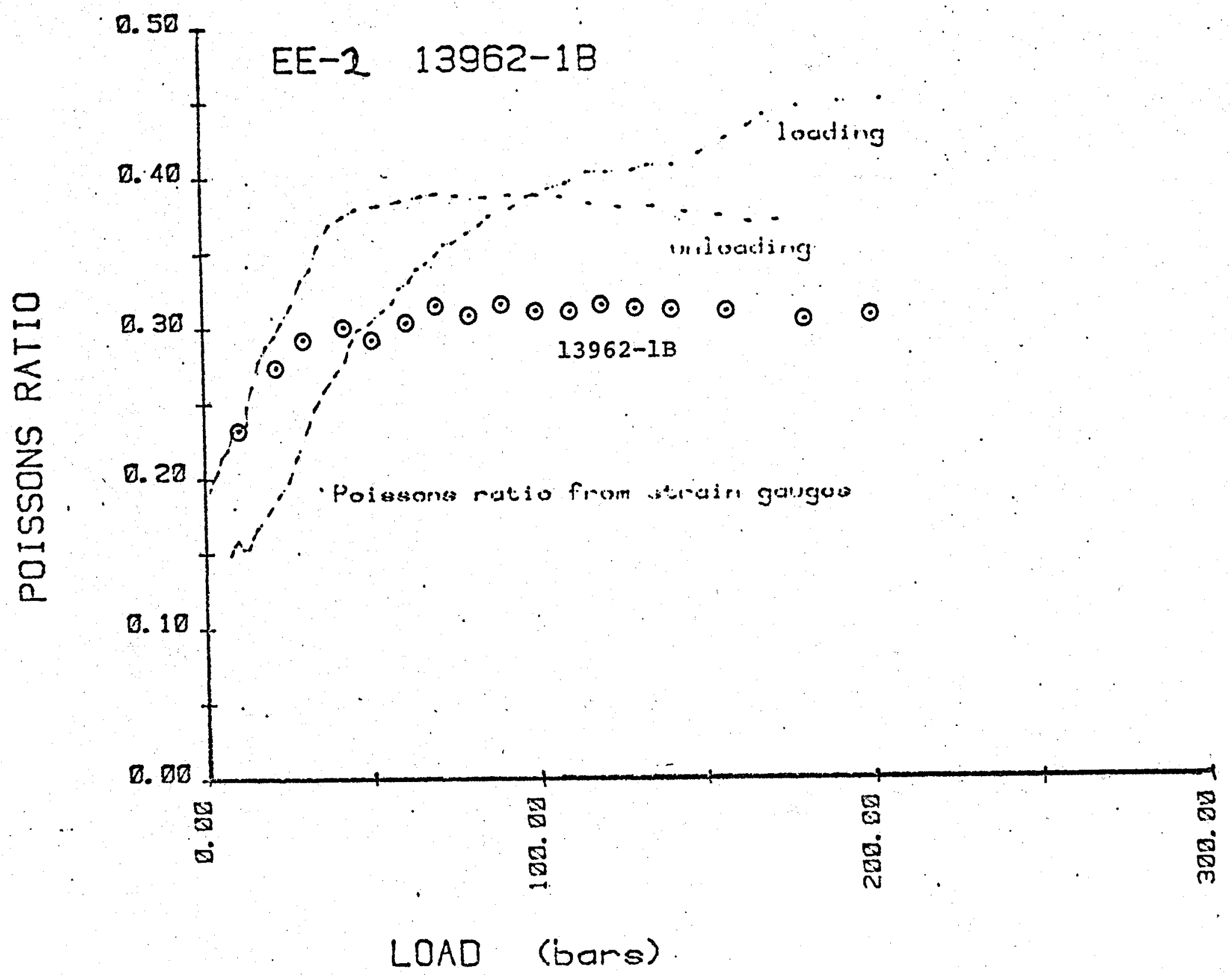




\section{ELBERTON GRANITE:}

\section{A COMPENDIUM OF VELOCITIES, DYNAMIC MODULI AND RELATED PHYSICAL PROPERTIES}

\section{by}

Nick Warren and Nick Coffey

\section{Institute of Geophysics and Planetary Physics}

University of California, Los Angeles

Final Technial Summary Report Under

DOE Grant \#DE-ASO3-765F-00034, PA\# DE-ATO3-76ER70224

Summary

During a three year period a variety of data were collected for samples of Elberton Granite at UCLA in conjunction with the Hot Dry Rock Geothermal Project (HDR) at Los Alamost National Laboratory. This compendium contains results from measurements of density, mineral modes, ultrasonic velocity, moduli and microstructure spectra. Data were obtained from dynamic velocity measurements with pressure to $0.2 \mathrm{GPa}$, borehole pressurization experiments on thick walled cylindrical cores, and from petrographic mapping.

\section{THE ELBERTON GRANITE}

For the purpose of comparing analytic techniques and the resulting data obtained from them by various workers it is desirable to have a 'standard' granite. The Elberton Granite (Berkeley Blue) has been used as a standard by a sufficient 
number of researchers that its properties are generally known. It shows a high degree of mineral isotropy and it has a fine grained texture. The Elberton Granite pluton is located in northeastern Georgia. The rock is quarried there for monuments and facing material for buildings. The pluton is some $6 \mathrm{~km}$. long and $7 \mathrm{~km}$. wide and is bounded by NE-SW trending faults (E1Iwood and Whitney, 1980).

The Elberton studies included static strain measurements on a large thick walled cylindrical sample as a function of varying pore pressure under triaxial loading. On smaller cylinders (minicores) we measured dynamic velocity and inverted those data into dynamic moduli and velocity spectra. We have mapped three orthogonal sections of the granite as a petrographic study of various grain boundaries. In addition modalities were tabulated on three samples. (These are given in Table 1.) The total study involved seven samples. One large core was used for the triaxial measurements and two sets of three orthogonal minicores were used for the petrographic work and for the acoustic velocity measurements. In addition the blocks from which the minicore sets were cut were used for room pressure velocity measurements.

In this report we will refer to the two orthogonal sets of minicores as set $\# 1$ and set $\# 2$. Minicore set $\# 1$ was oil cored, cleaned in trichloroethylene for at least 72 hours and dried and outgassed for several days. Minicore set $\# 2$ was water cored and dried and outgassed for several days. The remainder 
blocks were kept at ambient conditions in the laboratory and never dried or outgassed. The thick walled cylinder was water cored and stored under partial vacuum until saturation.

\section{PETROGRAPHIC STUDIES}

Whole dry bulk densities were determined for each orthogonal minicore section (see Table 1). Our calculated densities were in excellent agreement with that determined from large quarry blocks. Point counts were done on thin sections from minicore set $\# 1$. The number of counts in the point counts were 3000 to 4000 for each section. The modalities from the point counts are shown in Table 1. Agreement to counts made on other sections at Los Alamos were very. good.

Grain size determinations were made on an enlarged photograph of one thin section. The determination was over a11 grains and was a compromise between mineral grain size and fragment size. The step size was controlled by the mineralogical grain size at the upper end and the fragment grain size at the lower end. An estimate of both the mean grain size and the fragment size is therefore obtained, although not, with extreme accuracy. Grain size ranged from 0.3 to 0.5 millimeters with a mean of 0.45 millimeters. The standard deviation was 0.062 millimeters. We used 394 counts.

Petrographic studies indicate little mineral anisotropy. However, quarried blocks show a definite rift direction which is controlled by a strong orientation of microcracks. Gilles Russod (Halleck et al., 1982) indicates that for a quarry block similar to ours, the normals to an "open" set of cracks lie 
within a $20 \%$ cone of the B direction. A "closed" or "healed" set is located at about 45 degrees to the $\underline{A}$ and $\underline{C}$ axes. However, this last set is more discontinuous, appears as planar trains of opaques and is cross cut by the first set. The zero pressure and the $0.2 \mathrm{GPa}$ velocities for $6 \mathrm{dried}$ and outgassed samples are given in Table 2. They substantiate the crack anisotropy.

Petrostructure maps were made of three sections from minicore set 1 1. Grain boundary maps were made of the following :

1. Quartz-plagioclase

2. Quartz-alkali feldspar

3. Alkali feldspar-plagioclase

4. Biotites; full boundaries

The petrostructure maps were made as part of the extension from and continuation of the initial development of petrostructure analysis described in our earlier DOE reports and Warren (1982 $a, b)$. Examplar maps of the Elberton granite are included in appendix $\mathrm{C}$ of this report. 
Table 1

Densities, modes for Elberton granite

$\begin{array}{ccc}\text { Lab direction } & \text { Quarry direction } & \text { Density }\left(\mathrm{gm} / \mathrm{cm}^{3}\right) \\ \text { A } & \text { intermediate } & 2.625 \\ \text { B } & \text { rift } & 2.627 \\ \text { C } & \text { headgrain } & 2.627\end{array}$

Modes (\%)

Minicore

Set \#1 QZ K-Feld Plag Biotite Muscov Opag Chlor Other

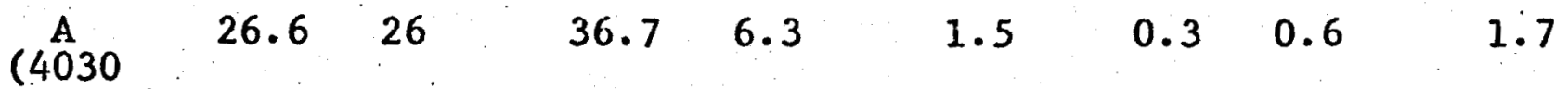

counts)

$\begin{array}{lllllllll}\begin{array}{l}\text { B } \\ (3660 \\ \text { counts })\end{array} & 29 & 25 & 37 & 4.6 & 2.8 & 0.3 & 0.7 & \begin{array}{c}0.5 \\ \text { sph? }\end{array}\end{array}$

$\begin{array}{llllllllll}\begin{array}{l}\mathrm{C} \\ (3326 \\ \text { counts) }\end{array} & 28.9 & 24.9 & 36.5 & 5.6 & 3.3 & 0.3 & 0.4 & 0.1 \\ \end{array}$

crack porosity $\leq 1 \times 10^{3}$

total porosity (based on bulk and mineralogical densities 


\section{Table 2}

ELBERTON GRANITE COMPRESSIONAL WAVE VELOCITIES $(\mathrm{km} / \mathrm{sec})$

Sample

$$
\text { at } \mathrm{p}=0.0 \mathrm{GPa}
$$

\begin{tabular}{|c|c|c|c|c|}
\hline \multirow{3}{*}{$\begin{array}{l}\text { minicore } 1 \\
\text { set } 1\end{array}$} & & $\underline{\mathbf{A}}$ & B & $\underline{\mathbf{C}}$ \\
\hline & vessel & 4.41 & 3.81 & 5.01 \\
\hline & table top & 4.53 & 3.86 & 4.59 \\
\hline minicore ${ }^{2}$ & vessel & & & 5.00 \\
\hline & table top & 4.95 & 3.98 & 5.05 \\
\hline $\begin{array}{l}\text { remainder }{ }^{3} \\
\text { block for } \\
\text { set } \| 2\end{array}$ & table top & $\begin{array}{c}5.18 \\
\text { to } \\
5.49^{4}\end{array}$ & $\begin{array}{l}4.68 \\
\text { to } \\
4.52^{4}\end{array}$ & 5.46 \\
\hline
\end{tabular}

$\mathrm{km} / \mathrm{sec}$

1 oil cut, cleaned in trichloroethylene, dried and outgassed for several days.

2 water cut, dried and outgassed over several days.

3 kept at ambient environment, never dried or outgassed.

4 systematic variation over block. 


\section{ACOUSTIC VELOCITY MEASUREMENTS}

Acoustic velocities were measured as a function of pressure on minicore set $\# 1$. Both compressional and shear wave velocities were determined. A technique describe by Warren (Warren, 1980) was employed. The basic technique is a pulse transmission method. Care was taken in those experiments in order to keep the precision as high as possible. This meant tracking the appearance of the first acoustic arrival and picking a fixed point on the wave form to track as a function of pressure. An electronic feducial mark was displayed in overlay on the first arrival. By tracking the displayed signal with the feducial mark, precision was held to a high tolerance. Three $\mathrm{MHz}$ piezoceramic transducers (PZT) were used for the compressional velocity measurements and $1 \mathrm{MHz}$ piezoceramic transducer was used to measure shear velocity. A four kilobar, 1.5 inch I.D. hydrostatic pressure vessel charged with kerosene was used for the velocity measurements. Pressure measurements were made using three cross-calibrated gauges and pressure transducers. A Heise $5000 \mathrm{~kg} / \mathrm{cm}^{2}$ gauge, a Heise 20,000 psi gauge, and a Sensor Industries, Inc. 10,000 psi transducer model $70052-5$ were used. The mutual calibrations were found to be consistent with factory calibrations.

In a second round of measurements table top (zero pressure) velocity determinations were conducted on minicore sets 1 and \#2 and on the block from which minicore set \#2 was cored. Before this second sets of measurements was made the minicores 
were kept in a vacuum oven at roughly $60^{\circ} \mathrm{C}$ for about two weeks. This second set of determinations was performed to confirm the zero pressure measurements of the core samples. Good agreement with the original zero pressure values was obtained (see table 2).

VELOCITIES, MODULI AND SPECTRA

Velocities, moduli and spectra are given in Appendix A. Velocities are presented in two forms in Tables $A-1$ and $A-2$. First are the original data in Table $A-1$ and second in $A-2$ are edited velocities at interpolated pressures. The original data include all the experimental values which were recorded. These include a few less precise points which were generated by varying experimental technique and/or change of operators. Certain points were therefore deleted before the standard pressure points were calculated. The are marked with asterisks and explained in the footnote.

Dynamic moduli were derived from the acoustic velocity data. The moduli were calculated from the edited data and appear in the Appendix.

We have generated two types of plots from the acoustic velocity data. The first plot is the edited dynamic velocity data as a function of pressure. Both shear and compressional velocity up-run data are presented for each of the three samples from minicore set $\# 1$. These are plots of the edited velocity data.

The second type of plot we have presented are spectra derived from the edited compressional velocities of the three 
samples. The spectra are derivatives of the respective velocity data and the method of generating the spectra is given originally in our 1980 DOE report (Tiernan, 1980). The interpretation was first given by Simmons, et al. (1974). The techniques we have used parallels the one used by simmons for static strain measurements.

Analysis of the spectra revealed that microcrack damage was generated in the Elberton granites by the pressure cycling during experiments. As a result it became possible to do an accurate hysteresis experiment and to resolve damage effects on velocities from friction effects. The velocity curves and the spectra from the hysteresis experiment (Warren and Coffey, 1982) are also given here in the Appendix.

Borehole Pressurization

In these experimental studies, a thick walled cylindrical core of Elberton granite was subjected to varying bore-hole pressures over a matrix of axial and confining stresses. Crack compliances were determined from the axial and circumferential strains. By choice of geometry the experiments were directed to the problems involved with inflating reservoirs by fluid injection from a borehole.

The complete experimental series had three parts: first, direct uniaxial stress cycles at zero confining pressure and small or zero borehole pressure; second, confining pressure cycling at zero borehold pressure (axial load was automatically driven during these cycles); and third, cycling borehole 
pressure over a matrix of fixed confining stress states. In the series approximately $1 / 2$ hour relaxations were allowed between measurements.

A detailed discussion and the full collection of data are given in Fisher, Warren and Blanton (in preparation). In appendix $B$ of this report we have presented the experimental results for uniaxial and differential stress loading to 7000 psi and the resultant moduli. We have also included one exemplar borehole pressurization curve along with the listing of the analytic quadratic fits to all the experiments. 


\section{REFERENCES}

Ellwood, B.B., and J.A. Whitney, "Magnetic fabric of the Elberton granite, northeast Georgia," Journal of Geophysical Research, 85, (B3), 1481-1486, March 10, 1980. Fisher, H., N. Warren and J.B. Blanton, "A rough-crack mode1 for pore compressibility: Application to data for crack compliance around a borehole", in preparation.

Halleck, P.M., T.N. Dey, G.Y. Bussod, A.J. Kumnick,

"Relationships between fracture toughness, tensile modulus, and microstructure in E1berton granite, submitted for publication (1982).

Simmons, G., R.W. Siegfried II, and M. Feves, "Differential strain analysis: a new method for examining cracks in rocks," Journal of Geophysical Research 79 (29) 4383-3485, Oct. $10,1974$.

Tiernan, M., "Crack spectra analysis," Technical Summary Report to Department of Energy under grant \#DE-AMO3-76 FOOO 34, September, 1980.

Warren, N., "Statistical characterization of complex crack and petrographic texture: application to predicting bulk physical propeties," in Issues In Rock Mechanics, 23rd Symposium on Rock Mechanics, Chapter 14, Berkeley, 1982 (Warren 1982a).

Warren, N., "Quantitative petrostructure analysis", in The relationship of rock physics to geothermal energy technology", in press, 1982. (Warren, 1982b). 
Warren, N. and N. Coffey, "Microcrack formation and hysteresis under hydrostatic cycling", abstract submitted to AGU, 1982. 


\section{ELBERTON GRANITE HEADGRAIN DIRECTION}

A measured compressional velocity with increasing pressure

B interpolated velocity with pressure

A

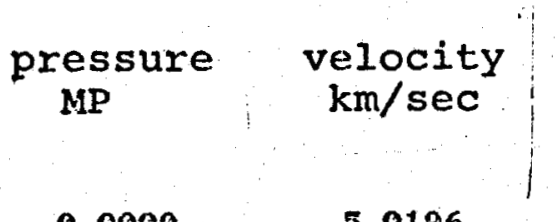

0.0000

3.0607

8.9634

12.680

15.741

19.229

22.955

25.707

29.782

33.414

36.073

30.914

40. $130: ?$

42.194

46.705

50.720

53.731

58.809

63.847

73.793

93.7\%4

104.43

113.10

133.10

$153.8 \%$

172. d?

161.81

\subsection{6}

5.1453

5.3902

5.5259

5.6098

5.6785

5.7299

5.7623

5.3144

5.3759

5.0783

5:B)29

5.9104

5.9242

5.9400

5.9599

5.9322

6.0136

6.0249

6.0733

6.1129

6.1479

6.1325

6.1740

6.1378

6.2010

6.2023
B

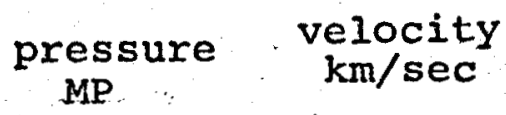

0.0000

1.0000

2.0000

4.0000

7.0009

10.000

15.000

20.000

$25.00 \mathrm{~J}$

30.000

35.003

40.000

45.000

50.003

55.000

60.000

70.000

80.000

90.000

100.00

125.00

150.00

175.00

130.00
5.0195

5.0602

5.1018

5.1045

5.3002

5.4330

5.6024

5.6900

5.7545

5.0179

5.8907

5.9014

5.943 3

5.9550

5.9906

6.0199

6.0 .80

6.0965

6.1250

6.1201

6.1644

6.1367

6.2026

6.2059 


\section{ELBERTON GRANITE HEADGRAIN DIRECTION}

i A measured shear velocity with increasing pressure

B interpolated velocity with pressure

A

$$
\begin{gathered}
\text { pressure } \\
\text { MP }
\end{gathered}
$$

0.0000

1.0931

2.1062

3.7160

4.8097

5.0841

6.9959

8.3076

10.712

12.461

14.129

16.397

19.020

20.550

20.616

20.769

21.425

22.031

23.611

25.579

27.103

28.530

30.179

31.919

33.449

34.979

36.510

38.259

40.003

41.533

12.859

44.599

46.785

49.190

50.203

52.005

54.764

$55.96 \%$

57.93

60.553

62.74

65.149

$67.55 \%$

72.114

77.5136

घ2.414

39.517

96.276

103.45

112.76

119.60

1231. 14

142.50

$157.2 \%$

102.50

174.93

106.7:

194.09

\author{
velocity \\ $\mathrm{km} / \mathrm{sec}$
}

2.5556

2.5931

2.6326

2.6500

2.6791

2.6959

2.7257

2.7601

2.7942

2.8357

2.0668

$2.0 \% 03$

$2.93 \% 4$

$3.0044 *$

$2.9034 *$

2.0065 *

2.9687 *

2.9267

3.0157

3.0158

3.0'77

3.1154

3.123r

3.1208

3.1479

3.1705

3.2508 *

3.2264

3.2787

3.2002

3.2312

3.2702

3.2766

3.2023

3.2964

3.3695

3.33140

3.3555

3.34.4.9

3.3504

3.3640

3.3653

3.0793

3.4700

3.4553

3. 4102

3.4290

3. 4453

3.4606

3.4719

3. A1370

3. 4329

$3.5 \% 21$

3.3307

3.5365

3.5550

3.5554

3.5661
B

$\begin{array}{cc}\text { pressure } & \text { velocity } \\ \mathrm{MP} & \mathrm{km} / \mathrm{sec}\end{array}$

2.5556

2.5981

2.6315

2.6571

2.7255

2.7991

2.8759

2.9549

3.0350

3.1320

3.1708

3.2731

3.2776

3.2256

3.3358

3.3519

3.0362

3.4100

3. 4002

$3.45 \times 3$

3.4962

3.5258

3.5550

3.5605

* points deleted. 


\section{ELBERTON GRANITE HEADGRAIN DIRECTION DYNAMIC MODULI}

SAMPLE: NGBB1

DENSI'TY: 2.627 (GM/CC)

PRESSURE \& MODULI ARE IN 'MP':

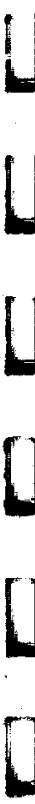

\begin{tabular}{|c|c|c|c|}
\hline & BULK & SHEAR & \\
\hline PRESS & HODULUS & MODULUS: & $B(=1 / K$ \\
\hline & 43.312 & 17.157 & .02309 \\
\hline 1.08 & 43.635 & 17.732 & .02292 \\
\hline & $4 A: 121$ & 18.191 & .02267 \\
\hline & 45.081 & 18.547 & .02180 \\
\hline 7.00 & 47,906 & 19.510 & .02084 \\
\hline 10.00 & 501099 & 20.582 & .01996 \\
\hline & 83.483 & 21.727 & .01870 \\
\hline & 54.468 & 22.937 & .01836 \\
\hline & 54.727 & 24.197 & .01 \\
\hline 30. & 54.322 & 25.947 & .01041 \\
\hline & 55.942 & 26.411 & .01734 \\
\hline & 53.964 & 20.143 & .01853 \\
\hline 45 & 55.180 & 20.220 & .01812 \\
\hline & 55.116 & 28.531 & .018 \\
\hline & 55.299 & 29.232 & .01803 \\
\hline & 55.847 & 29.514 & .01791 \\
\hline & 55.953 & 30.122 & .01737 \\
\hline & 56.909 & 30.5418 & .01757 \\
\hline 90.0 & 57.365 & 30.910 & $.017 \mathrm{di}$ \\
\hline 100 & 56.8378 & 31.3 & .01758 \\
\hline 125. & 57.011 & 32.110 & .01754 \\
\hline 150. & 56.949 & 32.675 & .01756 \\
\hline 175. & 56.799 & 33.200 & .01761 \\
\hline & & & \\
\hline
\end{tabular}

YOUIKG'S MODULUS 45.467

46.851

47.980

49.034

51.563

54.309

57.403

60.342

63.264

67.150

68.461

71.926

72.332

72.999

74.558

75.232

76.617

77.732

78.610

79.463

01.105

(12.2B13

03.358

03.567
POISSON

RATIO

.3250

.3210

.3183

.3219

.3209

.3193

.3211

.3154

.3973

.2940

.2960

.2779

.2315

.2793

.2753

.2753

.2718

.2724

.2716

.2672

.2629

.2592

.2554

.2547

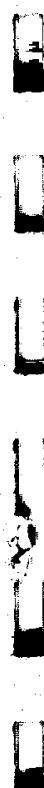



ELBERTON GRANITE HEADGRAIN DIRECTION

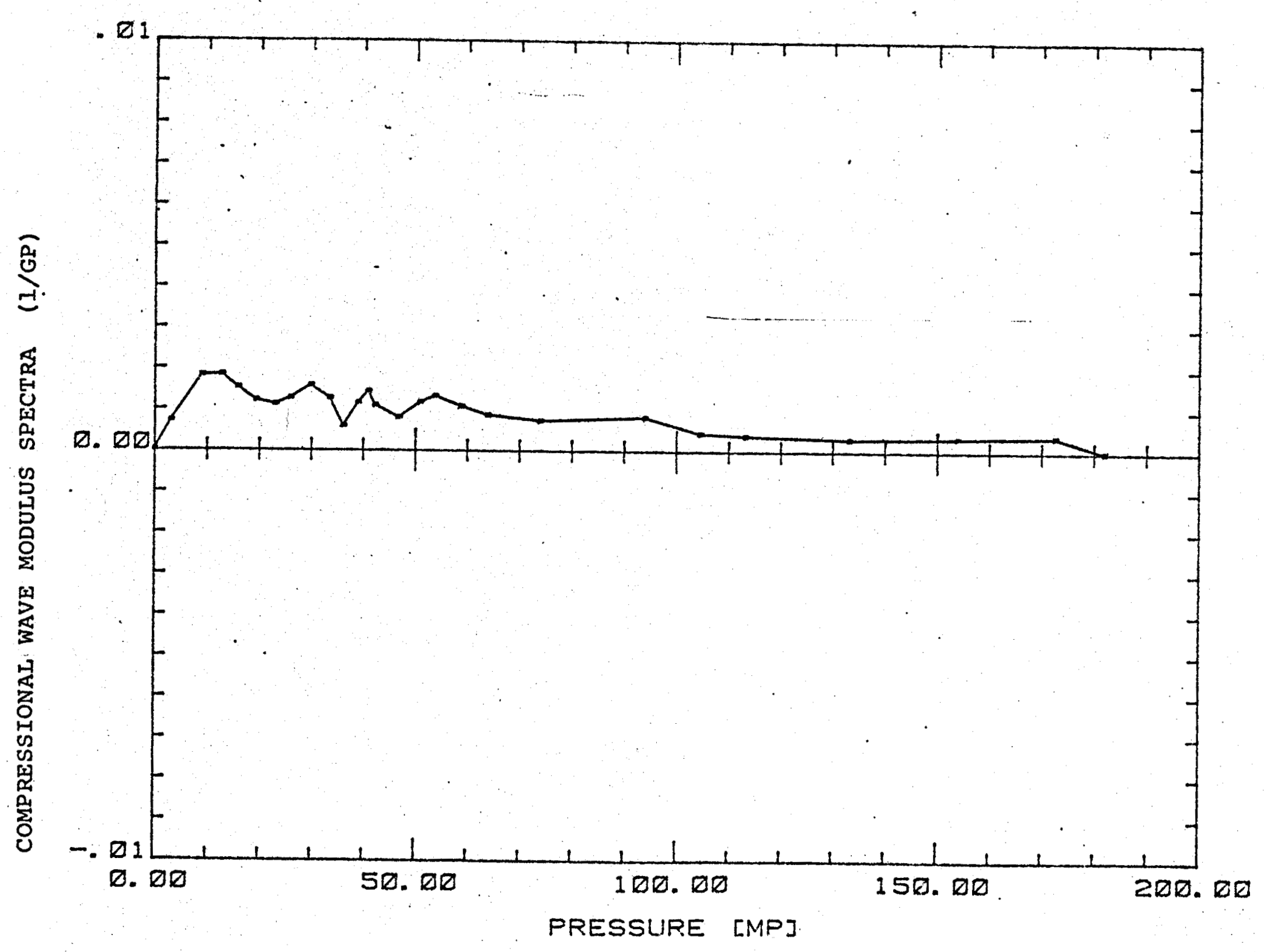




\section{EIBERTON GRANITE INTERMEDIATE DIRECTION}

A measured compressional velocity with increasing pressure (unedited data) B interpolated velocity with pressure

A

$$
\begin{gathered}
\text { pressure velocity } \\
\text { MP }
\end{gathered}
$$

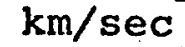

0.0000

1.0931

2.1862

3.7166

5.2169

6.5505

8.5262

10. 275

11.915

13. 55

15.393

16.72

18.911

21.316

2.001

23.720

25.369

27.213

$29.07 \%$

31.014

$33.01 \%$

33.669

34.971

36.291

37.021

10.991

42.740

44.703

$46.566^{\circ}$

20.097

52.141

53.343

55.311

56.623

59.023

61.651

$64.49 \div$

$67.77:$

70.724

77.41 .

130.690

92.062

$10 \%: 17$

113.93

129.31

136.55

$14 i 6.01$

156.95

173.40

102.11

215.52
4.4198

4.4603

4.5267

4. 5007

4. 3433 *

4.8629

4.9001

4.9705

5.01358

5.1110

5.1789

5.2173

5.3754

6.4159

5. $4.126 *$

5.4240

5. 4022

5. 3140

5,5462

5.5981

$5.6 \% 22$

5.6579

5.7050

5.714 .4

5.7314

5.7466

5.7394

5.8300

6.8237

5.0499

5.07512

5. 3556

$5.13 \times 34$

5.83081

5.13:34

5.9786

5.9310?

5. 9iklu

6.007 6

6.04156

$6.083: 36$

6.1215

6.1359

0.16339

6.1712

6.1326

6.2166

6.2332

6.:2.116

6.2900
5.03205
B

$\underset{M P}{\operatorname{pressure}} \begin{gathered}\text { velocity } \\ \mathrm{km} / \mathrm{sec}\end{gathered}$

0.0000

1.0000

2.0000

4.0000

$\% .0000$

10.60?

15.000

20.000

25.000

30.000

35.000

40.000

45.000

50.000

55.003

60.009

70.000

80.000

90.000

100.00

125.00

$-150.00$

175.00

200.00

215.00

4.4198

4. 4451

4.5020

4.7041

4.3778

4.9521

5.1613

5.4135

5. 5265

5.6459

5.7302

5.3290

5.13664

5.9097

5.9331

5.9672

5.9324

6.0203

6.0773

6.1112

6.1560

6.1971

6.2347

6.2595

6.2746 


\section{ELBERTON GRANITE INTERMEDIATE DIRECTION}
A measured shear velocity with increasing pressure
B . interpolated velocity with pressure

A

$$
\begin{aligned}
& \text { pressure } \\
& \text { MP }
\end{aligned}
$$

$$
\begin{aligned}
& 0.0009 \\
& 1.5303 \\
& 3.2793 \\
& 4.0097 \\
& 6.3400 \\
& 8.3070 \\
& 10.057 \\
& 11.806 \\
& 13.336 \\
& 14.976 \\
& 16.615 \\
& 18.364 \\
& 20.032 \\
& 22.031 \\
& 24.040 \\
& 25.360 \\
& 27.323 \\
& 28.967 \\
& 30.498 \\
& 32.350 \\
& 34.433 \\
& 37.821 \\
& 41.210 \\
& 44.599 \text {. } \\
& 48.534 \\
& 51.485 \\
& 55.092 \\
& 58.590 \\
& 62.416 \\
& 65.690
\end{aligned}
$$

B

$\begin{array}{cc}\text { pressure } & \text { velocity } \\ \text { MP } & \mathrm{km} / \mathrm{sec}\end{array}$

2.7877

2.6838

$2.0674^{\circ}$

2.9226

2.9991

3.0734

3.1564

3.2025

3.2347

3.2729

3.3012

3.3262

3.3496

3.3693

$3.3 \% 11$

3.4032

3.4246

3.4509

3.4719

3.4652

3.5101

3.5344

3.5552

3.5028

215.00 


\section{ELBERTON GRANITE INTERMEDIATE DIRECTION DYNAMIC MODULI}

SATPLE: NGBB2

DENSI'TY: $2.627^{\circ}$ (GM/CC)

PRESSURL \& MODULI ARE IT 'MP'

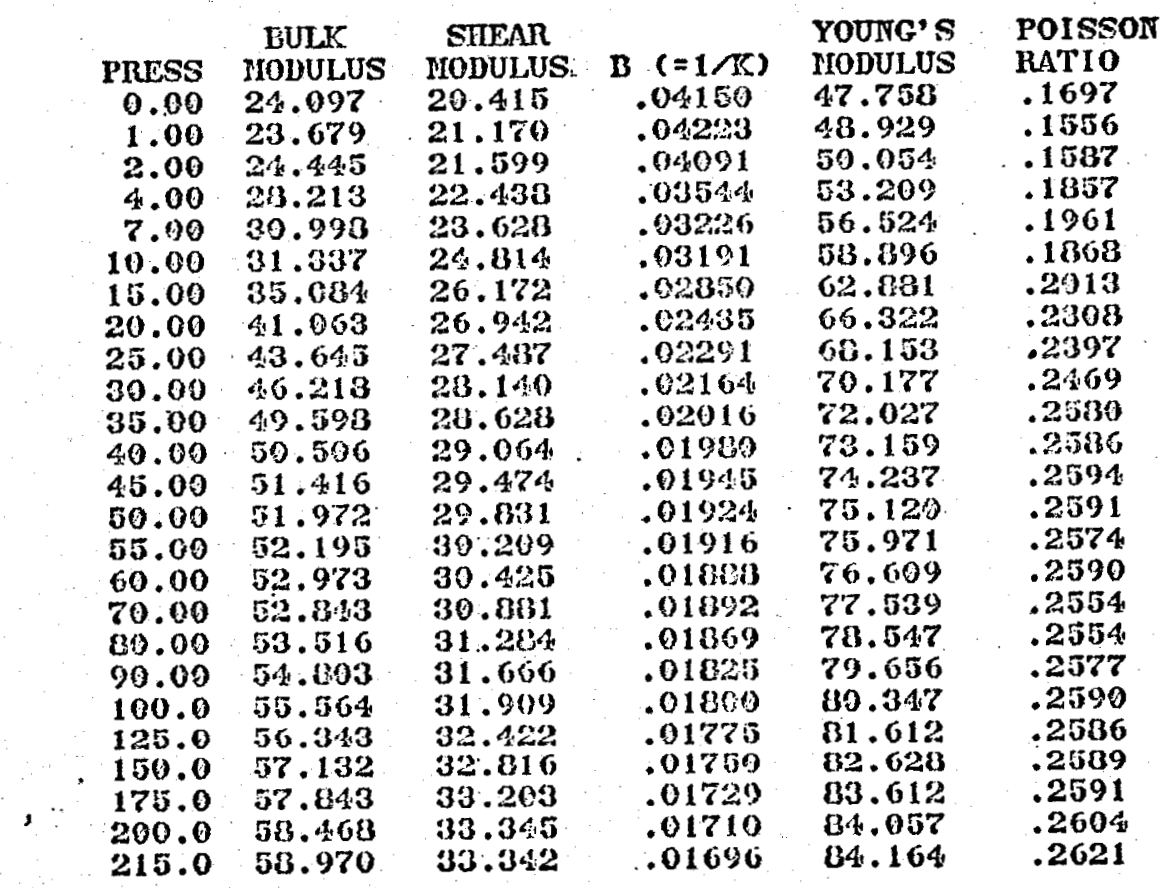




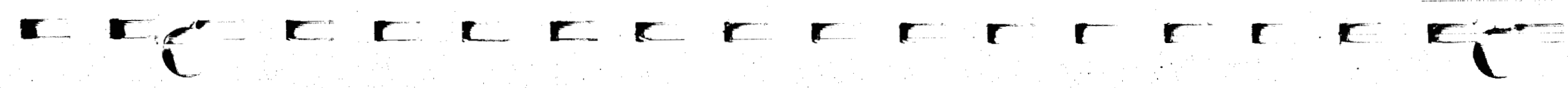

ELBERTON GRANITE INTERMEDIATE DIRECTION VELOCITY PROFILES

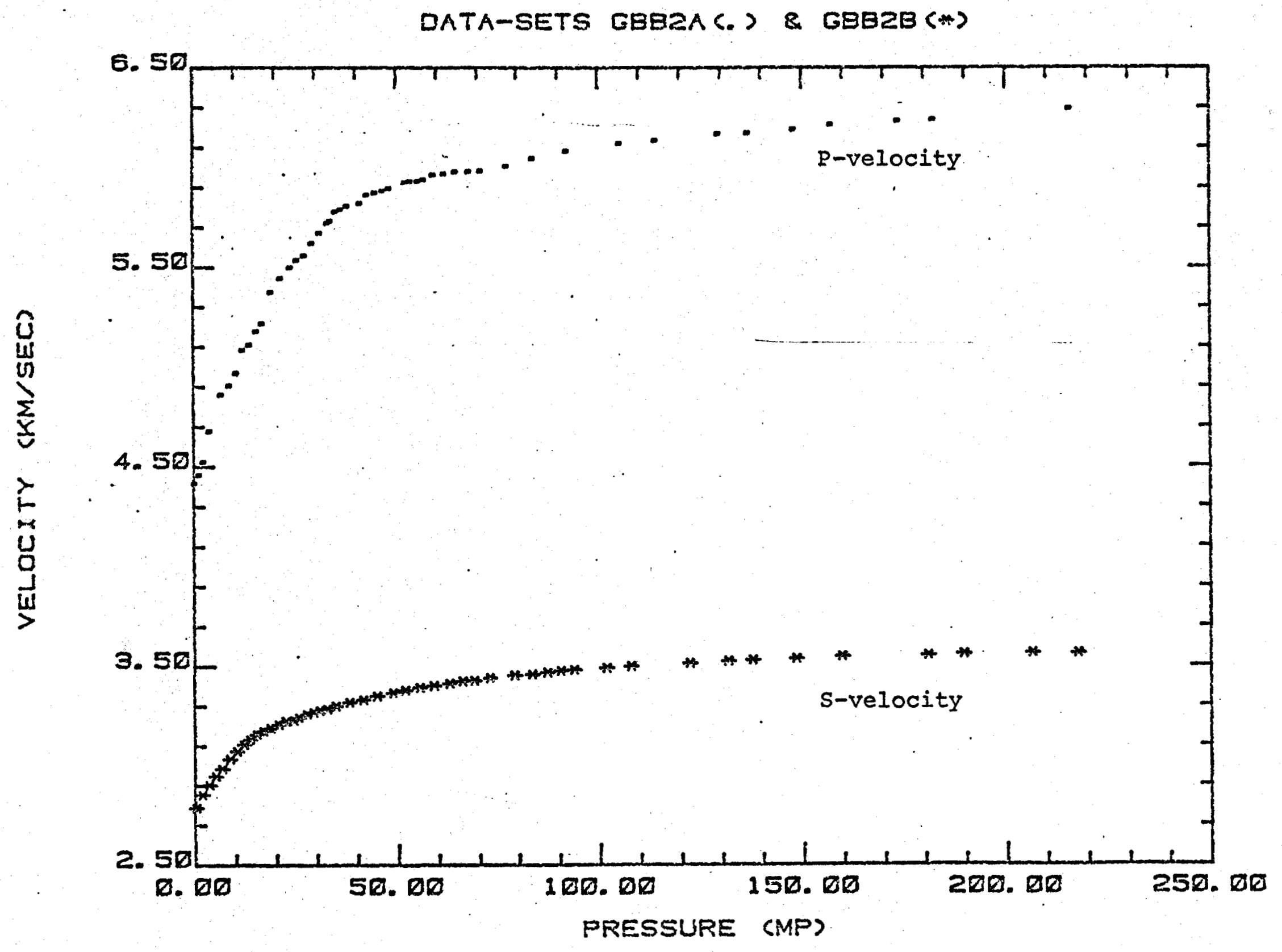




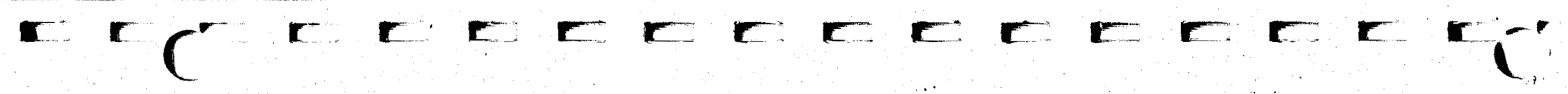

ELBERTON GRANITE INTERMEDIATE DIRECTION

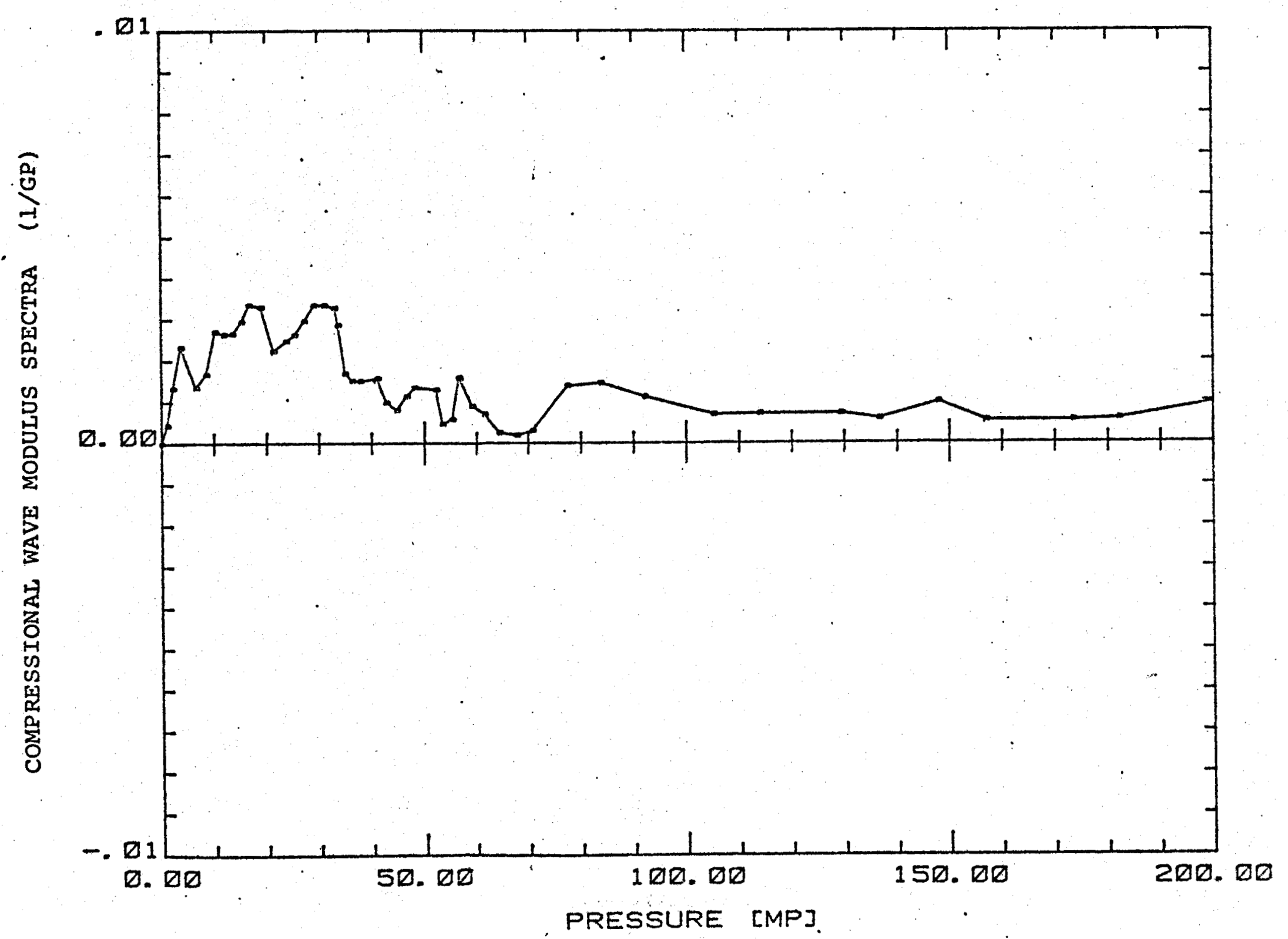


A measured compressional velocity with increasing pressure

B interpolated velocity with pressure

$\underset{\mathrm{MP}}{\operatorname{pressure}} \begin{gathered}\text { velocity } \\ \mathrm{km} / \mathrm{sec}\end{gathered}$

MP

0.0000

1.2024

2.40413

3.9352

5.3655

6.0121

6.7272

8.0609

9.9472

11.150

12.461

13.773

14.635

15.413

16.834

10.473

20.332

21.971

23.611

25.6043

27.923

28.050

30.607

32.023

34.552

36.619

39.6010

42.412

15.801

47.90\%

52.643

61.211

72.966

b3.793

96.185

113.45

130.00

147.41

161.60

163.25

126.69

10.17

100.16

190.136

196.10

234.19
3.8060

3.9567

3.0395

4.1775

4.2564

4.3173

4.3556

4.5386

4.5992

4.6336

4.7170

4.7457

4.0092

4.8523

4.6368

4.9140

4.9743

5.0903

5.0223

5.0676

5.1200

5.1251

5.2166

5.245

5.2397

5.33551

5.3945

5.4046

5.4611

5.5013

5.5 .135

5.5363

5.7247

$5.8 \% 47$

5.13917

5.9036

6.0023

6.0417

6.0661

6.1306

6.1101

6.1164

6.19443

6.11323

6. 1446

6.2321 pressure

1.0000

2.0000

4.0000

7.0009

10.003

15.000

20.000

25.000

30.003

35.000

40.000

45.003

50.009

55.000

60.003

70.005

80.000

90.000

100.00

125.00

150.00

175.00

200.00 velocity $\mathrm{km} / \mathrm{sec}$

4.0545

4.0996

4.1623

4.3798

4.6008

4.03364

4.9475

5. 0.130

5.1576

5. 2982

5.3230

5.4436

5. 5327

5.5587

5.5917

5.6581

5. 7772

5.8501

5.9213

5.9916

6.01374

6.1381

.0 .0037 


\section{ELBERTON GRANITE RIFT DIRECTION}

A measured shear velocity with increasing pressure

B . interpolated velocity with pressure

A

$\underset{M P}{\operatorname{pressure}}$

velocitý
$\mathrm{km} / \mathrm{sec}$

2. 6429

2.70213

2.7037

2.7737

2.7361

2.7967

2.7993

$2 . B 411$

2.8553

2. B783

2.8302

2.9255

2.9458

2.9643

2.0993

3.0133

3.0397

3.0608

$3.07 \% 6$

$3.0 \% 30$

3.0981

3.1209

3.1307

3.1548

3.1558

3.1813

3.1946

3.2071

3.2307

3.2461

3.2623

3.2755

3.2546

3.3019

3.9192

3.3319

3.3493

3.3678

3.3780

3.3910

3.4033

3.4207

3.4330

3. A.163

3.4567

3.4775

3.4673

3.4999
B

$\begin{array}{cc}\text { pressure } & \text { velocity } \\ \mathrm{MP} & \mathrm{km} / \mathrm{sec}\end{array}$

1.0000
2.0000
4.0009
7.0000
10.000
15.009
20.000
25.000
30.000
35.000
40.009
45.009
50.000
55.000
60.005
70.000
80.000
90.000
109.00
125.00
150.00
175.00
200.00

2.6782

2.7135

2.7151

2.7639

2.0478

2.9234

2.9341

3.0599

3.1056

3. $14 \% 6$

3.1795

3.2146

3.2413

3.2642

3.2319

3.3191

3.3400

3.3693

3.34357

3. 4224

3.4510

3. 41351

3.5034 


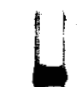

C

\section{ELBERTON GRANITE RIFT DIRECTION DYNAMIC MODULI}

SAMPLE: NGBE3:

DENSITY: 2.627 (GM/CC)

PRESSURE \& MODULI ARE IN ' MP':
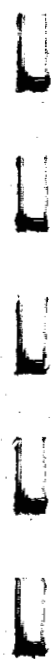

1
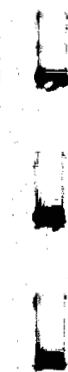

5

$$
\text { BULK SREAR }
$$

PRESS MODULUS MOUULUS: B

1.00

2.00

4.00

7.00

10.00

15.00

20.00

25.00

30.00

35.00

40.00

45.00

50.09

55.00

60.00

70.00

80.00

90.00

100.0

125.0

150.0

175.0

200.0

18.051

18.360

20.140

23.149

27.200

31.410

33.112

34.014

36.090

39.150

40.995

41.649

43.615

43.851

44.411

45.514

48.604

50.142

5.1 .956

53.231

54.357

56.432

71.569

18.642

19.342

19.365

20.432

21.304

22.527

23.394

24.506

25.336

25.944

26.556

27.14 .6

27.599

27.990

23.295

23.940

29.305 .

29.822

30.113

30.769

31.206

31.907

32.243
YOUNG'S

MODULUS'

$41.9: 2$

42.947

43.995

47.363

$50.68 \%$

54.543

56.004

59.457

61.598

63.750

65.522

66.904

63.375

69.239

70.015

71.636

73.204

74.664

75.712

77.407

78.749

B0. 542

B. 100
POISSON

RATIO

.1130

.1102

.1359

.1590

.1094

.2106

.2141

.2087

.2156

.2286

.2336

.2323

.2337

.2368

.2373

.2377

.2190

.2518

.2371

.2579

.2505

.2621

.3041 


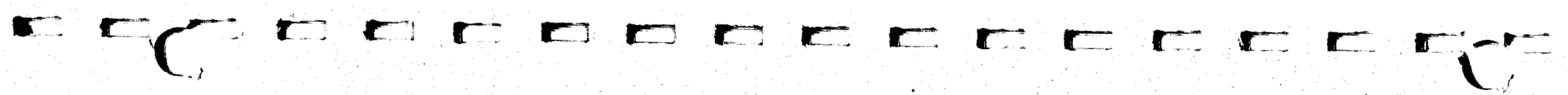

ELBERTON GRANITE RIFT DIRECTION VELOCITY PROFILES

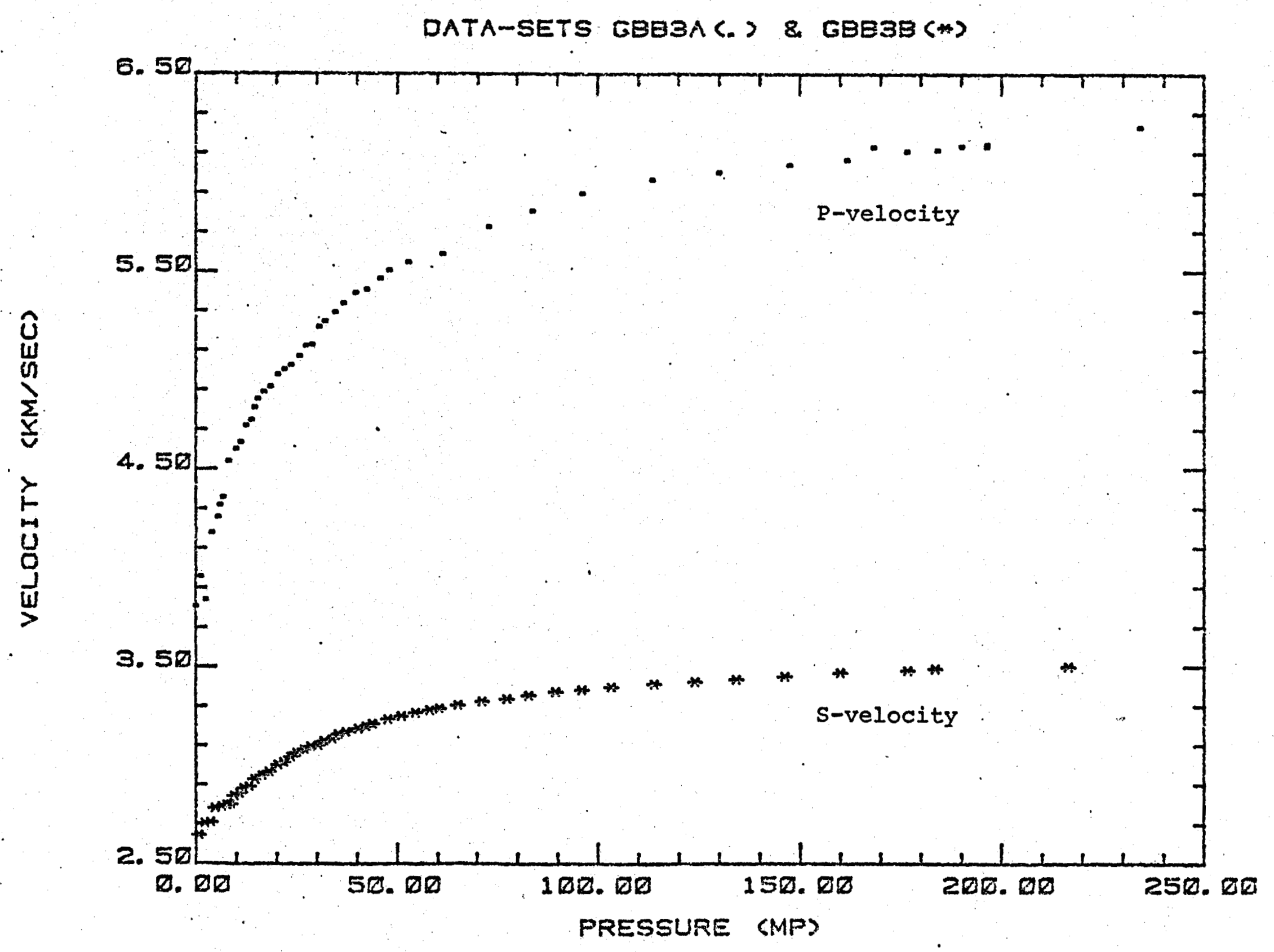


$-c$

ELBERTON GRANITE RIFT DIRECTION

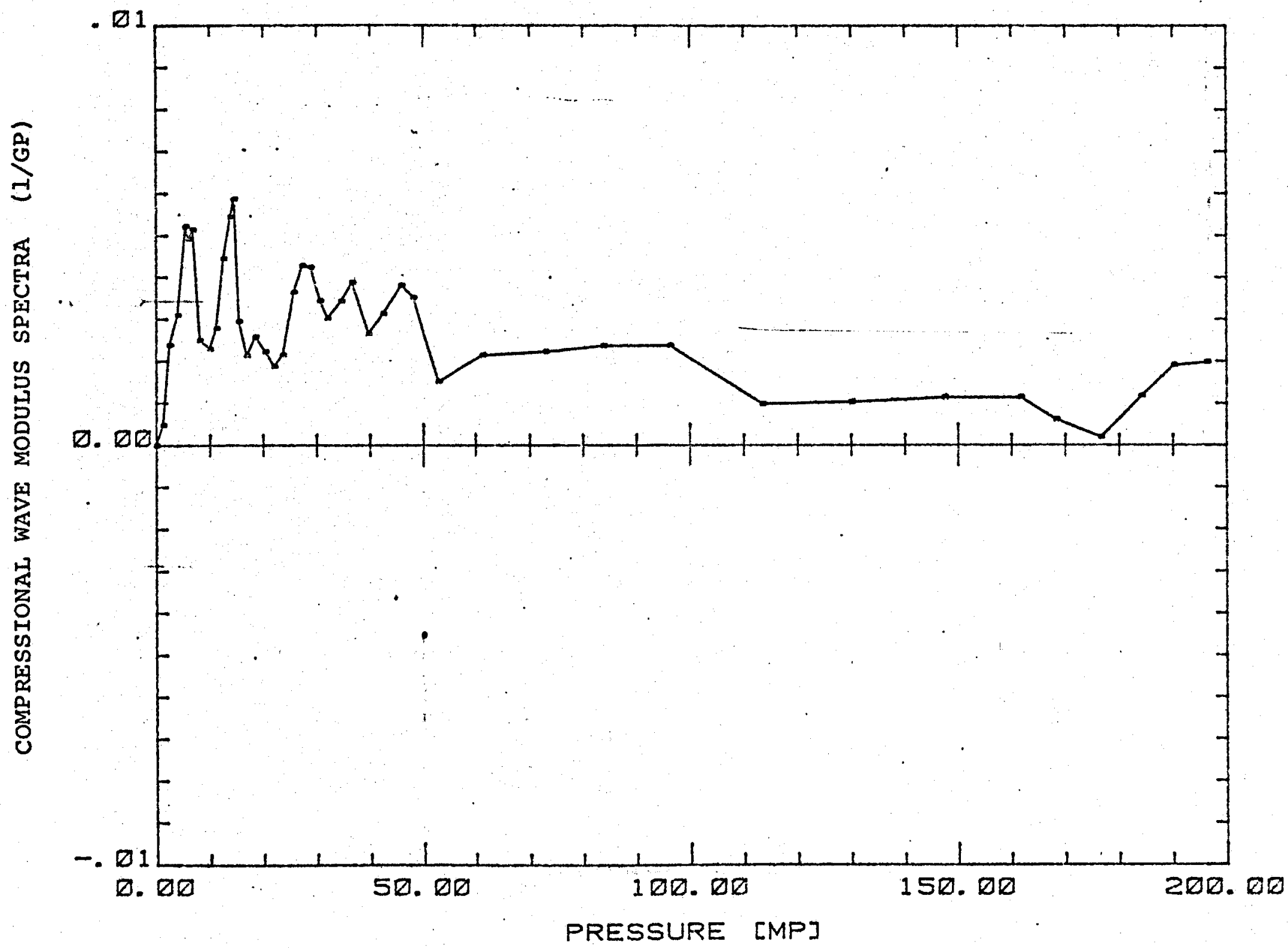




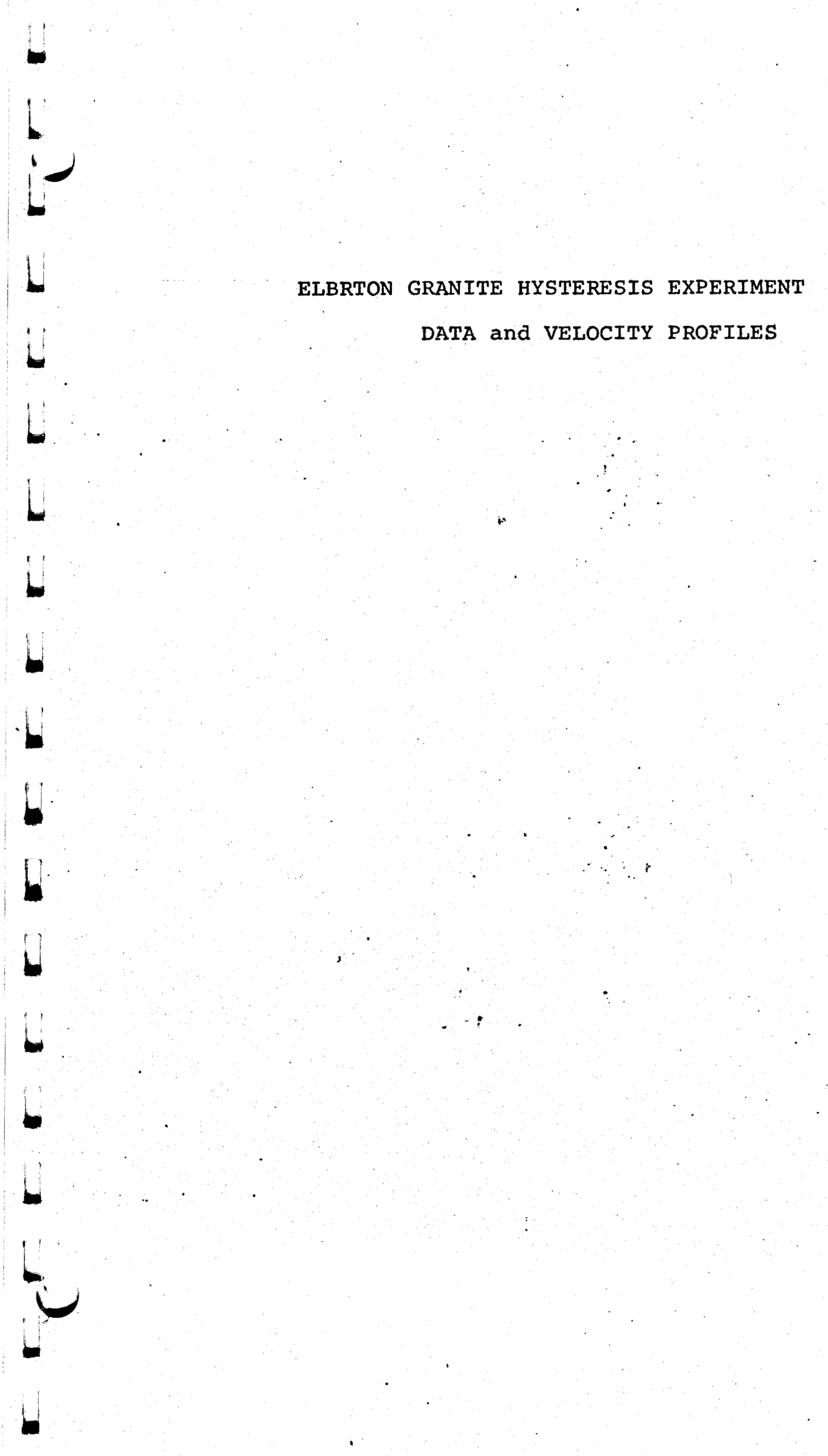




\section{ELBERTON GRANITE RIFT DIRECTION}

\section{HYSTERESIS EXPERIMENT COMPRESSIONAL VELOCITY DATA}

\begin{tabular}{|c|c|}
\hline UP-RUN & DATA \\
\hline $\begin{array}{l}\text { ressure } \\
\text { MP }\end{array}$ & $\begin{array}{r}\text { veloci } \\
\mathrm{km} / \mathrm{se}\end{array}$ \\
\hline $\begin{array}{r}-1.2024 \\
0.0000 \\
0.0000 \\
1.6397 \\
5.9020 \\
7.0703 \\
8.4169 \\
9.7286 \\
10.4938 \\
11.1497 \\
11.5869 \\
12.4614 \\
13.1172 \\
14.2103 \\
15.0840 \\
16.2872 \\
17.3803 \\
18.0014 \\
20.7690 \\
22.84 .59 \\
24.3762 \\
26.9159 \\
28.2021 \\
30.3643 \\
32.2024 \\
34.5421 \\
36.9469 \\
39.2424 \\
42.7403 \\
45.5824 \\
40.5338 \\
51.0479 \\
55.5297 \\
59.1369 \\
63.5093 \\
67.0072 \\
71.8615 \\
72.7531\end{array}$ & $\begin{array}{l}3.539 \\
3.517 \\
3.594 \\
3.725 \\
3.983 \\
4.139 \\
4.210 \\
4.224 \\
4.292 \\
4.314 \\
4.321 \\
4.359 \\
4.372 \\
4.424 \\
4.465 \\
4.497 \\
4.565 \\
4.577 \\
4.662 \\
4.736 \\
4.750 \\
4.024 \\
4.851 \\
4.902 \\
4.960 \\
5.013 \\
5.073 \\
5.090 \\
5.148 \\
5.189 \\
5.222 \\
5.242 \\
5.301 \\
5.360 \\
5.391 \\
5.446 \\
5.491 \\
5.506\end{array}$ \\
\hline
\end{tabular}

\section{DOWN-RUN DATA}

$\begin{array}{cc}\text { pressure } & \text { velocity } \\ \mathrm{MP} & \mathrm{km} / \mathrm{sec}\end{array}$

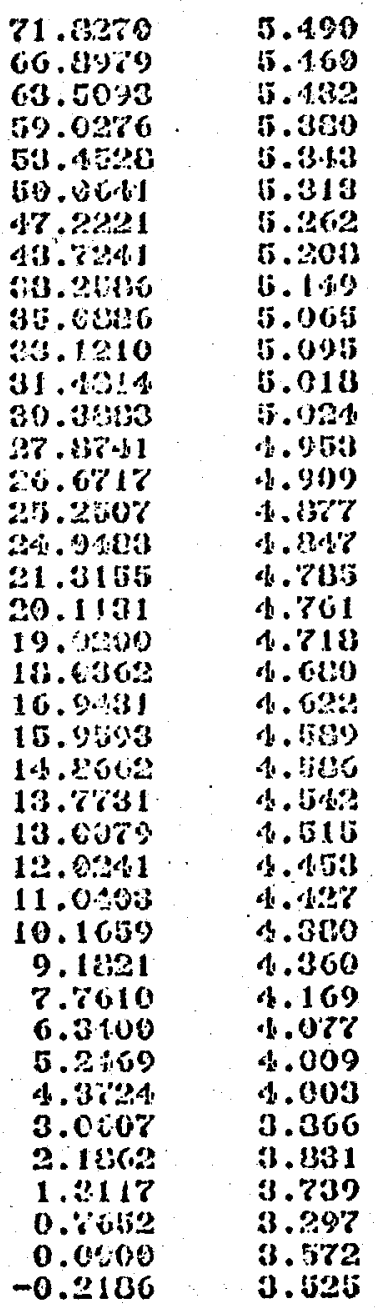




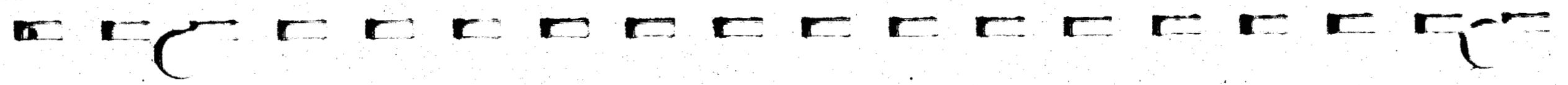

ELB. GRANITE-BB3 UP (. ) \& DOWN (*)

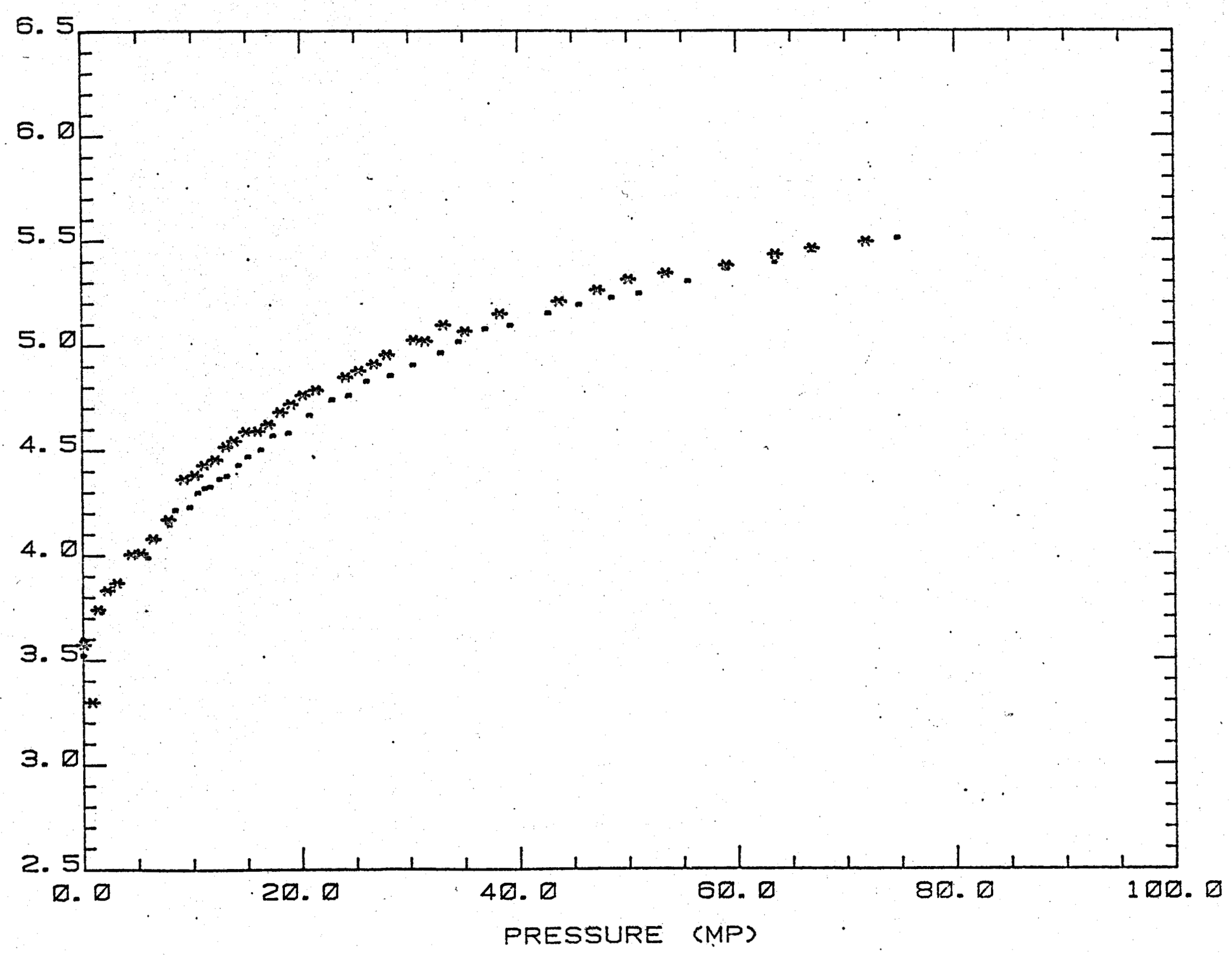



APPENDIX B

UNIAXIAL AND DIFFERENTIAL STRESS

LOADING CURVES AND STATIC MODULI

Exemplar Borehole

Pressurization Curve 



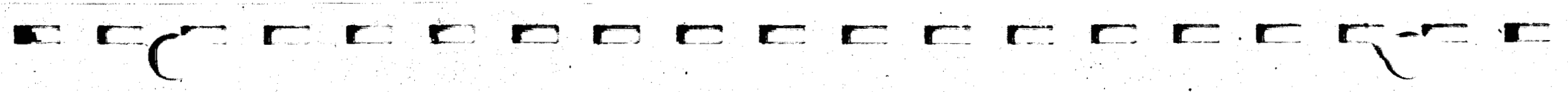

ELBERTON GRANITE, GA: TRIAXIAL EXP. STRAINS VS UNIAXIAL STRESS
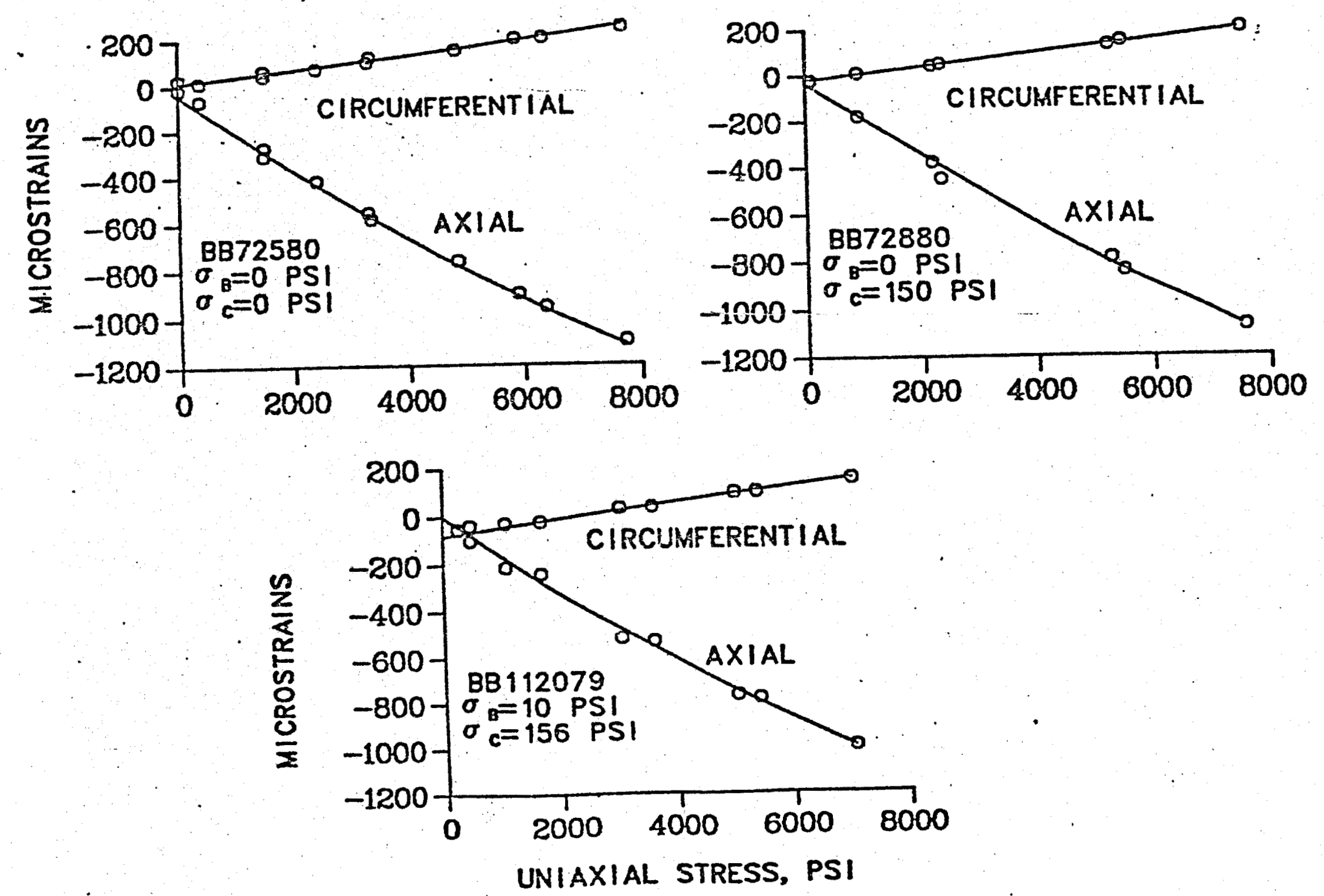



\section{$\sigma r$}

ELBERTON GRANITE, GA: TRIAXIAL

STATIC MODULI FROM COEFFICIENTS TO AXIAL STRESS
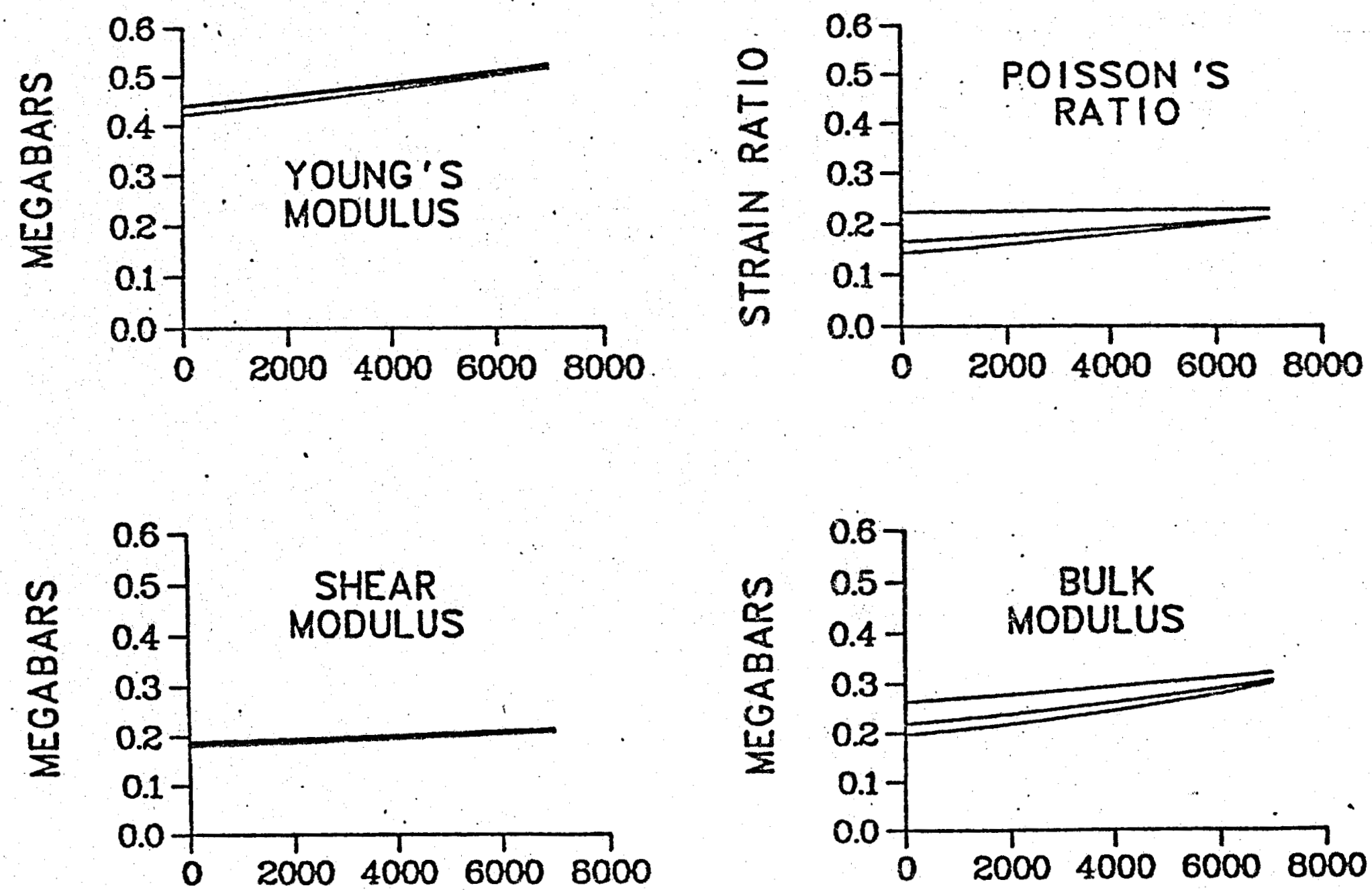

PRESSURE, PSI 


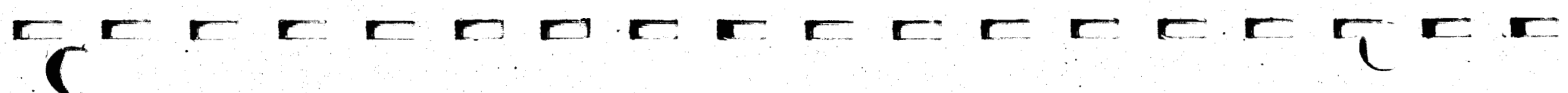

ELBERTON GRANITE, GA: TRIAXIAL EXP. BB 112079 STATIC MODULI FROM COEFFICIENTS TO CONFINING PRESSURE
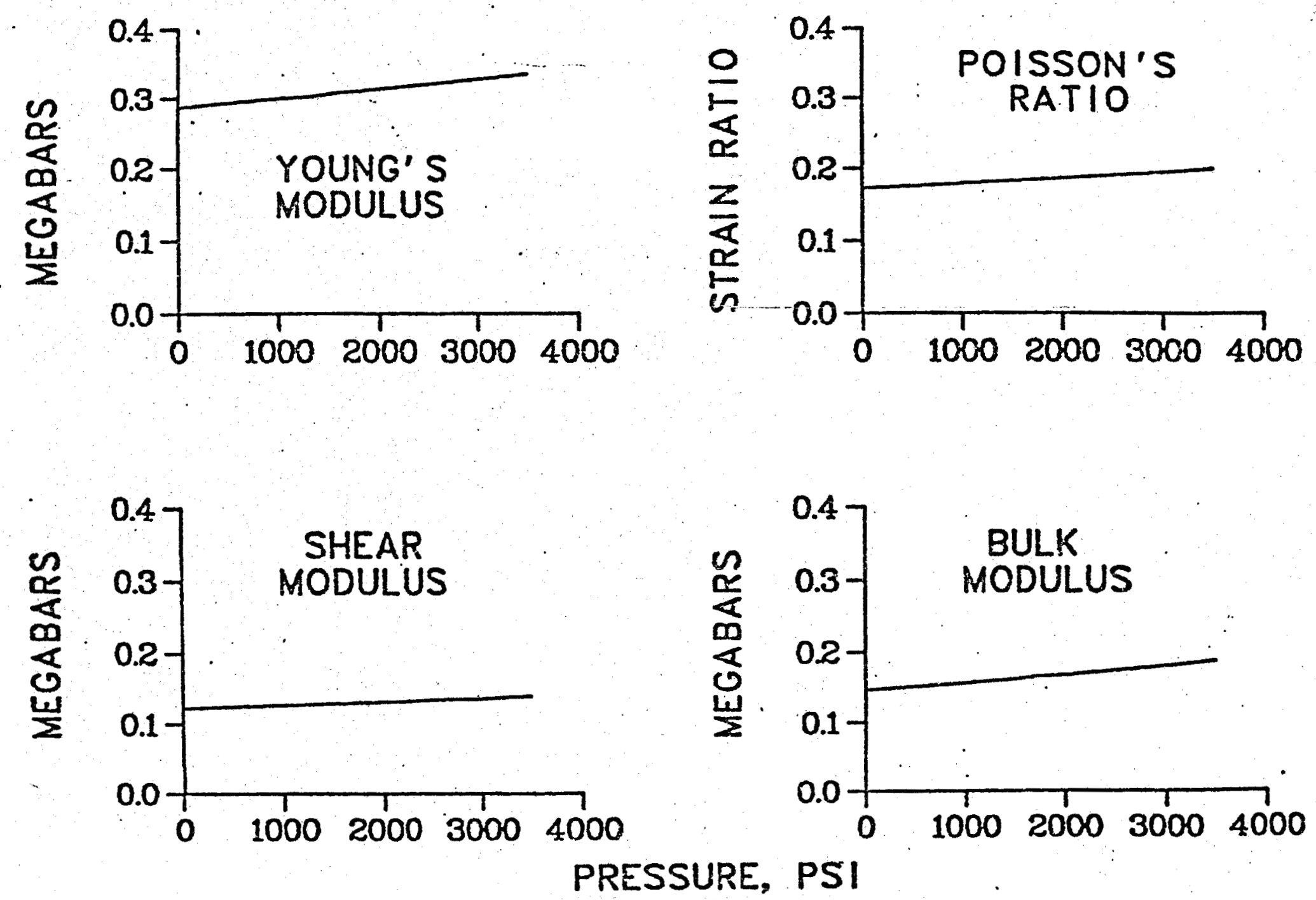

PRESSURE, PSI 


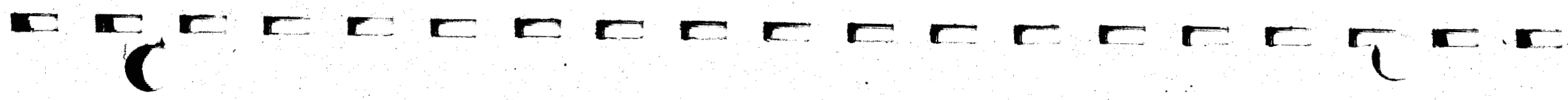

ELBERTON GRANITE, GA: HYDROSTATIC VELOCITY EXP. DYYAMIC MODULI FROM VELOCITY DATA
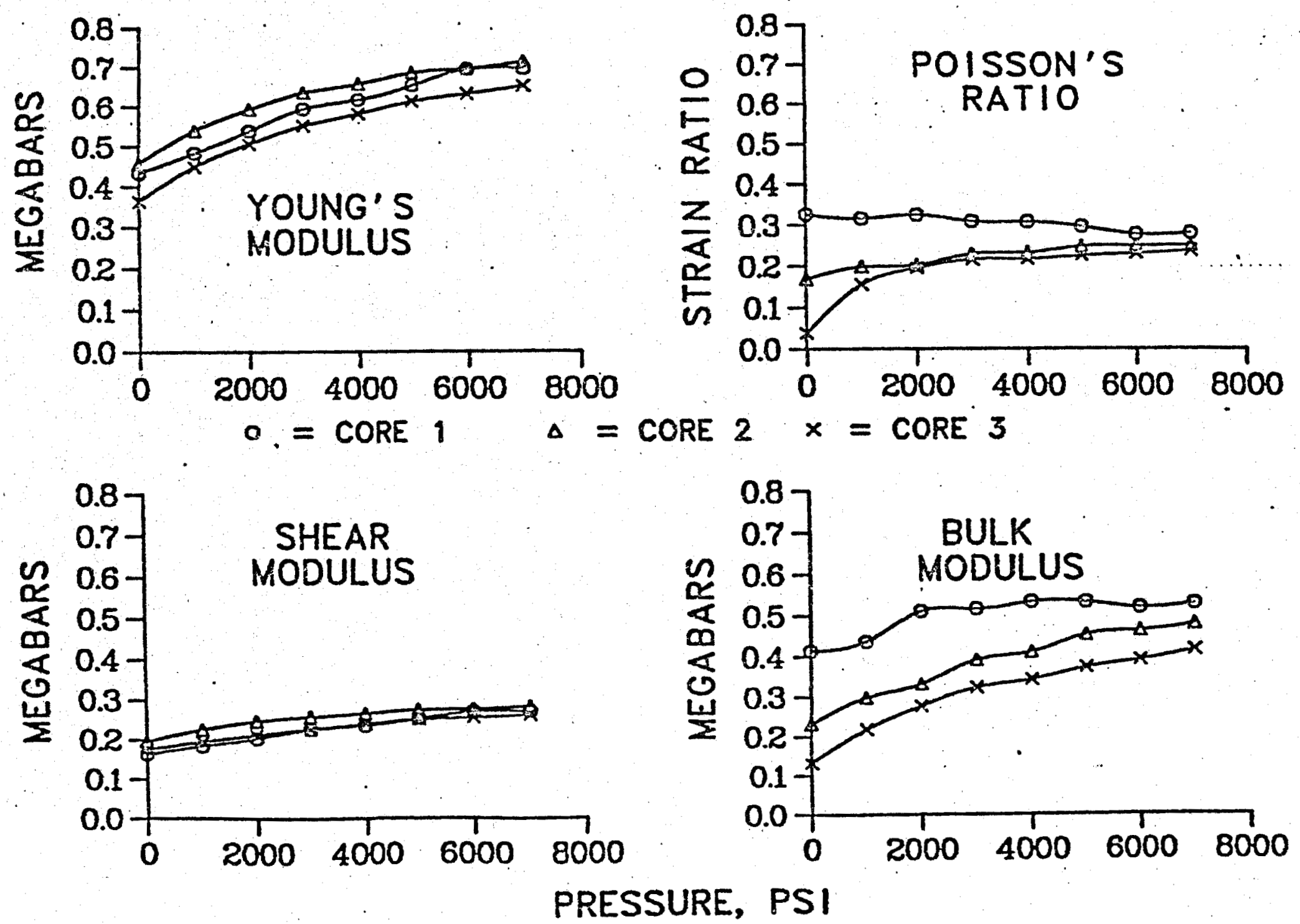


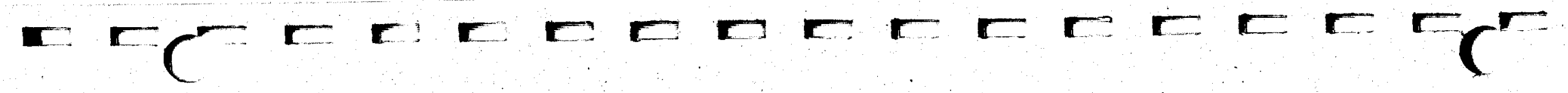

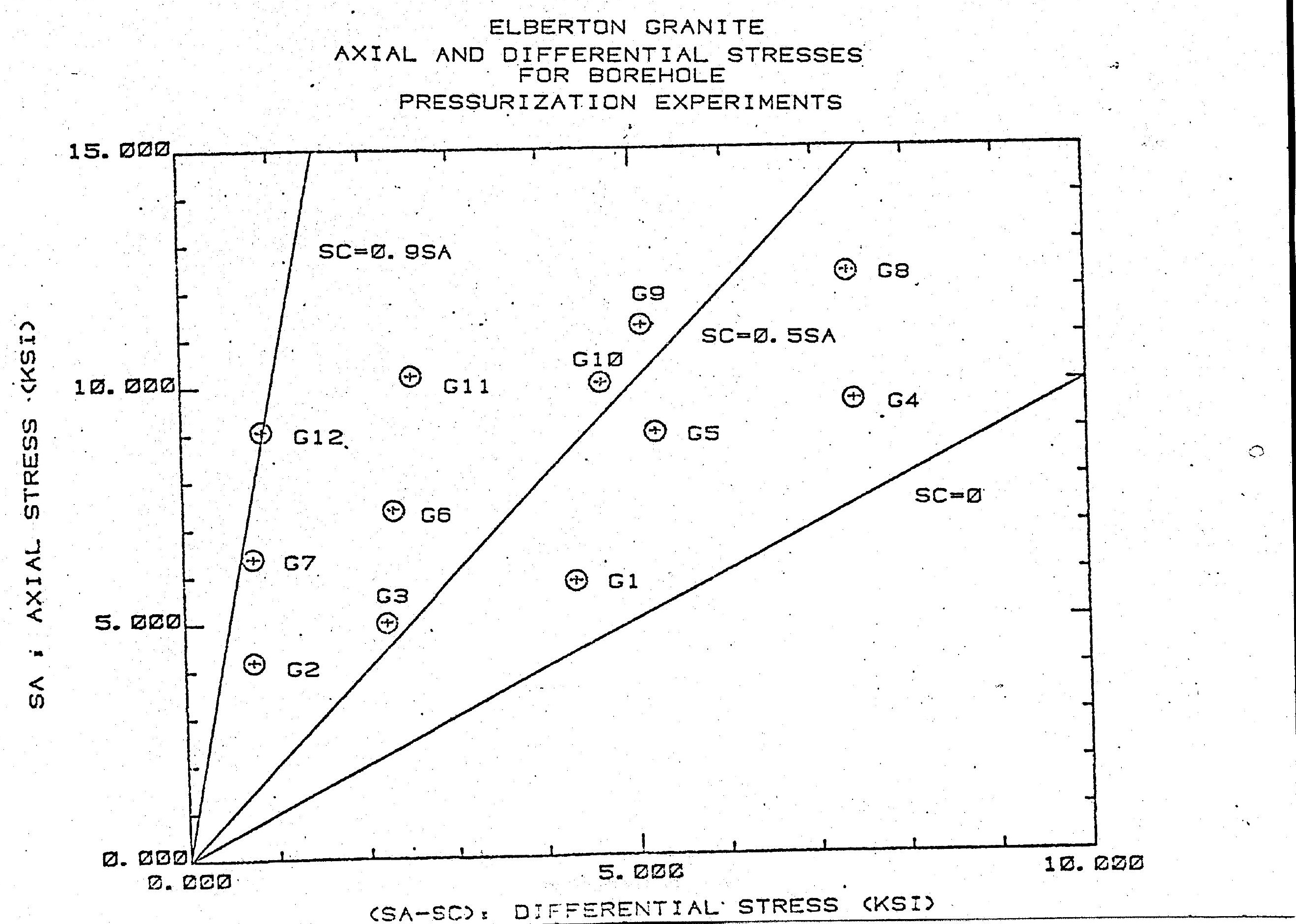




\section{FCr r r r}

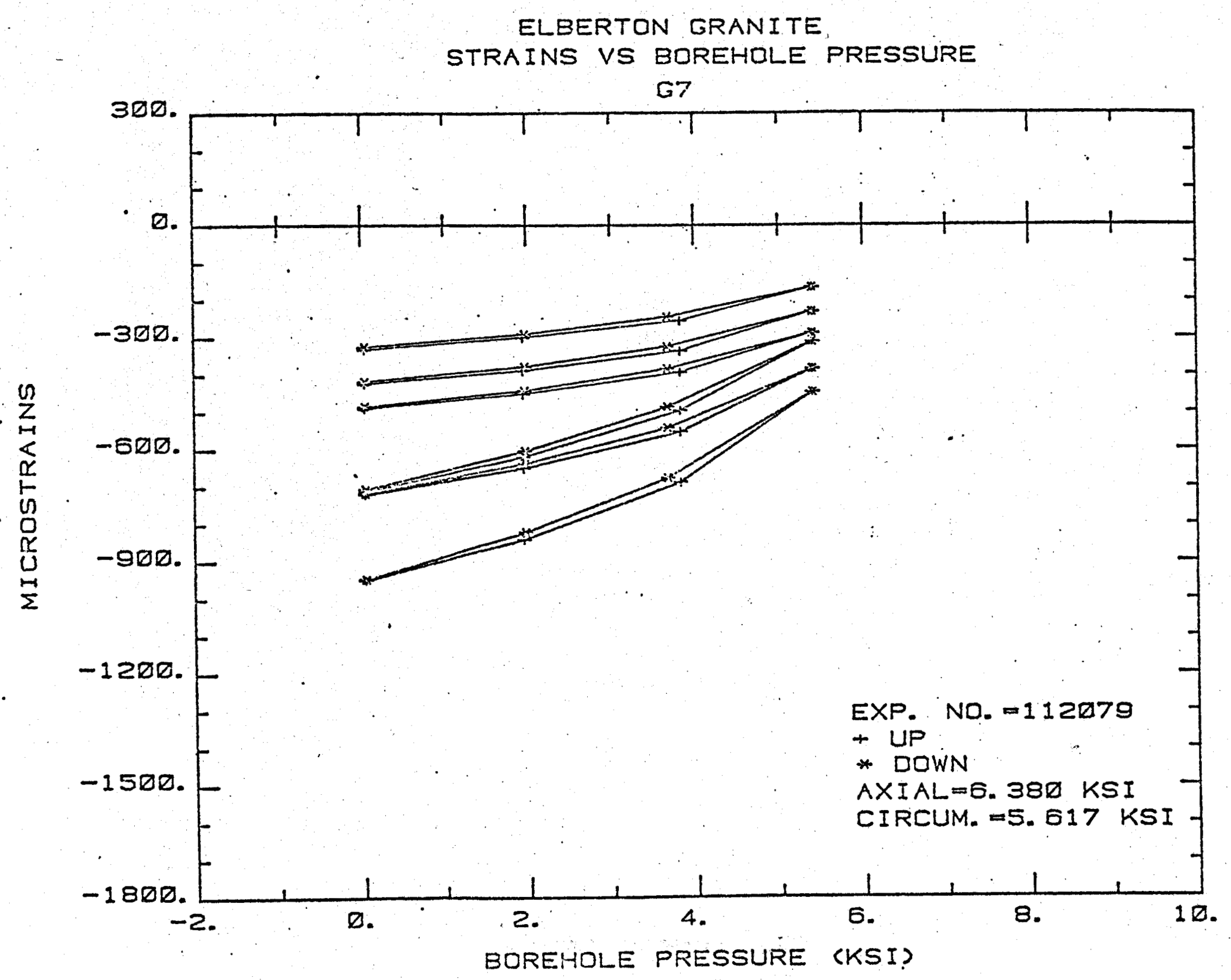


TABLE : Elberton Granite

BOREHOLE PRESSURATION EXPERIMENTS

strains with variation of borehole pressure at fixed axial and confining stresses

subtable A

STRESSES

\begin{tabular}{lllll}
$\begin{array}{l}\text { Group } \\
\#\end{array}$ & $\begin{array}{l}\text { diff. } \\
\text { stress } \\
\text { (psi) }\end{array}$ & $\begin{array}{l}\text { axial } \\
\text { stress } \\
\text { (psi) }\end{array}$ & $\begin{array}{l}\text { confin. } \\
\text { stress } \\
\text { (psi) }\end{array}$ & $\begin{array}{l}\text { max. bore- } \\
\text { hole stress } \\
\text { (psi) }\end{array}$ \\
\hline G2 & 750 & $\frac{4195}{3445}$ & $\frac{3480}{345}$ & 5249 \\
G7 & 763 & 6380 & 5617 & 524 \\
G12 & 882 & 9065 & 8183 & 7757 \\
G3 & 2219 & 5016 & 2797 & 3103 \\
G6 & 2310 & 7396 & 5086 & 5002 \\
G11 & 2539 & 10209 & 7670 & 7757 \\
G1 & 4345 & 5835 & 1490 & 1493 \\
G5 & 5236 & 8978 & 3742 & 3407 \\
G10 & 4653 & 10028 & 5375 & 6104 \\
G9 & 5100 & 11239 & 6139 & 5905 \\
G4 & 7435 & 9626 & 2191 & 2291 \\
G8 & 7378 & 12338 & 4960 & 4956 \\
\hline
\end{tabular}

subtable B

$$
\begin{gathered}
\epsilon \times 10^{-6}=a+\left(b \times 10^{3}\right) \sigma_{b}+\left(c \times 10^{5}\right) \sigma_{b}^{2} \\
\sigma_{b}=\text { boreliole prossore }
\end{gathered}
$$

Group circumferential

Group
G2
G7
G32
G6
G11
G1
G5
G10
G9
G4
G8

$6 \overline{14.46}$

789.446

1020.57

502.077

688.493

912.868

207.728

438.76

714.547

656.671

221.992

470.398

3.7365

\begin{tabular}{cc|}
$\mathrm{b}$ & $\mathrm{c}$ \\
\hline 4.019 & 1.4218 \\
2.604 & 0.9232 \\
1.991 & 0.5147 \\
4.4412 & 1.6716 \\
3.3810 & 0.8484 \\
3.3721 & 0.3134 \\
7.2571 & 2.6818 \\
4.0507 & 1.2853 \\
2.7240 & 0.6957 \\
1.9242 & 0.8757 \\
7.6956 & 0.6361 \\
3.7365 & 0.8807
\end{tabular}

$a$
345.251
410.685
553.379
509.781
622.190
765.712
754.453
971.489
935.953
1049.00
1142.56
1230.39

b

1.1438

0.5097

0.3476

1.5455

0.9375

0.4681

1.0049

0.7880

0.5835

0.5753

0.7950

0.6598

$c$
0.5006
0.5258
0.2679
0.0617
0.1658
0.0859
0.1567
-0.0243
0.0495
0.0627
0.1203
-0.0374




\section{FIGURE CAPTIONS}

Fig. 1: Mean strain derivatives for Berkeley Blue granite. The ordinate is the mean slope of the axial and circumferential rock strains as functions of borehole pressure. The abcissa is the deviatoric stress (axiai-confining).

Fig. 2: Circumferential strain derivatives for Berkeley Blue granite. Fig. 3: Axial strain derivatives for Berkeley Blue granite.

Fig. 4: Mean strain derivatives for Barre Granite sample \#2.

Fig. 5: Circumferential strain derivatives for Barre Granite sample \#2.

Fig. 6: Axial strain derivatives for Barre Granite sample \#2.

Fig. 7: Mean strain derivatives for Barre Granite sample \#l. 



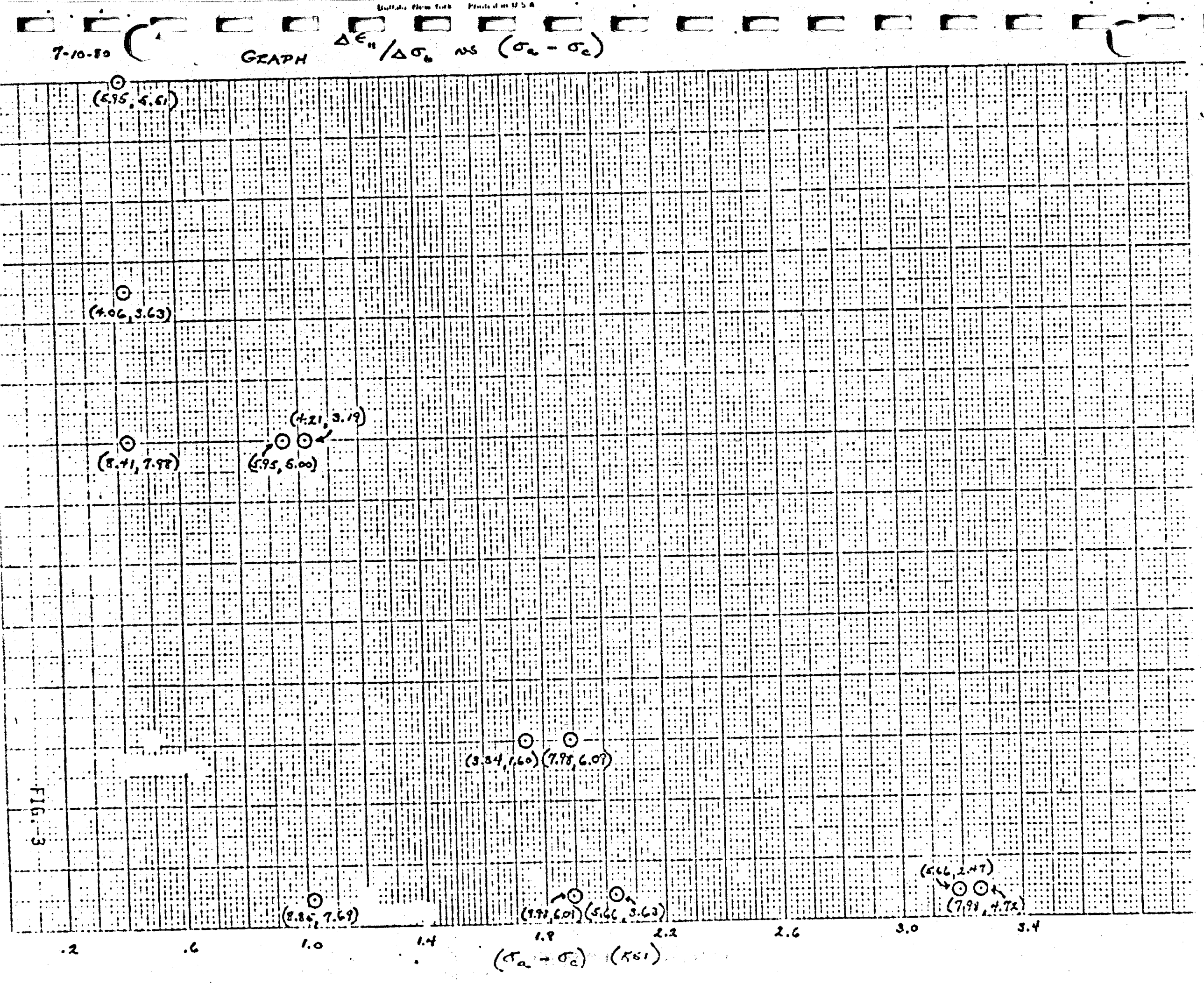




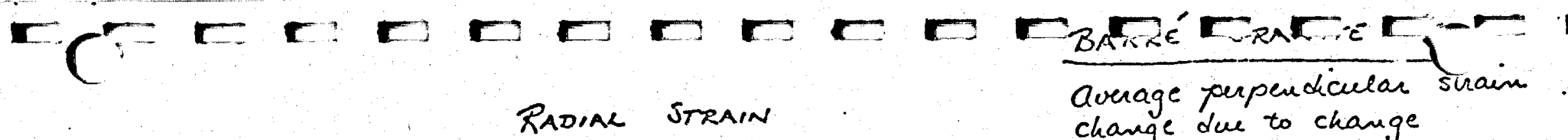
change due to change of boukole pressure at fixed axial and confine pressures

DATA, JUNE, JULY

POINTS DENOTED BY $\left(\sigma_{a}, \sigma_{c}\right)$ KS

$\overrightarrow{5}$
cr

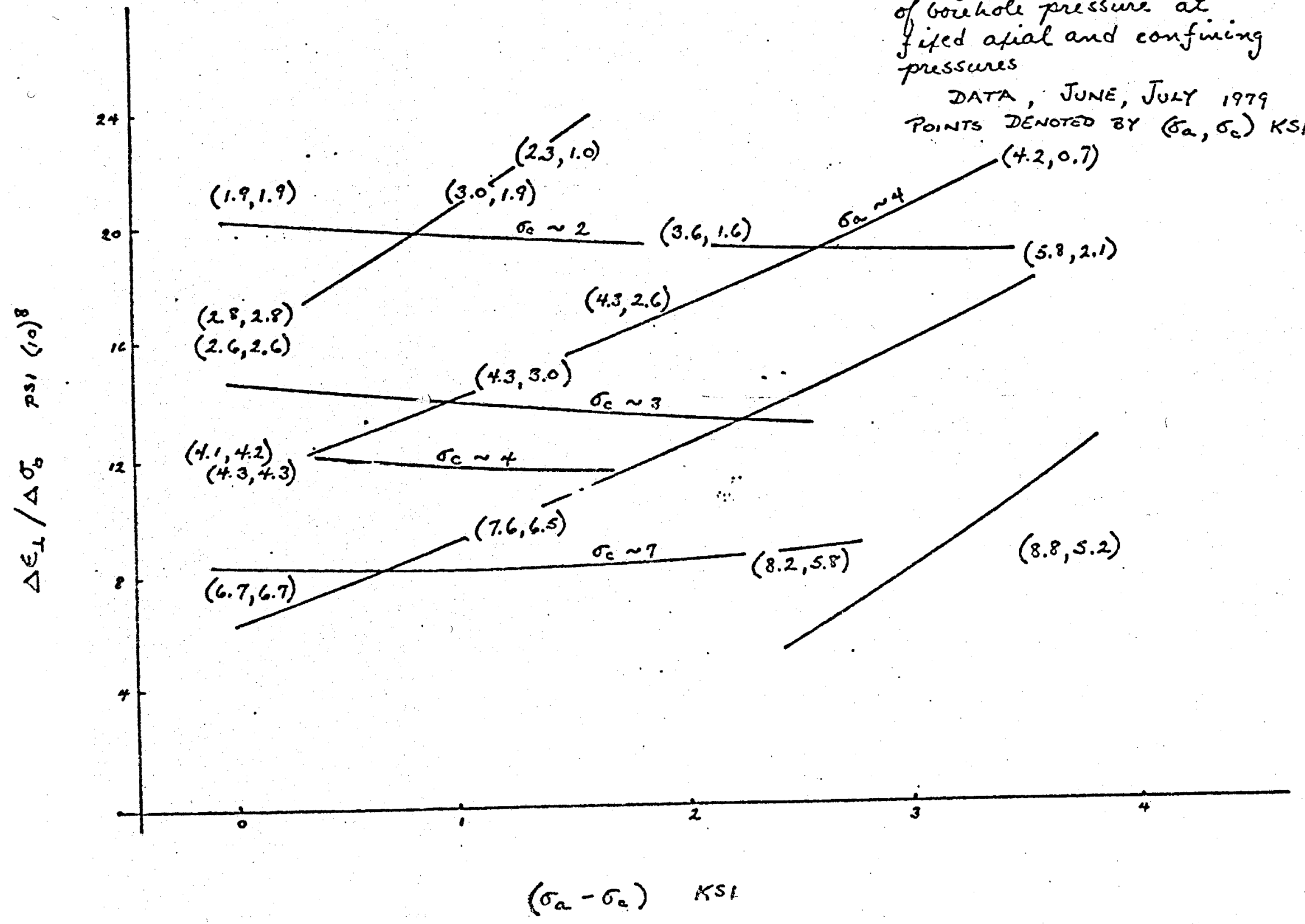




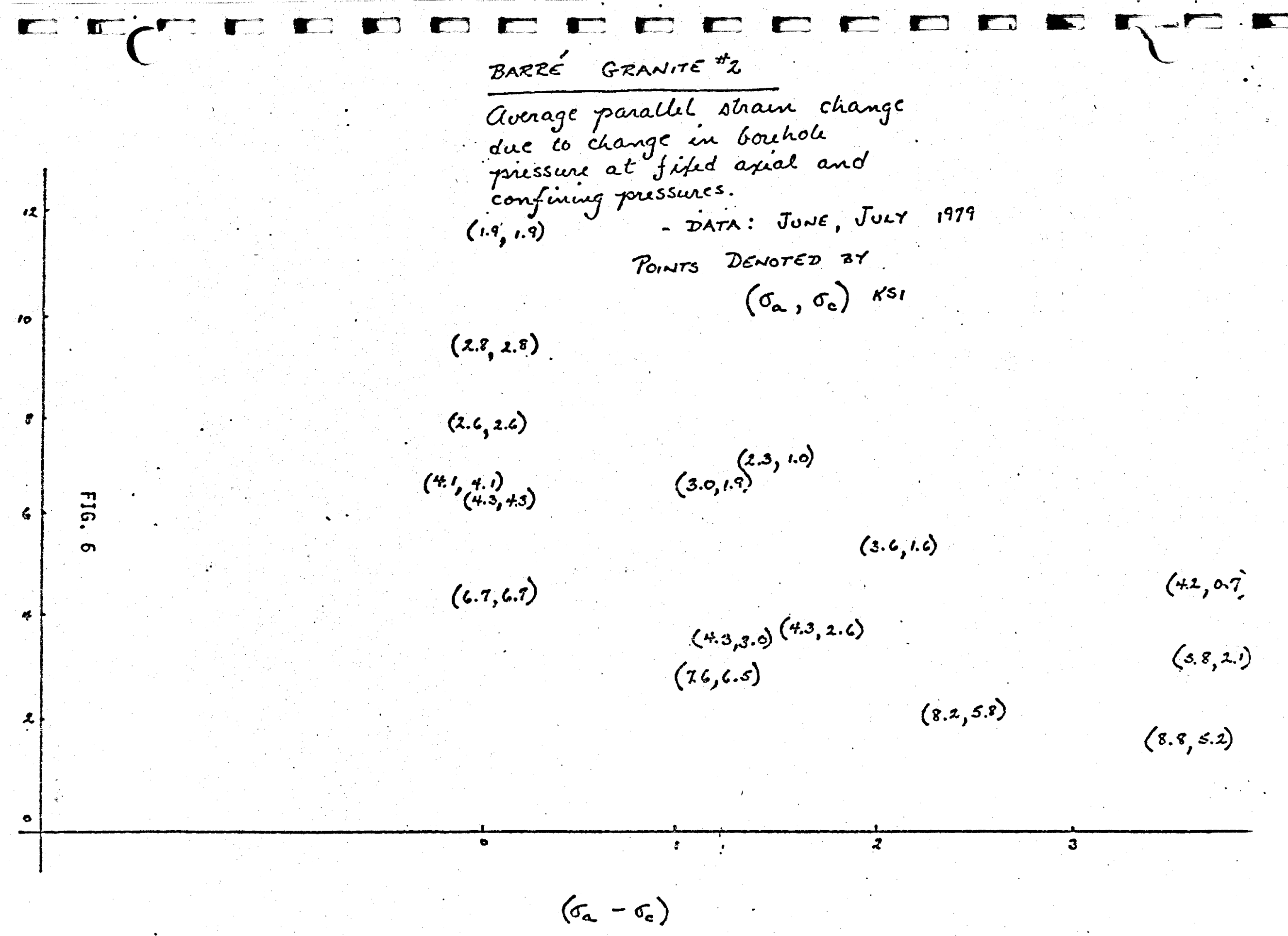




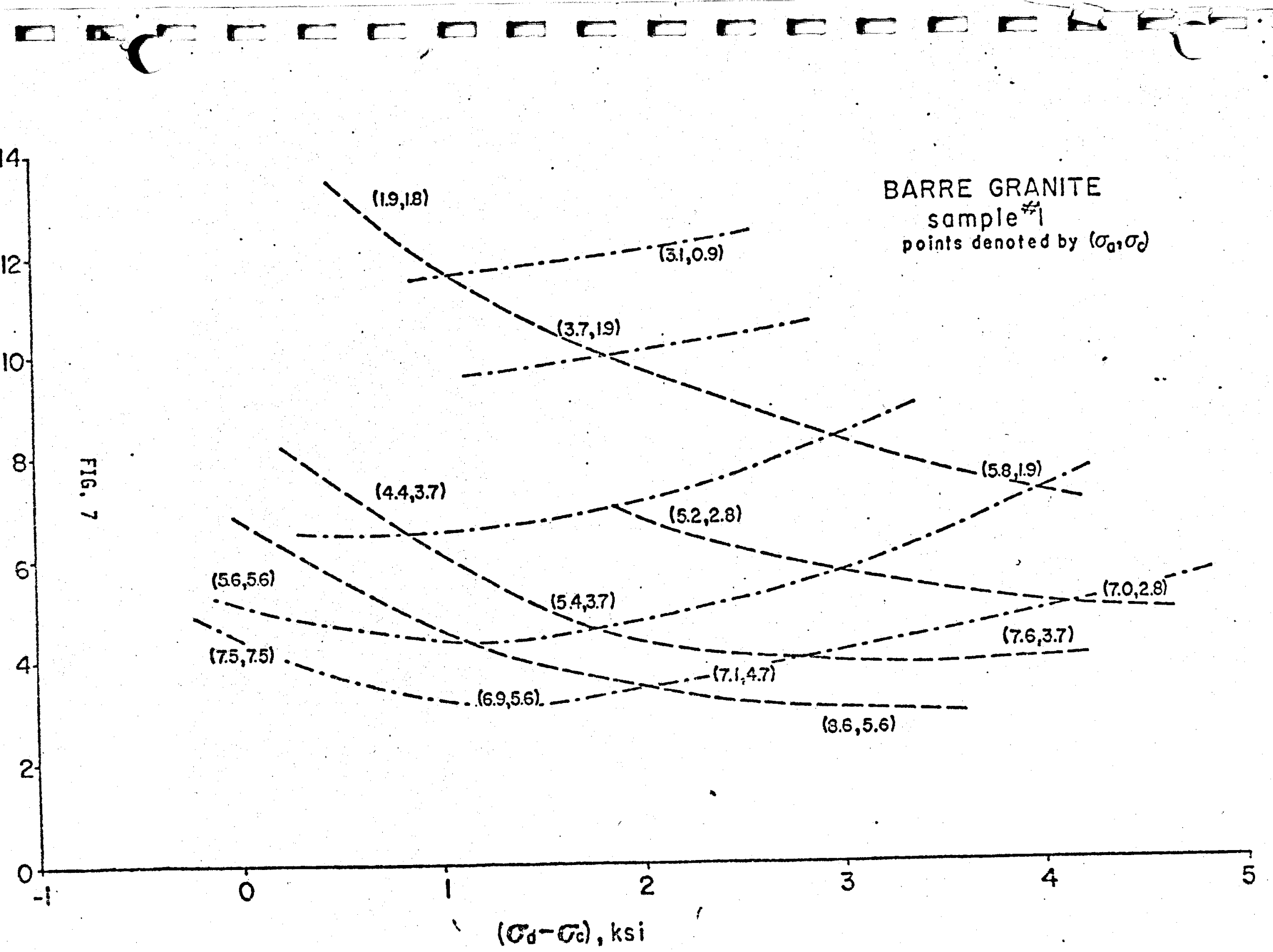


DETERMINATION OF CRACK POROSITY
FROM RATIOS OF STATIC AND DYNAMIC BULK MODULI

by

Nick Warren

Mike Tieman

and Nick Coffey

University of California, Los Angeles

Los Angeles, California 90024

\begin{abstract}
There appear to be serious inconsistencies with estimating porosities from static and dynamic strain measurements. Building on the work of Cheng and Johnston (1981), ratios of static to dynamic bulk moduli $\left(K_{s} / K_{d}\right)$ were compiled for a number of different igneous rocks. Porosity estimates were compiled separately. There appear to be systematic trends in $\mathrm{K}_{\mathrm{s}} / \mathrm{K}_{\mathrm{d}}$, but these cannot be directly correlated to, or used to predict crack porosities. We find that estimated porosity seems to be directly proportional to the strain amplitude sensitivity of the experiment.
\end{abstract}

\title{
INTRODUCTION
}

Rock stress-strain relations are directly effected by microstructural flaws. Therefore, in theory, the relations are a direct measure of volume average microstructure. As such, there are various schemes for inverting them into characterizations of the microstructure (Cheng and Johnston; 1981; Simmons et al., 1974; Warren, 1977; Budlansky and 
O'Connel1, 1976; Brace, 1965, Henyey and Pomphrey, 1982). As a first step the stress-strain relations themselves may be determined by static (e.g. strain gauge) or dynamic (velocity or resonance) techniques. Consequently, either, or a combination of both, may serve as a datum for an inversion scheme. It is difficult to test the comparative accuracy of the various methods since often the original datum cannot be directly compared. This difficulty arises since different types of experiments may be sensitive to different levels of strain effects (e.g. strain directly versus strain derivative) and/or because the range of porosities for one type of rock may be quite large as measured from sample to sample: In addition, it is often difficult to make sufficient sets of measurements, therefore, the computed porosities may be affected also by the uncertainties introduced by pore anisotropy in the samples.

In spite of these difficulties such a comparison needs to be made, for a number of physical properties depend quite sensitively on porosity and so it is important to study the precision to which stress-strain measurements yield porosity.

Here in this brief paper we focus on two questions. First, are there global or at least fairly general systematics of porosities determined by different experimental techniques? Second, do a combination of experimental techniques yield a best estimate or truest measure of crack porosity?

Our study started by our considering the empirical work of Cheng and Johnston (1981). They show that the ratio of static to dynamic bulk moduli $\left(\mathrm{K}_{\mathrm{s}} / \mathrm{K}_{\mathrm{d}}\right)$ appears to be directly 
proportional to crack porosity. We sought to see if their systematics could be extended. If they could, the significance would be two-fold. First, if a general empirical relation exists, then even though the spread in real data may be larger than one would like, this would nonetheless give a tool similar to that of the generalized velocity-density relation (Birch, 1961a, 1961b). Second, if an extrapolative trend could not be determined, then at least it might be possible to bound the expectation of porosity by one or more measurements.

Consider dry rocks: are the systematics in $\mathrm{K}_{\mathrm{s}} / \mathrm{K}_{\mathrm{d}}$ sufficient to sort rocks into classes of microstructure? Is the relation of this ratio to crack porosity sound and quantifiable?. To answer these questions, two steps are required. The first step is to test the uncertainties within $\mathrm{K}_{\mathrm{s}}-\mathrm{K}_{\mathrm{d}}$ ratios themselves. Do they show a reliability independent of experimental technique? To look at this, we have compiled $\mathrm{K}_{\mathrm{s}}-\mathrm{K}_{\mathrm{d}}$ ratios where the moduli have been determined from three types of experiments: 'classical' static strain measurements, in which strains are determined to a sensitivity of $10^{-4}$ to $10^{-5}$; Differential Strain Analysis (DSA, Simmons, et al., 1974) which has a stated sensitivity of $10^{-6}$; and ultrasonic velocity measurements which have strain sensitivities of $10^{-6}$ to $10^{-9}$.

Second, an important effort was made to treat porosity independently of strain data for this analysis. This procedure was not followed by Cheng and Johnston. They backed porosity out of the same static strain data used in the determination of $\mathrm{K}_{\mathrm{s}} / \mathrm{K}_{\mathrm{d}}$. 


$$
\mathrm{K}_{\mathrm{s}} / \mathrm{k}_{\mathrm{d}} \text { SYSTEMATICS }
$$

Figure 1 pertains to the question of systematics. The figure is a plot of various $\mathrm{K}_{\mathrm{s}} / \mathrm{K}_{\mathrm{d}}$ formed from the literature and from new experimental data. References and descriptive notes are given in the Appendix. In Figures 1 . a through $1 . d$ are shown ratios from a study on the Conway granites (New Hamphire). The groupings marked I, II, III a 11 refer to sortings which were established based on velocity data alone. Groups I and II are granitic and group III consists of 2 lamprophyre dike rocks. In the figure, open symbols denote $\mathrm{K}_{\mathrm{s}} / \mathrm{K}_{\mathrm{d}}$ values at $0 \mathrm{MPa}$ to $1 \mathrm{MPa}$, and closed symbols denote ratios at $20 \mathrm{MPa}$. As explained in the appendix, the variousiy shaped symbols denote different types of strain measurements. Differentiation between the three groups is apparent in the $\mathrm{K}_{\mathrm{s}} / \mathrm{K}_{\mathrm{d}}$ given here.

Figure 1.e shows a similar plot for Westerly granite. These data are from mixed sources. Cheng and Johnston's data are numbered 2. Figure 1.f is for Elberton granite (Georgia), a fine grained granite which is similar to Westerly granite in appearance, but with a pronounced crack anisotropy. The data used in $1 . f$ are combined from several experiments, and the spread in the data is indicated by the ellipse.

The last subsets in the figure $(1 . g, 1 . h)$ are for granodiorite and monzogranite samples from Fenton Hill on the Southflank of the Valle Grande Caldera, New Mexico. Two granodiorites from one borehole (GT2) are shown in $1 . g$ and $1 . h$ shows data for samples from a second borehole (EE2). 
The data indicates that there are consistent trends. of the data included here those for the Conway granites are the most complete and precise. The original velocity data were obtained for a study on systematics, and so were taken at high. resolution. The static strain data are less precise. Group I ... and Group II samples are differentiated by grain size and by homogeneity of mineral distributions. The group III lamprophyre samples are very fine grained. In hand sample, the group II samples are more similar to Westerly granite in grain size and petrostructure than are the group $I$ samples. It is seen that there is a strong demarcation between the $\mathrm{K}_{\mathrm{s}}-\mathrm{K}_{\mathrm{d}}$ ratios for Group III and the other two groups. The first two groups are more weakly separated. However, the data are sufficient to show a lower zero pressure mean value of $\mathrm{K}_{\mathrm{s}} / \mathrm{K}_{\mathrm{d}}$ for Group $\mathrm{I}$ than for Group II ( 0.3 versus 0.5 respectively). In addition to this difference in mean value, the pressure dependence of the convergence of static to dynamic bulk modulus for Group I appears to be fundamentally different than that for Group II. At $20 \mathrm{MPa}$ the mean value of the moduli ratio for Group $I$ is 0.6 versus 0.5 for Group II, indicating a much stronger convergency of $K_{s}$ and $K_{d}$ with pressure. Indeed, in figure 1 here, this Is a more marked difference than are the absolute values of the moduli ratios themselves. (See also figure 5 in Warren and Tiernan, 1981 for a more complete plot of the dynamic and static moduli with pressure.) The outrider in figure $1 . \mathrm{b}$ (537.4) is also anomolous in both velocity at low pressure and 
in bulk density. In summary, Groups $I$ and II, which are consistently differentiated by a number of measurements, are also separated by $\mathrm{K}_{\mathrm{s}} / \mathrm{K}_{\mathrm{d}}$ values and trends.

These consistencles carry through the other less well defined sets of data. That they do is important, for it implies that the moduli ratio systematics show through mixed data from a variety of experimental sources. The data for Westerly granite ( $1 . e$ ) averages around $0.45 \pm 0.15$. Although there is a good deal of current experimental results for Elberton granite, the experiments seem to reflect both the anisotropy and variability in different blocks of the rock. As a general statement, though, Elberton, Westerly, and the Group II Conway granites are similar in hand sample (grain size and petrostructure uniformity) and all of them show similar mean values of $\mathrm{K}_{\mathrm{s}} / \mathrm{K}_{\mathrm{d}}$.

The GT2 and EE 2 samples (figures $1 . g, 1 . h$ ) are variable coarse grained except for 12850 , which is a fine grained metavolcanic. The $\mathrm{K}_{\mathrm{s}} / \mathrm{K}_{\mathrm{d}}$ values for the Fenton Hill granodiorites are consistent with petrostructural coarseness, which is on par with or a bit more than that of the Group I Conway granites.

In conclusion, it can be strongly suggested that $\mathrm{K}_{\mathrm{s}} / \mathrm{K}_{\mathrm{d}}$ is indicative of petrostructure class, but the confidence level at which these ratios directly yield porosity remains to be resolved.

\section{POROSITY VARIATION}

The $\mathrm{K}_{\mathrm{s}}-\mathrm{K}_{\mathrm{d}}$ ratios for Westerly Granite are fairly consistent. What is the porosity of Westerly granite? 
Typically, it is quoted in the literature as being about 0.0018 to 0.002 . In figure 2, however, we see a much bigger variation. In $2 . a$, point 1 is from a model calculation (Warren), which for a single crack population fits both static and dynamic moduli data. Point 2 is determined from strain data and is from Cheng and Johnston. Point 3 is from 'classical" strain measurements of Brace. Point 4 is a 'typical' value quoted from Batzle; Point 5 is based on SEM observation by Hadely, and Point 6 is from Differential Strain Analysis (DS) by Simmons.

In addition to crack porosities obtained by these various methods, even higher connected crack porosities are estimated by such techniques as gas pycnometer measurements (H. Heard, personal communication). However, these high values of porosity begin to equal the 'total' porosities estimated by bulk versus theoretical densities. Brace (1965) distinguishes this total porosity into cracks which close at pressures below 1 to $2 \mathrm{~K}_{\mathrm{b}}$ - and pores which remain open but which may contribute to the connected porosity. Therefore higher crack porosity estimates are not included in the figure.

Ignoring these latter determinations, consider the porosity determinations in 2.a. Except for the crack counting work by Hadely, all of these porosities are calculated from stress-strain data. Porosity may be backed out from strain and moduli data by a variety of methods. The most reasonable and straightforward approach is to interpret the excess non-1inear strain in static strain measurements as being equal to the 
crack closure. Using this approach, Cheng and Johnston inverted static strain data by fitting it with high order Chebyshev polynomials and defining the static bulk modulus by

$$
1 / \mathrm{K}_{\mathrm{s}}=\frac{3 \mathrm{~d} \varepsilon_{\ell}}{\mathrm{dp}}
$$

where $\varepsilon_{\ell}$ is the strain in the direction of measurement, and then calculating crack porosity by

$$
\Phi_{c}(P)=\Phi_{c}-\varepsilon(P)-\frac{P}{K_{\varepsilon}}(P)
$$

where $\Phi_{c}$ is the total crack porosity and $\varepsilon$ is volumetric strain.

In his technique, Simmons made very precise strain measurements to $0.2 \mathrm{GPa}$, which are automatically referenced against the strain of fused quartz. Porosities and pore closure distribution with pressure are then obtained by fitting the data with a polynomial and differentiating the data up to two times.

In early classical work, porosities were determined from tangent fits to the strain curves directly.

In our work we have used two essentially different approaches. First, in an early technique, both static and dynamic data are inverted using a pore strain model which includes both pore and matrix material parameters. In the modelling, calculations of pore strains are made for a pore Imbedded in a solid material. Using a single crack population, 
both static and dynamic moduli can be modelled by allowing the solid matrix material to have a minimum stiffness (fully self-consistent calculation, e.g. as by Budiansky and O'Connel1), or a maxịum stiffness (non self-consistent calculation). By this technique, a single population of pores can be used to generate a range of moduli varying from higher "dynamic" values to lower "static" values.

Our more current method is an adaptation from Simmons. No material properties are built into the inversion of the original data, so that if velocity data are used, then the moduli are inherently stiffer and the resulting calculated porosites are less than for the case of starting with static strain data.

Simmons' approach applied to static strain data should yield a measure of porosity under most prevailing assumptions, notably that crack closure is essentially linear in pressure and that almost all the crack porosity closes by $0.2 \mathrm{GPa}$. Comparing high pressure data from a number of sources indicates that this is the case. Nevertheless, published DSA crack porosities generally have small values. A number of DSA porosities for GT2 samples are plotted in 2.b. They cluster near and below the DSA porosity for Westerly Granite. However, the Fenton Hill granodiorites show an averaged $K_{s} / K_{d}$ which is lower than that for Westerly granite. This contradicts the result expected from Cheng and Johnston which would Imply that these samples, since they have lower ratios, have a greater 
porosity. (This inference is limited, however, since there are no zero-pressure $\mathrm{K}_{\mathrm{S}} / \mathrm{K}_{\mathrm{d}}$ available for the samples plotted in 2.b.)

Applying Simmon's technique to our Conway data, two sets of porosities are generated and plotted in figure $2 . c$. In these inversions, as in Simmon's, no material properties are incorporated into the calculations. Porosity is determined strictly geometrically. In figure 2.c, open circles denote porosities obtained from the dynamic moduli data, diamonds denote values from the up-run static moduli, and squares indicate that the original data is from the release curve: Equation (1) was used to define $\mathrm{K}_{\mathrm{s}}$ here. The 'dynamic' porosities are quite uniform and average about $1 \times 10^{-4}$. The 'static' porosities scatter widely, but average about $12 \mathrm{X}$ larger than the dynamic porosities. On the average they are larger than DSA porosities, and closer to within the range of more classical values of crack porosities for granites.

Group II, the fine grained samples, show very slightly higher 'dynamic' porosities than those of groups I and III. Again, if these values are indicative of porosity, the results are not consistent with the assumed moduli ratio - porosity relation.

One systematic runs through this scatter of data. The lowest (i.e., the dynamic porosities) are not only from experiments at ultrasonic frequency, but also at low strains of less than $10^{-6}$. As noted, the resolving level for strains in DSA is about $10^{-6}$. The resolving strains for other static 
experiments are as high as $10^{-4}$. The static strain data for our Conway samples are sensitive at $10^{-4}$ or less. Therefore, Ignoring momentarily any consideration of frequency effects or time relaxation, there is an apparent relation between the strain sensitivity of the experiment used to determine moduli and the resultant calculated porosities. Porosities geometrically backed-out of strain data may be proportional to the strain sensitivity. That is, moduli may be more strongly strain amplitude dependent than frequency dependent.

Figure 3.a, 3.b show the situation in schematic. It would appear to be possible to separate amplitude and frequency effects experimentally. In $3 . a$ and $3 . b$, the bold curves are sketches typical of real data plots. Dynamic modulus is denoted by $\underline{d}$ and $\underline{s}$ indicates static modulus. The abscissa are given as $\log (P)$ and the ordinates as $\log (K)$, a technique which helps resolve moduli characteristics at low pressure (Birch, 1960, Warren, 1977)...

In a dynamic measurement, the sample is allowed to relax for 10 to 20 minutes at some pressure so that the pores have in fact closed to their equilibrium configuration at that pressure under static conditions. A strain gauge attached to the rock during a series of such measurements will show the loci of strain going from one equilibrium point to the next. It is the local slope of these equilibrium curves which is inverted into static moduli data. From analogy with constrained granular material (Warren and Anderson, 1973), it is expected that the dynamic moduli will be derived from excursions of the crack 
under the small strains caused by the ultrasonic stress. Therefore, at any pressure, the pore aspect ratios are the same in both the dynamic and the static case, but under the Infinitesimal and high frequency stress the pore walls appear stiffer, and so at any one pressure the slope of the stress-strain curves is much steeper than for the larger amplitude static stress step. This notion is incorporated into our method of modelling dynamic moduli by non-self-consistent calculations and static moduli by self-consistent calculations.

If crack strains are frequency dependent then as shown In $3 . a$, the dynamic moduli values should approach the static curve as frequency is decreased to zero. If amplitude dominates, then the situation in $3 . b$ would hold. A trend with frequency has not been resolved. A number of labóratory studies suggest that the dynamic moduli values do not change appreciably over the range of a Megahertz to a few tens of hertz. Rather, results may be more consistent with a dominating amplitude dependence. Bonner (Lawrence Livermore National Laboratory) has been measuring dry rock at room temperature and at high temperature at 1 hertz. He indicates that his data are consistent with this suggestion (private communication). Similar inference may be drawn from the work of Chu and Wang (1982) on fault-gauge and clay. At seismic frequencies nonlinearity in stress-strain relations have been established for strain levels as $10 \mathrm{w}$ as $10^{-6}$ (Brennan and Stacy, 1977). Their results support the constant $Q$ assumption used in seismic modelling and yield that the moduli variation over a thousand decade frequence range is only 1 to $3 \%$. 
Returning to the notion of modelling variable pore-wall stiffness, the question of amplitude dependence of the modulus becomes a consideration of the amplitude dependence of pore-pore interactions. How does the deformation of one pore shape the stress field around it and how large of a deformation does it take for another pore to interact strongly, therefore causing its local effective matrix moduli to decrease?

An experiment can be suggested to help further resolve this question of the dominance of amplitude versus frequency effects. Variable amplitude experiments can be conveniently done in the low kilohertz range. At such frequencies, it is fairiy easy to use both low stress piezoceramic tranducers and higher amplitude mechanical hammers as signal sources.

Our results here indicate the limit in using $\mathrm{K}_{\mathrm{s}} / \mathrm{K}_{\mathrm{d}}$ as a quantitative measure of crack porosity. Figure 4 indicates that since $\mathrm{K}_{\mathrm{s}} / \mathrm{K}_{\mathrm{d}}$ converges to 1 at $10 \mathrm{w}$ porosities that the observed spread in porosities at fixed $K_{s} / K_{d}(e . g$. for the case of Westerly Granite) prevents more than an estimate of reasonable empirfcal bounds on this porosity from moduli ratio values.

\section{ACKNOWLEDGEMENTS}

This work was done under DOE Contract No. DE-AMO3-765F00034 PA No. DE-AT 03-76ER70224 with partial support from the Hot Dry Rock Project, Los Alamos National Laboratory. 


\section{Appendix}

References and Descriptions for Figure 1.

Conway granite suite. References: Warren 1979, Warren and Tiernan, 1981. Static $\mathrm{K}_{\mathrm{S}}$ values under hydrostatic pressure were determined by two methods: first by axial strains using a null detector, and second from circumferential strains using a BLH 1200B digital strain indicator. The second method was more precise. The circumferential strains were measured in separate experiments from the axial strains. The two sets of data were not combined. Calculated $\mathrm{K}_{\mathrm{S}}$ were made using equation 2 . The dynamic $k_{d}$ were determined from axial velocity measurements, using 1 to $3 \mathrm{Mhz}$ PZT. In figure $1 . \mathrm{a}, \mathrm{b}, \mathrm{c}, \mathrm{d} \mathrm{K}_{\mathrm{S}}-\mathrm{K}_{\mathrm{d}}$ ratios formed using the axial $\mathrm{K}_{S}$ are indicated by circles, those formed using circumferential $\mathrm{K}_{\mathrm{S}}$, by diamonds.

Westerly granite: Data are from mixing various sources. Set 1 In figure 1.e uses $K_{S}$ from Brace 1965 and $K_{d}$ from Schock et a1., 1974. Set 2 is from Cheng and Johnston, 1981. Set 3 uses $K_{d}$ from Simmons and Brace, 1965; and $K_{S}$ from Brace 1965.

Elberton granite. The envelope in 1.f Indicates uncertainties associated with various experiments combined with the effects of crack anisotropy in Elberton granite. Reference: Warren and Coffey DOE/LANL reports 1982; T. Dey, LANL monthly reports 
1980; Fisher and Warren, 1982; Halleck et al., 1982. Dynamic $\mathrm{K}_{\mathrm{d}}$ are from velocity measurements made with 1 to $3 \mathrm{Mhz} \mathrm{PZT}$ in 3 directions on two sets of samples. $K_{S}$ is from triaxial strain experiments on a kerosene saturated thick walled cylindrical sample, and also from uniaxial experiments on small dry cylindrical minicores.

Fenton Hi11 granodiorites. EE2 references. Tom Dey LANL monthly reports, 1980; Warren, DOE/LANL reports, 1982. GT 2 references Trice and Warren, 1977 and Simmons and Cooper, 1976 and 1977. $\mathrm{K}_{\mathrm{S}}$ data for the EE2 samples are from uniaxial experiments in which axial strains were determined by some combination of strain guages and LVDT. $\mathrm{K}_{\mathrm{S}}$ data for the GT2 samples are from linear compressibilities in 3 directions determined from differential strain analysis. The dynamic $K_{d}$ are from velocity measurements at 1 to $3 \mathrm{Mhz}$. In figure $1 . \mathrm{h}$. Diamond versus round symbols indicate different combinations of strain data to estimate $K_{s}$. 


\section{REFERENCES}

Brennan, B.J. and F.D. Stacy, "Frequency dependence of elasticity of rock--test of seismic velocity dispersion," Nature, 268, 220-222, July 21, 1977.

Birch, F., The velocity of compressional waves in rock to 10 kilobars, part I, Journal of Geophysical Research, 65 (4), 1083-1102, Apri1, 1960.

Birch, F., "The velocity of compressional waves in rocks to 10 kilobars (2)," Journal of Geophysical Research, 66, 2199-2224, 1961a.

Birch, F., "Composition of the Earth's mantle," Geophysics Journal, 4 , 295-311, $1961 \mathrm{~b}$.

Brace, W.F., "Some new measurements of linear compressibility of rocks, Journal of Geophysical Research, 70, 391-398, 1965.

Budiansky, B. and R.J. O'Conne11, "Elastic moduli of a cracked solid," International Journal of Solids and Structures, 12 , $81-97,1976$.

Cheng, C.H., and D.H. Johnston, "Dynamic and static modul1," Geophysica1 Research Letters 8 (1), 39-42, Jan. 1981. Chu, Chow-long and Chi-Yuen Wang, "Time-dependent volumetric constitutive relation for fault gauge and clay at high pressure" in Issues in Rock Mechanics, 23rd Symposium on Rock Mechanics, 270-278, Society of Mining Engineers, AIME, New York, N.Y., 1982. 
Dey, T. (G-7), "Offlce memorandum to Jeff Tester (G-5) through Jim Albright (G-7), Subject: HDR Rock Mechanics, April 1980, (May 5, 1980).

Dey, T., P. Halleck, A. Kunnick, "Office memo to Jeff Tester (G-5) through Jim Albright (G-7), Subject: May Progress Report - HDR Rock Mechanics, (June 5, 1980).

Dey, T. (G-7), Office memorandum to Jeff Tester (G-5) through Jim Aibright (G-7), Subject: Progress Report - HDR Rock Mechanics, (July 2, 1980).

Fisher, H., and N. Warren, "Characterization of non-linear porous rock," report in progress, 1982.

Halleck, P.M., T.N. Dey, G.Y. Bussod, and A.J. Kumnick,

"Relationships between fracture toughness, tensile modulus, and microstructure in Elberton granite," submitted for publication, 1982.

Henyey, F.S., and N. Pomphrey, "Self-consistent elastic moduli of a cracked solid," Geophysical Research Letters 9 (8), 903-906, Aug. 1982.

Schock, R.N., B.P. Banner and H. Louis, "Collection of ultrasonic velocity data as a function of pressure for polycrystalline solids," Lawrence Livermore Laboratory UCRL-51.508, Apri1 10, 1974.

Simmons, G. and W.F. Brace, "Comparison of static and dynamic measurements of compressibility of rocks," Journal of Geophysica1 Research, 70, 5649-5656, 1965. 
Simmons, G., R.W. Slegfried II, and M. Feves, "Differential strain analysis: a new method for examining cracks in rocks," Journal of Geophysical Research, 79 (29), 4383-4385, Oct. $10,1974$.

Simmons, G. and H. Cooper, "DSA of the microcracks in GT-2 core: interpretation and implications," submitted to Los Alamos National Laboratory, 20 November 1976.

Simmons, G. and H. Cooper, "Final technical report--DSA of the microcracks in more GT-2 core: interpretation and implications," submitted to Los Alamos National Laboratory, 16 November 1977.

Trice, R., and N. Warren, "Preliminary study on the correlation of acoustic velocity and permeability in two granodiorites from the LASL Fenton Hill Deep Borehole, GT-2, near the Valles Caldera, New Mexico, "Informal report \#LA-6851-MS of the Los Alamos Scientific Laboratory, Los Alamos, New Mexico, 1977.

Warren, N., and O.L. Anderson, "Elastic properties of granular materfals under uniaxial compaction cycles, Journal of Geophysical Research, 78 (29), 6911-6925, 1973.

Warren, N., Characterization of modulus-pressure systematics of rocks: dependence on microstructure," in The Earth's Crust, Monograph \#20 of the American Geophysical Union, Washington, D.C., 1977. 
Warren, N., "Rock physics characterization of Conway granite from a DOE borehoe, Conway, New Hampshire," informal report \#LA-8102-MS of the Los Alamos Scientific Laboratory, Los Alamos, New Mexico, 1979.

Warren, N. and M. Tiernan, "Systematics of crack-controlled mechanical properties for a suite of conway granites from the White Mountains, New Hampshire," Tectonophysics, 73, 295-322, 1981.

Warren, N. and N. Coffey, "Compiliation of new experimental data on Elberton granite," Department of Energy Final Report, to be submitted, 1982 . 


\section{FIGURE CAPTIONS}

Figure 1. $\mathrm{K}_{\mathrm{s}} / \mathrm{K}_{\mathrm{d}}$ for eight groups of igneous rock. Open symbols denote zero pressure ratios, filled symbols are ratios at $20 \mathrm{MPa}$. See text and appendix for further discussion.

Figure 2. Porosity estimates obtained by various techniques. Figure 3. Schematic trends between dynamic and static bulk moduli; $\underline{3 a}$, Frequency dependency; $\underline{3 b}$, amplitude dependence.

Figure 4. Cross plot of $\mathrm{K}_{\mathrm{s}} / \mathrm{K}_{\mathrm{d}}$ against porosities. Data are from figure 1 and 2. Heavy trend shown is from Cheng \& Johnston for Westerly granite. 


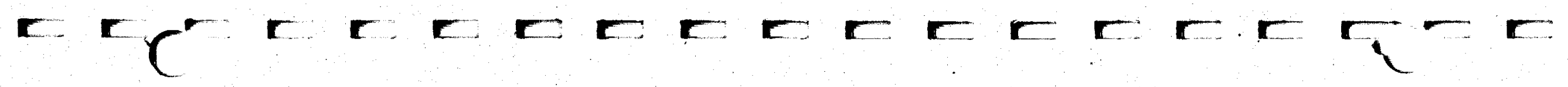

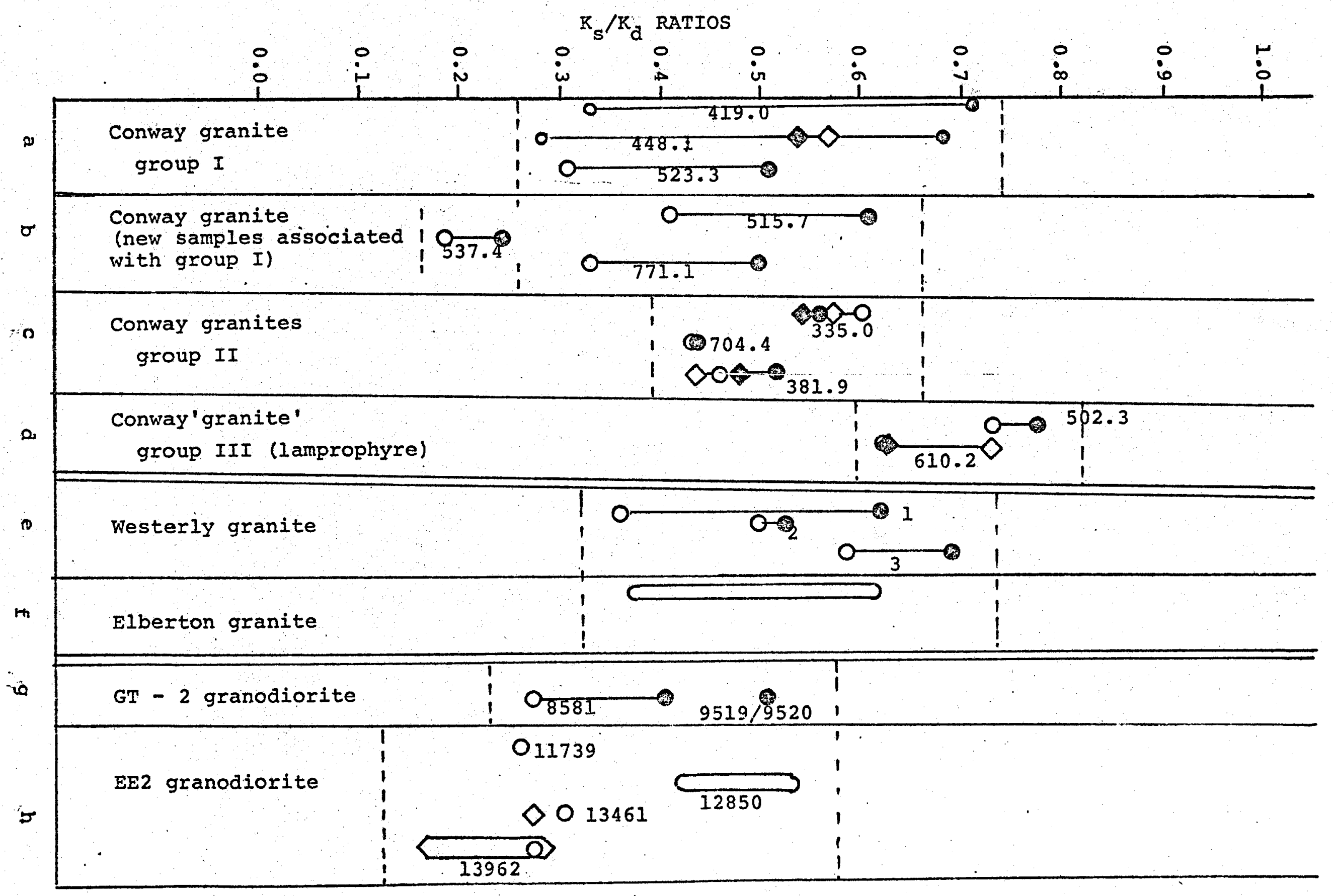




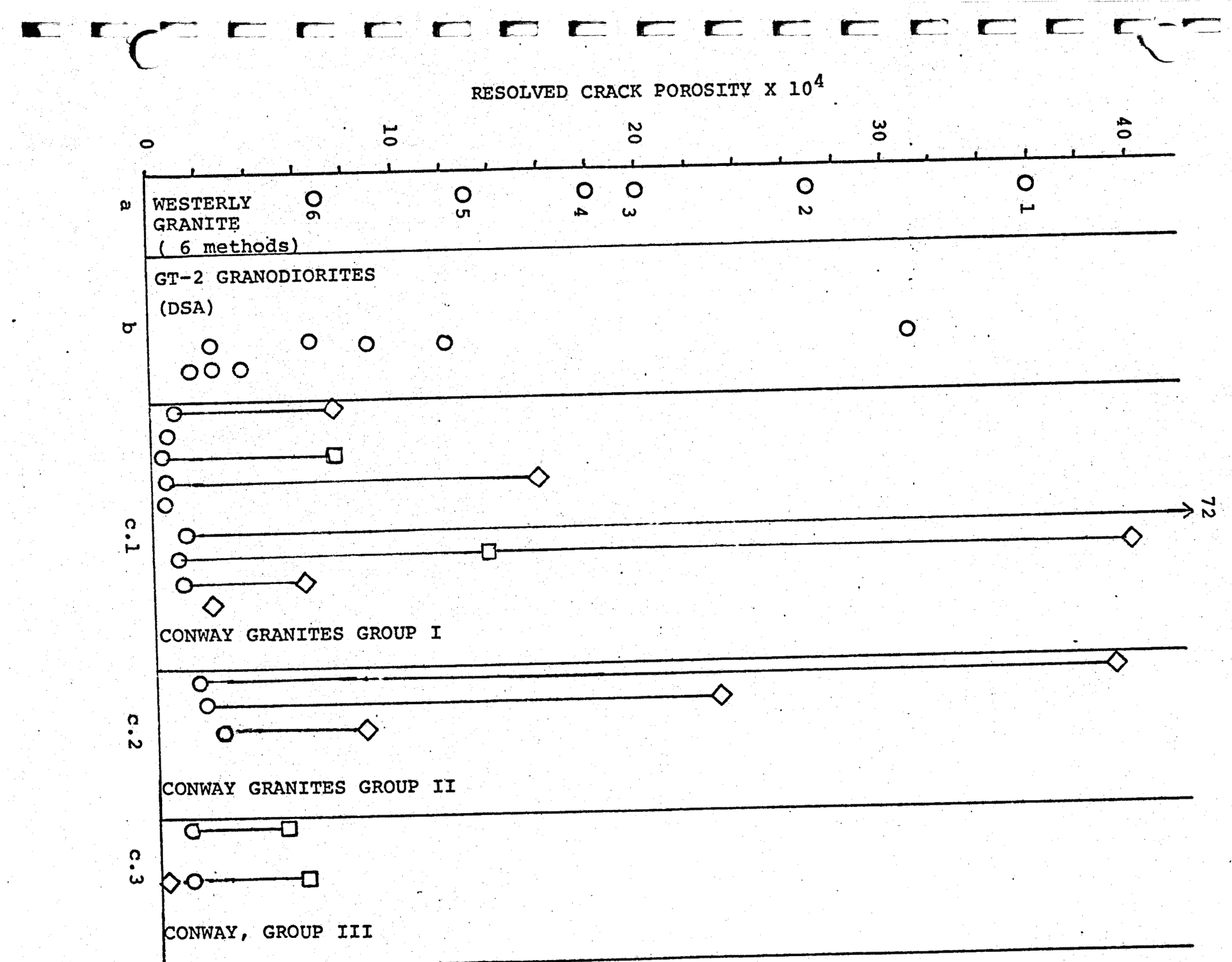



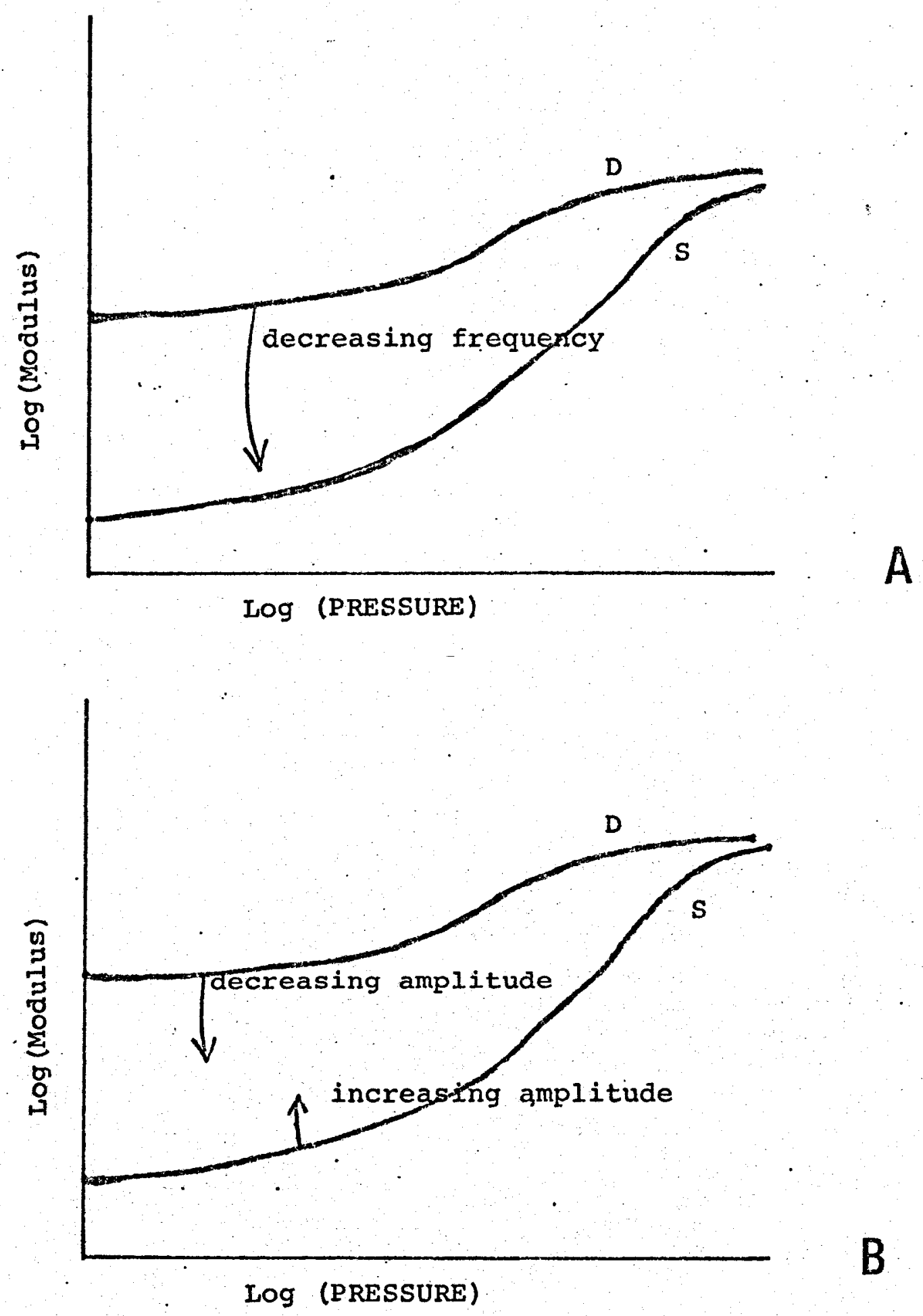



\title{
MICROCRACK FORMATION AND HYSTERESIS
}

UNDER HYDPOSTATIC CYCLING

\section{by}

\author{
Nick Warren and Nick Coffey \\ Institute of Geophysics and Planetary Physics \\ University of California \\ Los Angeles, CA 90024
}

\section{ABSTRACT}

Individual crack populations and changes in these populations were tracked over hydrostatic pressure cycles for a sample of Elberton (Berkeley Blue) granite. The sample was twice cycled to. $0.2 \mathrm{GPa}$ and once to $0.08 \mathrm{GPa}$. Ultrasonic velocities were differentiated to resolve the consistency and reproducibility of the velocity-pressure function. Local slopes were determined for small pressure intervals of about $0.005 \mathrm{GPa}$. Hysteresis was resolved from irreversible changes in the velocity-pressure function. Local slopes are controlled by crack closure. Crack populations opened at about $20 \%$ lower pressure than they closed. Crack porosity increased by about 16 to $25 \%$ during the experiments. This increase is accounted for primarily by the introduction of new populations with closing pressures in the range of 0.01 to $0.03 \mathrm{GPa}$ and near 0.06 GPa. These populations may represent the fallure of weakly sealed cracks under the first hydrostatic cycle to $0.2 \mathrm{GPa}$. The implied closing laws for cracks in these experiments are consistent with a 
model of cohesive tensile cracks which also satisfy strain data for stable (repeatable) dilatancy. Holcomb's crack models for stable dilatancy are discussed in the light of the experiments here.

\section{INTRODUCTION}

In velocity measurements on small samples of rock under hydrostatic pressure, both reversible (repeatable) hysteresis and irreversible changes are observed. Sometimes the changes for apparently very competent rock are striking and occasionally even bizarre (Warren, 1977; Trice and Warren, 1977). One may observe local cusps, positive second derivatives and predictable 'cross-overs'. (points at which the velocity on the down pressure cycle crosses over and drops below the velocity of the up pressure cycle where the slope on the original up-run was locally close to zero). All such effects are measures of microstructure populations and of changes in the populations with hydrostatic cycling.

In order to look at some of these effects in more detail, we conducted a series of precise velocity-pressure experiments on a sample of Elberton (Berkeley Blue) granite under hydrostatic pressure. The Elberton granite pluton is located in northeastern Georgla. The Elberton is a fine grained granite which is used for building monuments. The pluton is some $6 \mathrm{~km}$. long and $7 \mathrm{~km}$ wide, bounded by NE-SW trending faults (E11wood and Whitney, 1980). The grain size of the block used here is about $0.5 \mathrm{~mm}$. Mineral modes are given in Table 1. 
Table 1

D, ties, modes for Elberton granite

$\begin{array}{lll}\text { I b direction } & \text { Quarry direction } & \frac{\text { Density }\left(\mathrm{gm} / \mathrm{cm}^{3}\right)}{} \\ \text { A } & \text { intermediate } & 2.625 \\ \text { B } & \text { rift } & 2.627 \\ \text { C } & \text { headgrain } & 2.627\end{array}$

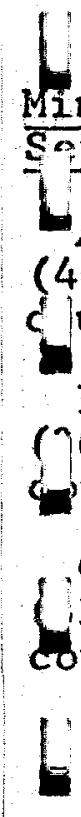
Modes (\%)

Minicore

Sot $\| 1$.

$\frac{\mathrm{QZ}}{26.6} \quad \frac{\mathrm{K}-\mathrm{Fe} 1 \mathrm{~d}}{26} \quad \frac{\mathrm{Plag}}{36.7} \quad \frac{\text { Biotite }}{6.3} \quad \frac{\text { Muscov }}{1.5} \frac{\text { Opag }}{0.3} \cdot \frac{\text { Chlor }}{0.6}$

Other

A $(4030$

(unts)

$B$

29

25

37

4.6

2.8

0.3

0.7

1.7

660

unts)

C

326

$28.9 \quad 24.9$

$36.5 \quad 5.6$

3.3

0.3

0.4

0.1

Petrographic studies indicate little mineral anisotropy. Wwever, quarried blocks show a definite rift direction which is controlled by a strong orientation of microcracks. Gilles Russod Halleck et al., 1982) indicates that for a quarry block similar to Grs, the normals to an "open" set of cracks lie within a $20 \%$ cone of the B direction. A "closed" or "healed" set is located at about Do degrees to the $\underline{A}$ and $\underline{C}$ axes. However, this last set is more iscontinuous, appears as planar trains of opaques and is cross cut by the first set. The zero pressure and the $0.2 \mathrm{GPa}$ velocities for dried and outgassed samples are given in Table 2. They substantiate the crack anisotropy. 
Table 2

ELBERTON GRANITE

COMPRESSIONAL WAVE VELOCITIES $(\mathrm{km} / \mathrm{sec})$

Sample

$\mathrm{km} / \mathrm{sec}$

at $\mathrm{P}=0.0 \mathrm{GPa}$

$\mathrm{km} / \mathrm{sec}$

sample

minicorel

set $\# 1$

A $\quad$ B $\quad$ C

at $P=0.2 \mathrm{GPa}$

1

$\therefore$

minicore ${ }^{2}$

vessel

4.41

3.81

5.01

$\underline{\text { A }}$

B

$\underline{\mathrm{C}}$

$$
\text { table top } 4.53 \quad 3.86 \quad 4.59
$$

$U$

vessel

5.00

table top $4.95 \quad 3.98 \quad 5.05$

remainder ${ }^{3}$

block for

set \#2

$$
\begin{aligned}
& \text { table top } 5.18 \quad 4.68 \quad 5.46 \\
& \begin{array}{cc}
\text { to } & \text { to } \\
5.494 & 4.524
\end{array}
\end{aligned}
$$

1 oil cut, cleaned in trichloroethylene, dried and outgassed for several days.

2 water cut, dried and outgassed over several days.

3 kept at ambient environment, never dried or outgassed.

4 systematic variation over block.

The minicore from set 1 , taken parallel to the rift direction, was used in this study. The basic experimental technique is described in Warren, 1979. The sample was $25.35 \mathrm{~mm}$ in diameter, and $29.557 \pm$ p.001 mm in length. It was jacketed in a soft two part elastomer (Sylgard 170). Transducers were bonded directly to the sample (figure 1 ).

Three pressure cycles were conducted. The first two runs were to $0.2 \mathrm{GPa}$, and were done to establish the general velocity characteristics of the sample. During the first cycle, compressional wave velocity $\left(V_{p}\right)$ was measured using $3 \mathrm{Mhz}$ 
piezoceramic transducers. Shear wave velocity $\left(V_{s}\right)$ was measured during the second run using $1 \mathrm{MHZ}$ PZT.

Cracked rock behaves as a low pass acoustic filter, so at low pressures (at which cracks are still open) acoustic wavelengths in the rock are considerably longer than the minimum predicted by the dominant frequency of the PZT. The minimum wavelengths are $2.18 \mathrm{~mm}$ for the compressional wave and $3.5 \mathrm{~mm}$ for the shear wave. At low pressures the sampling wavelengths in the rock are estimated to be closer to 6 to $8 \mathrm{~mm}$ since the rise time of the acoustic signal at low pressure corresponds to $\varepsilon$ frequency of about $0.5 \mathrm{Mhz}$.:

Velocity picks were spaced on the up-runs at pressure intervals $(\triangle P)$ of approximately $0.1 \mathrm{P}$, but no significant data were taken on the down-runs. This routine was followed simply because each experiment took about eight hours as it was. The third experiment was a hysteresis experiment from zero to $0.08 \mathrm{GPa}$ during which closely spaced $v_{p}$ data were taken on both the up and down runs.

\section{RESULTS}

Third cycle, hysteresis experiment

The velocity curves from the hysteresis experiment are shown in figure 2. The maximum offset in velocity at any fixed pressure above several $\mathrm{MPa}$ is about $1.6 \%$. (At pressures near zero, the down-run data suffer from the fact that the transducer and electrical couplings degrade near the end of the run.) In the pressure region of about $10 \mathrm{MPa}$ to $50 \mathrm{MPa}$ local kinks in the up-run velocity curve appear to be reproduced in the down-run data. These local changes in slope are the most obvious indicators of discrete populations of microcracks. 
Figure 3 shows the point by point slopes calculated from the velocity data. The slopes $\Delta V_{P} / \Delta P$ are plotted for convenience at the maximum pressure of each point pair. An important operation was performed on the data at this junction. The down-run data have been stretched along the pressure axis by $20 \%$. That is, velocity at any pressure $P$ is ascribed to a pressure 1.2P for the slope calculation. This hysteresis of $20 \%$ is an overall number. At the experimental level of confidence, it appears that the factor itself may be proportional to pressure, and is closer to or less than $10 \%$ for crack populations which have closing pressures below about 25 MPa. This pressure dependence is suggested by fourier analysis of the residuals formed between the up-run and the stretched down-run velocity data. Residuals are dominantly negative below $20 \mathrm{MPa}$ and dominantly positive above about $27 \mathrm{MPa}$.

A linear regression was formed of the stretched down-run data (y) on the up-run data (x). Slope values were picked at 25 bar intervals. The coefficient of correlation is 0.9477 . The regression line is

$$
\begin{aligned}
& y=a+b x \\
& a=-4.182 \\
& b=1.109
\end{aligned}
$$

It may be noted that the effect of picking at fixed pressures is to somewhat smooth the data.. Some of the original data points are peaks, and since the chance of landing on a peak at an exact 25 bar interval is sma11, the result is that the uniformly picked slope values have a variance which is less than that of the original data.

Based on this agreement indicated by a high correlation coefficient between the distribution of slopes, modulus spectra were 
formed which are shown in figure 4. The spectra were generated by fitting the velocity data by a spline curve which is continuous through the first derivative. In the procedure, a cubic curve is fit through each overlapping group of 5 points yielding the functional value for the curve at the center point of each group (Akima, 1970; Warren and Tiernan, 1981).

The spectrum $F_{p}$ is defined by

$$
F_{p}(P)=-P \cdot \frac{d\left(V_{p}{ }^{2} \rho^{-1}\right.}{d \bar{P}}
$$

Density is denoted by $\rho . F_{p}$ will be called here the Compressional spectrum, distinguished from the shear spectrum $F_{S}$, defined by an analogous equation. The quantity $F_{p}(P)$ dP is proportional to the amount of cracks that are pinned closed in the pressure interval $P$ to $P+d P$. This result is clear if the volumetric compliance is substituted for the compressional wave compliance in eq. 2. In that case $\mathrm{F}_{\mathrm{V}}$ may be interpreted as a porosity closure-pressure density, namely the zero-pressure porosity which closes between $P$ and $P+d P$ (Morlier, 1971; Simmons, et al., 1974).

The uncertainty bars in the spectra are dominated by two effects; the uncertainty in pressure itself, and the uncertainty in the slope. The pressure uncertainty is $<1 \mathrm{MPa}$ independent of pressure. The uncertainty in slope was estimated from the data shown in figure 3. The estimated percentage standard deviation of the data at any pressure was obtained from the measured percentage variation of the data at that pressure. This standard deviation 
proved to be independent of pressure and is about $21 \%$. The center point of the uncertainty bars 1 ie on a smoothed spectrum generated by a 3-point running average of the velocity derivative data.

These results set the confidence level establishing reproducibility and reality of the various spectral features. Three major peak regions exist at pressures of about $10 \mathrm{MPa}, 15$ to $25 \mathrm{MPa}$, at $35 \mathrm{MPa}$ and broadly at around $60 \mathrm{MPa}$. It will be seen that some of these peaks were formed during the first two pressure cycles.

First and Second Hydrostatic Cycles

The basic spectrum of the sample was altered by the first pressure run to $0.2 \mathrm{GPa}$. Figure $5 \mathrm{a}$ shows a portion of the spectrum from this very first up-run. It is significantly lower than that of the hysteresis experiment for pressures near $20 \mathrm{MPa}, 35 \mathrm{MPa}$, and 60 $\mathrm{MPa}$. During this first run, the compressional velocities were higher by an average of $6 \%$ over the $80 \mathrm{MPa}$ range ( $7 \%$ at $10 \mathrm{w}$ pressures, decreasing to $5 \%$ at high pressure). By the second pressure run, the characteristic spectral shape seems to be nearly established. This is suggested by figure $5 \mathrm{~b}$ which shows the spectrum formed from the shear velocity data plotted along with the hysteresis up-run spectrum. The magnitude of the Shear spectra is expected to be greater than the Compressional spectrum since the spectrum is sensitive to $1 / \mathrm{V}^{3} \cdot \Delta \mathrm{V} / \Delta \mathrm{P}$. For this experiment the local slopes $\Delta V_{s} / \Delta P$ are consistently smaller than those for $V_{p}$, but not by enough to completely offset the effect arising from the inverse cube of the velocity. It must be noted that the quality of the Shear spectrum is somewhat lower than that of the 
Compressional spectrum since the shear arrivel was not as pure and not as easily picked as that of the compressional wave arrival. Given these qualifiers, the Shear spectrum is similar to the Compressional spectrum (with the obvious exception of the peak at 45 $\mathrm{MPa}$ ).

To summarize, three key results interest us here. First, the 2-point velocity derivatives show a high degree of cross correlation and therefore spectrum features are reproducible. Second, the stretch needed to best fit the up and down spectra over the entire experimental pressure range is 0.2 but it may be less at low pressure. Third, new crack populations were generated on the first cycling experiment.

Based on these results we can address questions on the effects of pressure and pressure cycling on internal friction, porosity, and crack population changes.

\section{ANALYSIS}

Spectral Shapes

The spectrum is a characteristic signature giving the distribution of measurably abrupt changes in strain (and hence in velocity) due to the pinning of populations of flaws. In the general interpretation Iinear crack closure is assumed and peaks mark the pressures at which significant populations of cracks close completely. However, as a general caveat, it must be remembered that as long as the strain or velocity function can be differentiated a spectrum can be formed. Therefore a spectrum in and of itself does not impute any particular set of properties to the cracks. In the general case nelther linear closure nor complete 
closure is required. Only pinning is required. For granites however, there are numerous justifications for assuming fairly simple crack models. Therefore, the data here will be viewed as controlled by cracks that are coupled to pressure through a one dimensional variable (the crack width) only.

Three particular spectral shapes are derived in the Appendix and are shown in Figure 6. They are based on models typically assumed for cracks in granite. The first (6a) assumes a population which at zero pressure is characterized by cracks having equal lengths a and a uniform density distribution of widths from $b_{0}=0$ to $b_{0}=$ $\mathrm{m}^{\mathrm{b}} \mathrm{o}$ (a maximum width). The second ( $6 \mathrm{~b}$ ) assumes an initial modified-exponential distribution in length

$$
N(a) \mathrm{da}=\frac{1}{a^{3}} \cdot \mathrm{e}^{-\left(a-a_{0}\right)} \mathrm{da}, a \geq a_{0} \text { only }
$$

and again a uniform distribution in width $\underline{b}$.

$$
\mathrm{N}(\mathrm{b}) \mathrm{db}=\mathrm{c} \mathrm{db}, \mathrm{c}=\text { constant } \mathrm{b} \text { less than } \mathrm{m}_{\mathrm{o}} \text { only }
$$

(The introduction of $a^{-3}$ serves to simplify the calculation.)

The third population (6c) is modified-exponential in a but all cracks have an initial width $\mathrm{m}^{\mathrm{b}} \mathrm{o}^{\text {. }}$

It is seen that the overall spectral shape in Figure 4 is consistent with a high power-law or an exponential distribution of crack length, with variation in crack width. The sharper, higher order spectral features may well reflect variations in width distributions for varlous ranges of crack lengths. In particular, from equation 2, a spectral peak corresponds to a maximum in $1 / V^{3} \cdot \Delta \mathrm{V} / \Delta \mathrm{P}$; that is, to a point of inflection in the velocity profile going from concave-upward to concave-downward. Such upward 
concavity was predicted to exist by Warren (1977). The best defined concave-upward portions of the velocity curve (Figure 2) can be seen in the data between $\mathrm{P}=20 \mathrm{MPa}$ and $34 \mathrm{MPa}$. Linearly increasing sections of both the up and down spectra similar in appearance to $6 \mathrm{a}$ are observable in figure 4 between 25 and $35 \mathrm{MPa}$. Spectral Changes

The changes between the spectra shown in figure 5 a are a measure. of induced damage. Three observations support this argument. The introduction of new damage during the experiment would cause lowered velocities in later experiments. This is observed. The mean amplitude of the later spectrum must be increased since its integral is proportional to the crack porosity that closes over the pressure range. This is observed. The area under the unstretched down-run and the up-run spectra between 0 and $55 \mathrm{MPa}$ agree to $1 \%$. The area under the very first up-run spectra over the same pressure range is about $16 \%$ less. Extending the range to $72.5 \mathrm{MPa}$ gives $9 \%$ and $20 \%$ respectively. Finally, broad minimums or troughs in a spectrum indicate a pressure range over which no cracks are pinned. This can imply that for cracks of some length distribution, the cracks are already pinned, bridged, or sealed. Therefore if poorly sealed cracks fall during pressure cycling troughs can grow into peaks as is observed most clearly in the region of the peak at $35 \mathrm{MPa}$.

It is not expected that troughs in the later spectra should fall much below the amplitude (base line) of the first run spectrum unless the induced damage causes a fundamental shift in length and width distributions such that in some pressure range, the conditions 
of crack closure are no longer met. In figure 5a the later (upper) spectrum does not fall significantly below the first run spectrum at any pressure.

Hysteresis

The generation of damage on the first cycle implies that at the grain size level; stress distributions in the rock are very complex even for uniform external hydrostatic pressure. In illustrative experiments Batzle et a1. (1980) directly observed and documented crack opening, new crack formation, and shear movement of cracks at applied uniaxial stress levels of only 5 to $30 \mathrm{MPa}$. Here, results indicate that under sufficient external compression, the same results occur.

This induced damage is not self healing, but causes permanent changes in velocity and the generation of spectral peaks which are reproducible over a complete stress cycle. (It is taken that the peak stress on such stable cycles do not exceed the peak stress that generated the damage in the first place.) Therefore, the observed hysteresis is to be accounted for by mechanics of rough cracks such as observed by Batzle et al. using SEM. A form for the proposed stress-strain relation for a crack is suggested by comparison of the Shear spectrum to the Compressional spectrum (Figure 5b). It appears that the crack is pinned to shear at essentially the same pressure as it is pinned to normal displacement. Therefore, the mechanism causing hysteresis corresponds to a static making and breaking of contact surfaces with subsequent changes in pore volume as distinguished from pure volumeless sliding. 
The hysteresis results, therefore, can be explained using a simple cohesion model of crack surfaces, deplcted in Figure 7a. The crack that is initially open closes linearly to $P_{c}$, at which point it becomes pinned. The elastic restaining force $\left(\sigma_{n e}\right)$ which tends to open the crack, is overcome by the local nomal stress $\left(\sigma_{n}\right)$ plus the cohesion that develops on contact $\left(s_{0}\right)$.

$$
\sigma_{n e}<s_{0}+\sigma_{n}
$$

The crack reopens at the lower pressure $P_{0}$, given by

$$
\sigma_{n}+s_{0}<\sigma_{n e} \text { or } P_{c}-P_{0}=s_{0}
$$

and since it is now unpinned, it rebounds to the initial closure law curve. For our experiments, $s_{0}$ is pressure dependent and an average is given by $s_{o}=0.2 P_{c}$. A resultant schematic velocity curve is shown in figure $7 \mathrm{~b}$. If a stable crack population is assumed, then if the pressure is repumped from a point (i.e. A in the figure) velocity increases along the original up-run curve. Although we did not perform such a minicycle as an explicit experiment here, we have often observed during experiments that after a partial pressure dump, the travel time can be recovered fully on repumping to the original pressure (point $\underline{B}$ in Figure $7 \mathrm{~b}$ ). Dilatancy

These results apply to the general problem of dilatancy. There are three aspects to the comparison. The first is that permanent strain is caused during the first stress cycle(s). In dilatancy, a rock sample at a flxed confining pressure is cycled to a sufficiently great differential stress $\sigma_{D}$ to cause crack volume to increase. Under repeated cycling to some maximum differential 
stress $\sigma_{\max }$ the sample first shows irreversible changes in strain and then repeatable strain cycles which may be termed stable dilatancy. This result is similar to ours here. The second aspect is that after this the hysteresis hoop becomes stable. There is, however, also an important difference. In our experiment, as shown in Figure $8 a$, the down-run strain curve is overall subparallel to that of the up-run curve. That is, spectral peaks are simply shifted over pressure. In stable dilatancy, the down-run curve is almost turned end for end to the up-run curve so that a single cycle resembles a modified Caulomb cycle (Jeager and Cook, 1968). See Figure 8b. This difference is the third aspect. .

Stevens and Holcomb (1980a) and Holcomb and Stevens (1980b) introduce the notion of self healing reversible Griffith cracks in order to model this stable dilatancy. However, we find it difficult to imagine that cracks can instantly self-heal or that the mechanical properties of cracks induced in our study differ fundamentally from those formed under dilatancy. We expect that both the similar and different aspects of these experiments can be accounted for by similar crack models.

In respect to the first aspect, a conceptual difficulty appears In Holcomb's work in that only the stable hysteresis is modelled by reversible Griffith cracks. This seems to distinguish the physics occuring in the stable cycles (in which, by hypotheses, cracks self-heal) from that causing the original permanent strain damage (which since 1t's permanent, doesn't heal). Two regions of physics need not exist. In both stable dilatancy and hydrostatic 
experiments we are looking at the mechanical effect of stable microcrack populations, some portion of which is introduced in the course of the experiment. Therefore, the question is whether the stress-strain model given in Figure $7 a$ can be applied to the case of dilatancy. As will be seen, a cohesive crack is symmetrically a tensile-crack and, as shown in Figure 9, dilatancy may simply turn the stress-strain model around.

To develop this, first note that in the hydrostatic case the majority of cracks are open at zero pressure and so the elastic restoring force acts to resist closure. In stable dilatancy, we assume a large population of damage cracks which at zero differential stress remains closed, and which is forced open by ${ }^{\sigma} D^{>\sigma} \mathrm{d}$. In this process, the elastic restoring force $\sigma_{n e}$ acts to keep the cracks closed and must be overcome. Therefore, tensile cracks under stable dilatancy are equivalent to the open cracks of the hydrostatic experiment.

For the tensile crack to open, it is required that

$$
\sigma_{D}=\left(\sigma_{1}-\sigma_{3}\right)>s_{0}+\sigma_{n e}+\sigma_{n}
$$

where the mean stress $\sigma_{\mathrm{n}}$ is proportional to $\left(\sigma_{1}+\right.$ $\left.\sigma_{3}\right) / 2$. As before, $S_{0}$ is the cohesion of the closed broken surface. The elastic stress $\sigma_{\text {ne }}$ at $\sigma_{D}=0$ is intrinsically equal to or greater than zero depending on local grain architecture and residual stresses. The cohesion at $\sigma_{D}=0$ may then be proportional to $\sigma_{n e}+\sigma_{n}$.

If $S_{0}$ is greater than zero, then when the crack opens it Instantly opens to the open crack stress-strain curve along which 
$\sigma_{n e}+\sigma_{n}$ balance the net tension introduced by $\sigma_{D^{*}}$. If the crack acts purely tensional, then the stress-strain curve is simply as shown in 9a. Here the strain is taken as a function of crack width since we presume that the crack has already grown to length a under the initial stress cycling.

In this model, the shape of the hysteresis curve is fundamentally controlled by the nature of the crack distribution. It is clear that the distribution of crack lengths and widths generated in a dilatancy experiment have a more specific relation to the experimental stress function than does the distribution of cracks in the pure compression experiment in which, for the most part, the cracks exist pre-experiment. Furthermore, if in growing any crack tends to keep a fixed aspect ratio, (Soga, et al., 1978) then once formed its width can only extend by a certain amount before either the crack extends in length or a new crack forms to relieve the additional stress build up. This implies that the stress-strain tail (i.e. c-d-e in Figure $9 a$ ) is finite since indeed, dilatancy results in the generation of a multiple of small cracks. Any one microcrack sees some maximum local stress since it is shielded by a halo of other microcracks. Under these conditions any applied differential stress has to drop below a certain value before the local stresses around any particular crack also start to drop and the crack is allowed to reclose. In this case, the number of cracks which start to reclose is portional to the extent that $\sigma_{D}$ has dropped below $\sigma_{\max }$, until at some stress (which is clearly 
$\left.\geqslant \sigma_{d}\right)$ all the cracks are closing or are already closed and the strain derivative reaches a maximum. This model is illustrated in Figure $9 \mathrm{e}$.

Our basic crack model therfore is tensile; is cohesive but not self-healing, and has an explcit volumetric dependence on crack width $\underline{b}$. The basic triangular stress-strain cycle assumed here is very similar to that in Holcomb's original model (Holcomb, 1978) except that a strain tail (c-d-e) is not assumed. In comparison, self-healing reversible Griffith cracks are also tensional but have a square rather than a triangular hysteresis cycle and likewise do not exhibit a tail for $\sigma_{D}>\sigma_{d}$. This follows since for Holcomb, cracks volume is portional to length and cracks open catastrophically to their maximum length.

It needs to be noted that in stevens and Holcomb's analysis of sliding crack model of Brace, et al. (1966), volumetric strain is taken to be linearly proportional to slip on the coupled shear crack. The result is that in all three models the volumetric strains are proportional to each other and therefore the actual variable corresponding to strain does not effect comparisons between the models at this level.

Various other stress-strain cycles are also possible. Figures $9 \mathrm{~b}$ and $9 \mathrm{c}$ lllustrate the case of 'blocked door' cracks which open freely in tension but become pinned on closing (due, for example, to rotating grain chips, etc.) or cracks nay stick both to opening and closing (Figure 9d). These variations duplicate aspects of both sliding crack models (Brace, et al., 1966) and Holcomb's reversible self-healing Griffith cracks. 
Case 9c becomes equivalent to the stress-strain cycle of reversible Griffith cracks in the limit that point $f$ approaches point a. and the maximum strain is given at point c. Note that at point $f$ the crack as modelled here is unjammed and can elastically open and close. Figure 9d shows stick-slip sliding everywhere. In this case, strain corresponding to motion from point c to point $d$ is stick slip. As discussed by Holcomb and Stevens, this introduces both the unwanted irreproducibility of model hysteresis cycles and the unwanted dead-band at the start of stress relaxation: These factors seem to limit Brace's model.

Physically, all such stress strain curves must be manifest, but the overall rock strain behavior will be dominated by the most easily straining elements providing they are of sufficient number density. We concur with Holcomb that terisile cracks may dominate stable dilatancy but find no reason to assume the self-healing aspects of his mode.

Experiment Proposa1

Experimental Resolutions of Models

Three sets of underlying assumptions distinguish Brace, et al., Holcomb and Stevens, and the models here. In the case of Brace, et al., slip is assumed to occur in preference to tension. Volumeless slip opens volumetric cracks which exist at the leading and back ends of the slip region. In Holcomb's thesis, tension occurs in preference to slip, cracks self-heal, and crack length distributions are not physically justified. In our thesis, tension also predominates, cohesion replaces self-healing, and cracks are assumed to become imbedded in a "halo" of other cracks which relleve stress 1ocally. 
Therefore, each model can be criticized on grounds of whether various sets of these assumptions are reasonable. Resolving questions are: Can cohesion be resolved from self-healing? Do cracks open catastrophically to their maximum extension and volume? Do microcrack fields generate in a way which limits the stress Intensity around any one microcrack?

The analysis offered by Holcomb and Stevens seems to solidly establish real difficulties in essuming stick-slip in sliding crack models.

If cohesion is controlled by surface roughness, then self-healing may possibly be resolved from cohesion by comparing experiments in clean versus "messy" gaseous environments. It then becomes also necessary to establish that the cracks expressed by stable dilatancy are not a special intragranular set which remains isolated from environments. The answer here may be further resolved by monitoring acoustic emissions over repeated cycles of stable dilatancy, and correlating resistivity with dilatancy. In most cycling experiments of which we are aware, acoustic emissions decrease to zero after a few cycles (for example, Warren and Latham, 1970). The problem of arguing from resistivity or permeability changes with dilatancy is that two crack populations may be proposed. However, within this limit, the set of connected dilatant cracks could be resolved from the isolated set.

Finally, there is increasing evidence that major cracks extend by microcrack flelds that form around the crack tip (Hoagland, 1980). The question of how such crack fields partition the 
differential stress field is largely unanswered. The following experiment can be suggested: By performing dilatancy experiments on severely necked samples, it is possible to characterize the functional dependence of microcrack formation on differential stress $\left(\max \sigma_{D}\right)$. The experimental trick then would be to combine SEM with stable dilatancy cycling for small sections cut from various portions of the necked sample (Batzle, 1980). The quantity to resolve is whether the number density of cracks increases proportionally to $\max \sigma_{D}$ sufficiently to keep the average local stress per crack (and the resultant crack size) essentially constant.

\section{ACKNOWLEDGEMENTS}

This study was done in conjunction with DOE grant No. DE-AM03-76SF00034, PA No. DE-AT 03-76ER70224 and with partial support from the Space Sciences Division, Los Alamos National Laboratory. We thank Prof. William Newman and Dr. Tom Dey for important discussions and suggestions. 


\section{REFERENCES}

Akima, H., "A new method of interpolation and smooth curve fitting based on local procedures," Journal Assoc. Comput Mach. 17, 589-602, 1970.

Batzle, M.L., G. Simmons, and R.W. Siegfried, "Microcrack closure in rocks under stress: direct observation," Journal of . Geophysical Research 85 (B12) 7072-7090, Dec. 10, 1980.

Brace, W.F., B.W. Paulding, Jr., and C.H. Schulz, "Dilatancy in the fracture of crystalline rock," Journal of Geophysical Research, 71, 3939-3953, 1966.

Ellwood, B.B., and J.A. Whitney, "Magnetic fabric of the Elberton granite, northeast Georgia," Journal of Geophysical Research, 85, (B3), 1481-1486, March 10, 1980.

Halleck, P.M., T.N. Dey, G.Y. Bussod, A.J. Kumnick, "Relationships between fracture toughness, tensile modulus, and microstructure in Elberton granite, submitted for publication.

Hoagland,

Journal of American Ceramic Society, 1980.

Holcomb, D.M., "A quantitative model of dilatancy in dry rock and its application to westerly granite," Journal of Geophysical Research, 83, 4941-4950, 1978.

Holcomb, D.J., and J.L. Stevens, "The reversible Griffith crack: a viable model for dilatancy," Journal of Geophysical Research, 85 (B12), 7101-7107, Dec. 10, 1980.

Jaeger, J.C., and N.G.W. Cook, Fundamentals of rock mechanics, 513 pages, Methuen \& Co., Ltd., London, 1969. 
Morlier, P., "Description de l'etat de fissuration d'une roche a partir d'essais non-destructifs simples," Rock Mechanics, 3 , $125-138,1971$.

Simmons, G., R.W. Siegfried II, and M. Feves, "Differential strain analysis: a new method for examining cracks in rocks," Journal of Geophysical Research, 79, (29), 4383-4385, Oct. 10, 1974.

Soga, N., H. Mitzutani, H. Spetzler, and R.J. Martin, III, "Effects of dilatancy on velocity anisotropy in westerly granite," Journal of Geophysical Research, 83, 4451-4458, 1978.

Stevens, J.L. and D.J. Holcomb, "A theoretical investigation of the sliding crack model of dilatancy," Journal of Geophysical Research, 85, (B12), 7091-7100, Dec. 10, 1980.

Trice, R. and N. Warren, "Preliminary study on the correlation of acoustic velocity and permeability in two granodiorites from the LASL Fenton Hill deep borehold, GT-2, near the Valles Caldera, New Mexico," Informal Report \#LA-6851-MS of the Los Alamos Scientific Laboratory, Los Alamos, New Mexico, 1977. Walsh, J.B., The effects of cracks on the compressibility of rock, Journal of Geophysical Research, 70 (2), 381-389, 1965. Warren, N. and G. Latham, "An experimental study of thermaily Induced microfracturing and its relation to volcanic seismicity," Journal of Geophysical Research, 75 (23), 4455-4464, 1970.

Warren, N., "Characterization of modulus-pressure systematics of rocks: dependence on microstructure, in The Earth's Crust, Monograph \#20 of the American Geophysical Union, Washington, D.C., 1977. 
Warren, N., "Rock physics characterization of Conway granite from a DOE borehole, Conway, New Hampshire," Informal Report \#LA-8102-MS of the Los Alamos Scientific Laboratory, Los Alamos, New Mexico, 1979.

Warren, N. and M. Tiernan; "Systematics of crack-controlled mechanical properties for a suite of Conway granites from the White Mountains, New Hampshire," Tectonophysics, $73,295-322$, 1981. 


\section{APPENDIX \\ DERIVATION OF SPECTRAL SHAPES SHOWN IN FIGURE 6}

The Spectrum $F$ is generated by the derivative of a compliance $\phi$. Normalizing $\phi$ to the equivalent compliance $\phi_{0}$ of the solid rock and writing this as $\phi^{*}$

$$
\phi^{*}(P) \approx 1+\int_{a} \int_{b} \eta(p) \frac{\epsilon_{n}(a, b)}{\epsilon_{0}} d a d b
$$

and

$$
F=-P \frac{d \phi}{d P}
$$

Here crack length is denoted by a and b is crack width. The quantity $n(P)$ is porosity. The strain ratio $\varepsilon_{h} / \varepsilon_{0}$ is pore strain normalized to solid rock strain under the same stress perturbation which defines the chosen compliance. The spectra are generated assuming that crack length is independent of pressure, and that width is characterized by a linear closure law.

$$
b=b_{0}[1-P *] \quad A-3
$$

The normalized pressure $\mathrm{P} *$ is referenced to the maximum closing pressure $\left({ }_{m} P_{c}\right)$ of any particular crack in the population.

$$
\begin{array}{ll}
\mathrm{P}^{*}=\mathrm{P} / \mathrm{m}_{\mathrm{C}} & \mathrm{A}-4 \mathrm{a} \\
\mathrm{P}_{\mathrm{c}}=\mathrm{m}_{\mathrm{o}} \mathrm{b}_{\mathrm{min}} \cdot \mathrm{E} & \mathrm{A}-4 \mathrm{~b}
\end{array}
$$

where $\mathrm{E}$ is the Young's modulus of the solld rock (Walsh, 1965). 
Letting $\mathrm{K}_{\mathrm{a}}$ and $\mathrm{K}_{\mathrm{b}}$ represent the number density distributions of $\underline{a}$ and $\underline{b}$ as functions of pressure, equation $A-1$ can be written as

$$
\phi^{*}(\mathrm{P}) \simeq 1+\int_{a_{\min }}^{a} \max (\mathrm{P}) \mathrm{C}_{1} \mathrm{~K}_{\mathrm{a}} \mathrm{a}^{3} \int_{\mathrm{b}_{\min }}^{\mathrm{max}}(\mathrm{P}) \mathrm{K}_{\mathrm{b}} \mathrm{dbda} \quad A-4
$$

where $C_{1}$ is the coefficient arising from pore geometry and the solid rock moduli. Other such coefficients which arise will be similarly denoted.

For Figure $6 a$, a 11 cracks are of equal length and the distribution of widths is uniform between zero and a maximum width $\mathrm{m}^{\mathrm{b}} \mathrm{o}^{\circ}$

$$
\phi^{*}(P) \approx 1+c_{2} a^{3} \int_{0}^{b_{\max }^{(p)}} d b
$$$$
A-5 a
$$

from $A-3$,

$$
\phi *(P)=1+C_{2} a^{3}{ }_{m}^{b}\left[1-P^{*}\right]
$$

and

$$
F^{*}\left(P^{*}\right)=\left.\frac{\dot{C}_{2^{a}} m^{b} o}{m^{P}} P^{*}\right|_{P^{*}=0} ^{P^{*}=1}
$$

For Figure $6 b$ and $6 c$

$$
\mathrm{K}_{a} \sim \frac{1}{a^{3}} \exp -\left.\left(\frac{\left(a-a_{\min }\right)}{a_{\min }}\right)\right|_{a_{\min }} ^{a_{\max }}
$$


For Figure $6 c$, all cracks have an initial width of $\mathrm{m}^{\mathrm{b}} \mathrm{o}^{\circ}$ Therefore

$$
\Phi *(P) \simeq 1+C_{5} a_{\min }\left[1-\exp \left(1-1 / P^{*}\right)\right]
$$

and $F^{*}\left(P^{*}\right)=C_{5} a_{\min } \frac{e^{\left(1-1 / P^{*}\right)}}{P^{*}} \quad A-14$ 
.

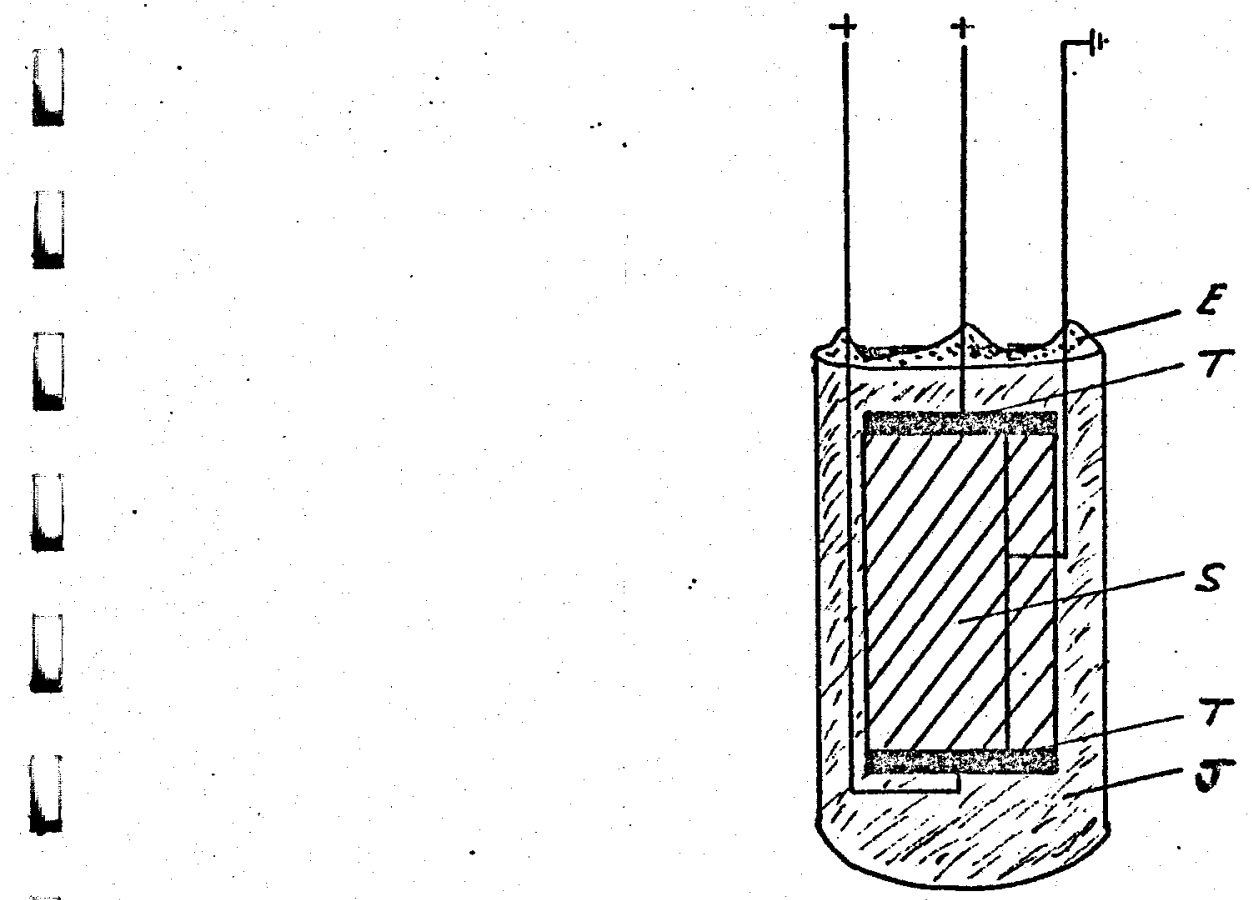

H

L
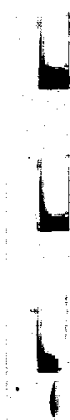

. 


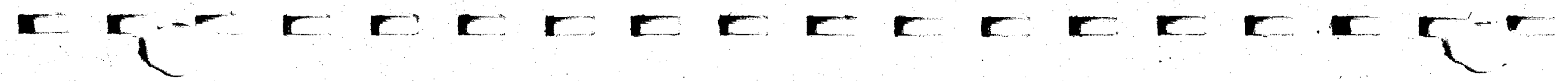

ELBERTON GRANITE-BB3

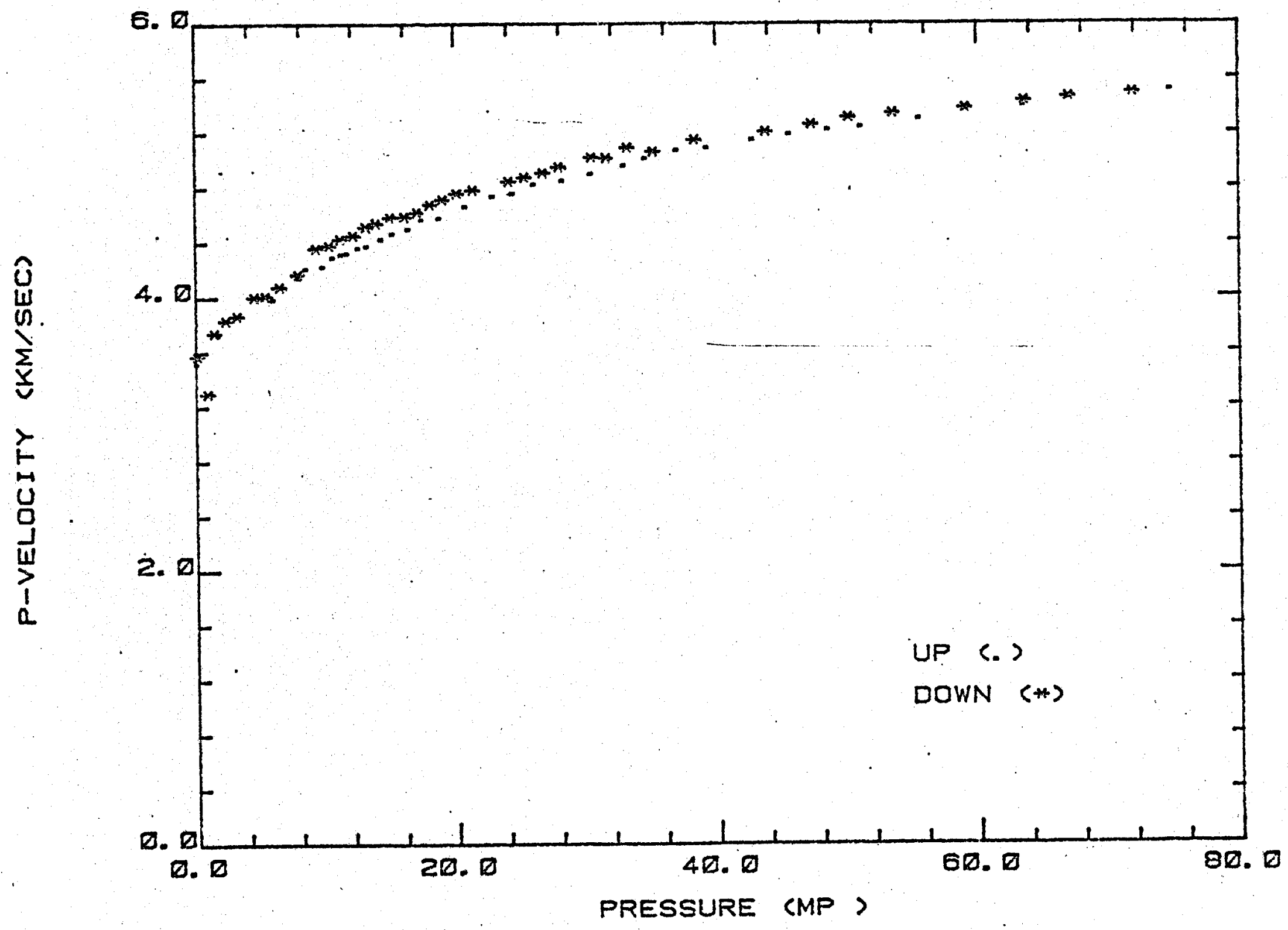



ELBERTON GRANITE BB3

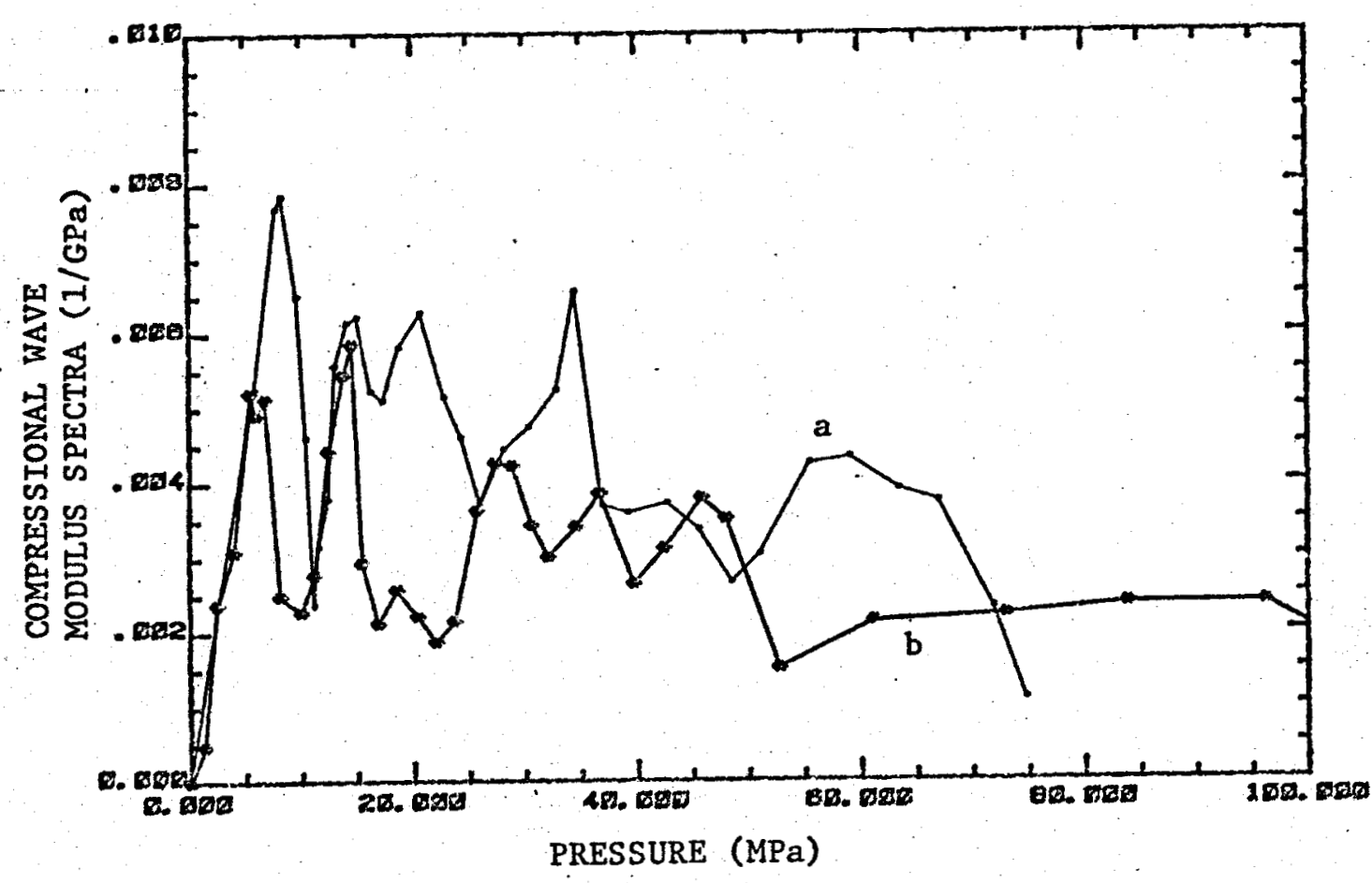

2

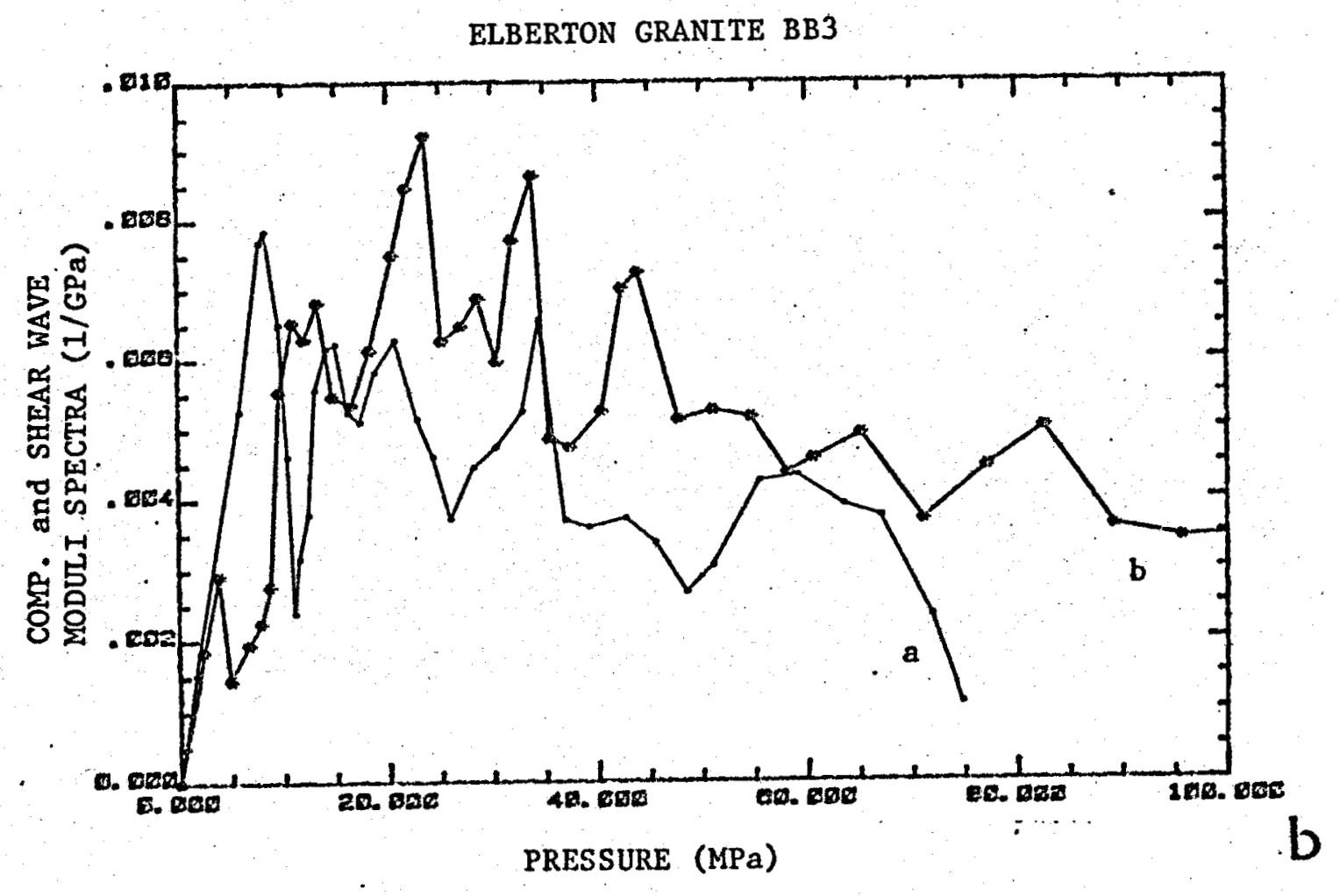


[

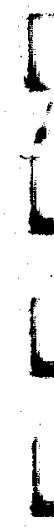

1

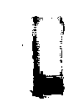

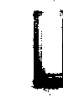

$L$
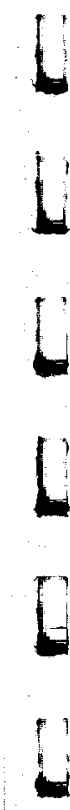

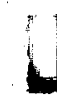
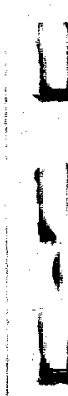

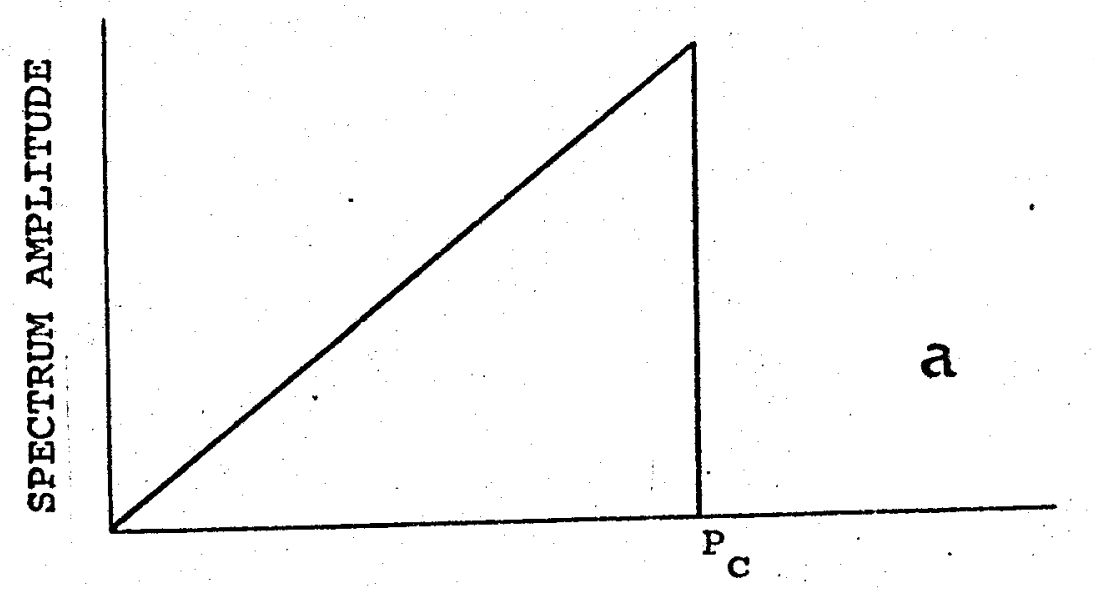

PRESSURE

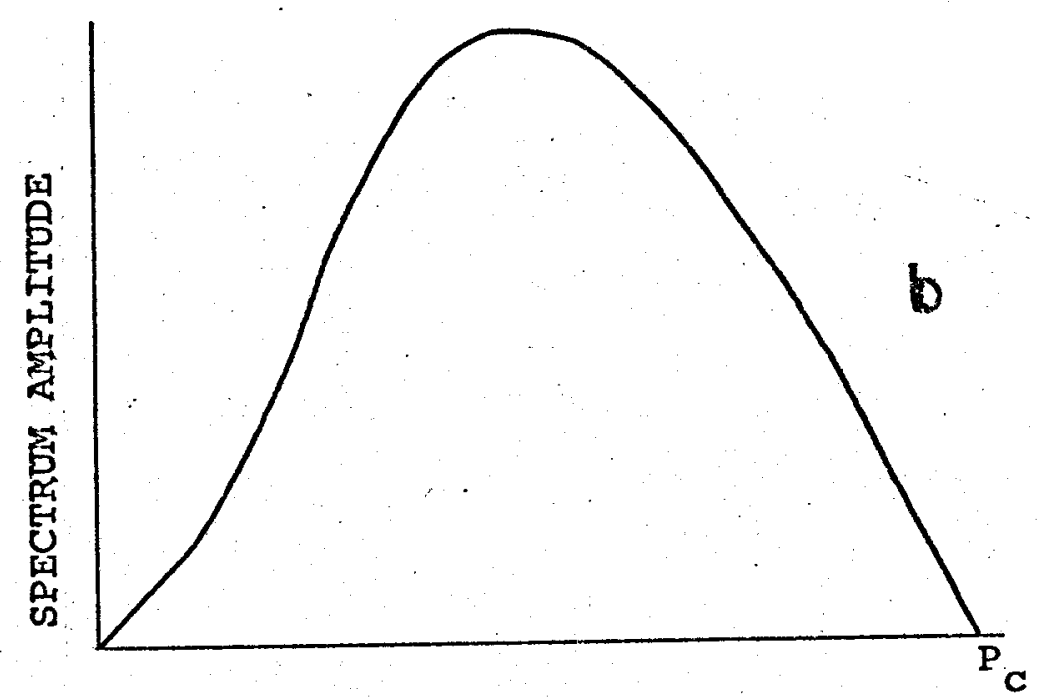

PRESSURE

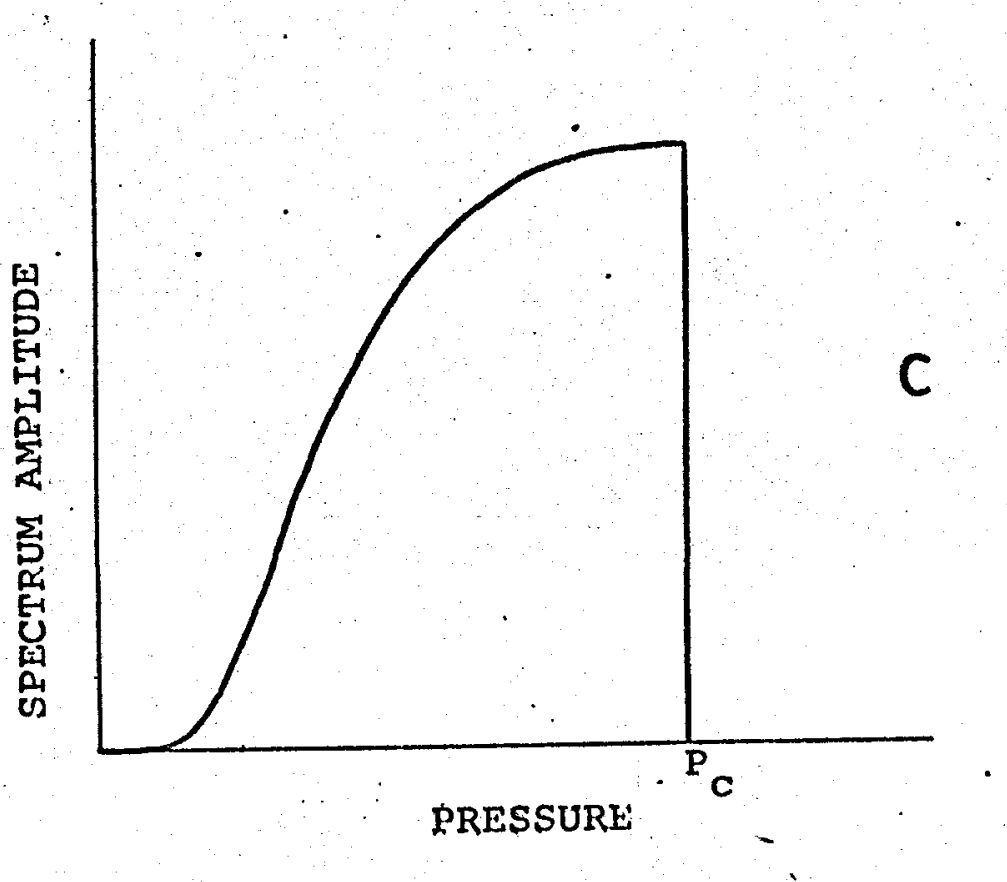




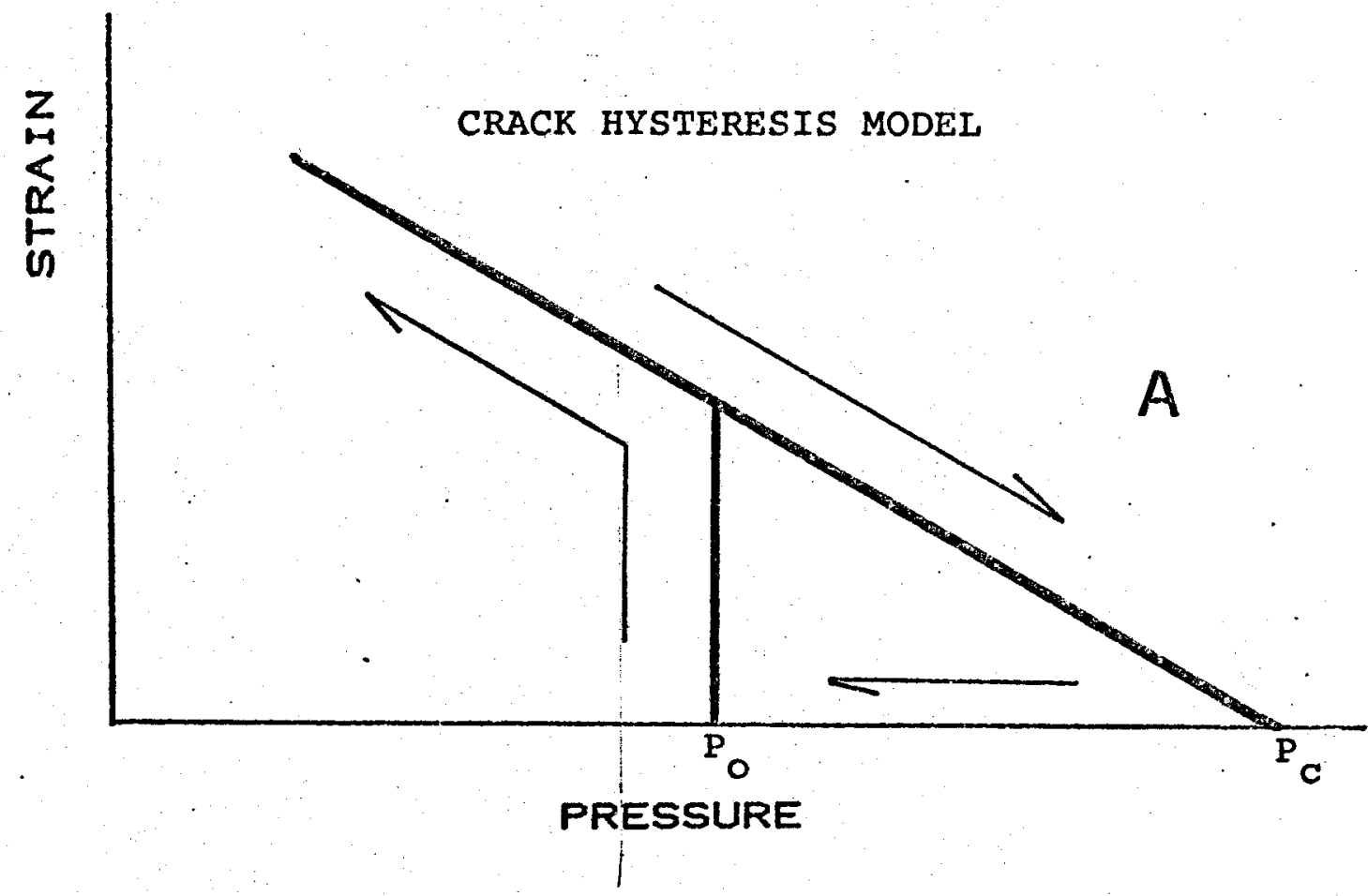

CONSISTENT VELOCITY - PRESSURE MODEL

hysteresis = ๑. 1P| D. $2 P$

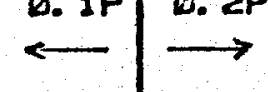

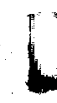

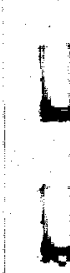

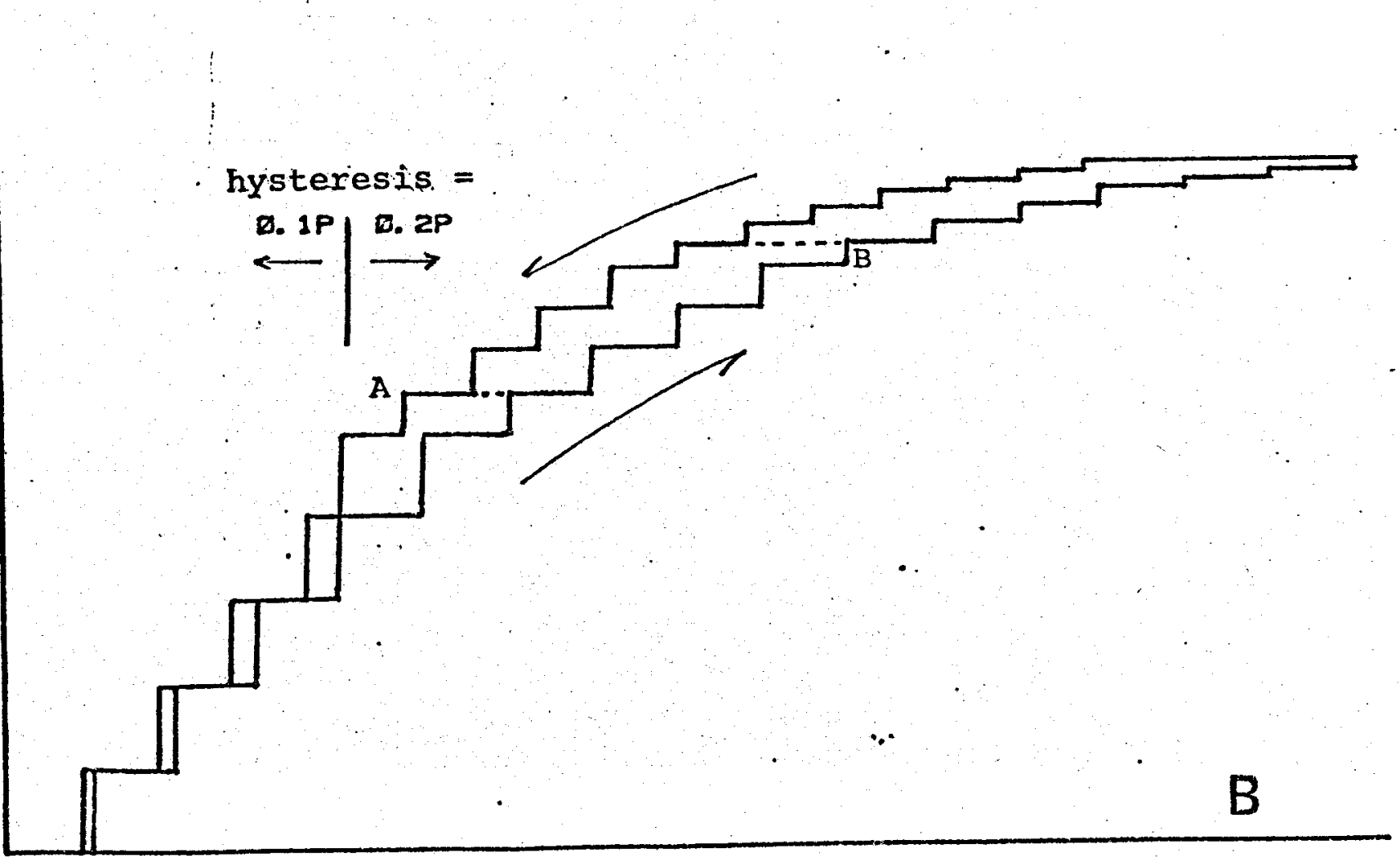

PRESSURE 

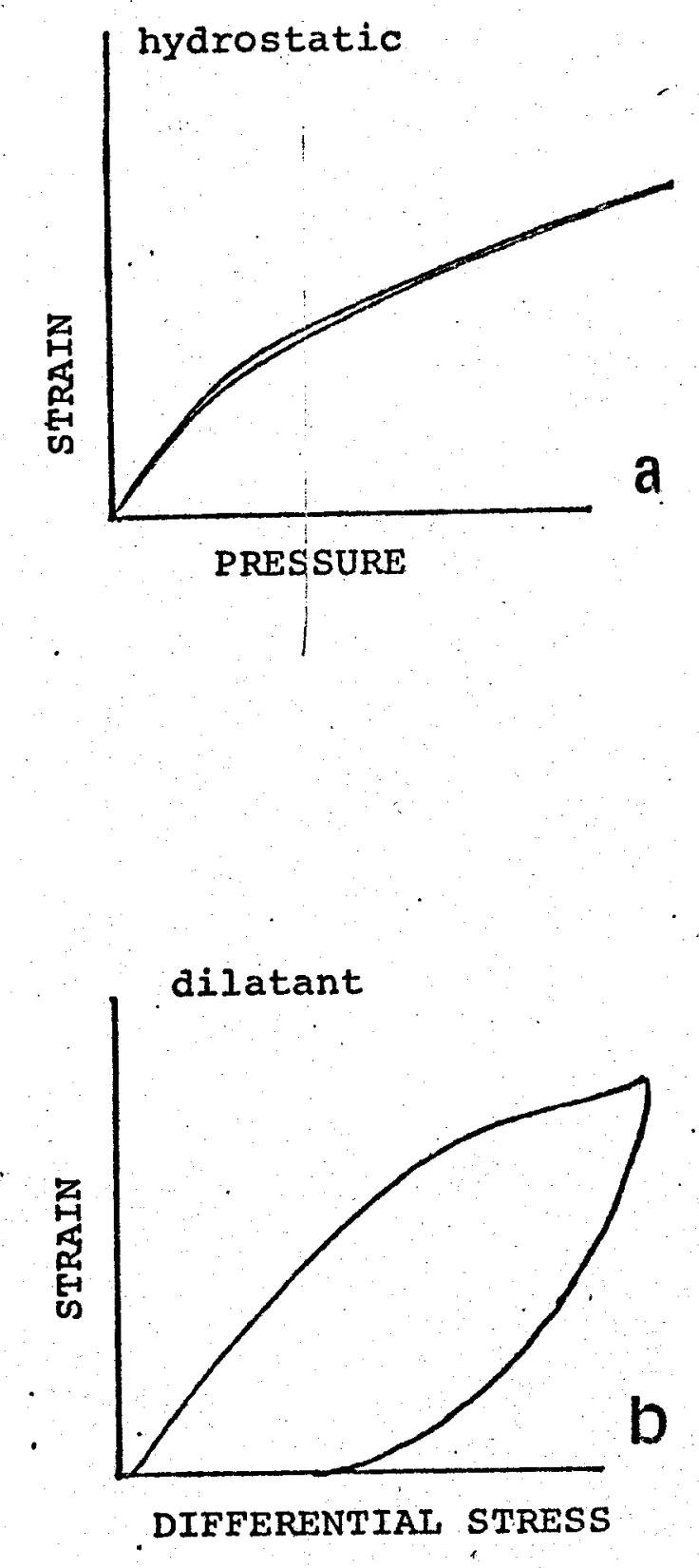

1

1

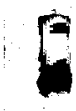

?



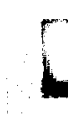

r

$$
!
$$

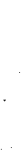


A DILATANCY CRACK MODELS
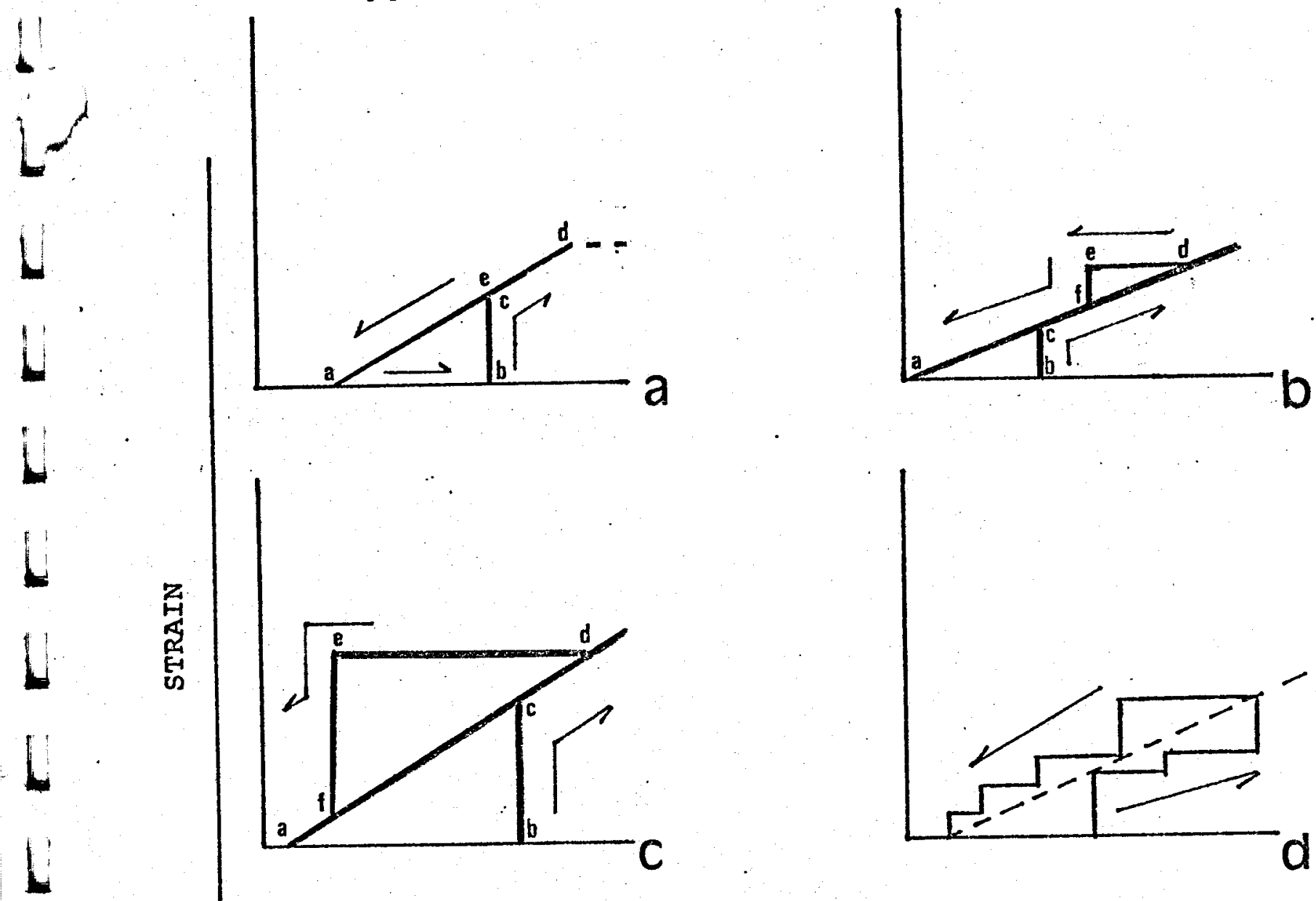

$i$
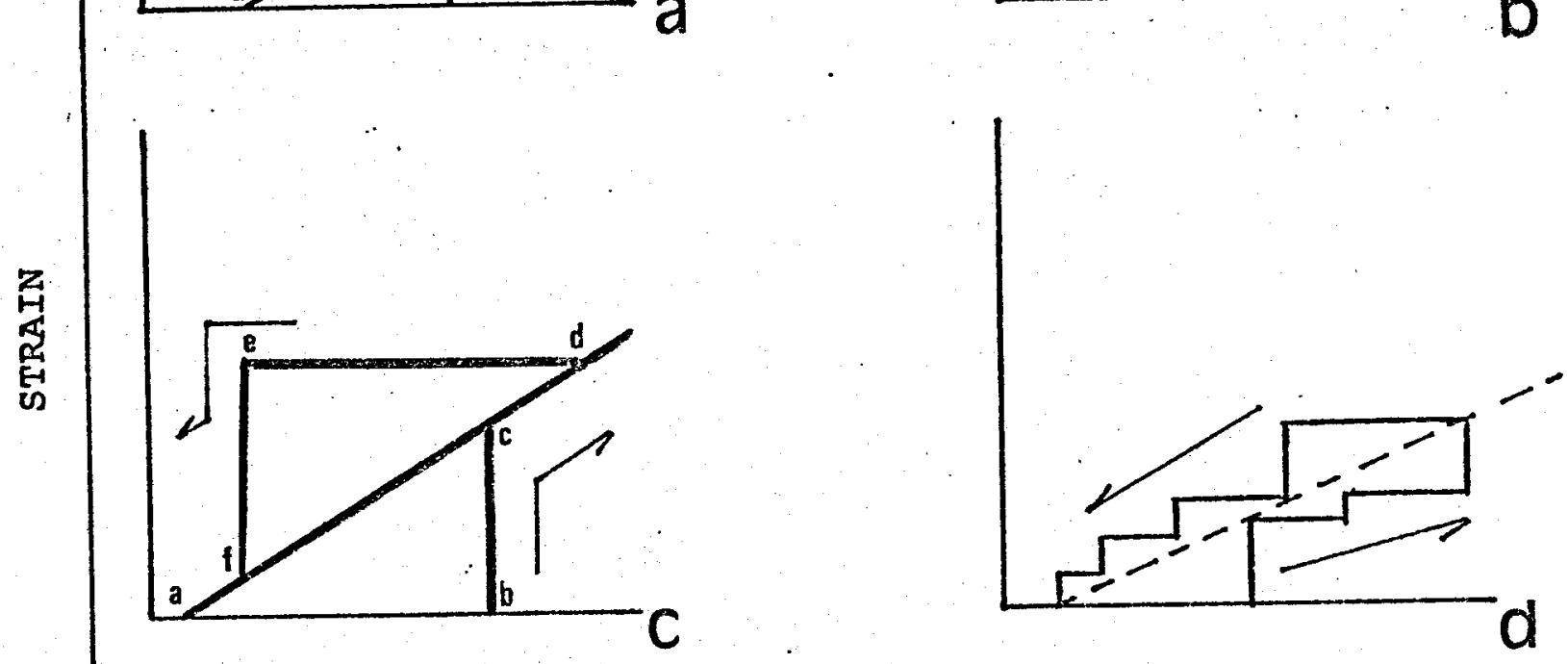

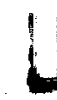

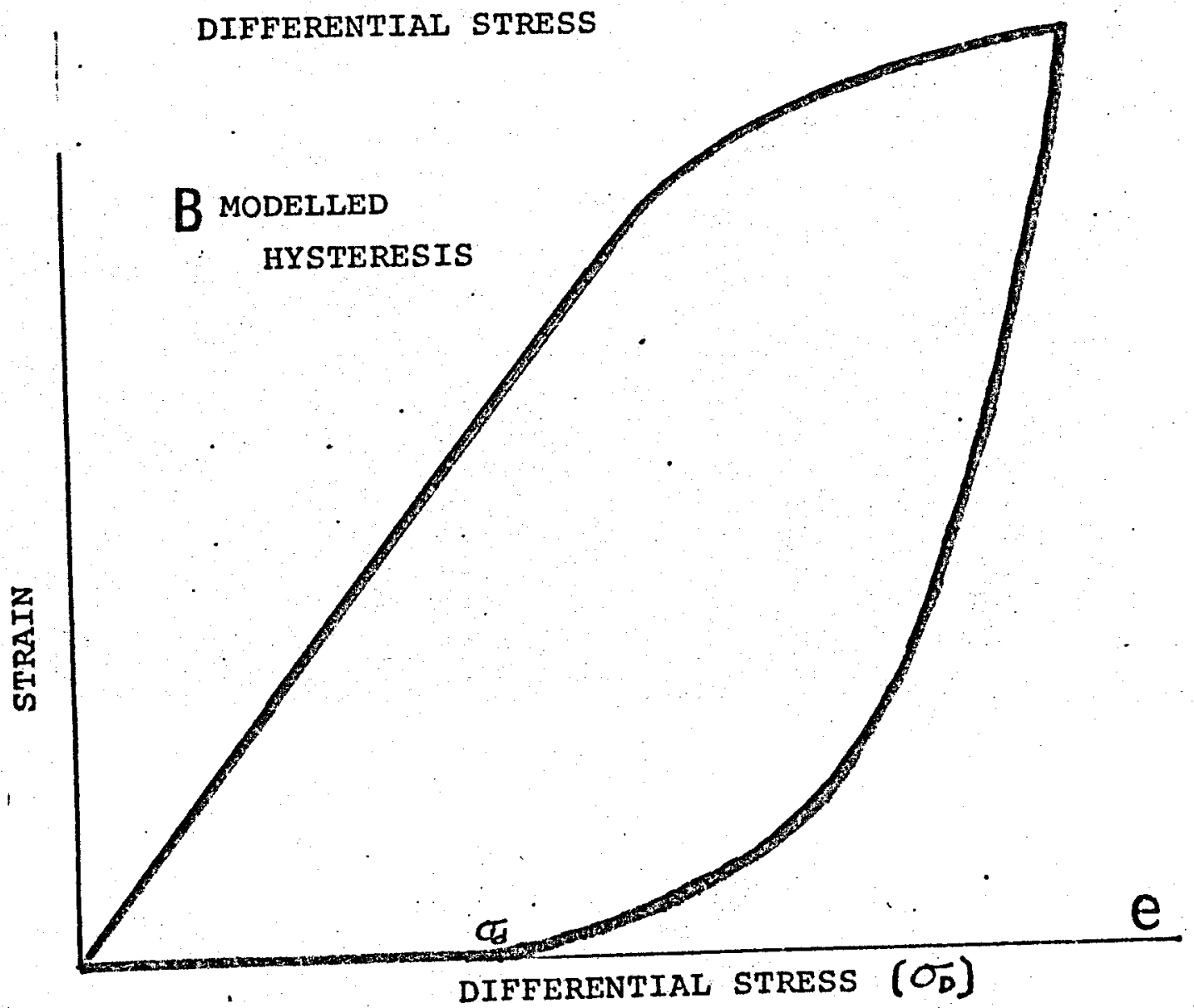


Nick Warren

cracks more) or by decreasing the deviatoric stress (unpinning the horizontal cracks).

In an equidimensional-grained rock like granite, the number of crack connections, or flow paths, may be proportional to the power of the number of connected accessible crack networks. In the experimients here, the flow paths through the vertical open cracks become'fünnected by opening or unpinning the horizontal cracks as a function of the deviatoric stress and the absolute value of the confining stress. Hence in superpositioning modelling, the exponent involved in coupling the networks may be 1.5 to 2 .

Distribution:
J. Tester
P. Halleck
H. Fisher
D. Brown
J. Bridwell
G-5 file 